\title{
VARIAÇÃO ESTACIONAL DE PREÇOS DE PESCADOS NA CIDADE DE SÃO PAULO
}

\author{
ANTONIO CARLOS MANDUCA FERREIRA
}

Orientador: JOAQUIM JOSÉ DE CAMARGO ENGLER

Dissertação apresentada à Escola Superior de Agricultura "Luiz de Queiroz", da Universidade de São Paulo, para obtenção do titulo de Mestre em Economia Agrária.

PIR A CI C A B A

Estado de São Paulo - Brasil

Dezembro, 1980 


\title{
A meus pais João (in memoria) e Maria
}

\author{
A minha esposa \\ Nivia Maria \\ A meus filhos \\ Junior, \\ Rogério e \\ Maurício
}




\section{A G R A D E C I M E N T O S}

Ao Prof. Dr. Joaquim José de Camargo Engler pe la orientação.

Aos Profs. Dr. Evaristo M. Neves e Dr.Tsunehisa Tamaki pelos incentivos e orientações no início deste trabalho;

Ao Departamento de Pescado da CEAGESP pelo for necimento dos dados básicos e informações complementares;

Ao Setor de Computação da ESALQ, na pessoa da sra. Djanira, pelo processamento;

Ao Prof. Dr. Rodolfo Hoffmann pelo elaboração dos programas de computação usados neste trabalho;

Ao Instituto de Economia Agrícola e Instituto de Pesca nas pessoas do Sr. Nelson Giulietti e Dr. Helio Valen tini pelas informações que permitiram uma análise mais ampla;

Aos Profs. M.S. Josē Garcia Gasques, M.S. José Jorge Gebara, Dr. João Luiz Cardoso e Dr. Geraldo Santana de Camargo Barros pelas críticas e sugestões apresentadas;

Aos demais colegas do Departamento de Economia Rural da FCAVJ. Dr. José Roberto Medina Landim, Dr. Manoel An tonio de Almeida Monteiro, Maria Madalena Zocoller, M.S. Fran cisco Graziano Neto pelos incentivos;

Ao Prof. Argemiro Oliveira Sousa pelas correções deste texto;

Ao Sr. Aparecido Luiz Cremonez e Sra. Ercy Ho mem de Oliveira pela paciência e dedicação nos serviços de dạ tilografia;

A todos aqueles que colaboraram direta ou indi retamente para que este trabalho fosse realizado. 
1 - INTRODUÇÃO $\ldots \ldots \ldots \ldots \ldots \ldots \ldots \ldots \ldots \ldots \ldots \ldots \ldots \ldots \ldots \ldots \ldots \ldots \ldots \ldots$

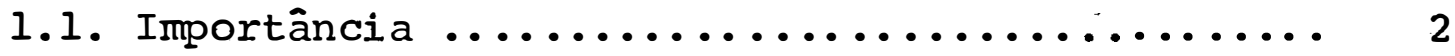

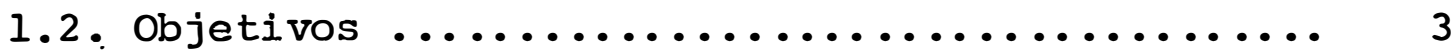

2 - REVISÃo DE LITERATURA $\ldots \ldots \ldots \ldots \ldots \ldots \ldots \ldots \ldots \ldots \ldots \ldots \ldots \ldots \ldots$

3 - CARACTERISTICAS GERAIS, DOS PESCADOS .............. 14

3.1. Biologia, Captura e Oferta ............... 14

3.2. Situação Mundial do Pescado ............. 16

3.2.1. Situação do Pescado no Brasil ........ 21

3.3. O Mercado de Pescado na CeAgesP ............ 22

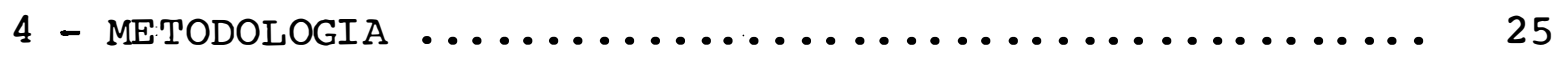

4.1. Material ......................... 25

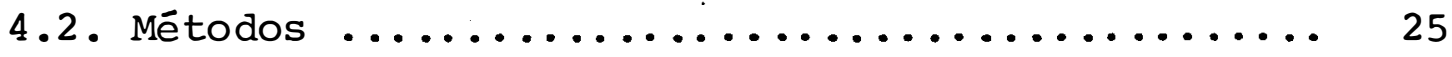

4.2.1. Método da Média Aritmética Móvel ...... 27

4.2.2. Método da Nédia Geométrica Móvel ...... 28

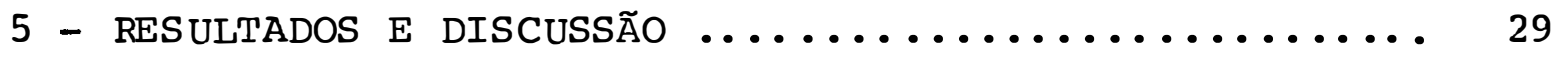

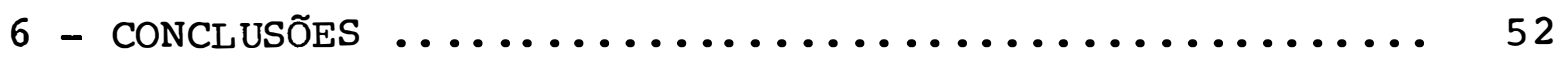

BIBLIOGRAFIA $\ldots \ldots \ldots \ldots \ldots \ldots \ldots \ldots \ldots \ldots \ldots \ldots \ldots \ldots \ldots \ldots \ldots \ldots \ldots \ldots \ldots$

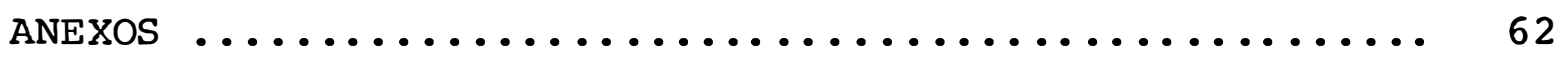




\section{N D I C E D O S Q UADROS}

Página

QUADRO 1: Principais Épocas de Capturas,-,1968/75......

QUADRO 2: Indices de Preços e de Quantidades utilizando - método da média aritmética centralizada de 12 meses (1968 a 1975)

QUADRO 3: Coeficiente de Determinação $\left(R^{2}\right)$ para os méto dos da média aritmética e média geométrica par tindo-se de preços correntes, preços reais e quantidades ........................ 31

QUADRO 4: Distribuição dos índices de preços, ao longo dos meses no mercado atacadista de São Paulo (CEAGESP) - período 1968 a 1975 ............

QUADRO 5: Distribuição dos índices de quantidades comer cializadas no mercado atacadista de São Paulo (CEAGESP) - período 1968 a 1975 ........... 
I $N$ D I C E D A S T A B E L A S

Pāgina

TABELA 1: Produção mundial de organismos aquaticos vivos. 18

TABELA 2: Demanda estimada para produtos da pesca, 1980, $1990-2000$ (em peso vivo) ................. 20 
FIGURA 1: Pescada Goete - Indices Sazonais e seus Limi: tes Superior e Inferior, obtidos a partir do método da média aritmética e da média geomé trica com preços correntes, preços reais e

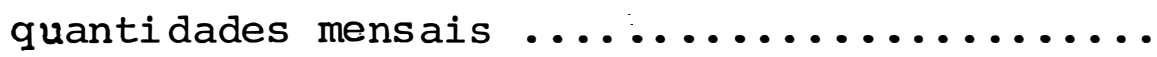

FIGURA 2: Pescada Tortinha - Indices Sazonais e seus Li mites Superior e Inferior, obtidos a partir do método da média aritmética e da média geo métrica com preços correntes, preços reais e

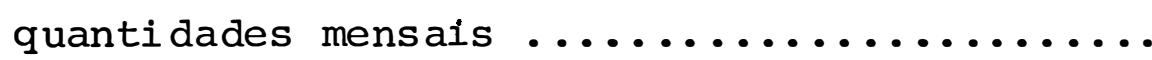

FIGURA 3: Pescada Pequena - Indices Sazonais e seus Li mites Superior e Inferior, obtidos a partir do método da média aritmética e da média geo métrica com preços correntes, preços reais e quantidades mensais .................

FIGURA 4: Pescada Média - Indices Sazonais e seus Limi tes Superior e Inferior, obtidos a partir do método da média aritmética e da média geomé trica com preços correntes, preços reais e

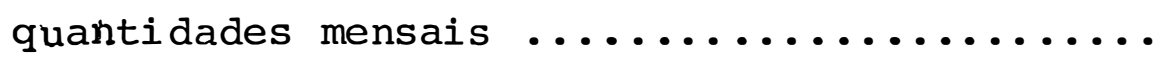

FIGURA 5: Pescada Grande - Indices Sazonais e seus Limi tes Superior e Inferior, obtidos a partir do método da média aritmética e da média geomé trica com preços correntes, preços reais e

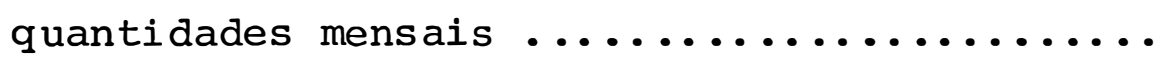


Página

FIGURA 6: Sardinha - Indices Sazonais e seus Limites Superior e Inferior, obtidos a partir do mé todo da média aritmética e da média geomé trica com preços correntes, preços reais e

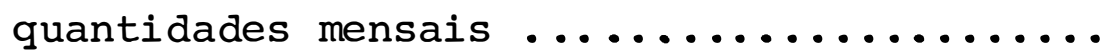

FIGURA 7: Enchova - Indices Sazonais e seus Limites Superior e Inferior, obtidos a partir do mé todo da média aritmética e da média geomé trica com preços correntes, preços reais e quantidades mensais ..................

FIGURA 8: Pescada Branca - Indices Sazonais e seus Li mites Superior e Inferior, obtidos a partir do método da média aritmética e lda média geométrica com preços correntes, preços reais e quantidades mensais .............

FIGURA 9: Pescada Cambucu - Indices Sazonais e seus Limites Superior e Inferior, obtidos a par tir do método da média aritmética e da mé dia geométrica com preços correntes, preços reais e quantidades mensais .............

FIGURA 10: Camarão Médio - Indices Sazonais e seus Li mites Superior e Inferior, obtidos a partir do método da média aritmética e da média geométrica com preços correntes, preços reais e quantidades mensais ............ 
FIGURA 11: Tainha - Indices Sazonais e seus Limites Supe rior e Inferior, obtidos a partir do método da média aritmética e da média geométrica com preços correntes, preços reais e quantidades mensais .........................

FIGURA 12: Camarão Rosa - Indices Sazonais e seus Limi tes Superior e Inferior, obtidos a partir do método da média aritmética e da média geomé trica com preços correntes, preços reais e quantidades mensais ..................

FIGURA 13: Camarão Sete Barbas - Indices Sazonais e seus Limites Superior e Inferior, obtidos a partir do método da média aritmética e da média geo métrica com preços correntes, preços reais e quantidades mensais .................. 
ANEXO 01: Pescada Branca .................. $62-68$

ANEXO 02: Pescada Goete .................... $69-75$

ANEXO 03: Pescada Cambucu $\ldots \ldots \ldots \ldots \ldots \ldots \ldots \ldots .76$. 82

ANEXO 04 : Pescada Tortinha ................ $83-89$

ANEXO 05: Pescada Grande ................. 90 - 96

AnExo $06:$ Pescada Média ................. $97-103$

ANEXO 07: Pescada Pequena ................. $104-110$

ANEXo 08: Camarão Médio ................ 111 - 117

ANEXO 09 : Camarão Rosa ................. $118-124$

ANEXO 10: Camarão Sete Barbas ............. $125-131$

ANEXO $11:$ Sardinha $\ldots \ldots \ldots \ldots \ldots \ldots \ldots \ldots \ldots \ldots . \ldots \ldots$

ANEXO 12: Tainha ...................... $139-145$

ANEXO 13: Enchova .................... $146-152$ 
No presente estudo procurou-se identificar os padrões estacionais de preços e de quantidades de pescados na cidade de são paulo, a nível de atacado, ao mesmo tempo em ợe se estabeleceram comparações entre os índices estacionais obti dos através do método da média aritmética móvel centralizada de 12 meses e da média geométrica móvel centralizada de 12 me ses.

Analisou-se os seguintes produtos marinhos: Pes cada Goete (Cynoscion jamaicensis), Pescada Cambucu (Cynoscion. virescens), Pescada Branca (Cynoscion leiarchus), Pescada Tor tinha (Isopisthus Gill), Pescadas: Pequena, Média e Grande (Macrodon ancylodon), Camarão Rosa (Penaeus paulensis e P.bra siliensis), Camarão Sete Barbas (Xỹphopenaeus kroyeri), Camarão Médio $1 /$ (Penaeus schimitti, Penaeus paulensis, Penaeus brasi.

$1 /$ Comercialmente por camarão médio entende-se uma mistura de camarão legí timo ou branco, camarão rosa na fase Juvenil e outros tipos de camarões. 
liensis), Tainha (Mugil brasiliensis), Enchova (Pomatomus sol tatrix)-e Sardinha (Sardinella bräsiliensis).

o período de análise do presente estudo é de 1968 a 1975 para todos os produtos, exceto para a pescada bran ca que é de 1968 a 1974, dado que, para esse produto os dados relativos a 1975 não eram satisfatórios. As informações bási cas (preços e quantidades mensais) foram coletadas junto ao Entreposto Terminal de São Paulo (ETSP) - Companhia de Entre postos e Armazens Gerais do Estado de São Paulo (CEAGESP).

Efetuou-se a análise através dos dois métodos (mëdia aritmética e média geométrica) a partir de preços cor rentes, preços reais e quantidades. Para a obtenção dos pre ços reais utilizou-se o "Indice 2" (Indice geral de preços) da Fundação Getúlio Vargas para deflacionar os preços correntes.

Com relação aos índices estacionais de preços, os resultados mostraram que não existem diferenças que possam recomendar preferencialmente $o$ uso de um ou de outro preço. Entretanto, parece que a obtenção dos indices a partir de pre ços correntes deva ser preferida, uma vez que para a obtenção a partir de valores reais incorre-se, desnecessariamente, numa fase de transformação de dados, ou seja, a deflação dos valo res correntes.

No tocante aos indices de quantidades os resul tados do presente estudo indicam a equivalência entre os méto dos da média aritmética e da média geométrica. Entretanto ao se verificar as figuras de 1 a 13, parece que o método da mé dia aritmética apresenta um erro padrão ou coeficiente de va riação menor do que quando se utiliza para o cálculo, a média geométrica. Este fato entretanto não foi verificado ao se cal cular $\circ \mathrm{R}^{2}$ (coeficiente de determinação) pois em ambos os mé todos estes apresentaram-se muito próximos.

A determinação dos indices de quantidades teve por objetivo melhorar e facilitar a análise das variações de 
preços, tendo-se em conta que os produtos analisados, como os demais pescados, não apresentam um perỉodo de safra e/ou entre safra bem definidos.

Dos 13 produtos analisados, 5 (pescada branca, pescada cambucu, camarão médio, camarão sete barbas e tainha) não apresentaram o comportamento esperado, ou seja, a ocorrên cia de índice de preços máximo em março/abril, ocasionado por um aumento na quantidade demandada. Isto deveria ocorrer devi do ao fato de que naquele período acontece a Semana Santa em que, por tradições religiosas, principalmente, deve-se consu mir preferencialmente peixes. Existem portanto outras influên cias que condicionam o comportamento observado.

Essas outras influências poderiam ser dadas por outros tipos de tradições; como a de se consumir "pescado fí no" nos festejos de Natal e Fim de Ano, ou ainda devido ao fa to de que o pescado pode substituir outros tipos de carnes co mo a bovina, nos perỉodos de entre-safra desta.ültima. 


\section{SEASONAL PRICE VARIATION OF FISH PRODUCTS IN THE CITY OF SÃO PAULO}

\section{SUMMARY}

The objective of the present study was to identify the patterns of seasonal price variation of fish products in the city of são Paulo at wholesale level and to establish comparisons between the estimated price indexes through the Centered 12-Month Moving Arithmetic Mean and the Centered 12-Month Moving Geometric Mean.

The following marine products were analyzed: "Pescada Goete" (Cynoscion jamaicensis), "Pescada Cambucu" (Cynoscion virescens), "Pescada Branca" (Cynoscion leiarchus), "Pescada Tortinha" (Isopisthus Gill), "Pescadas: Pequena, Média e Grande" (Macrodon ancyladon), "Camarão Rosa" (Penaeus paulen sis and Penaeus brasiliensis), "Camarão sete Barbas" (xyphope naeus kroyeri), Medium Size Shrimpl/ (Penaeus Schimitti, Pe

1/ Commercially, Mediun Size Shrimp means a mix of several types and sizes of Shrimp. 
naeus paulensis, Penaeus brasiliensis), Tainha (Mugil brasi liensis), Anchovy (Pomatomus soltarix), and sardine (Sardinel la brasiliensis).

The period covered by the analysis spans from 1968 to 1975 for all products except for "Pescada Branca" wich is 1968 to 1974 because the data for 1975 were not appropriate for the purpose of the present study. The basic information on monthly prices and quantities was colected at Terminal Market in São Paulo - "Companhia de Entrepostos e Armazens Gerais do Estado de São Paulo" (CEAGESP).

Two methods were utilized to estimate the price indexes (Arithmetic Mean and Geometric Mean). Those methods were applied on current prices, real prices, and quantities. Real prices were obtained by deflating current prices through the Index 2 (General Price Index) from "Fundação Getúlio Var gas" •

The results showed that there is no significant difference between the estimate price indexes to warrant preference of one method over the other. However,it seems that the procedure using current prices is more appropriate because by using real prices a further step is introduced and it does not lead to improved estimates.

As far as the estimated indexes of quantities are concerned it is possible to infer from the results that there is an equivalence beteween the indexes calculated through both methods. But, by looking at figures 1 to 13 , it seems that the method of Arithmetic Mean leads to a smaller standard error or coefficient of variation than the method of Geometric Mean. Monetheless, when $\mathrm{R}^{2}$ (coefficient of determination)were calculated the results were very close indicating no significant difference between the indexes.

The purpose of estimating the indexes of quantities was to help in analyzing the results of price indexes because the fish and related products do not show a 
well-defined catch season.

The indexes of five products ("Bescada Branca, Pescada Cambucu, Camarão Médio, Camarão sete Barbas e Tainha") out of thirteen fish products analyzed did not show expected seasonal price movements with maximum prices around March/April due to increased demand for fish products during this period. This is somehow expected because Holy week lies in that period and people, for religious folclore should consume fish. Thus, there are other factors that may affect the seasonal price variation.

Two factors are mentioned that might be acting to smooth out the seasonal price movement. The first is "related to the consumption of high quality fish products during the Christmas and New Year holidays and the second is related to the substitution of fish products for meat such as beef during its off season production period. 


\section{1 - INTRODUÇÃO}

Os pescados, de modo geral, representam uma boa fonte alternativa de proteina para a alimentação, principalmen te a humana. Além do aspecto nutricional do pescado, outro fa tor importante ligado ao consumo desses produtos reside no fa to de que tradições, notadamente religiosas, promovem aumento significativo no consumo em determinadas épocas do ano.

Isto posto, pode-se, de imediato, avaliar a im portância crescente do pescado, quer seja ao nível da captura ou em relação ao consumo final, tendo-se em conta a crescente carência proteica na alimentação humana provocada quer pela de ficiência na quantidade ofertada, quer pelo baixo poder aquisi tivo de grande parte da população, quer por hábito alimentar que, em última instância, provocarão uma deficiência na quanti dade procurada. 


\subsection{Importância}

Estudos de preços apresentam-se com grande uti lidade para o governo, comerciantes, produtores (armadores) e consumidores. A importância para o setor estatal está no for necimento de subsídios que auxiliem na formulação e aplicação de políticas de abastecimento, notadamente, nos assuntos liga dos à armazenagem e transporte. No presente estudo,tem-se pro dutos perecíveis e produzidos relativamente longe dos centros consumidores, acarretando portanto problemas de armazenamento e transporte.

Aos comerciantes pode-se dar indicações do com portamento da oferta e da demanda, proporcionando-lhes informa ções que melhoram suas atuações no fluxo desses bens, desde os centros produtores ou de distribuição até os consumidores fi nais.

Do lado dos consumidores, as informações de pre ços propiciam que estes, dada sua renda e os preços dos bens, procurem adquirir quantidades tais dos diversos bens que maxi mizem o seu nível de satisfação.

Para os produtores (armadores) as indicações dos indices de preços promovem subsídios no sentido de concen trar esforços na captura de determinados produtos que apresen tam preços elevados no mercado.

Todas essas informações poderão ser obtidas, en tre outros,através de estudos de variação estacional.

Sendo o pescado um produto influenciado pelas condições de crescimento biológico que está na dependência de outros fatores tais como: características biológicas das espê cies, temperatura da água, mudanças nas correntes marítimas, etc.; apresenta portanto variação periódica anual e em conse quência disto maior ou menor produção em determinadas épocas do ano. Portanto qualquer modificação naqueles fatores podem provocar um deslocamento do cardume. Neste aspecto, um exem 
plo pode ser dado para a sardinha, que ao se deslocar, p.e, pa ra o litoral do Rio de Janeiro, faz com que são Paulo fique com escassez de oferta, tendo-se em conta que, dado o preço do produto no mercado e o alto custo do transporte, a sardinha capturada no litoral do Rio de Janeiro provavelmente não venha a ser transportada até São Paulo.

Por outro lado, além da estacionalidade da pro dução, existem influências do lado da demanda que se refletem nas condições de preço do produto no mercado. 0 consumo de pescado é influenciado não apenas pelos componentes usuais da demanda como o preço do pescado, preços dos produtos substitú tos ou complementares, população e renda, mas também por fato res ligados à tradição (Semana Santa, festejos de fim de ano, etc...).

Dado essas considerações onde se verifica o com portamento a que o pescado está sujeito, pode-se então aplicar os métodos de estudos de variação estạcional.

1.2. Objetivos

Neste trabalho procurar-se-á determinar os pa drões de variação estacional de preços e de quantidades de pes cados comercializados na CEAGESP (mercado atacadista). Serão objetos de estudos os seguintes produtos marinhos: pescadas (branca, tortinha, cambucu, goete, pequena, média e grande); camarões (rosa, sete barbas e médio); enchova; tainha e sardi nha totalizando 13 produtos.

A determinação desses padrões tem como objetị vos gerais:

a) obter indicações que auxiliem no estabeleci mento de politicas de preços, armazenamento e transporte, ou seja, nas políticas de abastecimento;

b) fornecimento de subsídios aos comerciantes e 
produtores visando melhores condições no fluxo desses produtos dos centros produtores aos consumidores finais:

c) aos consumidores, informações para que conhe cendo o comportamento dos preços possam adquirir esses produ tos em épocas de menores preços, ou sej̣a, maximizar a sua utí lidade.

Por outro lado em termos de objetivos específi cos, tentar-se-á estabelecer comparações entre os padrões obti dos a partir de preços reais, preços correntes e quantidades utilizando-se para isso o método da média aritmética móvel cen tralizada de 12 meses e o método da média geométrica móvel cen tralizada de 12 meses. 
2 - REVISÃO DE LITERATURA

PEREIRA et alii (1963) estudaram a variação es tacional dos preços agrícolas no Estado de são Paulo, referen tes a produtos de origem animal e vegetal. Foram analisados os seguintes produtos: a) produtos de origem animal: bezerro até 1 ano, bezerro de 1 a 2 anos, boi magro, boi gordo, vaca gorda, porco magro com caixa para até $60 \mathrm{~kg}$, porco magro com caixa para mais de $60 \mathrm{~kg}$, porco gordo, leite, vaca holandesa, vaca comum e ovos, analisados no período 1954/1962; b) produtos de origem vegetal: café beneficiado, arroz em casca, arroz be neficiado, feijão, amendoim em casca, milho, mamona, batata e cebola, estudados no período 1948/1962.

o método utilizado para o cálculo dos índices de variação foi o da média centrada de 12 meses, sendo utiliza dos os preços médios mensais recebidos pelos agricultores.

Entre as conclusões dos autores pode-se citar que quanto maior for o grau de perecibilidade do produto maio 
res serão as amplitudes das flutuações nos índices médios. Em termos do coeficiente* houve uma perfeita concordância quanto aos maiores indices ocorrer com produtos mais perecíveis.

$$
\text { *C= } \frac{\text { Ind.máx }- \text { Ind.mínimo }}{\frac{\text { Ind.max }+ \text { Ind.mínimo }}{2}} \cdot 100
$$

PANIAGO (1966) estudou as flutuações estacio nais no preço do milho no Estado de São Paulo no período de 1951 a 1963. Nesse estudo o autor utilizou os preços corren tes publicados em Agricultura em São Paulo - I.E.A., deflacio nando-os e em seguida usou o processo da média móvel centralí zada de 12 meses para eliminar as flutuações estacionais devi das ao acaso. Verificou que as flutuações estacionais relatí vas dos preços reais de milho, no Estado de São Paulo, experí mentaram, no período 1.951 a 1963, comportamentos diferentes, durante os periodos de safra e entre-safra. Assim, segundo o autor, ao que tudo indica, houve, com o passar dos anos, decrés cimos das flutuações nos perỉodos de safra e acréscimos dessas flutuações, nos perỉodos de entre-safra.

HOFFMANN (1968) estudou a variação estacional do preço da cebola no Estado de São Paulo no perỉodo de 1954 a 1967, tentando verificar se o padrão da variação estacional de preços da cebola havia se modificado e procurando atualizar os resultados do trabalho de PEREIRA et alii (1963) sobre a varia ção estacional dos preços de 21 produtos agrícolas, entre os quais o que apresentou o maior coeficiente de amplitude da va riação estacional foi a cebola.

o autor esperava encontrar uma diminuição na in tensidade da variação estacional nos últimos anos devido à in trodução de técnicas que permitem colher o produto em meses nos quais normalmente haveria escassez. Entretanto isso não foi verificado na análise feita. Entre outras conclusões do 
autor, verifica-se que de 1956 a 1965 houve, de ano para ano uma alternância do padrão da variação estacional do preço da cebola no Estado de São Paulo. Nos anos pares desse perỉodo o indice de variação estacional assume valores máximos, sempre nos meses de junho, julho e agosto. Nos anos impares, por ou tro lado, o índice apresenta variações mais irregulares, assu mindo valores máximos inclusive em abril e setembro, com ampli tude de variação menor, sendo que o indice máximo é sempre me nor que 160 .

ARRUDA e JUNQUEIRA (1969) estudaram a variação estacional de preços do algodão em plúma e em caroço no Estado de São Paulo, de 1948 a 1968. Os preços estudados eram os re cebidos pelos produtores, pagos pelas usinas de beneficiamento. A determinação do padrão estacional dos preços do algodão em caroço foi feito por meio de médias móveis de 8 meses, tendo em vista que as cotações do produto, praticamente, só ocorrem de março a outubro, porque a colheita é realizada, via de regra, de março a julho. A determinação do padrão estacional para al godão em pluma foi feita também usando médias centradas, porém agora com 12 meses. Os autores identificaram que nos meses de julho e agosto ocorrem índices estacionais mínimos, pois é nes se período que é comercializada grande parte da produção. período ascensional do padrão inicia-se a partir de agosto, atingindo seu máximo em dezembro a março, apresentando a par tir daí características descensionais.

HOFFMANN (1969) estudou a variação estacional dos preços de 27 produtos agropecuários. O autor utilizou-se dos métodos da média aritmética e da média geométrica para a obtenção dos índices de variação estacional. Para os dois mé todos foram analisados os preços correntes e os preços reais, utilizando nesse caso o "Indice 2" da F.G.V. para deflacionar os preços correntes. Conclui o autor que tanto um quanto ou tro método levam à obtenção de índices semelhantes.

ARRUDA e CRISCUOLO (1970) estudaram o padrão es tacional dos preços de ovos no Estado de São Paulo no período 
de 1954 a 1968. Tendo em vista que o desenvolvimento técnico da avicultura paulista foi maior após o ano de 1960, os auto res determinaram os padrões estacionais para os subperíodos 1954/60 e 1960/68, a fim de estabelecer comparações. O método utilizado para determinação dos padrões foi o das médias cen tradas de 12 meses.

Os autores constataram, pela comparação dos ín dices estacionais para os dois subperíodos, que houve uma evi dente diminuição da flutuação estacional do primeiro para o se gundo subperíodo, bem como uma redução da zona de variabilida de, evidenciando no subperíodo 1960/68 maior homogeneidade dos preços em relação ao índice estacional médio mensal. Isso ocor reu porque a partir de 1960 grande parte dos granjeiros intro duziu linhagem de postura de alta produtividade e passaram a adotar um manejo bastante técnico.

LINS et alii (1972) identificaram que a produção de pescado (inclui peixes, crustáceos, moluscos, mamíferos aquáticos e quelôneos) no Estado de São Paulo se expandiu em 65\% no período 1965/68, entretanto esse aumento foi menor que - registrado para o Brasil, 114\%. Finalmente os autores citam que a participação do Estado de são Paulo na produção brasilei ra decresceu de 16\% em 1956/68 para 13\% em 1966/68.

BRANDT (1974) afirma que a persistência de flü tuações temporais nos preços agrícolas não é, em si, um proble ma tão grave como o da amplitude dessa oscilação, a qual gera desequilíbrios nas formas de produção, comercialização e consü mo, e resulta em uso não econômico dos recursos produtivos. Um sistema ideal de mercado é aquele que se ajusta rapidamente no sentido do equilíbrio, após um "choque" exógeno, com um mínimo de "superajustamento". Entretanto, considerando-se os benefí cios derivados da liberdade de decisão individual, poder-se-ia tolerar algumas flutuações em torno do equilíbrio.

Finalmente, segundo o autor, as variações perió dicas ou cronológicas de caráter repetitivo de preços agríco 
las, podem ser enquadradas nos seguintes tipos principais: ci clos, variações anuais, tendências, variações estacionais, va riações de prazo muito curto e "choque".

CARVALHO e GIULIETTI (1977) estudaram a comer cialização e consumo do camarão no Estado de São Paulo durante o período 1968 a 1976, tendo como base os dados de preços e quantidades a nível de atacado na CEAGESP.

Os autores analisaram, entre outros tópicicos, a variação estacional dos preços e da quantidade através das mé dias móveis e verificaram que, de forma geral, quando o indice de quantidade situa-se acima da média, o índice de preço en contra-se abaixo da média.

Ainda, segundo os autores, com relação ao consu彑 mo de camarão pode-se verificar que somente as classes de ren das mais altas consomem camarão. Isto deve-se ao fato deste produto apresentar elevado coeficiente de elasticidade-renda . CRUZ (1974), citado pelos autores, calculou as elasticidadesrenda para camarão rosa e sete barbas sendo estas 1,395 e 0,884 respectivamente.

CARVALHO e GIULIETTI (1977), ao estudarem $\circ$ abastecimento de sardinha à população paulistana de baixa ren da, analisaram a estacionalidade de preço e da quantidade co mercializada a nível de atacado (CEAGESP) e utilizaram para is so o método das médias móveis centradas de 12 meses. Verifica ram ọue as entradas de sardinhia no ETSP da CEA.GESP é bastante irregular, como é mostrado pelo comportamento dos índices de quantidades, e mais que a própria estrutura de comercialização varejista é bastante deficiente e parece haver, segundo os au tores, um mercado potencial bastante amplo para a sardinha fresca.

BORTOLETO e UENO (1979) estudaram a variação es tacional dos preços e das quantidades de 25 hortaliças comer cializadas pela CEAGESP durante o período 1968/1977. Para a de terminação dos padrões estacionais, utilizaram o método da mé 
dia geométrica móvel centralizada de 12 meses proposto por HOFFMANN (1969). Os dados básicos foram utilizados através de suas médias mensais.

Para a quase totalidade dos produtos analisados observa-se através dos gráficos, que houve uma certa correspon dência entre indices altos de quantidade e índices baixos de preços, ou seja, no(s) período(s) de safra(s) há uma queda de preços, ocorrendo o inverso em época(s) de entre-safra(s). En tretanto, para alguns produtos como a batata doce e mandioca, os indices de preços quase não se alteram, apesar de apresenta rem altos índices de quantidade.

Em seguida apresenta-se alguns trabalhos onde são discutidos os aspectos metodológicos para a obtenção dos indices estacionais.

LANGE (1961) discute o uso do método da média aritmética e da média geométrica para a obtenção dos índices estacionais e afirma que a utilização do método da média geomé trica gera "cálculos muito complicados e, na prática, utiliza mos um método aproximado que é contudo menos lógico". Segundo - autor o uso do método da média aritmética é bastante difundi do pela sua facilidade de aplicação, entretanto, parte-se do pressuposto de que o valor da média aritmética não difere da média geométrica. Esse pressuposto tem por base que os valo res da média geométrica e da média aritmética entre dois núme ros estarão tanto mais próximos quanto menor for a diferença relativa entre os números.

SPIEGEL (1969) classifica os movimentos caracte rísticos das séries temporais em: a) movimento a longo prazo ou seculares $(T)$; b) variações cíclicas $(C)$; $C$ ) variações por estações (S) e d) movimentos irregulares ou aleatórios (I). Pa ra o autor a variável (Y) de uma série temporal seria dada pe lo produto dos quatros componentes da série temporal, ou seja, $\mathbf{Y}=$ T.C.S.I.. Sugere ainda o autor, para a avaliação das va riações por estação (S), quatro métodos para se calcular os 
Indices: a) o método da porcentagem média, b) da tendência ou relação percentual, c) método da média percentual ou da rela ção entre as médias móveis e d) método dos elos relativos.

HOFFMANN (1969) discute o uso da média aritméti ca e da média geométrica para a obtenção dos índices estacio nais e analisa quatro modelos econométricos para isolar o com ponente (S) - variações por estações. Assume o autor os mes mos componentes citados por SPIEGEL (19.69) e adota $\mathrm{P}_{t}=\mathrm{D}_{t} \cdot \mathrm{S}_{t} \cdot \mathrm{C}_{t} \cdot \mathrm{I}_{t}$ $\left(D_{t}=T\right)$.

Modelo I: o componente estacional se soma a uma média aritmétí ca móvel constante.

$$
\text { } \begin{aligned}
P_{i j}=A+X_{i j} \text { onde } A & =\text { constante } \\
X_{i j} & =\text { componente estacional do preço } \\
i & =1,2 \ldots N(\text { anos }) j=1,2 \ldots 12 \text { (meses) }
\end{aligned}
$$

12

sendo que

$$
\sum_{j=1} x_{i j}=0
$$

Neste caso a média aritmética de 12 valores con secutivos de $P_{i j}$ fornece $O$ valor de A bastando subtrair-se A dos diferentes $P_{i j}$ para obter-se os $x_{i j}$.

Modelo II: o componente estacional é multiplicado por uma mé dia geométrica móvel constante:

$$
P_{i j}=A X_{i j}
$$

\section{2}

onde,

$$
\begin{aligned}
& \prod_{j=1} x_{i j}=1 \text { ou aplicando-se logaritmos } \\
& \log P_{i j}=\log A+\log x_{i j}
\end{aligned}
$$


onde,

$$
\sum_{j=1} x_{i j}=0
$$

Assim a média aritmética de 12 valores consecu tivos de $\log P_{i j}$ dá $\circ$ valor de $\log A$ e pode-se então obter A. Basta dividir os diferentes $P_{i j}$ por $A$ para se obter os respec tivos $x_{i j}$.

Os modelos I e II não levaram em conta a exis tência de tendências de variação a longo prazo, o que o autor passa a considerar nos modelos III e IV.

Modelo III: o componente estacional é somado a uma média ariţ mética móvel que varia linearmente em função do tempo.

$$
P_{i j}=A+B[12(i-1)+j]+x_{i j}
$$

12

onde

$$
\sum_{j=1} x_{i j}=0
$$

$A$ e $B$ são constantes e as variáveis são idênticas às anterio res. Neste caso $P_{i j}$ não é uma variável periódica. E possível, entretanto, obter-se os valores do componente $x_{i j}$ subtraindo de cada $P_{i j}$ a média aritmética móvel centralizada corresponden te.

$$
\text { Fazendo-se } 12(i-1)+j=t \circ \text { modelo III se }
$$
transforma em $P_{t}=A B t+X_{t}$ de onde se obtem após algumas subs tituições e simplificações que $M_{t}=A+B t$ onde $M_{t}=$ média arit mética móvel centralizada. Ressalta o autor que o modelo I é um caso particular do modelo III quando $B=0$.

Modelo IV: o componente estacional é multiplicado por uma mé dia geométrica móvel que varia exponencialmente em função do tempo. 


$$
P_{t}=A \cdot B^{t} \cdot X_{i j} \quad \text { onde } \prod_{j=1}^{12} x_{i j}=1
$$

A e B são constante, $t=12(i-1)+j$

aplicando-se logarítmos resulta:

$$
\log P_{t}=\log A+t \log B+\log x_{i j}
$$

\section{2}

onde

$$
\sum_{j=1} \log x_{i j}=0
$$

No caso deste modelo os valores do componente estacional $\mathrm{x}_{i j}$ são obtidos dividindo-se os preços $\mathrm{P}_{t}$ pela mé dia geométrica móvel centralizada correspondente, pois nesse caso temos $P_{t}=A B^{t} \cdot x_{t}$ e $G_{t}=A B^{t}\left(G_{t}=\right.$ média geométrica) logo $x_{t}=\frac{P_{t}}{G_{t}}$.

Nesse modelo, segundo o autor o componente esta cional apresenta periodicidade relativa e não absoluta como no modelo III.

Finalmente, argumenta o autor, que o componente estacional dos preços de produtos agropecuários apresenta pe riodicidade relativa e assim sendo o modelo IV é o que melhor serviria de base teórica para a determinação do componente es tacional das variações dos preços dos produtos agropecuários. não obstante essa colocação o autor utilizou também o método da média aritmética móvel centralizada para que fossem possí veis comparações entre os métodos. 
3 - CARACTERISTICAS GERAIS DOS PESCADOS

\subsection{Biologia Captura e Oferta}

As informações a seguir foram colhidas junto ao Instituto de Pesca, órgão da Secretaria da Agricultura na cida de de Santos.

Biologia: em relação a esse aspecto tem-se a considerar que via de regra, não há equivalência entre a clas sificação biológica do pescado e a classificação comercial da da pela CEAGESP. Como exemplo pode-se citar que Pescada Peque na, Pescada Média e Pescada Grande biologicamente são conhecí das como Pescada Foguete.

Outro exemplo desse fato ocorre com o Camarão Médio que é na verdade uma "mistura" de Camarão Rosa na fase juvenil (a sua cor não é bem rosada ainda nesta fase), de Cama rão Branco ou Legítimo e de outras espécies de camarão.

Com relação à época de maior ou menor captura 
(safra e entresafra) não se tem bem definida essas épocas devi do a vários fatores, entre eles: comportamento das espécies, temperatura das águas, existência ou não de outros fenômenos marítimos e/ou climáticos. Como exemplo pode-se citar que a sardinha até pouco tempo atrás apresentava um dos plicos máxí mos de captura nos meses mais quentes do ano e mais recentemen te esse pico tem ocorrido em meses de temperaturas mais bàixas.

Para que se tenha idéia da variação quanto às principais épocas de capturas, apresenta-se a seguir um quadro ilustrativo.

QUADRO 1: Principais Epocas de Captura - 1968/1975

Meses de maior Captura

\begin{tabular}{|c|c|c|c|c|c|c|c|c|c|c|c|c|}
\hline \multirow{2}{*}{ Produtos } & \\
\hline & $\mathrm{J}$. & F. & M & A & M & $J$ & $\mathrm{~J}$ & A & $\mathrm{S}$ & 0 & N. & D \\
\hline Tainha & & & & & & $\mathrm{x}$ & $\mathrm{x}$ & & & & & \\
\hline Pescada Goete & $\mathrm{x}$ & $x$ & & & & & & & & & & $\mathrm{x}$ \\
\hline Pescada Branca & $\mathrm{x}$ & $\mathrm{x}$ & $\mathrm{x}$ & & & & & & & & & $\mathrm{x}$ \\
\hline Pescada Cambucu & $\mathrm{x}$ & $\mathrm{x}$ & & & & & & & & & & $\mathrm{x}$ \\
\hline Sardinha & & & $\mathrm{x}$ & $\mathrm{x}$ & & & & & $\mathrm{x}$ & $\mathrm{x}$ & & \\
\hline Enchova & & & & $\mathrm{x}$ & $\mathrm{x}$ & & & & $\mathrm{x}$ & $\mathrm{x}$ & & \\
\hline Pescada Foguete & & & & & & & & & & & & \\
\hline Peq.Média Grande & & & & & & & $x$ & $\mathrm{x}$ & $\mathrm{x}$ & & & \\
\hline Pescada Tortinha & $\mathrm{x}$ & $\mathrm{x}$ & $\mathrm{x}$ & $\mathrm{x}$ & $\mathrm{x}$ & & & & & $\mathrm{x}$ & $\mathrm{x}$ & $\mathrm{x}$ \\
\hline Camarão Branco & & & & $x$ & $\mathrm{x}$ & $\mathrm{x}$ & $\mathrm{x}$ & & & & & \\
\hline Camarão Rosa & & & & $\mathrm{x}$ & $\mathrm{x}$ & $\mathrm{x}$ & $\mathrm{x}$ & & & & & \\
\hline Camarão Médio & & & & $x$ & $\mathrm{x}$ & & $x$ & $x$ & $\mathrm{x}$ & & & \\
\hline $\begin{array}{l}\text { Camarão Sete } \\
\text { Barbas }\end{array}$ & & & & $\mathrm{x}$ & $\mathrm{x}$ & $\mathrm{x}$ & $\mathrm{x}$ & & & & & \\
\hline
\end{tabular}

FONTE: Instituto de Pesca - Secretaria Agricultura - Santos 
Captura: a frota comercial do Brasil, segundo a mesma fonte, pode ser classificada, basicamente,em quatro gran des grupos a saber:

a) Frota Traineiras ou de peixes de superficie: esses barcos efetuam a captura das referidas espécies através de redes que são lançadas ao mar e rapidamente os barcos se mo vimentam para éfetuar o chamado "cerco" ao cardume.

b) Frota Arrastão por Portas: essas embarcações são destinadas à captura, basicamente, dos camarões que são en contrados tanto próximos à costa (camarão sete barbas e cama rão braṇco) quanto mais afastados da costa (camarão rosa).

c) Frota Arrastão por Parelhas: destinados a captura de espécies (Pescadas, Corvina, etc.) cujo "habitat" é em águas mais fundas.

d) Frota Atuneiros: capturam basicamente os atuns e os agulhões.

De posse dessas informações sobre a frota brasi leira conclui-se que existe uma certa especificidade das embar cações, o que na maioria das vezes não permite a transformação de um tipo de embarcação em outro, num curto espaço de tempo.

Oferta: das considerações anteriores conclui-se que a oferta de pescados depende muito da interação biologia/ captura, o que vem determinar maior ou menor disponibilidade desses produtos no mercado. Existem entretanto outros fatores que podem afetar essa disponibilidade, pelo menos de algumas espécies, p.e., o camarão, que dada a distância da costa em que são capturados, os barcos demoram um tempo muito maior des de a sua saída até sua volta quando comparado com barcos traí neiros que saem à noite e voltam ao amanhecer.

3.2: Situação Mundial do Pescado

De um modo geral tem-se que até 1969 houve dimi 
nuição das capturas com uma retomada a partir de 1970 porém, esse crescimento se deu de forma lenta e irregular.

Entre 1960 e 1970 a pesca destinada à produção de farinhas e óleos foi responsável por $60 \%$ do crescimento da produção.

A produção de peixes para consumo alimentar di reto vem crescéndo desde 1960, entretanto a partir de 1970 apre senta taxas decrescentes no crescimento.

Ainda, segundo a FAO, a produção mundial de pes cado apresenta os seguintes elementos (ver Tabela 1 p.18).

Em quase todos os países onde os pescados repre sentam elemento importante na dieta alimentar, o consumo/habitante aumentou a partir de um quinzena de anos $(1945 / 55)$.

Tem-se verificado que a expansão da produção de pescados para consumo direto nos países em desenvolvimento é uma das raras tendências das pescas mundiais, que se mantive ram durante os anos 60 e 70, mas ela não foi suficiente para impedir um declínio rápido da taxa de crescimento das capturas mundiais totais, que cairam de 6\% durante os anos 60 a menos de $1 \%$ nos anos 70. Esse declínio deve-se à redução de esto ques de peixes convencionais (aqueles que se pode explorar com as técnicas e equipamentos disponíveis e que são de fácil co mercialização por já serem conhecidos) .

Assim, segundo a FAO, é necessário uma gestão racional, isto é, uma limitação rigorosa do esforço da pesca, se se desejar que as capturas subam a seus níveis de outrora.

Entretanto, existem no hemisfério sul e águas tropicais recursos inexplorados, mas como uma boa parte deste potencial consiste de espécies diversas, sendo que nenhuma mui to abundante, sua utilização comercial colocará e coloca desde jā problemas difíceis de comercialização.

Para os países em desenvolvimento as perspecti vas de aumento nas capturas são maiores do que nos países de 


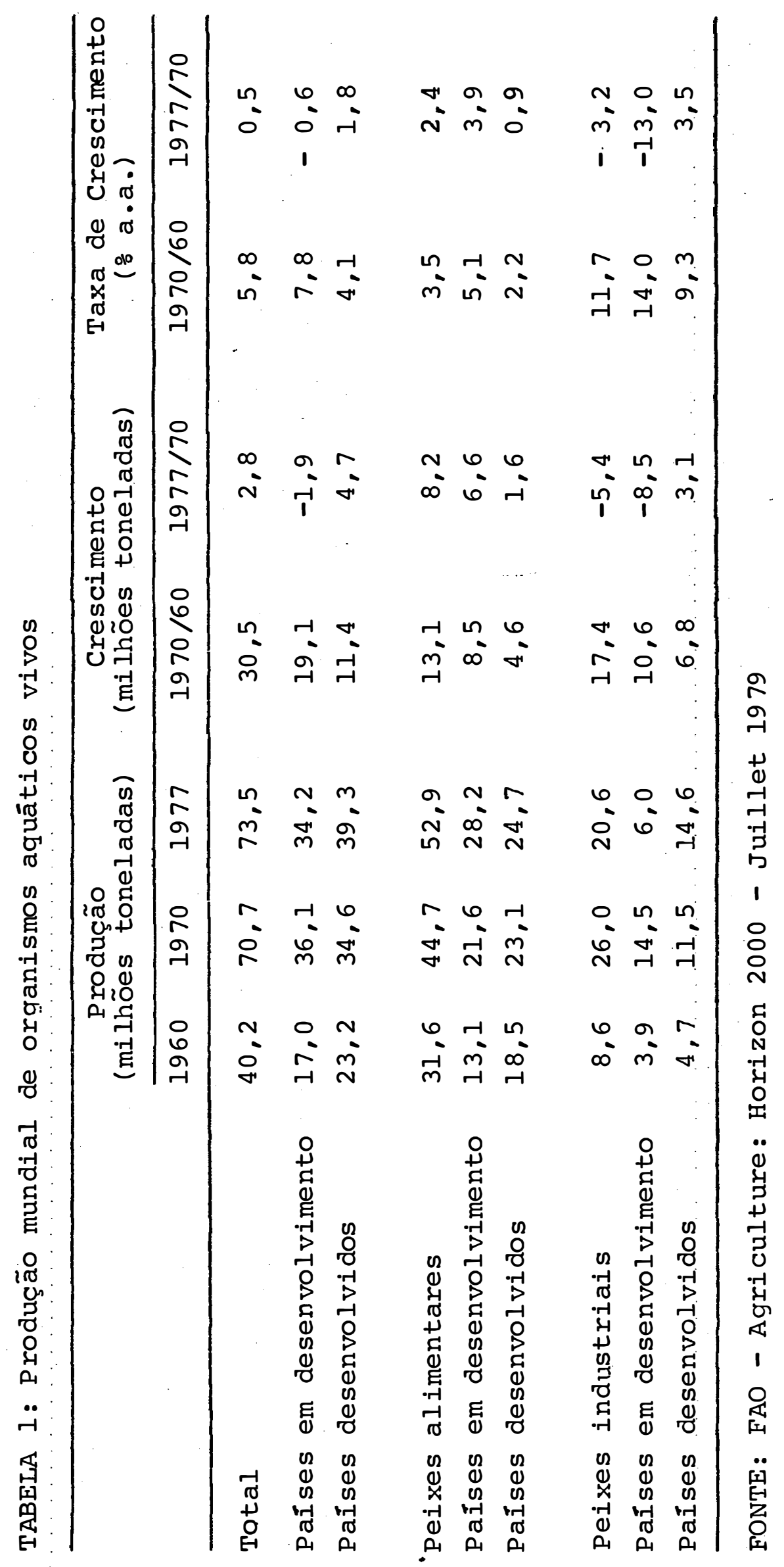


senvolvidos tendo-se em conta a abundância relativa de recur sos fracamente explorados até então.

Adotando-se uma taxa de crescimento demográfico da ordem, de 2\%, a produção nos países em desenvolvimento será, em média, menor e não poderá manter a oferta por habitante: apesar da possibilidade de se utilizar para o consumo humano parte das capturas atualmente destinadas à produção de farinha e de óleo.

A despeito da forte queda na produção de pesca dos, os fatores que determinam a demanda, em particular, popu lação e renda, perseguirão sua expansão a um rítmo próximo das taxas históricas. A tabeḷa 2 (p. 20) apresenta o crescimento estimado da demanda de peixe.

Pode-se constatar com base nas tendências atuais, e na hipótese de que os preços relativos permanecerão constan tes, a demanda mundial aumentará daqui até o final do século a uma taxa anual de cerca de 3,3\%, cifra esta que é necessário comparar à taxa de $1 \%$ no crescimento da produção anual. Isto significa que se persistir essas tendências haverá escassez de oferta de produtos da pesca em termos mundiais. 


\begin{tabular}{|c|c|c|c|c|c|c|c|c|c|c|c|}
\hline \multirow{4}{*}{ 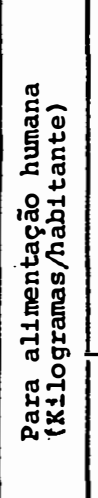 } & \multirow{3}{*}{ 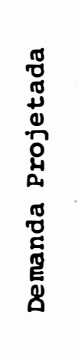 } & * & 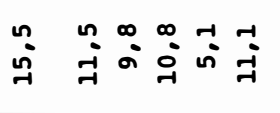 & $\dot{n}$ & $\underset{m}{\sim}$ & $\ddot{\sigma}$ & $\vec{i}$ & $\ddot{a}$ & $\stackrel{\infty}{\dot{m}}$ & 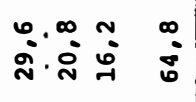 & \\
\hline & & * & 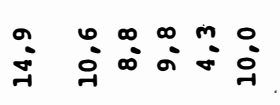 & $\dddot{\vdots}$ & $\stackrel{\sim}{\infty} \underset{\infty}{\infty}$ & $\stackrel{0}{\infty}$ & $\dot{i}$ & $\stackrel{n}{\infty}$ & $\stackrel{\infty}{\infty}$ & 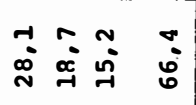 & \\
\hline & & $\begin{array}{l}\circ \\
\vdots \\
\rightarrow\end{array}$ & 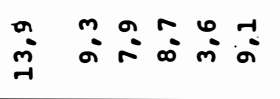 & $\dot{\xi}$ & 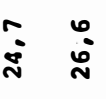 & $\ddot{0}$ & สิ & $\stackrel{\infty}{\infty}_{0}^{\infty}$ & : & $\begin{array}{c}n \\
n \\
n=-1\end{array}$ & \\
\hline & 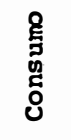 & 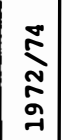 & 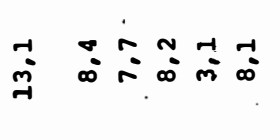 & $\overrightarrow{0}$ & $\stackrel{n}{m} \quad \stackrel{n}{n}$ & ตे & ने & $\dddot{0}$ & $\overrightarrow{0}$ & 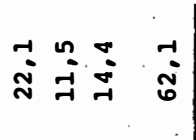 & \\
\hline \multirow{4}{*}{ 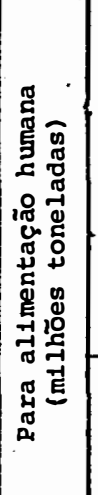 } & \multirow{3}{*}{ 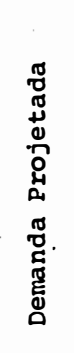 } & * & 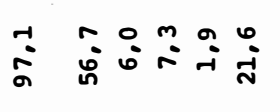 & $\ddot{9}$ & $\ddot{\circ}:$ & in & $a$ & $m$ & $: \stackrel{\infty}{m}$ & 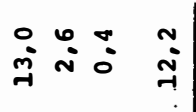 & \\
\hline & & * & 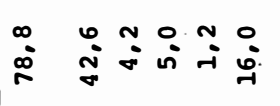 & 0 & $\dddot{m}$ & $\dddot{0}$ & $\stackrel{\sim}{\infty}$ & $\stackrel{\infty}{\infty}$ & $: \frac{\infty}{m}$ & 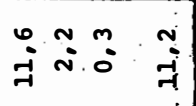 & \\
\hline & & $\begin{array}{l}0 \\
\$ \\
\text { ने }\end{array}$ & 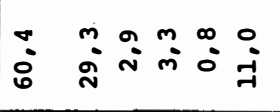 & $\stackrel{\text { İ }}{\exists}$ & $\because \quad \vec{m}$ & $\cong$ & $\ddot{r}$ & $\dot{\sigma}$ & $\stackrel{a}{i}$ & $\begin{array}{cccc}\infty & m & \vdots \\
0 & -1 & 0 & a\end{array}$ & \\
\hline & 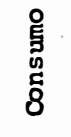 & 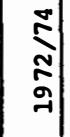 & 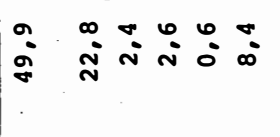 & $\stackrel{9}{\infty}$ & $\because \frac{i}{i}$ & $\hat{m}$ & 9 & $\dddot{*}$ & $\stackrel{\infty}{\infty}$ & 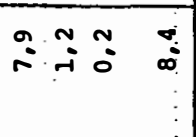 & \\
\hline \multirow{2}{*}{$\mid$} & 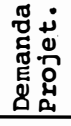 & 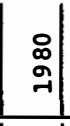 & 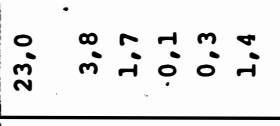 & $\stackrel{m}{0}$ & $\because$ & $\stackrel{0}{i}$ & $\stackrel{\infty}{\sim}$ & 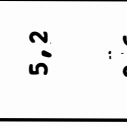 & $\stackrel{0}{i}$ & $\stackrel{\infty}{\infty} \underset{-}{m}=\frac{n}{j}$ & \\
\hline & 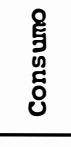 & 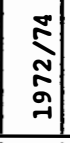 & 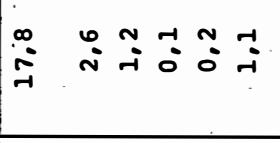 & $\dddot{n}$ & $\because \stackrel{n}{n}$ & $\stackrel{\infty}{-i}$ & $\hat{0}$ & $\stackrel{n}{0}$ & $\vec{i}$ & $\dot{m}=\begin{array}{ccc}\infty & m \\
-i & 0\end{array}$ & R \\
\hline \multirow{4}{*}{ 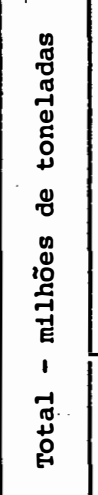 } & \multirow{3}{*}{ 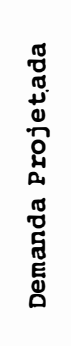 } & * & 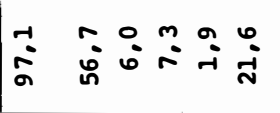 & $\stackrel{\circ}{9}$ & 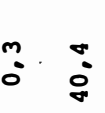 & $\hat{n}$ & $a$ & in & $\stackrel{\infty}{m}$ & 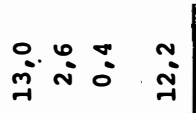 & \\
\hline & & $\left|\begin{array}{c}* \\
\circ \\
\text { ने }\end{array}\right|$ & 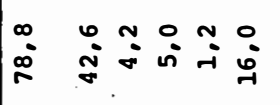 & $\stackrel{0}{0}$ & $\because \quad \stackrel{m}{0}$ & $\stackrel{9}{\sigma}$ & $\stackrel{\infty}{\infty}$ & $\stackrel{\infty}{\infty}$ & $\stackrel{\infty}{m}$ & 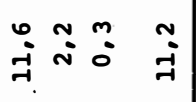 & 미 \\
\hline & & 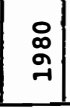 & 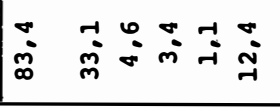 & $\stackrel{n}{7}$ & $\because \quad m$ & $\because$ & 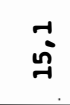 & $\stackrel{0}{\circ}$ & $\tilde{n}$ & 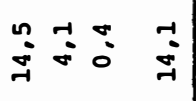 & 。 \\
\hline & \begin{tabular}{l}
8 \\
\multirow{g}{0}{} \\
$\tilde{0}$ \\
8
\end{tabular} & 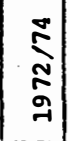 & 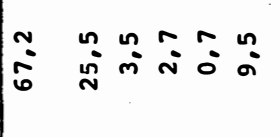 & $\because$ & $\because \frac{2}{n}$ & $\tilde{n}$ & $\stackrel{0}{m}$ & $\tilde{\infty}$ & $\stackrel{9}{*}:$ & 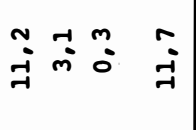 & $\bar{z}$ \\
\hline & & & 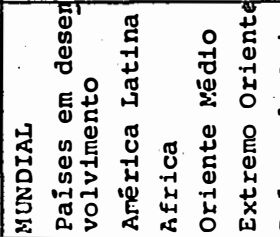 & 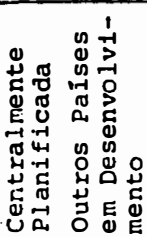 & 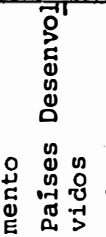 & 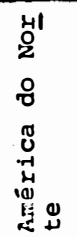 & 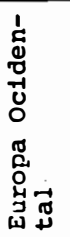 & 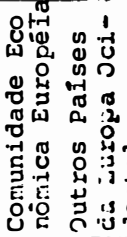 & 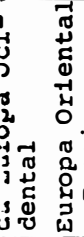 & 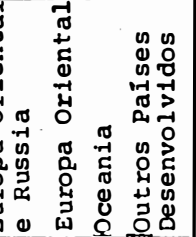 & \& \\
\hline
\end{tabular}


3.2.1. Situação do Pescado no Brasil

Segundo dados do Anuário Estatístico do Brasil, o Estado de São Paulo ocupou, no período 1968/1970, o segundo lugar na produção de pescado, com uma média anual de 63.450 to neladas contra 91.389 toneladas produzidas pelo Rio Grande do Sul, sendo que a produção média do Brasil para o mesmo período foi de 509.292 toneladas proporcionando ao Rio Grande do Sul uma participação de 17,94\% e para são Paulo 12,46\%. Entretan to, mais recentemente, o Estado de São Paulo tem tido sua par ticipação reduzida na produção total brasileira de pescado. No período 1973/1975 o Rio de Janeiro passou a ocupar o primeiro lugar na produção de pescado com uma média anual de 156.180 to neladas, seguido por Santa Catarina com 121.862 toneladas, Rio Grande do Sul com 66.700 toneladas.

Ao considerar-se o valor da produção de pescado no período 1968/1970, O Estado de São Paulo ocupava o primeiro lugar com cerca de 77 milhões de cruzeiros, enquanto que no pe ríodo de 1973/1975 perdeu essa posição para o Estado do Rio de Janeiro que participou com $16,72 \%$ do valor total da produção, ficando o Estado de São Paulo em segundo lugar com 12,85\% sen do que estes Estados contribuiram respectivamente com Cr\$ ... $338.906 .000,00$ e $\operatorname{Cr} \$ 260.372 .000,00$.

MORIMOTO (1975) afirma que a demanda pelo pesca do no Estado de São Paulo apresentou-se, em 1969, com os seguin tes componentes básicos: $47 \%$ da produção paulista destinou-se ao Entreposto Terminal de São Paulo (ETSP) - CEAGESP; 31\% às indústrias; $15 \%$ enviado ao interior do Estado de São Paulo e a outros Estados, os restantes $7 \%$ foi destinado ao consumo nas próprias regiões pesqueiiras.

JUNQUEIRA et alii (1971) mostram que os volumes de pescado comercializados no Entreposto Terminal de São Paulo (ETSP) no periodo 1968 a 1970 foram 43.141 t;41.382 t.e 45.684 t., respectivamente para os anos 1968, 1969, e 1970. Esse vo 
lume comercializado participou, respectivamente, com $3,9 \%, 3,8 \%$ e 3,6\% no volume total comercializados no ETSP. Indicam ainda que os valores da comercialização do pescado no mesmo período foram de $\operatorname{Cr} \$ 31.145 .000,00, \operatorname{Cr} \$ 45.136 .000,00$ e $\operatorname{Cr} \$ 52.511 .000,00$, participando dessa maneira com $9,9 \%, 8,7 \%$ e 9,2\% respectivamen te, no valor total das comercializações realizadas pelo ETSP naquele período.

\subsection{O Mercado de Pescado no CEAGESP}

As informações que se seguem foram obtidas jun to ao Departamento de Pescado da CEAGESP.

o funcionamento normal do mercado de pescado ocorre no periodo compreendido entre as 3 e 7 horas, sendo que antes das 3 horas não é permitido a abertura de nenhum veículo.

Esse fato deve-se a dois motivos básicos: pri meiro para que não haja distorções quanto ao processo de comer cialização e segundo para manter a integridade do lacre do se $\underline{r}$ viço de Inspeção Federal (SIF) que é obtido no local de origem do veículo. Entretanto se não for possível obter essa inspe ção no local de origem ou num local próximo, a mesma será efe tụada na própria CEAGESP antes das 3 horas.

O ETSP/CEAGESP recebe, em média, 250 toneladas de pescados por dia o que é feito com aproximadamente 50-60 ca minhões. Entretanto na Semana Santa cheọa-se a 700 toneladas por dia.

Dado o elevado número de veículos e o pequeno espaço de tempo não tem a CEAGESP condições materiais e huma nas para um controle rígido da quantidade e qualidade dos pro dutos declarados na nota fiscal, que é a condição básica para que o veículo tenha acesso ao Departamento de Pescado.

Entretanto a CEAGESP efetua o controle anterior através de uma amostra de $10 \%$ dos veículos, aleatóriamente, con 
frontando quantidades e qualidades (ou tipos) dos produtos de clarados na nota fiscal.

Nessas condições se houver fraude incorrerá o infrator numa "TARIFA ESPECIAL" que em muitos casos não chega a ser coberta pelo preço do produto, ou seja, o valor da tari fa é maior do que o preço do produto.

Quanto aos elementos que participam do processo de comercialização do pescado na CEAGESP, não se tem informa ções precisas para o perỉodo em questão (1968 a 1975), entretan to, mais recentemente (1979) tem-se a seguinte composição: 30 vendedores sendo que 3 deles produzem e vendem e os 27 restan tes são apenas vendedores. Do lado da demanda existem 1040 va rejistas ambulantes, 600 feirantes e 510 estabelecimentos do tipo supermercados, hotéis, peixarias, etc..

No tocante à origem dos produtos tem-se basica mente os seguintes componentes: 45 a $50 \%$ do pescado comerciali zado na CEAGESP vem de Santos e os 50 a 55\% restantes vem de outras cidades do litoral paulista e de outros estados. Essa composição, entretanto, não é rígida pois em determinadas épo cas a participação paulista ultrapassa os $50 \%$ e outras épocas aparece o Rio Grande do Sul abastecendo com mais de $50 \%$ do pes cado comercializado pela CEAGESP.

Vale a pena lembrar que nem sempre a origem de clarada, p.e., Santos, é a real, pois os barcos pesqueiros se deslocam tanto para outras cidades do litoral paulista como também para outros estados desembarcando os produtos da pesca em Santos, p.e., e dai a origem declarada.

Quanto ao tipo de produto sabe-se que, em média, de 40 a $50 \%$ do total (em peso) de pescado comercializado pela CEAGESP é constituído pela sardinha, existindo inclusive um setor específico para esse produto, dado, basicamente pelo vo lume que é comercializado.

Das considerações anteriores e lembrando que a 
CEAGESP é a "única fonte atacadista destes produtos (pescados) na Capital" (GUIMARÃES 1969 citado em GALLO, J. 1976) deduz-se facilmente que o ETSP-CEAGESP é o responsável pela comerciali zação da quase totalidade do pescado fresco consumido na Gran de são Paulo. 
4 - METODOLOGIA

4.1. Material

As informações básicas para esse estudo foram coletadas junto ao-Entreposto Terminal de são Paulo (ETSP) da CEAGESP e referem-se a preços médios mensais e quantidades a nível de atacado. O período de análise é de 1968 a 1975 para todos os produtos exceto para a pescada branca cujo período abrange 1968 a 1974. Para a obtenção dos preços reais o "Indi ce 2" da Fundação Getúlio Vargas foi utilizado para deflacio nar os preços correntes.

\subsection{Métodos}

Pela revisão de literatura apresentada pode-se concluir que o método da média aritmética móvel centralizada tem sido usado com grande frequência, não obstante, as conside rações feitas por LANGE (19.61) e HOFFMANN (1969), principalmen 
te, onde são discutidas e justificadas a melhor adaptação do método da média geométrica móvel centralizada para a obtenção dos índices estacionais de preços dos produtos agropecuários. Este fato deve-se, notadamente, à complexidade dos cálculos ne cessários para a obtenção dos indices estacionais a partir do segundo método.

A disponibilidade de uso de computadores eletrô nicos, mais recentemente, tem proporcionado aos pesquisadores a eliminação dessa barreira e como consequência a obtenção de índices estacionais, por um ou outro método, pode se dar com igual facilidade.

Assim sendo, neste trabalho, procurou-se identi ficar os índices estacionais de preços de pescado utilizandose da média aritmética e da média geométrica, partindo-se de preços correntes e de preços reais, na tentativa de reforçar os resultados obtidos por HOFFMANN (1969), quando estudou a va riação estacional de preços de 27 produtos agropecuários. Os resultados básicos do referido trabalho resumem-se em: não ha ver diferenças quanto ao uso de preços reais ou preços corren tes para a obtenção dos índices de preços, quer seja utilizan do-se da média aritmética ou da média geométrica.

Por outro lado, HOFFMANN (1969), não utilizou as quantidades dos produtos, em termos de índices, o que para este estudo é de suma importância, dado que o pescado apresen tando,além de crescimento biolóạico, uma mobilidade física, ge ra problemas na oferta do mesmo no mercado (CEAGESP). Esse fa to sugere que não basta o conhecimento do ciclo biológico, ou seja, as indicações das épocas de maior ou menor captura; tor na-se necessário conhecer essa mobilidade em todos os seus as pectos o que sem dúvida é uma das limitações do presente estū do.

métodos. 2 /

Passa-se a seguir a um comentário suscinto dos

2/ Para maiores detalhes ver HOFFMANN (1969) 


\subsubsection{Método da Média Aritmética Móvel}

A média aritmética móvel de uma série temporal (de preços mensais p.e.) é definida como a soma de 12 termos consecutivos da série devidida por 12. Assim sendo perdem-se. 6 meses do início da série e mais 6 meses ao final da série, tendo-se em conta que a soma dos 12 primeiros termos dividida por 12 é a média aritmética entre $\circ 6 \%$ e $07 \%$ mês do primeiro período. A soma dos últimos 12 termos da série dividida por 12 fornece a média aritmética entre $06 \%$ e $07 \%$ mês do último período. Assim sendo, para possibilitar a comparação da média aos valores da série, define-se a média aritmética móvel cen tralizada de 12 meses, como sendo a soma de 13 termos consecu tivos sendo somados a metade do primeiro e a metade do décimo terceiro dividida por 12 assim agindo essa média será corres pondente ao 79 mês do primeiro período (19 ano da série). Mate máticamente esta relação pode ser assim expressa:

$$
\begin{aligned}
& M_{t}=\frac{1}{k}\left(0,5 v_{t-\lambda}+v_{t-\lambda+1}+\ldots+v_{t}+\ldots+v_{t+\lambda-1}+0,5 v_{t+\lambda}\right) \\
& \text { onde } \\
& k=12=2 \lambda
\end{aligned}
$$

Obtidas as médias aritméticas móveis centraliza das, o próximo passo será a determinação dos índices estacio nais de cada mês do período.

Para a obtenção dos indices mensais basta que seja cada preço (real ou corrente) dividido pela respectiva mé dia aritmética e o resultado dessa divisão multiplica-se por 100. Tem-se então os índices mensais em número de 12.(n-1), - onde $\mathrm{n}=\mathrm{n}$ o anos da série. Assim têm-se para caāa mês $(\mathrm{n}-1)$ repetições e o passo seguinte é a obtenção dos índices estacio nais médios.

Os Indices estacionais médios são obtidos soman do-se os $(n-1)$ índices de cada mês e dividindo-se por $(n-1)$. 
Para que seja verificada a dispersão dos indi ces estacionais em torno de sua média calcula-se o erro padrão (s) dos índices de variação estacional através de

neiro, por exemplo.

$$
s_{j a n}=\sqrt{\frac{\sum\left(^{I} j a n-\bar{I} j a n\right)^{2}}{n-1}} \text {, para o mês de Ja. }
$$

A seguir efetua-se a análise de variância dos índices, como se segue:

\begin{tabular}{|c|c|c|c|}
\hline C.V. . . & G.L. & $S \cdot Q$. & Q.M. \\
\hline Meses (estacionalidade) & $11 \cdots$ & & \\
\hline Resíduo & $12(n-2)$ & & \\
\hline Total. & $12(n-1)-1$ & . & \\
\hline
\end{tabular}

4.2.2. Método da Média Geométrica Móvel

Nesse método o raciocínio é completamente análo go ao anterior bastando modificar o cálculo da média para:

$$
G_{t}=\sqrt{v_{t-\lambda}^{0,5} \cdot v_{t-\lambda+1} \cdots v_{t} \cdots v_{t+\lambda-1} \cdot v_{t+\lambda}^{0,5}}
$$

onde $\mathrm{k}=12=2 \lambda$, e que a média qeométrica $g_{t}=\ln G_{t}$

A medida da dispersão dos indices estacionais em torno da média pode ser obtida calculando-se

$$
\mathbf{s}_{j a n}=\sqrt{\frac{\sum(\log I \text { jan }-\log \bar{I} j a n)}{n-1}} \text {, para } 0
$$

mês de Janeiro, por exemplo. 


\section{5 - RESUltados E DISCUSSÃo}

Verificou-se que a utilização de preços reais ou preços correntes, para a obtenção dos índices estacionais, não apresenta diferenças tais que possam recomendar preferen ciallmente $\mathrm{o}$ uso de um ou de outro processo.

Com relação ao emprego da média geométrica ou da média aritmética para a obtenção de indices de preços os re sultados vem reafirmar o trabalho de HOFFMANN (1969) que indi ca a equivalência entre os índices de preços obtidos por um ou por outro método.

Para os indices de quantidades os resultados mostraram que tanto um como outro método levam : a resultados muito semelhantes, como pode ser observado no Quadro 3 (p. 31) através dos $R^{2}$, ou através das figuras de 1 a 13 .

Ao mencionar-se que os preços de pescado eram afetados por uma estacionalidade de demanda, assumia-se, como hipótese, que durante a Semana Santa, p.e., esperar-se-iam os 
maiores indices de preços tendo-se em vista que durante esse perïodo (março/abril) haveria um deslocamento da curva de de manda agregada de pescado, pois pela tradição religiosa nesse periodo deve-se consumir peixe 3 /. Essa hipótese foi, entretan to, parcialmente derrubada ao constatar-se que 5 (pescada bran ca, pescada cambucu, camarão médio, camarão sete barbas e tai nha) dos 13 produtos analisados não apresentaram tal comporta mento.

Tendo-se em vista essas considerações, efetuarse-á as análises com base no método da média aritmética e quan do se fizer necessário o método da média geométrica será consí derado.

Passa-se a seguir a uma análise mais detalhada dos 13 produtos onde procurou-se agrupar aqueles que apresen tam comportamento semelhante com a finalidade de facilitar a análise eliminando-se assim a repetitividade que fatalmente ocorreria.

$$
\text { Apresenta-se a seguir um quadro (Quadro 2) onde }
$$
são relacionados os meses que apresentaram os indices de pre ços e de quantidades máximos e mínimos no presente estudo, en globando o período de 1968/1975 (exceto pescada branca-68/74). QUADNO 2: Indices de Preços o de Quant1 dades utillzácio o método da mëcia aritmäticá centra $11 z a c a$ de 12 moses (i963 a 1975).

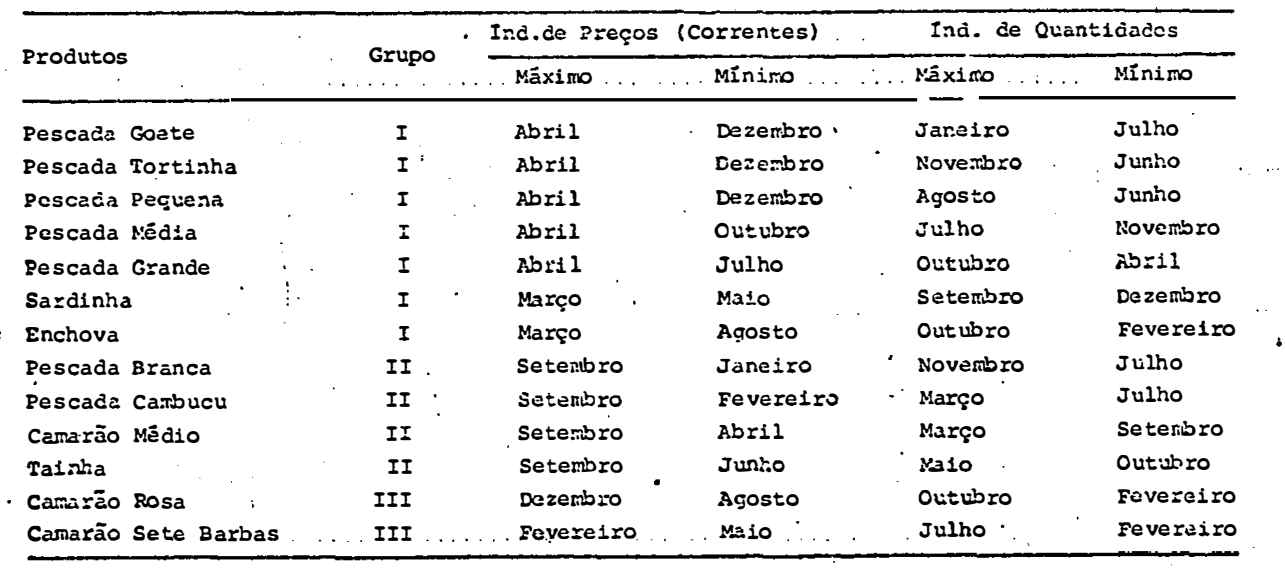

3/ Vale a pena lembrar que devido à influências da colonização européia no Brasil, durante a Semana Santa consumia-se grande quantidade de baca 1hau até pouco tempo atrás, sendo que mais recentemente, dado o altō preço do bacalhau (importado) passou-se a substituí-1o por similares na cionais e outros como o cação que são encontrados no mercado a preços bem mais acessiveis. 


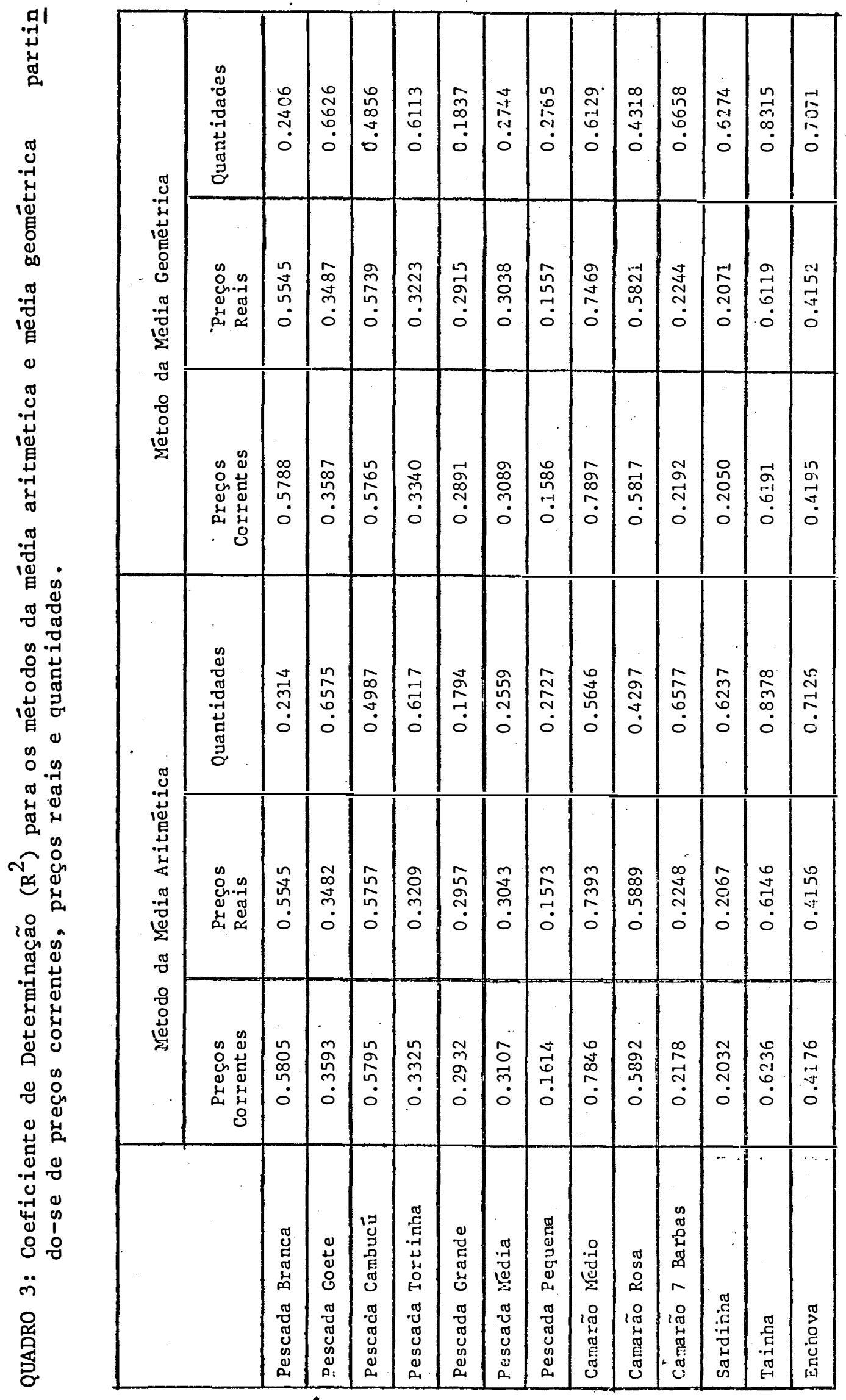


O Instituto de Pesca da Secretaria da Agricultu ra do Estado de São Paulo, através do controle de desembarque no Porto de Santos, indica as principais épocas de captura pa ra o período em análise (1968 a 1975), tomando por base as quan tidades desembarcadas, como sendo aquelas apresentados no qua dro 1 ( $p .15)$.

Comparando-se os dados dos Quadros 1 e 2 verifi ca-se que existe uma certa coerência entre as principais épo cas de capturas e os índices máximos das quantidades comercia lizadas pela CEAGESP, entretanto para alguns produtos como a pescada grande, enchova, pescada branca, pescada cambucu, cama rão médio, tainha e camarão rosa observa-se a existência de de fasagens entre as principais épocas de captura e os respecti vos índices máximos das quantidades comercializadas.

Com base nos dados do Quadro $2 \circ$ agrupamento proposto é o que se segue:

GRUPO I: Pescadas (goete, tortinha, pequena, média e grande) com índice máximo de preços em abril, Sardinha e Enchova com indice máximo de preços em março.

GRUPO II: Pescadas (branca e cambucu), Camarão Médio e Tainha com índice máximo de preços em setembro.

GRUPO III: Camarão Rosa e Camarão sete Barbas com índice máxi mo de preço em dezembro e fevereiro respectivamente.

Em seguida efetua-se a análise de cada um dos três grupos propostos.

Todos os produtos do grupo I apresentaram o com portamento esperado, ou seja, que os índices máximos de preços ocorreriam nos meses de março/abril, tendo-se em conta a exis tência da Semana Santa nesse período, e que devido a tradições religiosas deve-se consumir peixe. A ocorrência daqueles índi ces máximos se deve a um aumento na quantidade demandada des ses produtos, o que fatalmente elevaria seus preços.

Entretanto șe faz necessário uma análise detą 
Ihada dos sete produtos desse grupo para uma melhor caracteri zação da ocorrência da hipótese básica deste trabalho.

Observando-se as figuras de 1 a 7 (p.p.35 a 41) verifica-se claramente que durante a Semana Santa(março/abril) a demanda por pescados aumenta, isto provoca elevação dos pre ços desses produtos, ou seja, os índices de preços são máximos. Ainda pelas figuras 1 a 7 , nota-se que em ter mos de tendência, há equivalência entre as características des censionais dos indices de quantidades e as caracteristicas as censionais dos indices de preços, sem que contudo se possa ex plicar os máximos indices de preços estarem ocorrendo devido aos mínimos índices de quantidades. Senão veja-se:

a) pescada goete (fig̣ura 1 p. 35 ) se o máximo índice de preço fósse explicacio pelo mínimo índice de quantida de, aquele deveria ocorrer em julho e não em abril.

b) pescada tortinha (figura $2 \mathrm{p} .36$ ) o indice máximo de preço deveria ocorrer em julho e não em abril. Outro fato importante é que este produto apresenta um índice de pre ço elevado em setembro (próximo ao valor do máximo), que não se justificaria em termos do indice de quantidade, pois este se apresenta na fase ascensional. Tal fato pode estar indican do que este produto estaria sendo usado como substituto (além de outros pescados) para a carne bovina, que neste período se apresenta em condições de entre-safra.

c) pescada pequena (figura $3 \mathrm{p} .37$ ) nota-se que de janeiro a abril o índice de quantidade apresenta-se em cres cimento, ao mesmo tempo em que 0 índice de preços tem $\circ$ mesmo comportamento o que não justificaria o máximo índice de preço em abril.

d) pescada média e grande (figura 4 e 5 p.38/39) se os índices de preços fossem dados em função direta da quan tidade comercializada na CEAGESP, para esse produto esperarse-iam que aqueles indices deveriam apresentar preços mais constantes e não uma variação como apresentada, ou seja, o au 
mento ou a queda nos preços próximo de abril (índice máximo) indica modificações na demanda.

e) sardinha (figura 6 p. 40) verifica-se que 0 indice de quantidade apresenta-se, de janeiro a maio, com ca racterísticas ascensionais, o que levaria os índices de preços a apresentar tendência descensional. Isto foi verificado, en tretanto, mesmo assim de fevereiro a março o índice de preço aumentou quando deveria cair.

f) enchova (figura 7 p. 41) apesar deste produ to apresentar sua captura concentrada nos meses de julho a no vembro, de fevereiro a abril observa-se um pequeno acréscimo nos indices de quantidades o que não justificaria o aumento dos índices de preços de fevereiro para março, justificando entre tanto a queda de março para abril nos índices de preços.

Comparando-se o quadro 1 (p. 15) com o quadro 2 (p. 30) no tocante às principais épocas de capturas para os produtos desse grupo, nota-se que somente a pescada grande não apresentou o seu indice máximo de quantidade comercializada, compatível com as épocas indicadas, para o mesmo perỉodo, pelo Instituto de Pesca. Tal fato não nos parece claro, pois tendo em vista que pescada pequena, média e grande são conhecidas co mo pescada foguete e assim sendo, deveriam apresentar o mesmo comportamento.

A única justificativa, para essa defasagem, pa rece estar ligada à captura, ou seja, os dados do quadro 1 re ferem-se à pescada foguete e não especificamente à pescada pe quena, média ou grande. 

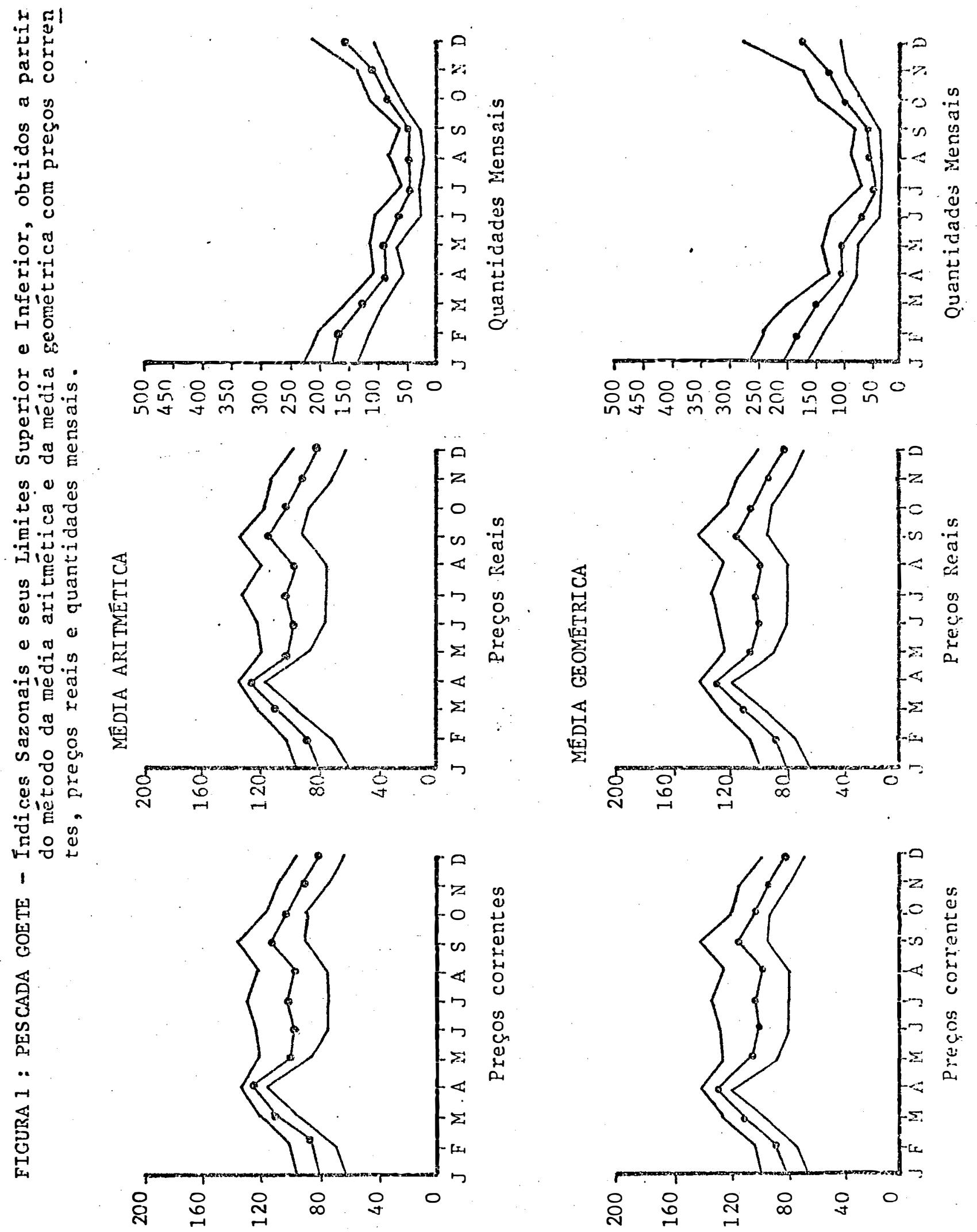

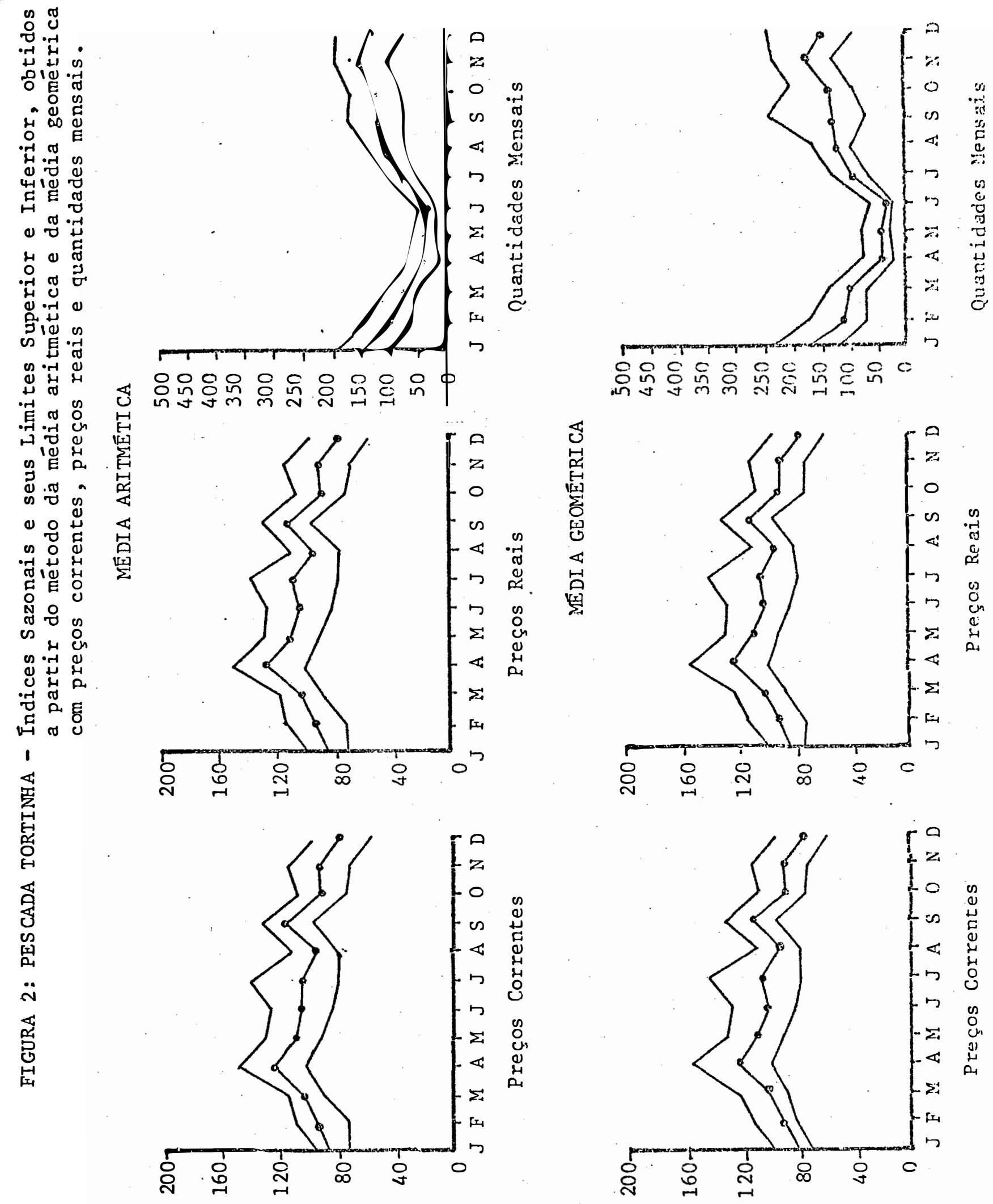


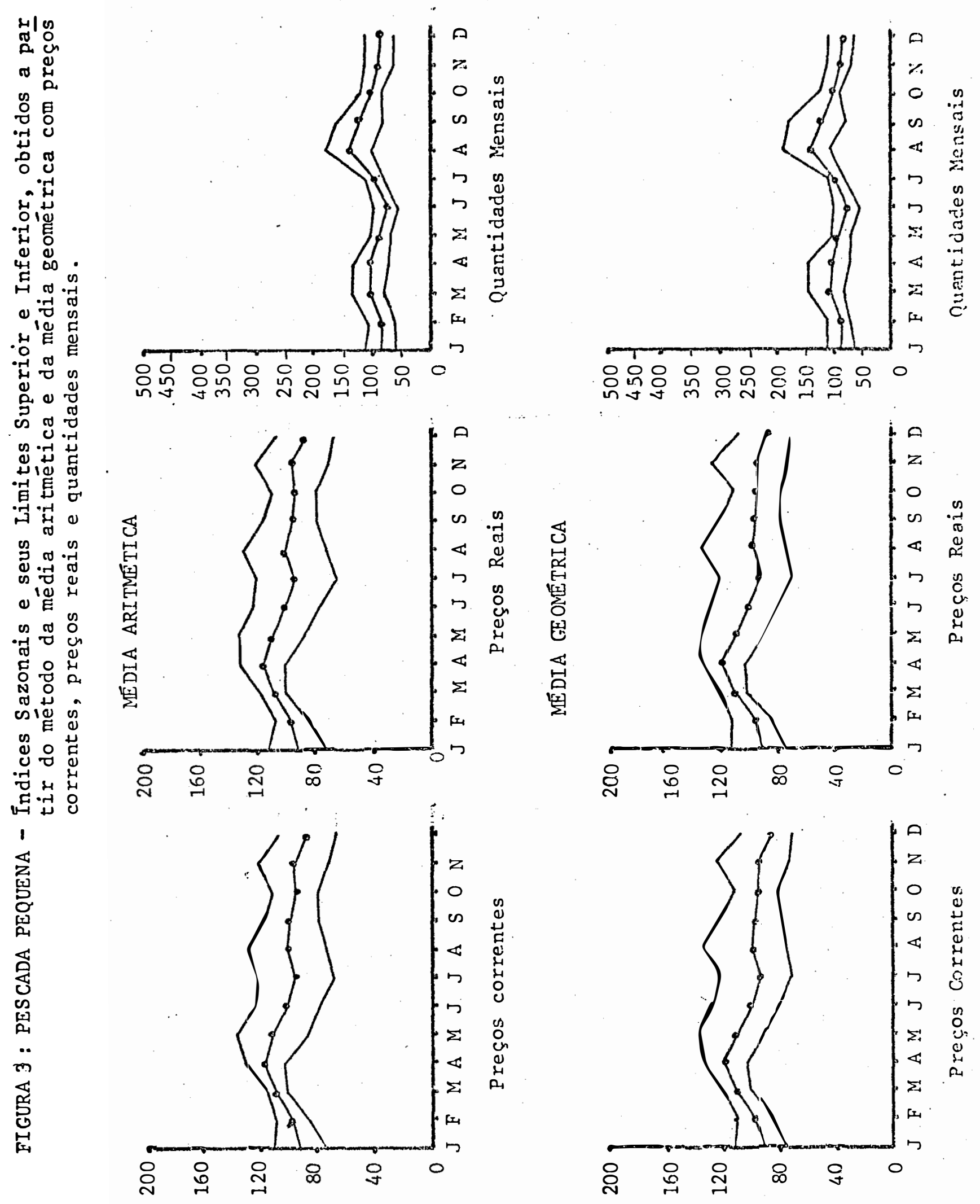




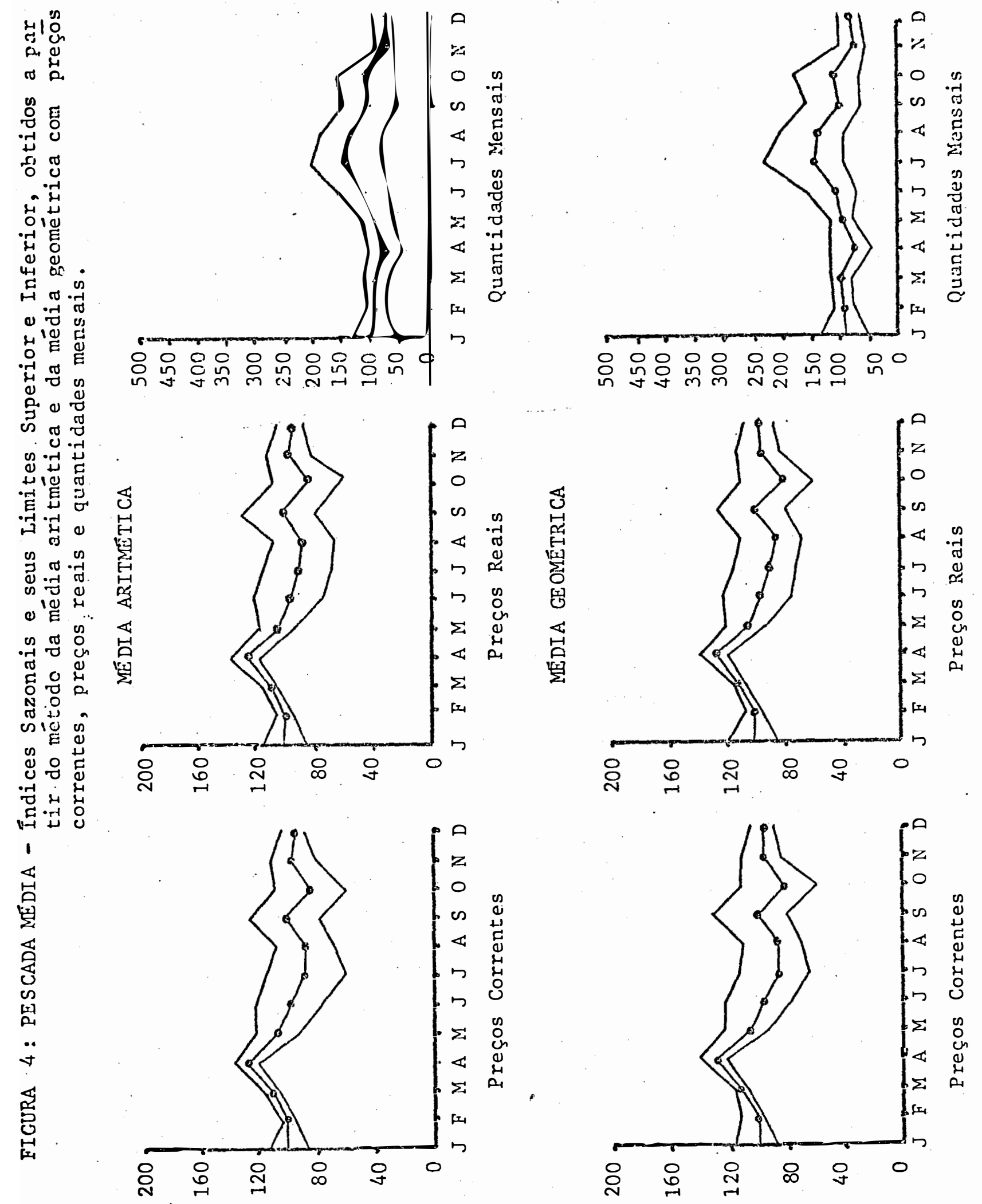



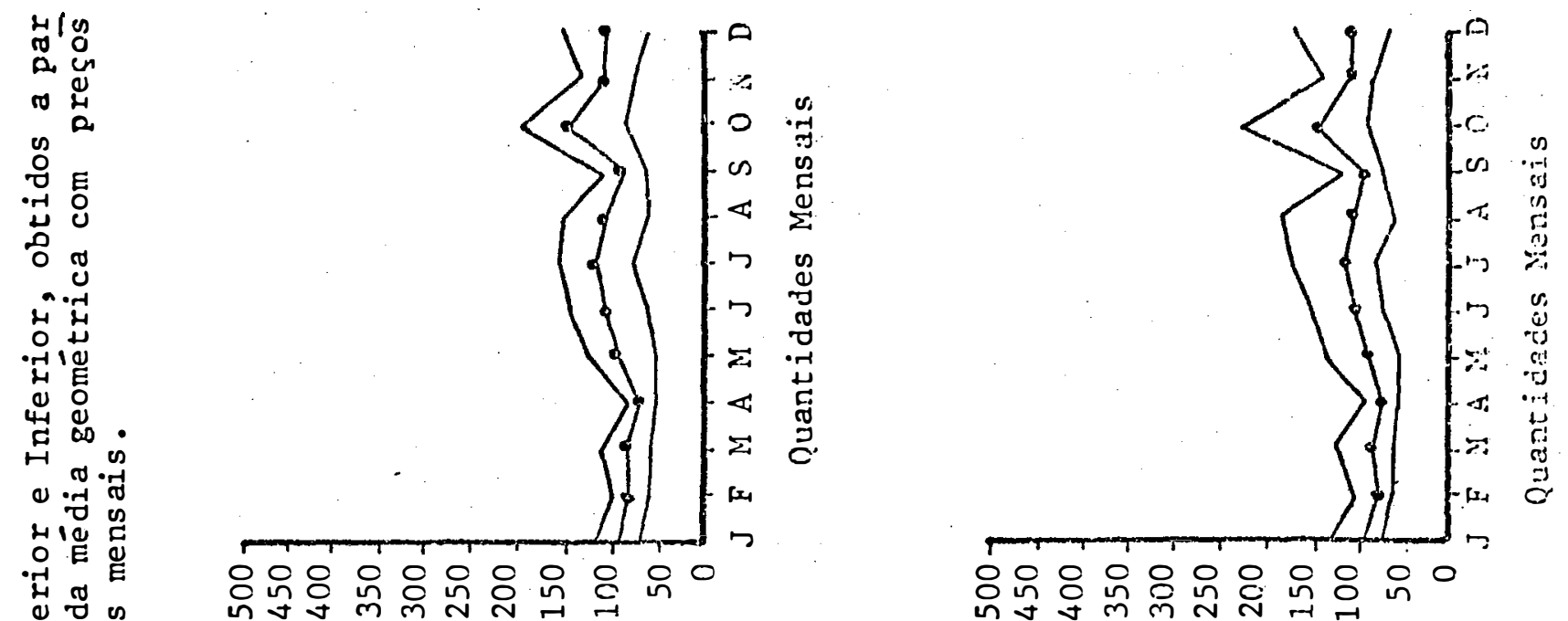

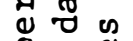

วิ

थ ช ฮ

U

-

点

出

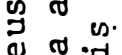

क. न्त

Q IO

in
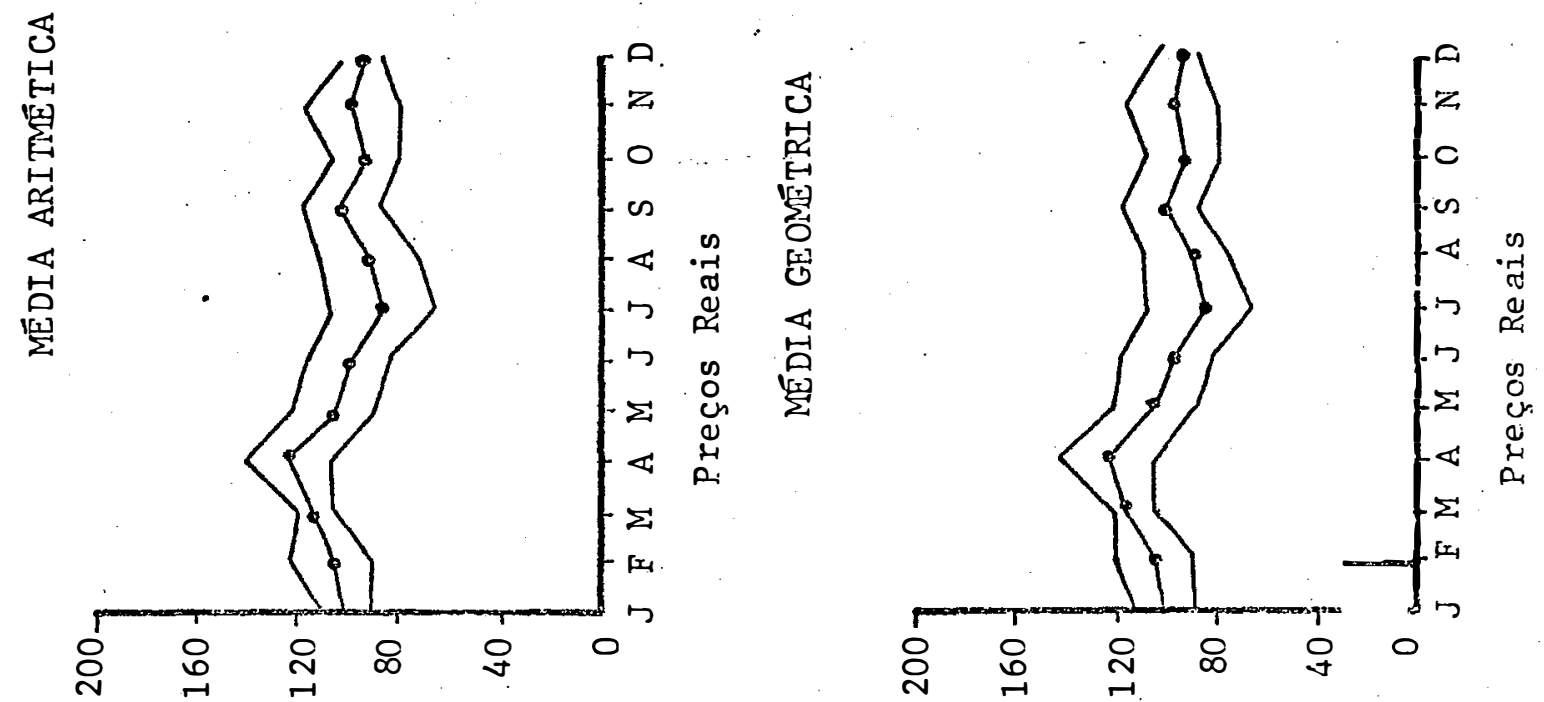

- 4 म

政出

'
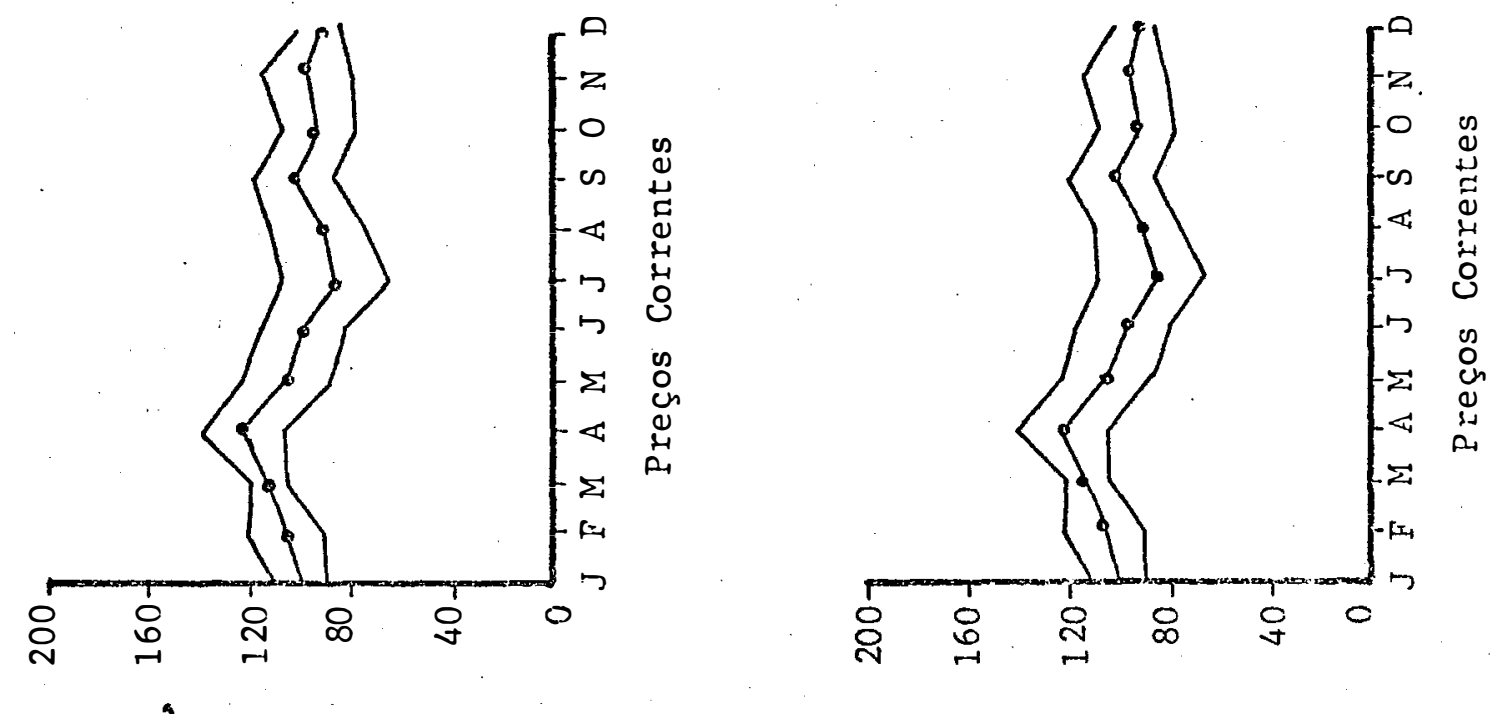

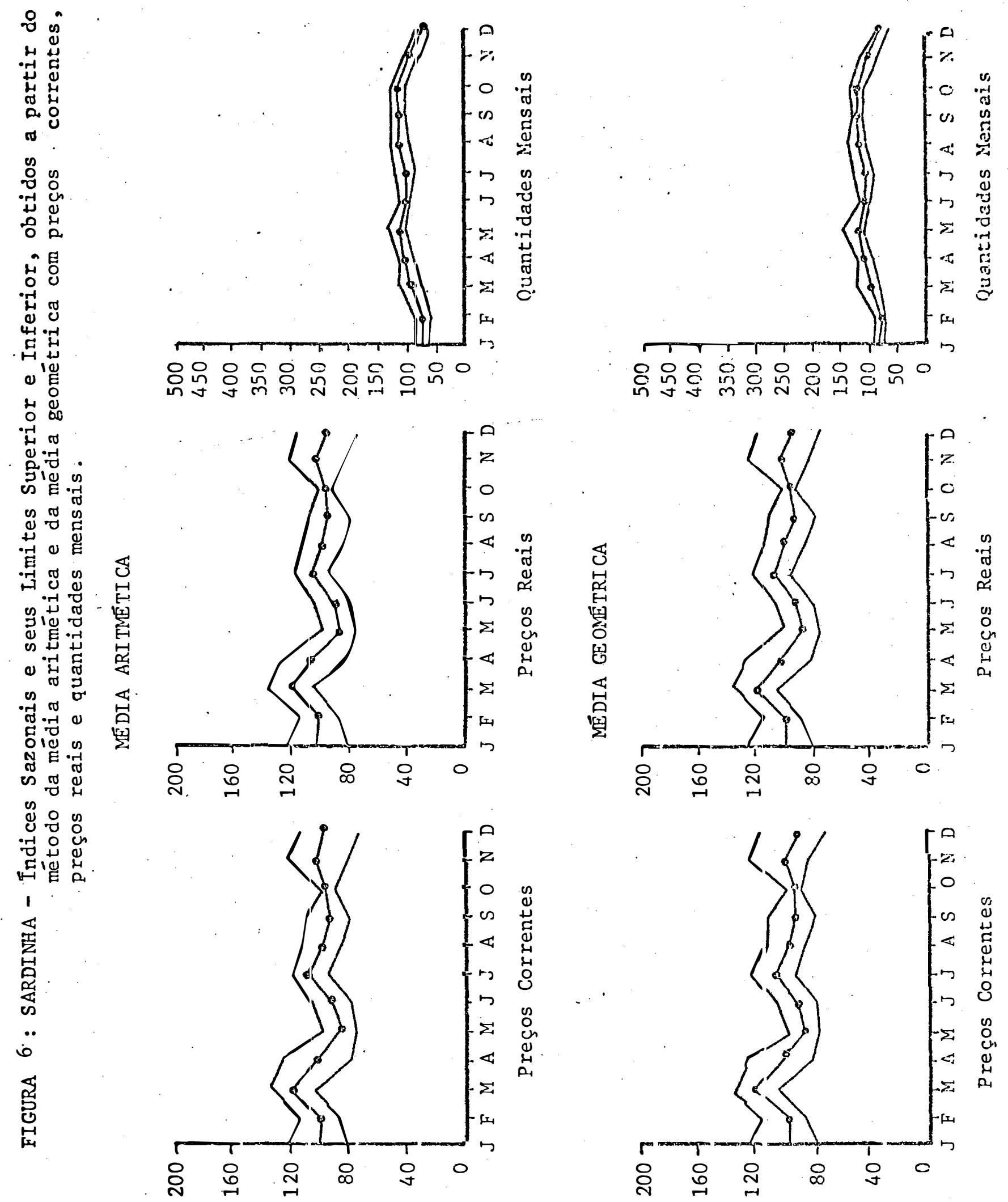


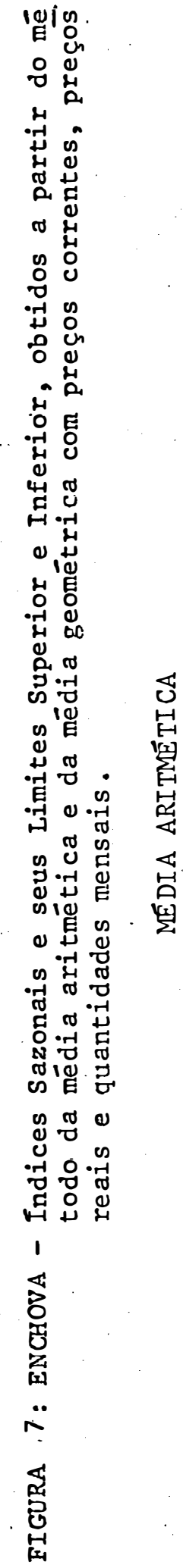

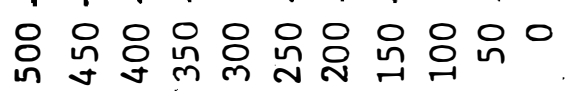
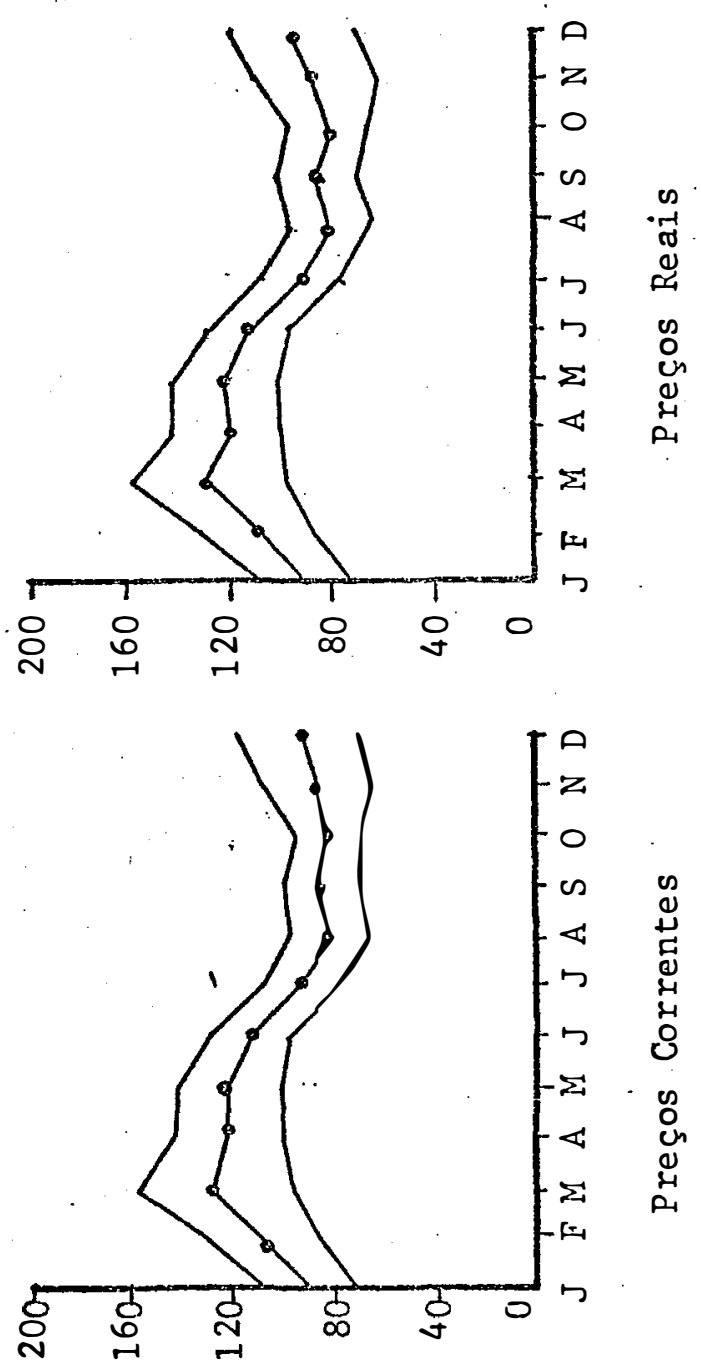
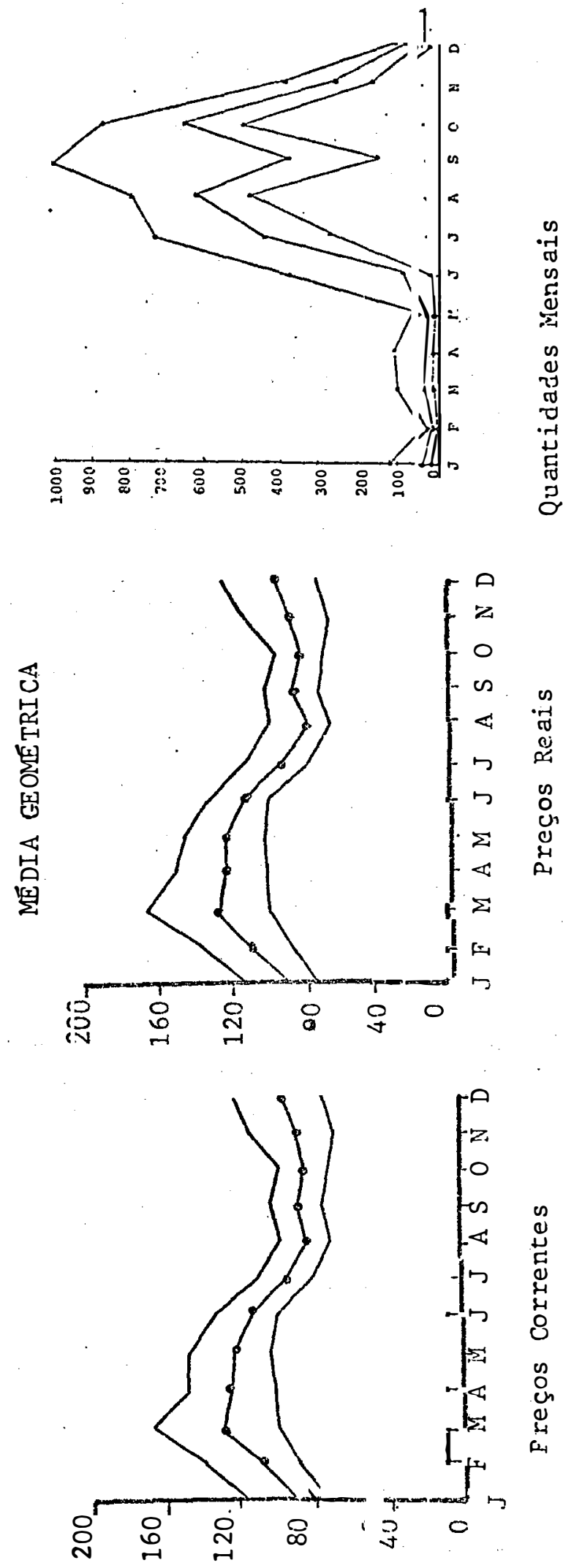
Com relação aos produtos do grupo II, ou seja, aqueles que apresentam seus índices máximos de preços no mês de setembro, verifica-se pelo quadro 1 (p. 15) bem como atra vés das figuras 8 a 11 (p.p.43 a 46) que existe uma defasagem entre os meses que apresentam indice mínimo de quantidade e que, seria lógico, esperar-se com que ocorressem os índices má ximos de preços dado a redução na quantidade ofertada.

Esse fato sugere que outros determinantes do la do da demanda concorrem para alterar o preço desses produtos (excessão feita ao camarão médio) naquele mês.

Acredita-se, que no mês de setembro a pescada branca, pescada cambucu e a tainha estariam sendo usadas como um dos produtos substitutos à carne bovina. Isto deve-se, ao tipo de exploração da pecuária brasileira, que na sua maioria é feita no regime extensivo e portanto naquele período a ofer ta de carne bovina ainda se ressentiria do período de estiagem (época das secas) que em última análise representaria elevação do preço da carne bovina, o que concorreria para aumentar a quantidade demandada desses três produtos.

Quanto ao Camarão Médio, dado que o seu indice máximo de preço ocorre em setembro, tal fato não apresenta ex plicação melhor do que naquele mês estar ocorrendo o mínimo no seu indice de quantidade.

Vale a pena lembrar que como Camarão Médio (co mercialmente) são agrupados tipos distintos de camarão, o Cama rão Branco, o Camarão Rosa na fase juvenil, pois este só tem coloração rosada na fase adulta, além de outros.

No tocante às principais épocas de capturas, pa ra os produtos desse grupo, tem-se a existência de uma defasa gem de um mês anterior (tainha, camarão médio e pescada branca) ou posterior (pescada cambucu.) entre os resultados do presente estudo (quadro $2 \mathrm{p} .30$ ) e as épocas indicadas pelo Instituto de Pesca (quadro $1 \mathrm{p} \cdot 15$ ). Com os dados disponíveis no presen te estudo não se pode inferir, com precisão, a causa. Entretan to essa defasagem de um mês, acredita-se não interferir nos re sultados deste trabalho. 

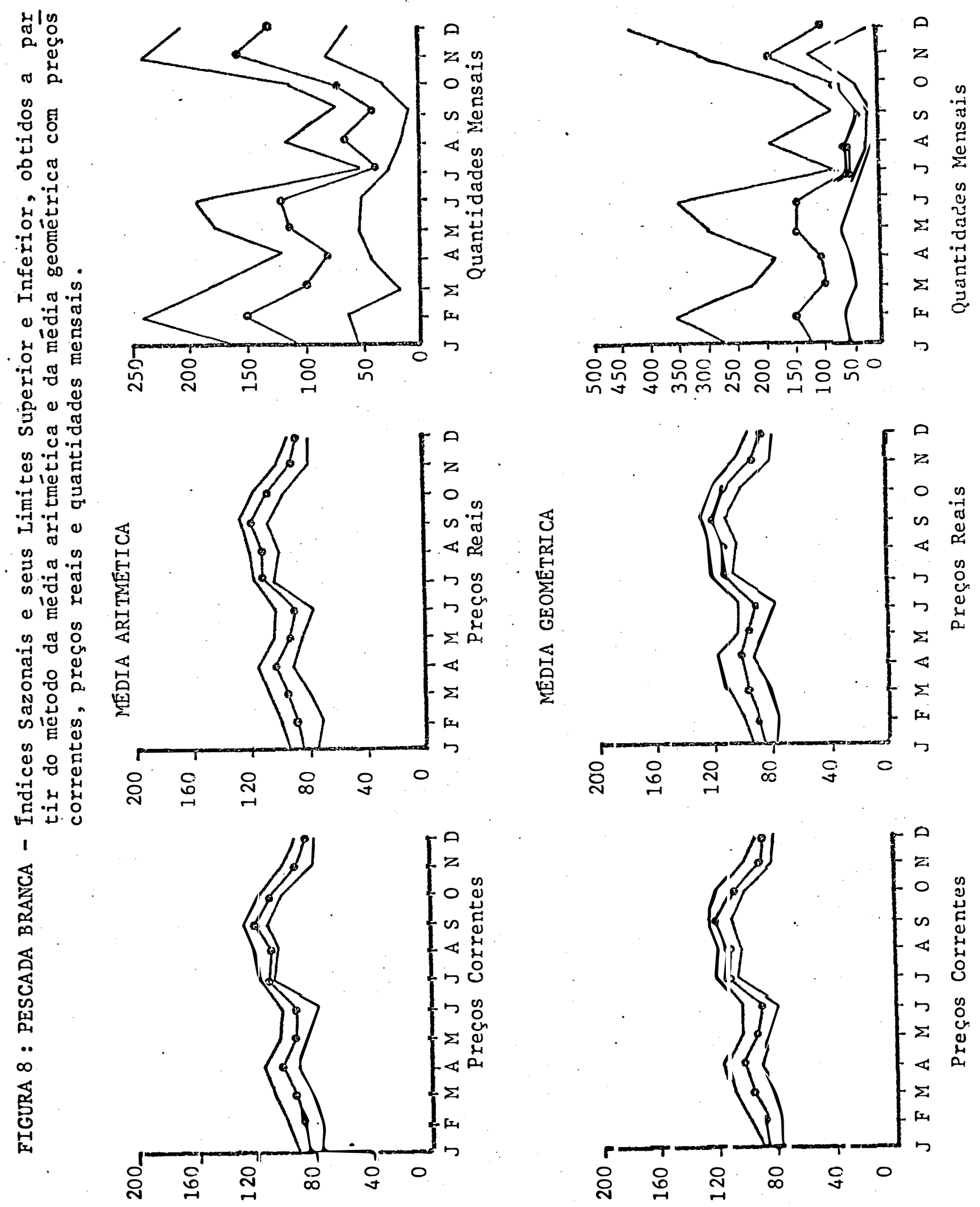

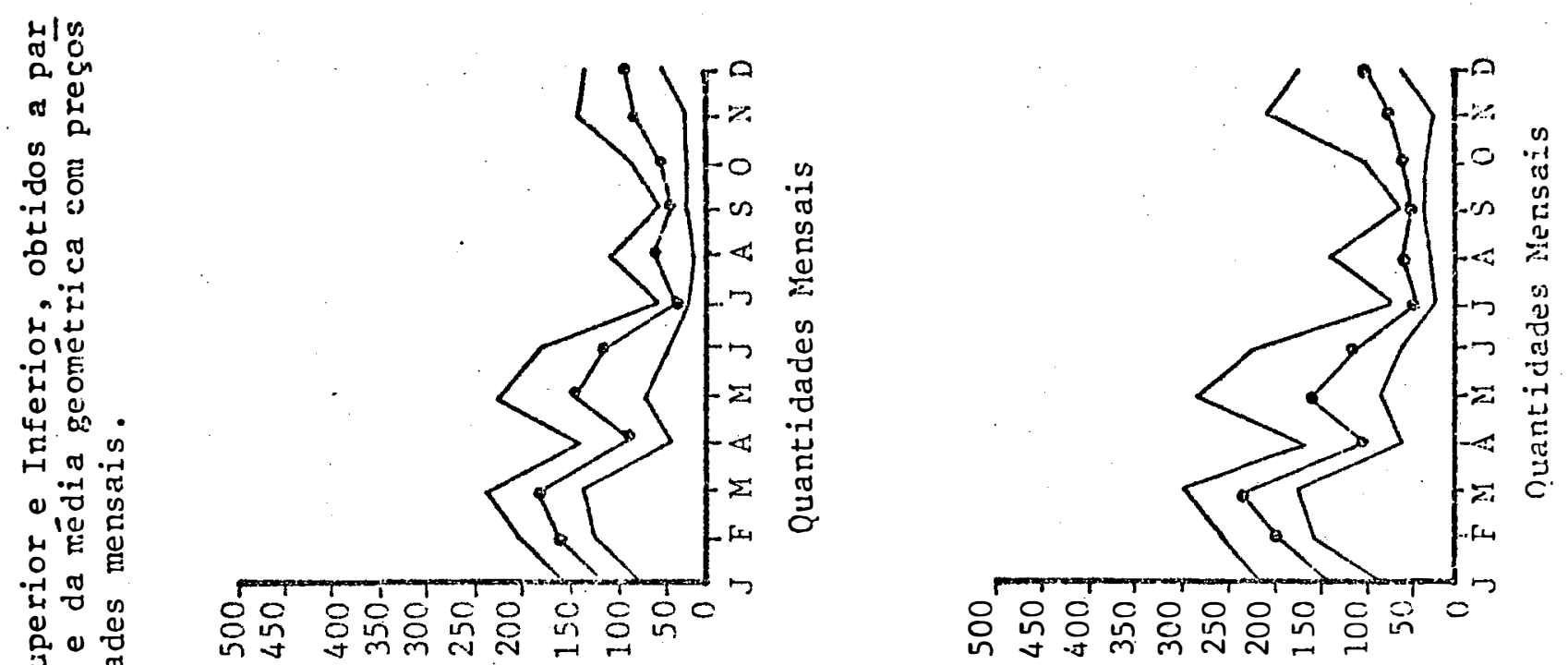

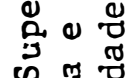

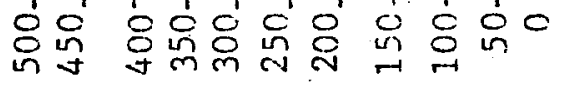

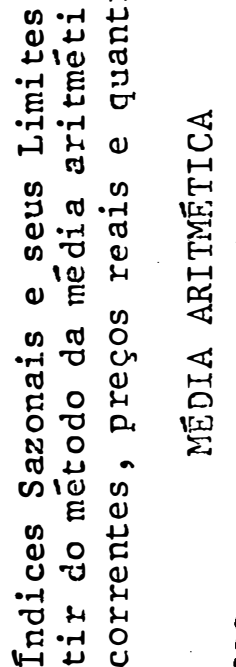

1

曷
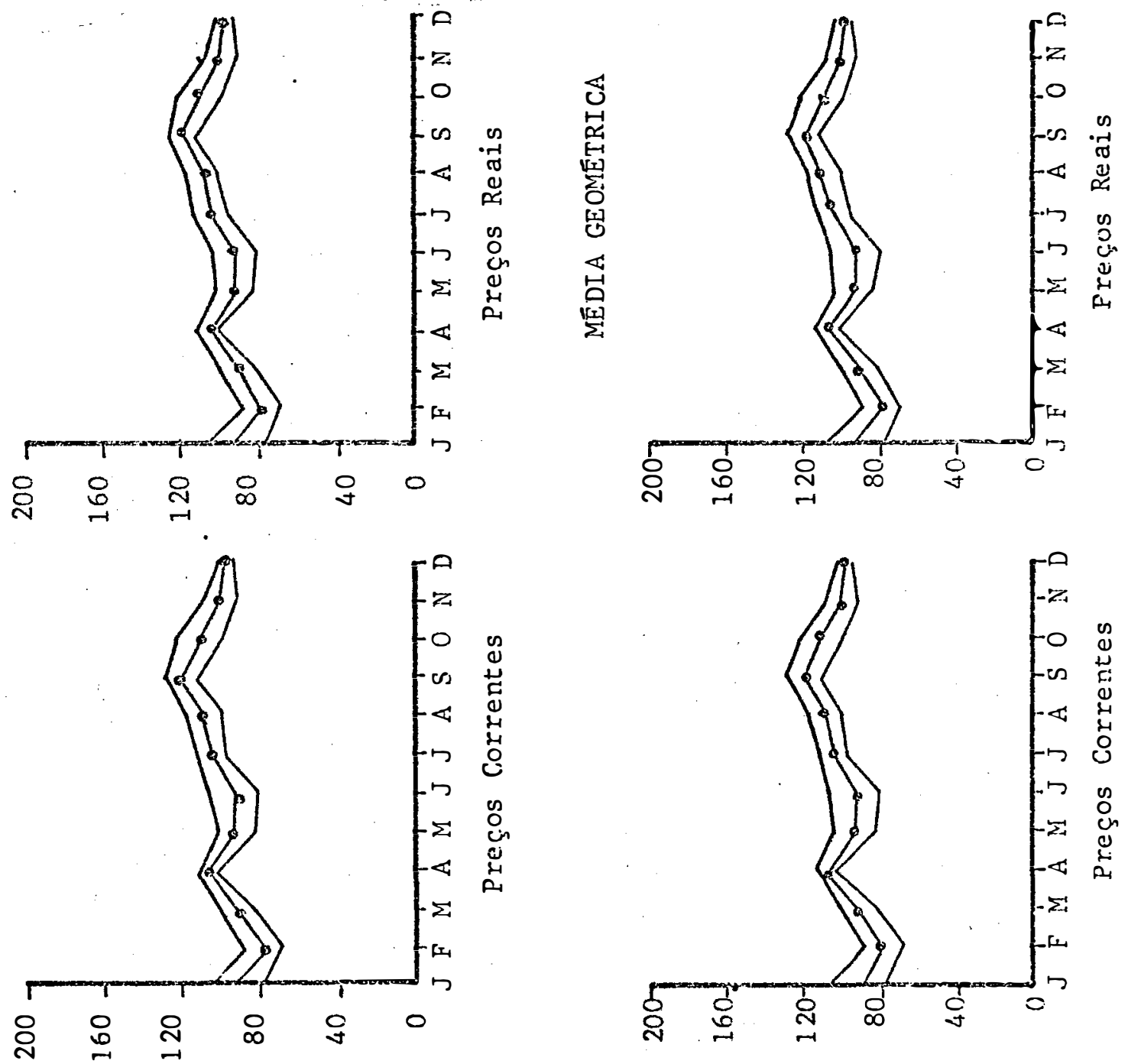


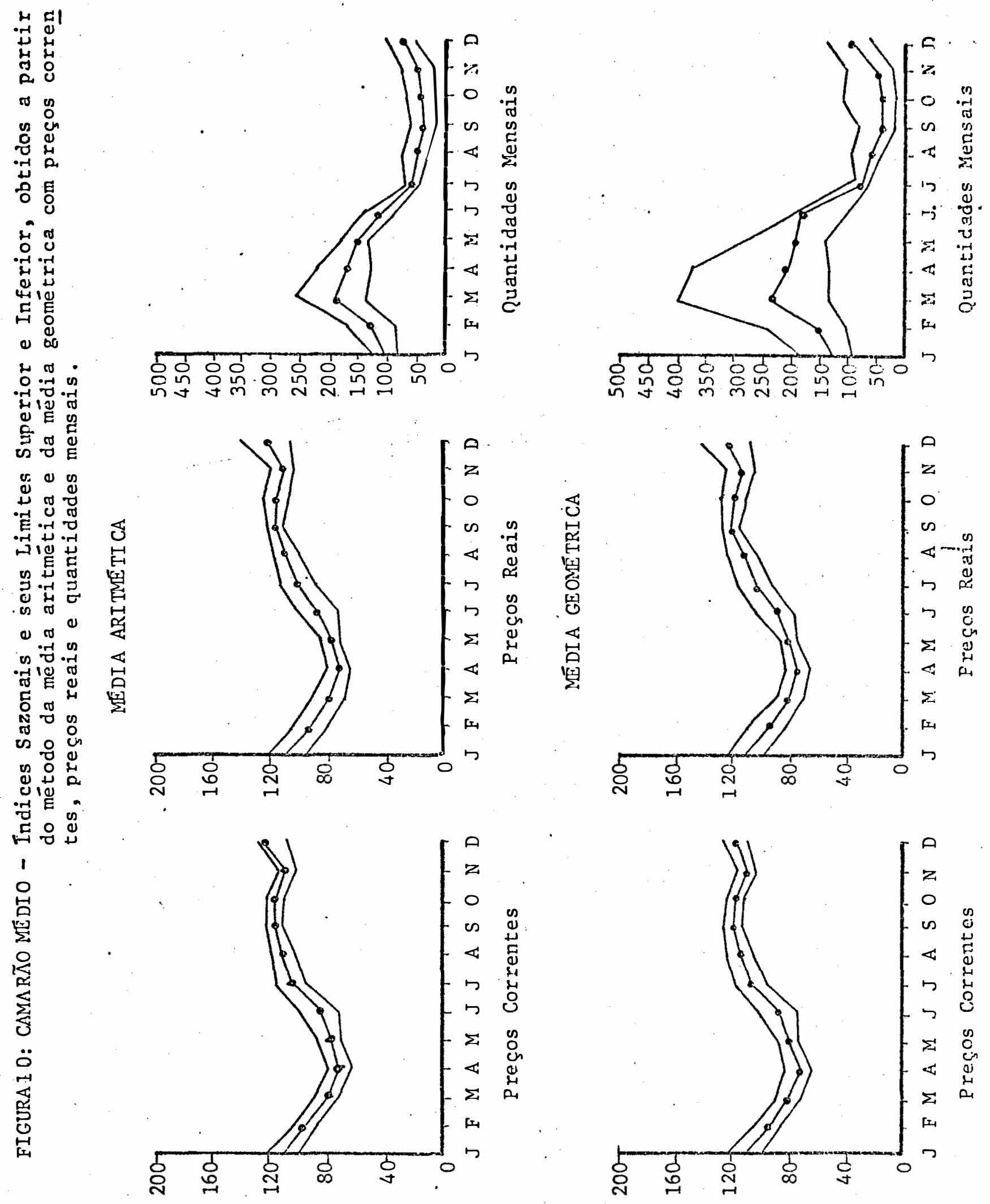



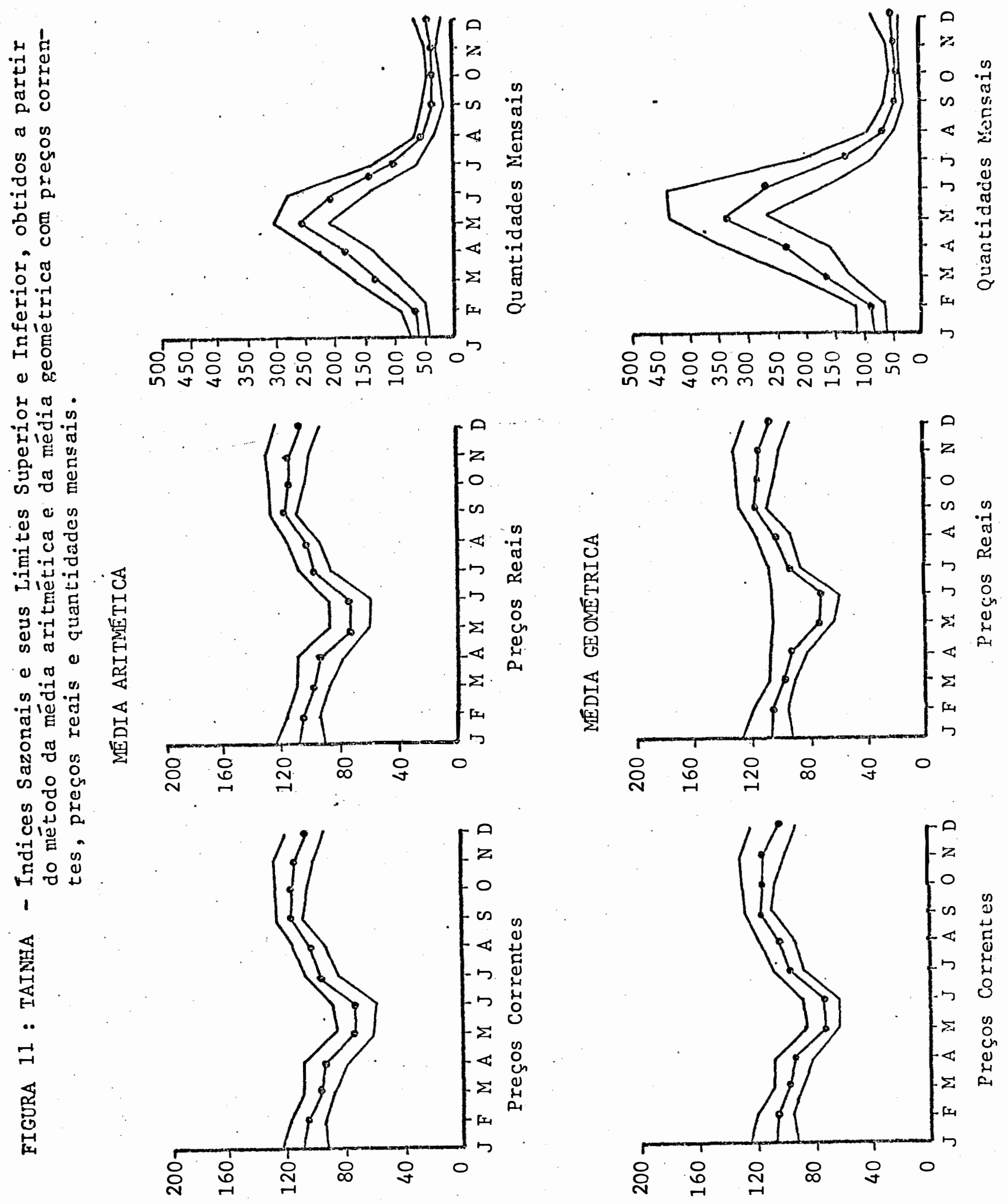
o grupo III, é composto pelo Camarão Rosa e Cá marão Sete Barbas. Com respeito ao Camarão Sete Barbas verifí ca-se pelo Quadro 2 que a ocorrência do máximo índice de preço é perfeitamente explicado pelo indice de quantidade que atinge seu minimo em fevereiro. Deve-se notar também na figura 13 (p. 49) que no final do ano, ou seja, de novembro para dezem bro há um aumento no índice de quantidade sendo que, fato idên tico, ocorre com o indice de preços.

Para o camarão rosa, pelo quadro 2 (p. 30 ) ou figura 12 (p. 48), não se consegue explicar o índice máximo de preço em dezembro através do índice de quantidade.

Assim sendo, tanto o camarão sete barbas como o rosa, sofrem influências da demanda no mês de dezembro (princi palmente). Dado que, sendo produtos "finos" e portanto tendo seu consumo pelas classes de rendas mais altas $\stackrel{4}{4}$, e o fato de que naquele mês os consumidores (classe média) tem suas rendas aumentadas ( 130 salário, comissões, bonus, etc.). Isto leva a um aumento na procura do camarão naquele periodo elevando as sim seus preços. Tais aumentos dos preços poderiamsermaiores não fosse $o$ aumento na quantidade ofertada.

4/ CARVALHo e GIULIETTI (1977) a pontam as elasticidades rendas para Camarão Rosa e Sete Barbas como sendo 1,395 e 0,884 respectivamente, calculadas por CRUZ (1974). 


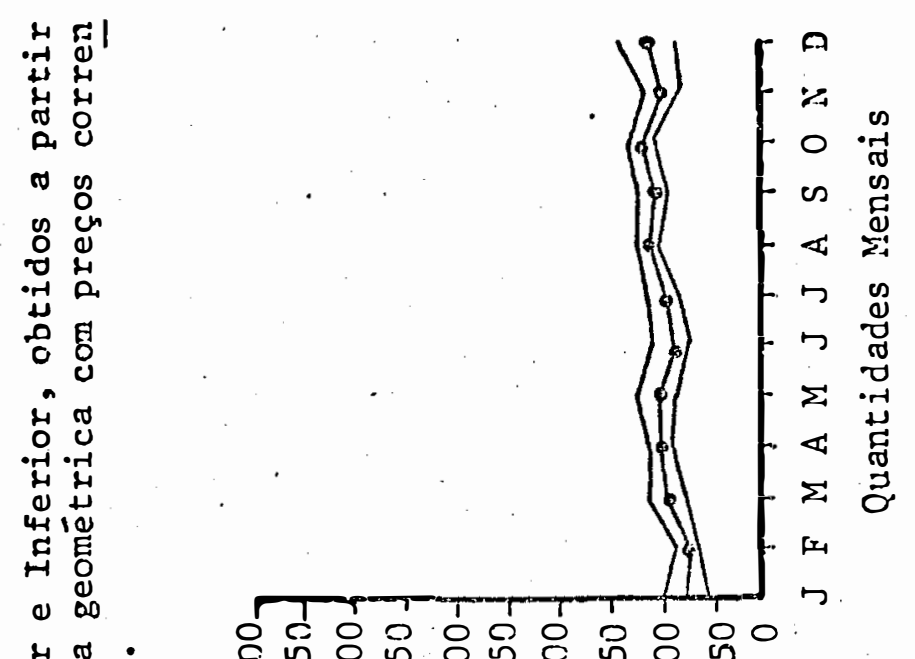

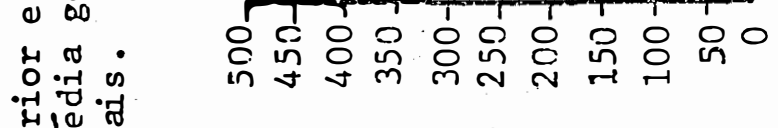

d)

号 艺

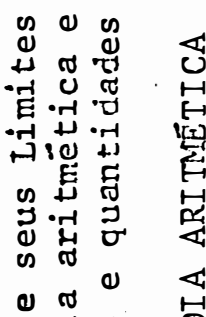

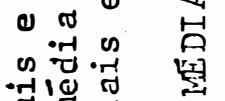
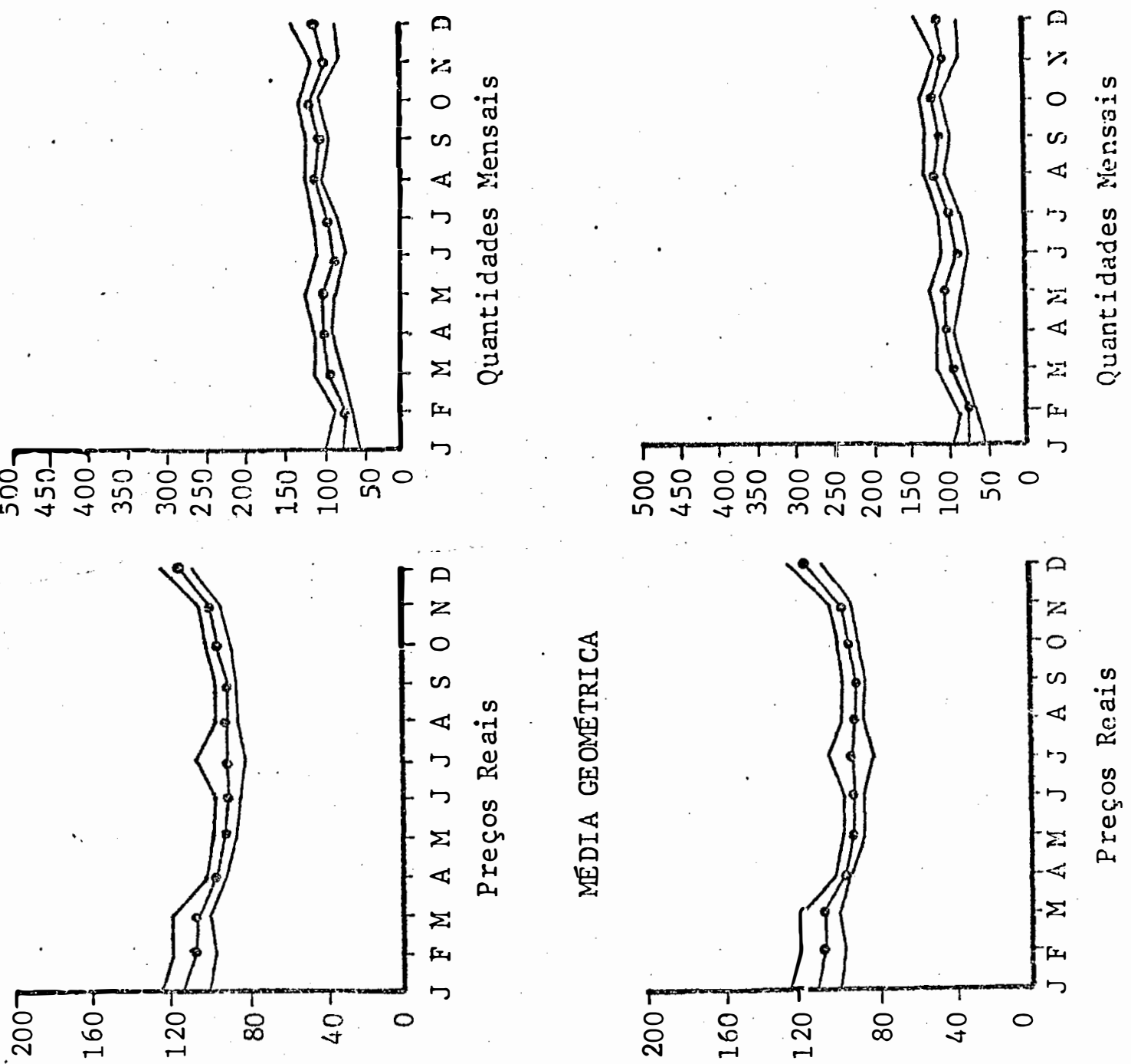

要

赎

i 0 in

« 웜

ฏ故

of $E$ is

면웜

崩
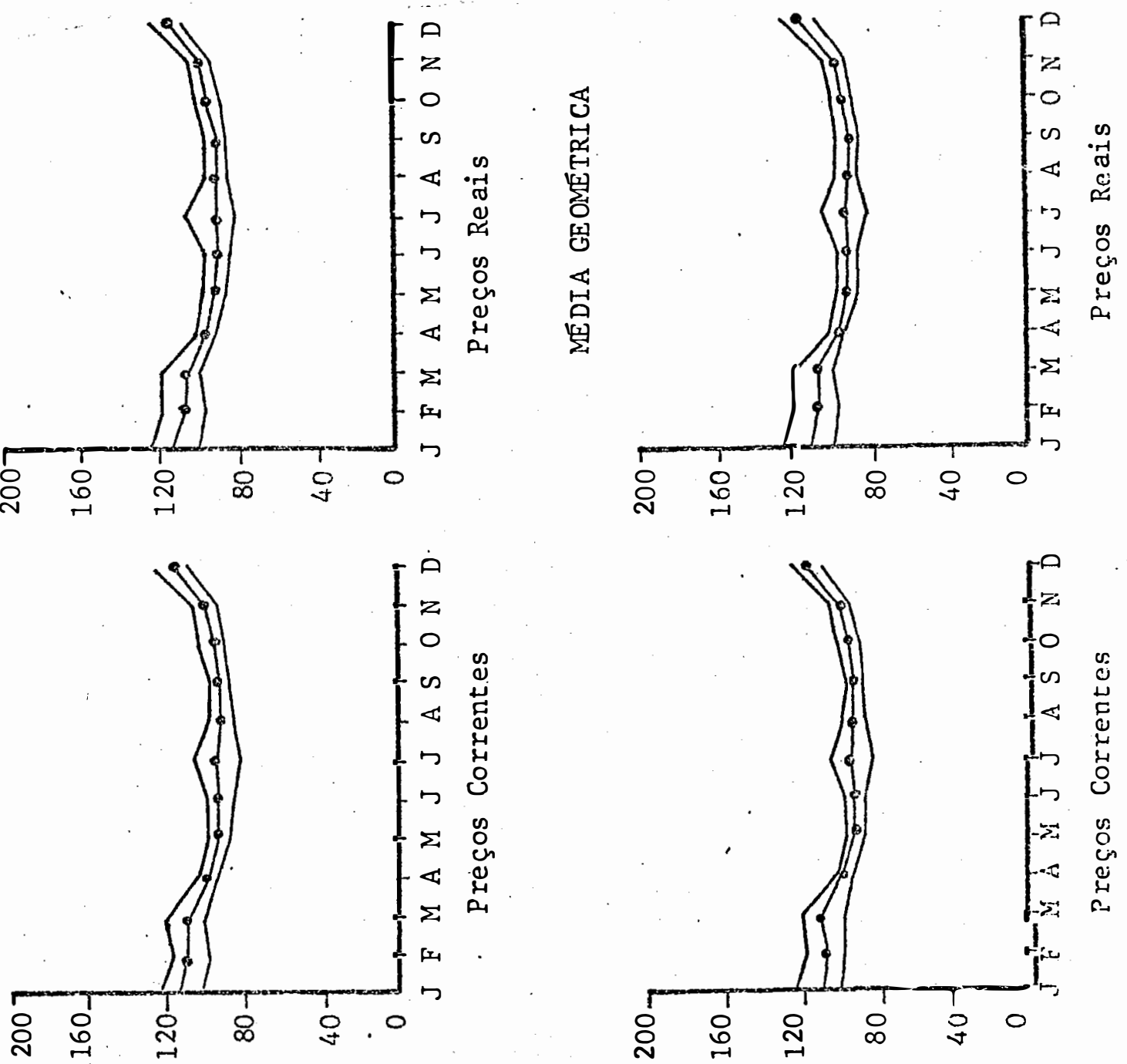

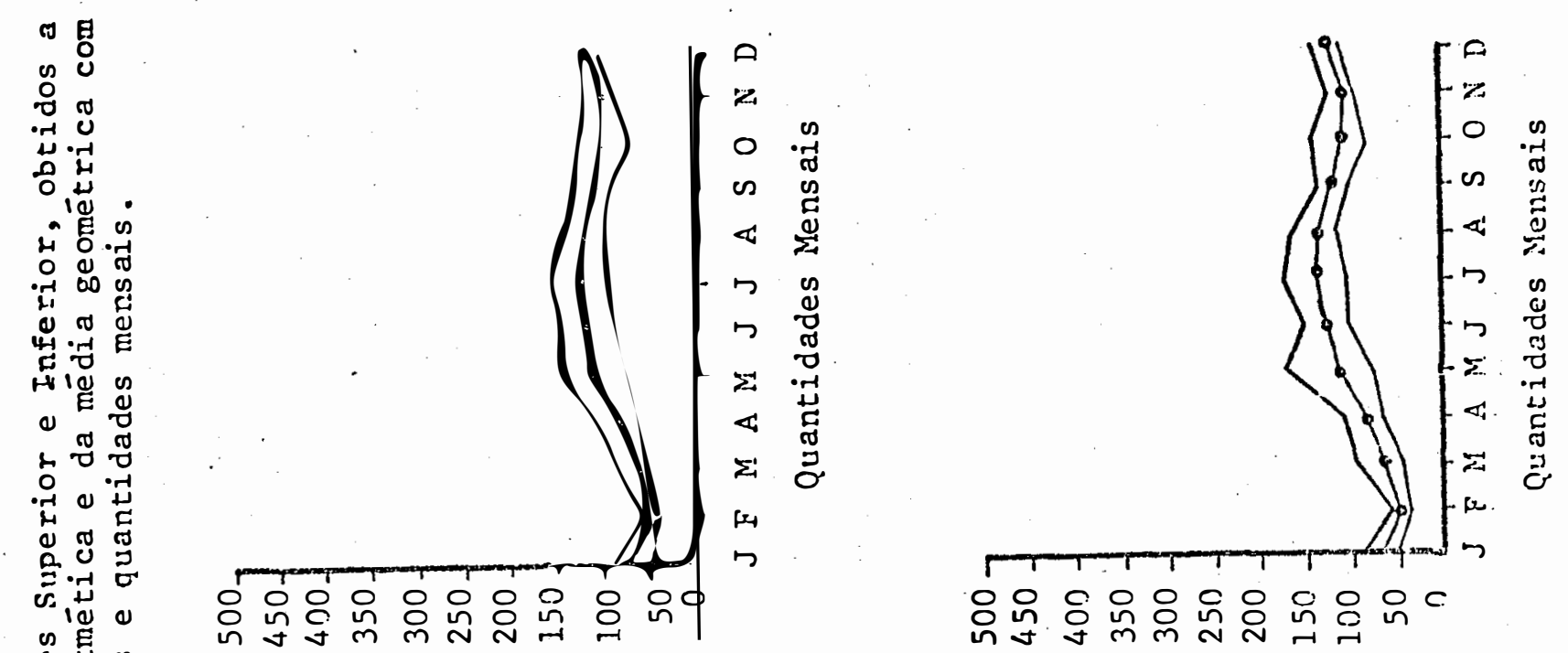

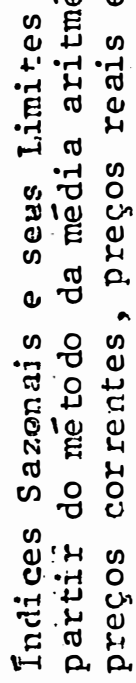

1

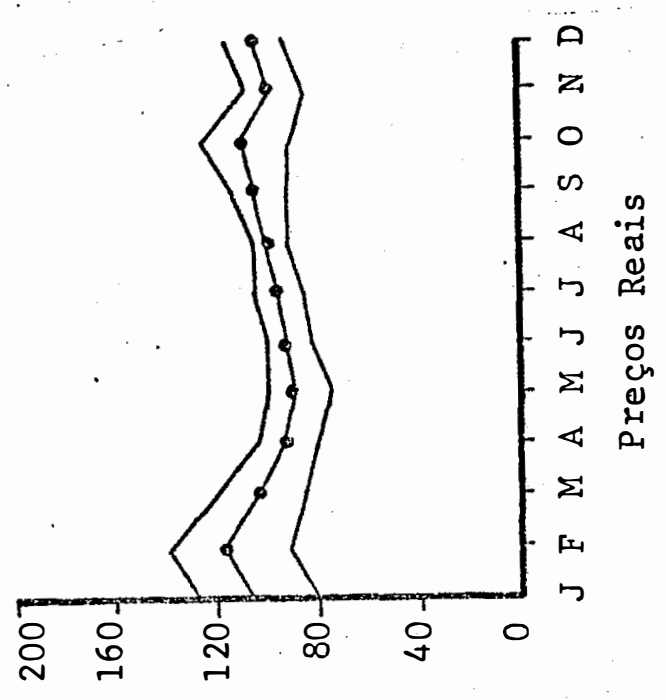

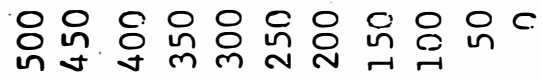

告
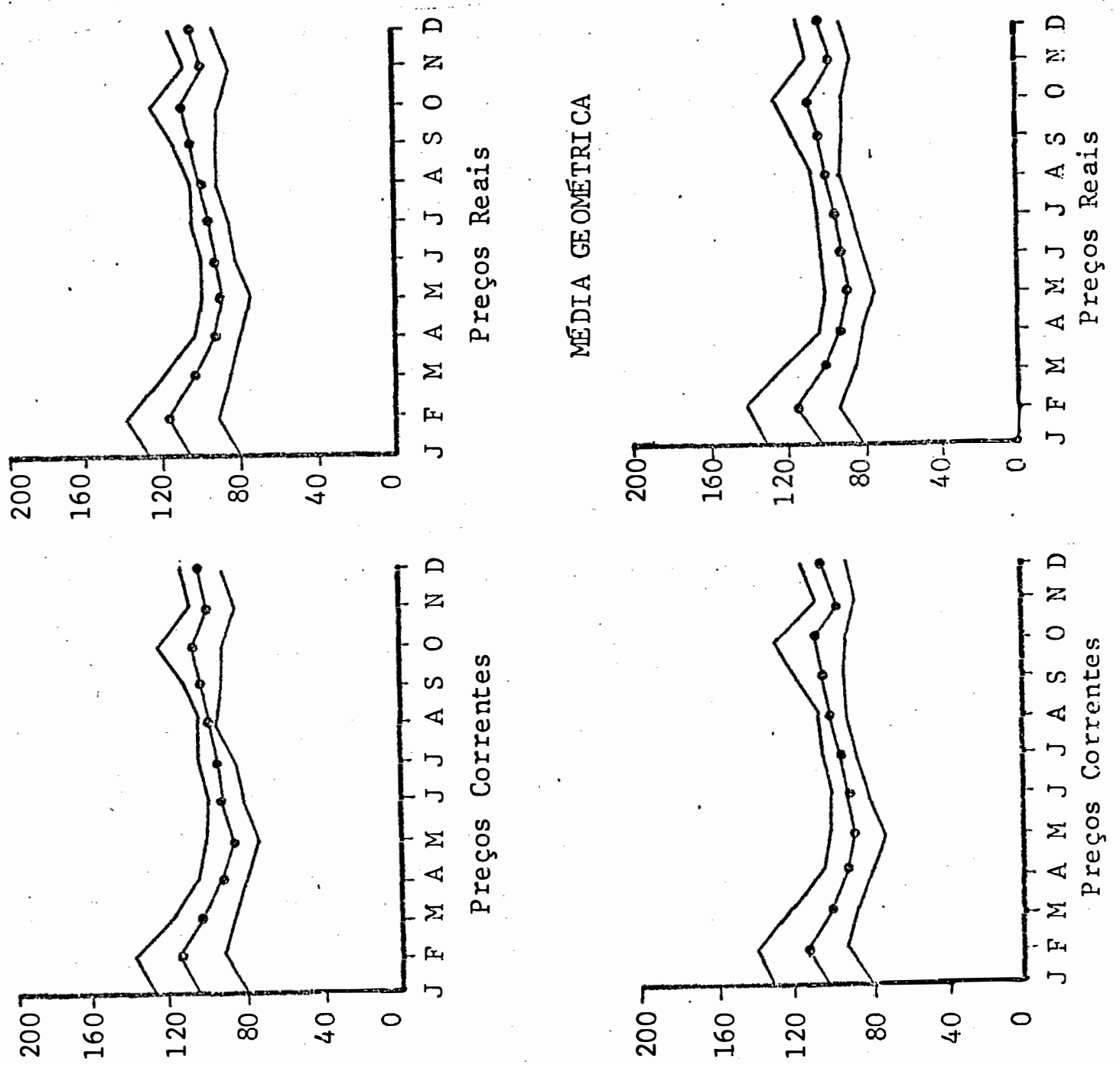
Analisando-se as figuras de 1 a 13 observa-se que alguns produtos como a pescada goete, pescada tortinha, pescada pequena e sardinha, apresentam os índices de quanti dades mais estáveis (menor coeficiente variação) do que os cor respondentes indices de preços. Em outras palavras a "deman da" por esses produtos é menos estável do que a "oferta".

Para outros produtos, entretanto, a situação é inversa, ou seja, para a pescada branca, pescada cambucue cama rão médio, os índices de preços são mais estáveis (menor coefí ciente de variação) do que os respectivos índices de quantida de, logo a "demanda" é mais estável do que a "oferta".

Estes fatos podem ser explicados pela própria natureza dos produtos, pois o primeiro conjunto (pescada goete, pescada tortinha, pescada pequena e sardinha) é conhecido como produtos inferiores (relativo a preço) ou populares e assim sendo são adquiridos pelas classes de renda mais baixa, cujo consumo é mais instável. Situação inversa acontece com os ou tros (pescada branca, pescada cambucu e camarão médio) que são tidos como produtos "finos".

Com relação ao camarão rosa e camarão sete bạ bas, tanto os índices de preços como os índices de quantidade são bem coerentes. Isto estaria indicando que a "oferta" e a "demanda" tem se mantido praticamente em equilíbrio (constan te).

Com base nos resultados apresentados pode-se ve rificar que a hipótese adotada neste estudo foi verificada pa ra a maioria dos produtos ( 9 dos 13 produtos analisados). Esta hipótese foi que: dado um conjunto de tradições, a demanda por pescados sofre alterações no sentido de promover aumento na quantidade demandada em determinados períodos (Semana Santa e Festejos de Fim de Ano).

Por outro lado encontrou-se produtos (pescados) que poderiam estar substituindo a carne bovina durante a en tre-safra. 
A guiza de informação, em anexos, apresentam-se tabelas onde são encontrados os dados básicos do presente estú do bem como os indices estacionais, indices de irregularidade, índices sazonais e seus limites bem como a análise de variân cia, obtidos a partir dos métodos das médias aritmética e geo métrica móveis centralizadas de 12 meses usando-se os preços correntes, preços reais e quantidades mensais, no mercado ata cadista (CEAGESP) no período de 1968 a 1975 para os 13 produ tos analisados. 
6 - CONCLUSÕES

Como pode-se observar na análise dos 13 produ tos não se verificou diferenças que possam indicar a utiliza ção de um ou de outro método para a obtenção dos índices de preços, haja visto que tanto o método que utiliza a média arit mética quanto o que usa a média geométrica levam a resultados muito semelhantes.

Com relação ao uso dos preços correntes ou reais para a obtenção dos índices não mostraram, assim como no caso dos métodos, diferenças tais que indiquem a preferência de um ou outro. Entretanto parece que os preços correntes devam ser preferidos pois assim agindo, elimina-se uma fase que é a trans formação dos preços correntes, através de deflatores (Indice 2 da F.G.V. no presente estudo), para que seja possível utilizarse dos preços reais.

Esses resultados reforçam aqueles obtidos por HOFFMANN (1969). 
Apresenta-se a seguir, no Quadro 4, a distribui ção dos indices de preços ao longo dos meses. Efetuou-se a di visão entre preços elevados(índices superiores a 100) e preços baixos (índices inferiores a 100).

QUADRO 4: Distribuição dos índices de preços, ao long̣o dos me ses no mercado atacadista de São Paulo (CEAGESP) - pe ríodo 1968 a 1975.

\begin{tabular}{|c|c|c|c|c|c|c|c|c|c|c|c|c|}
\hline Produtos. & J. & $F$ & $\mathbf{M}$ & $A$ & $\mathrm{M}$ & $\mathrm{J}$ & $\mathrm{J}$ & A & $S$ & $\mathrm{o}$ & $\mathrm{N}$ & $\mathrm{D}$ \\
\hline Pescada Goete & o & o & $\mathrm{x}$ & $\mathrm{x}$ & $\mathrm{x}$ & $\mathrm{x}$ & $\mathrm{x}$ & o & $\mathrm{x}$ & $\mathrm{x}$ & o & o \\
\hline Pescada Tortinha & $\circ$ & o & $\mathrm{x}$ & $\mathrm{x}$ & $\mathrm{x}$ & $\mathrm{x}$ & $\mathrm{x}$ & o & $\mathrm{x}$ & $\circ$ & o & 0 \\
\hline Pescada Pequena & $\circ$ & 0 & $\mathrm{x}$ & $\mathrm{x}$ & $\mathrm{x}$ & $\mathrm{x}$ & $\circ$ & $\mathrm{x}$ & o & ० & o & $\circ$ \\
\hline Pescada Média & $\mathrm{x}$ & o & $\mathrm{x}$ & $\mathrm{x}$ & $\mathrm{x}$ & ० & $\circ$ & o & $\mathrm{x}$ & $\circ$ & ○ & $\circ$ \\
\hline Pescada Grande & o & $\mathrm{x}$ & $\mathrm{x}$ & $\mathrm{x}$ & $\mathrm{x}$ & o & o & o & $\mathrm{x}$ & 0 & o & 0 \\
\hline Sardinha & $\mathrm{x}$ & ० & $\mathrm{x}$ & $\mathrm{x}$ & $\circ$ & $\circ$ & $\mathrm{x}$ & $\circ$ & ० & $\circ$ & $\mathrm{x}$ & $\circ$ \\
\hline Enchova & $\circ$ & $\mathrm{x}$ & $\mathrm{x}$ & $\mathrm{x}$ & $\mathrm{x}$ & $\mathrm{x}$ & $\circ$ & o & ○ & $\circ$ & $\circ$ & $\circ$ \\
\hline Pescada Branca & ○ & ० & $\circ$ & $\mathrm{x}$ & ० & o & $\mathrm{x}$ & $\mathrm{x}$ & $\mathrm{x}$ & $\mathrm{x}$ & ○ & 0 \\
\hline Pescada Cambucu & $\circ$ & o & $\circ$ & $\mathrm{x}$ & $\circ$ & o & $\mathrm{x}$ & $\mathrm{x}$ & $\mathrm{x}$ & $\mathrm{x}$ & $\mathrm{x}$ & $\circ$ \\
\hline Camarão Médio & $\mathrm{x}$ & ० & $\circ$ & o & $\circ$ & ० & $\mathrm{x}$ & $\mathrm{x}$ & $\mathrm{x}$ & $\mathrm{x}$ & $\mathrm{x}$ & $\mathrm{x}$ \\
\hline Tainha & $\mathrm{x}$ & $\mathrm{x}$ & $\circ$ & ० & ○ & o & $\circ$ & $\mathrm{x}$ & $\mathrm{x}$ & $\mathrm{x}$ & $\mathrm{x}$ & $\mathrm{x}$ \\
\hline Camarão Rosa & $\mathrm{x}$ & $\mathrm{x}$ & $\mathrm{x}$ & o & o & o & $\circ$ & o & o & $\circ$ & 0 & $\mathrm{x}$ \\
\hline Camarão Sete Barbas & $\mathrm{x}$ & $\mathrm{x}$ & $\mathrm{x}$ & 0 & o. & 0. & 0. & o & $\mathrm{x}$ & $\mathrm{x}$ & o. & $\mathrm{x}$ \\
\hline
\end{tabular}

o Índices inferiores a 100 (preços baixos)

$x$ índices superiores a 100 (preços elevados)

Com base no quadro 4 pode-se verificar que para o consumidor os meses de novembro, dezembro, janeiro e fevere $\underline{i}$ ro são os melhores para se adquirir as pescadas de um modo ge ral, e assim podem ser determinados os melhores meses para 0 consumidor adquirir os outros pescados analisados aqui.

Do lado dos produtores o raciocínio seria o in verso.

Quanto aos índices estacionais obtidos a partir 
de quantidades mensais comercializadas na CEAGESP, os dados do presente estudo, parecem indicar que o método que utiliza a mé dia aritmética adapta-se melhor uma vez que, na maioria dos cá sos (figuras de 1 a 13 p.p. 35 a 49), observa-se uma menor va riação em torno do índice médio, ou seja, os limites superio res e inferiores estão mais próximos da média quando o método da média aritmética foi usado. Em outras palavras, o desvio padrão do índice médio, na maioria dos casos, é menor quando se usa a média aritmética do que quando a média geométrica foi utilizada.

Entretanto, ao observar-se os coeficientes de determinação $\left(R^{2}\right)$ no Quadro 3 ( $p .31$ ), verifica-se claramente que tal afirmativa não pode ser feita, pois em ambos os casos (média aritmética e média geométrica) os $\mathrm{R}^{2}$ se apresentaram semelhantes. Isto sugere que ambos os métodos apresentam o mesmo poder explicativo o que indica que tanto um quanto outro possa ser utilizado.

O Quadro 5 apresenta a distribuição dos índices de quantidades ao longo dos meses do ano.

QUADRO 5: Distribuição dos indices de quantidades comercializą das no mercado atacadista de são Paulo (CEAGESP) - período 1968 a 1975

\begin{tabular}{|c|c|c|c|c|c|c|c|c|c|c|c|c|}
\hline Produtos & $\mathrm{J}$ & $F$ & $M$ & $\bar{A}$ & $\bar{M}$ & $\mathrm{~J}$ & $\mathrm{~J}$ & $\mathrm{~A}$ & $\mathbf{S}$ & $\mathrm{O}$ & $\mathrm{N}$ & $\overline{\mathrm{D}}$ \\
\hline Pescada Goete & $\mathrm{x}$ & $\mathrm{x}$ & $\mathrm{x}$ & 0 & 0 & 0 & 0 & 0 & 0 & 0 & $\mathrm{x}$ & $\bar{x}$ \\
\hline Pescada Tortinha & $\mathrm{x}$ & $\mathrm{x}$ & 0 & 0 & 0 & 0 & 0 & $\mathrm{x}$ & $\mathrm{x}$ & $\mathrm{x}$ & $\mathrm{x}$ & $\mathrm{x}$ \\
\hline Pescada Pequena & 0 & 0 & $\mathrm{x}$ & $\mathrm{x}$ & O & $\mathrm{O}$ & 0 & $\mathrm{x}$ & $\mathrm{x}$ & $\mathrm{x}$ & O & $\mathrm{O}$ \\
\hline Pescada Média & 0 & 0 & 0 & 0 & 0 & $\mathrm{x}$ & $\mathrm{x}$ & $\mathrm{x}$ & $\mathrm{x}$ & $\mathrm{x}$ & 0 & 0 \\
\hline Pescada Grande & 0 & $\mathrm{O}$ & 0 & 0 & 0 & $\mathrm{x}$ & $\mathrm{x}$ & $\mathrm{x}$ & 0 & $\mathrm{x}$ & $\mathrm{x}$ & $\mathrm{x}$ \\
\hline Sardinha & 0 & 0 & 0 & $\mathrm{x}$ & $\mathrm{x}$ & $\mathrm{x}$ & $\mathrm{x}$ & $\mathrm{x}$ & $\mathrm{x}$ & $\mathrm{x}$ & o & 0 \\
\hline Enchova & 0 & 0 & 0 & 0 & 0 & 0 & $\mathrm{x}$ & $\mathrm{x}$ & $\mathrm{x}$ & $\mathrm{x}$ & $\mathrm{x}$ & 0 \\
\hline Pescada Branca & $\mathrm{x}$ & $\mathrm{x}$ & 0 & 0 & $\mathrm{x}$ & $\mathrm{x}$ & 0 & 0 & 0 & 0 & $\mathrm{x}$ & $\mathrm{x}$ \\
\hline Pescada Cambucu & $\mathrm{x}$ & $\mathrm{x}$ & $\mathrm{x}$ & 0 & $\mathrm{x}$ & $\mathrm{x}$ & 0 & 0 & 0 & 0 & $\mathrm{O}$ & 0 \\
\hline Camarão Médio & $\mathrm{x}$ & $\mathrm{x}$ & $\mathrm{x}$ & $\mathrm{x}$ & $\mathrm{x}$ & $\mathrm{x}$ & 0 & 0 & 0 & 0 & $\mathrm{O}$ & $\mathrm{O}$ \\
\hline Tainha & 0 & $\mathrm{O}$ & $\mathrm{x}$ & $\mathrm{x}$ & $\mathrm{x}$ & $\mathrm{x}$ & $\mathrm{x}$ & 0 & 0 & 0 & $\mathrm{O}$ & $\mathrm{O}$ \\
\hline Camarão Rosa & 0 & 0 & 0 & $\mathrm{x}$ & $\mathrm{x}$ & o & 0 & $\mathrm{x}$ & $\mathrm{x}$ & $\mathrm{x}$ & $\mathrm{x}$ & $x$ \\
\hline Camarão Sete Barbas & 0 & 0 & 0 & 0 & $\mathrm{x}$ & $\mathrm{x}$ & $\mathrm{x}$ & $\mathrm{x}$ & $\mathrm{x}$ & $\mathrm{x}$ & $\mathrm{x}$ & $X$ \\
\hline
\end{tabular}

o indices inferiores a 100

$\mathrm{x}$ indices superiores a 100 
Com base nos Quadros 4 (p. 53) e 5 (p. 54 ) po de-se recomendar, p.e., as épocas mais adequadas para a aquisi ção dos pescados, quer seja pelos comerciantes quer pelos con sumidores.

No tocante às principais épocas de capturas,apre sentadas no Quadro 1 (p. 15), nota-se que em quase todos os pro dutos analisados neste estudo, os índices máximos de quantida des comercializadas na CEAGESP (Quadro 2 p. 30), apresentaramse coerentes com os primeiros havendo em alguns casos uma defa sagem entre essas informações que acredita-se não alterar ou influir significativamente nesse contexto.

Tal fato (defasagem) deve ter ocorrido devido a interação biologia/captura, ou seja, "... que o próprio siste ma de comercialização reflete efeitos sobre a produção pesquei ra, uma vez que a quantidade de produto que se consegue distrí buir aos consumidores depende, em parte, da organização e apa relhamento de tal sistema, sem falar do efeito que este mesmo sistema exerce sobre os níveis de preços" (LINS et alii, 1972) fato este reafirmado por CARVALHO e GIULIETTI (1977) ao consta tarem problemas na estrutura de comercialização a nível de va rejo no caso da sardinha.

Soma-se a estes, o fato do baixo consumo de pes cado pela população, que segundo MOPAES (1968), citado em GAL LO (1976), numa pesquisa determinou as seguintes causas:

- Produto caro

$52 \%$

- Má qualidade 38\%

- Não gostavam 19\%

- Faz mal $11 \%$

- Não é encontrado $8 \%$

- Desconhecimiento do preparo 3\%

- Receio de espinhos 1\%

- Limpeza difícil 1\%

MORAES (1968) determinou ainda que na cidade de São Paulo são comercializados cerca de 420 toneladas de carnes 
por dia, enquanto que de pescado esse volume está ao redor de 100 toneladas. "É evidente que a série de erros cometidos des de o desembarque do pescado até a sua venda ao consumidor, re sultam na apresentação de um produto pouco atraente. Se infe rirmos a isso a presença da carne, que é um produto de conser vação mais fácil e vendida a preços próximos àqueles do peixe, compreender-se-á porque a população paulistana não sente muita atração para esta categoria de alimento".

Portanto, problemas existem dos dois lados (ofe $\underline{r}$ ta e demanda), à medida que se melhorar o equipamento de pesca com melhorias concomitantes no sistema de armazenagem e come $\underline{r}$ cialização, e que do lado da demanda sejam intensificadas as campanhas que visem mudanças no hábito alimentar dos consumido res, ter-se-á assim alcançado um mercado de pescado mais está vel, o que em última análise deverá orientar as políticas go vernamentais no sentido de proporcionar um suprimento protéico alternativo, a custos menores, à população.

Vale a pena ressaltar que a partir da criação da CEAGESP em 1966 e a vigorar o Decreto Lei no 221 de 28/02/67 observa-se já um incremento no setor de pescados quer seja a nível de captura quer na comercialização atacadista.

Assim a frota pesqueira baseada em Santos (GALLO 1976) evoluiu lentamente até 1965, sendo que em 1943/44 não se registrou nenhuma barco na Capitania dos Portos, entretanto a partir de 1966 esse crescimento foi mais rápido, atingindo um máximo em 1970, quando 64 barcos foram registrados.

Antes de 1966 o mercado atacadista de São Paulo funcionava, em condições precárias, ao lado do Mercado da Can tareira onde a comercialização se realizava a "céu aberto". Com a criação da CEAGESP em 1966, único centro atacadista de comercialização do pescado em são Paulo, passou-se a desfrutar de condições hiọiênicas muito melhores além da disponibilidade de câmaras frị̣oríficas adeợuadas à conservação do pescado, permitindo assim que o conșumidor tenha à sua disposição prodụ tos de boa qualidade. 


\section{SUGESTÕES PARA NOVOS ESTUDOS}

No desenrolar deste estudo detectaram-se vários pontos que necessitam ser melhor estudados, afim de complemen tar os resultados presentes. Assim sendo sugere-se analisar:

1 - o comportamento mais recente dos preços dos pescados, tendo em vista compará-los com os deste estudo, no sentido de detectar outras possíveis influências da demanda.

2 - a produção desembarcada nos portos, visando conhecer a produção/barco, dado o relativo aumento na frota pesqueira a partir de 1967 .

3 - o comportamento do consumo "per capita" de pescado.

4 - os efeitos das técnicas de captura na produ tividade dos barcos e consequentemente na produção de pescados. 
BIBLIOGRAFIA

\author{
ARRUDA, M.L.C. e JUNQUEIRA, P.C. 1969. O Padrão Estacional \\ dos Preços do Algodão. Agricultura em São Paulo, XVI, no 3 \\ e 4 . \\ ARRUDA, M.C. e CRISCUOLO, P.S. 1970. Uma Previsão para o \\ Padrão Estacional dos Preços de Ovos. Agricultura em são \\ Paulo, XVIII, no 1 e 2 . \\ BRANDT, S.A. 1974. Pesquisa de Mercados e Preços Agrícolas. \\ ne Brasil. Revista de Economia Rural Vol.no 5. \\ BRASIL - Anuário Estatístico - diversos. \\ BRASIL - Anuário da Pesca - 1974 . \\ BRASIL - Revista Nacional da Pesca - diversos.
}


BORTOLETO, E.E. e UENO, L.H. 1979 . Variação Estacional' ' de Hortaliças a Nível de Atacado. Informações Econômicas -IEA $-3 / 79$.

CARVALHO, F.C. e GIULIETTI, N. 1979. Abastecimento de Sardi nha à População Paulistana de Baixa Renda - Informações Eco nômicas - IEA - 1/78.

CARVALHO, F.C. e GIULIETTI, N. 1977. Comercialização e Con sumo de Camarão no Estado de São Paulo - Inf̣ormações Econô micas - IEA - 2/78

CRUZ, P.R.D.C. 1974. Projeção da Demanda de Produtos Horti. frutigranjeiros e de Pescado para a Região Metropolitana de São Paulo. Plan. e Conj. São Paulo, (72):67-73 Janeiro 1974 .

FAO 1979. Agriculture: Horizon 2000.. C 79/24 juillet 1979 .

FUNDAÇÃO GETULIO VARGAS - Conjunturas Econômicas - diversas.

GALLO, J. 1976. Participação dos Entrepostos de Pesca e Pon tos de Desembarque no Abastecimento da Cidade de são Paulo. Série Teses e Monografias no 23 - IGEOG-USP.

HOFFMANN, R. 1968. Variação Estacional dos Preços da Cebola no Estado de São Paulo - Série Estudos no 1, DCSA-ESALQ/USP - Piracicaba.

HOFFMANN, R. 1969. Variação Estacional dos Preços dos Produ tos Agropecuários no Estado de São Paulo. ESALQ/USP, Pira cicaba (tese de doutoramento).

HICKS, J. 1972. Capital and Growth. Oxford University Press pp. 76-83. 
IWAI, M. 1969/71. O Camarão no Centro-Sul do Brasil.Secreta ria Economia e Planejamento/SUDELPA/PA/Inst. Oceanográfico (USP) .

JUNQUEIRA, P.C. 1971. Entreposto Terminal de São Paulo Expe riência e Avaliação. Agricultura em São Paulo, Ano XVIII, no 5 e 6 .

LANGE, O. 1961. Introdução à Econometria. Editora Fundo de Cultura pp. 24-81.

LINS, E.R. et alii. 1972. Diagnóstico dos Sistemas de Arma zenamento a Frio de Pescado, Aves, Frutas e Sucos de Frutas. no Estado de São Paulo. Agricultura em São Paulo, Ano XIX, tomo 1.

MORAES, J.R. 1968. Distribuicão ou Consumo de Pescado. Re vista Nacional da Pesca. Ano IX no 74.

MORIMOTO, P.T. 1975. Demanda de Pescado no Mercado da Gran de são Paulo. Viçosa (dissertação de mestrado).

PANIAGO, E. 1966. Flutuações Estacionais no Preço do Milho no Estado de São Paulo. Revista Ceres, Vol. XIII, no 73, U.R.M.G.

PEREIRA, I.F. et alii. 1963. Variação Estacional dos Preços. Agrícolas no Estado de São Paulo. Agricultura em São Paulo $\mathrm{x}, \mathrm{n} \% 4$. 
SPIEGEL, M.R. 1969 . Estatística - Ao Livro Técnico S/A. Rio de Janeiro pp. 468-513.

VALENTINI, H. et alii. 1972. Considerações sobre a Pesca no. Estado de São Paulo. Boletim do Instituto de Pesca - Série de Divulgação, no 1, Junho. 


$$
\begin{gathered}
\text { A N E X O } 01 \\
\text { P E S C A D A B R A N C A }
\end{gathered}
$$



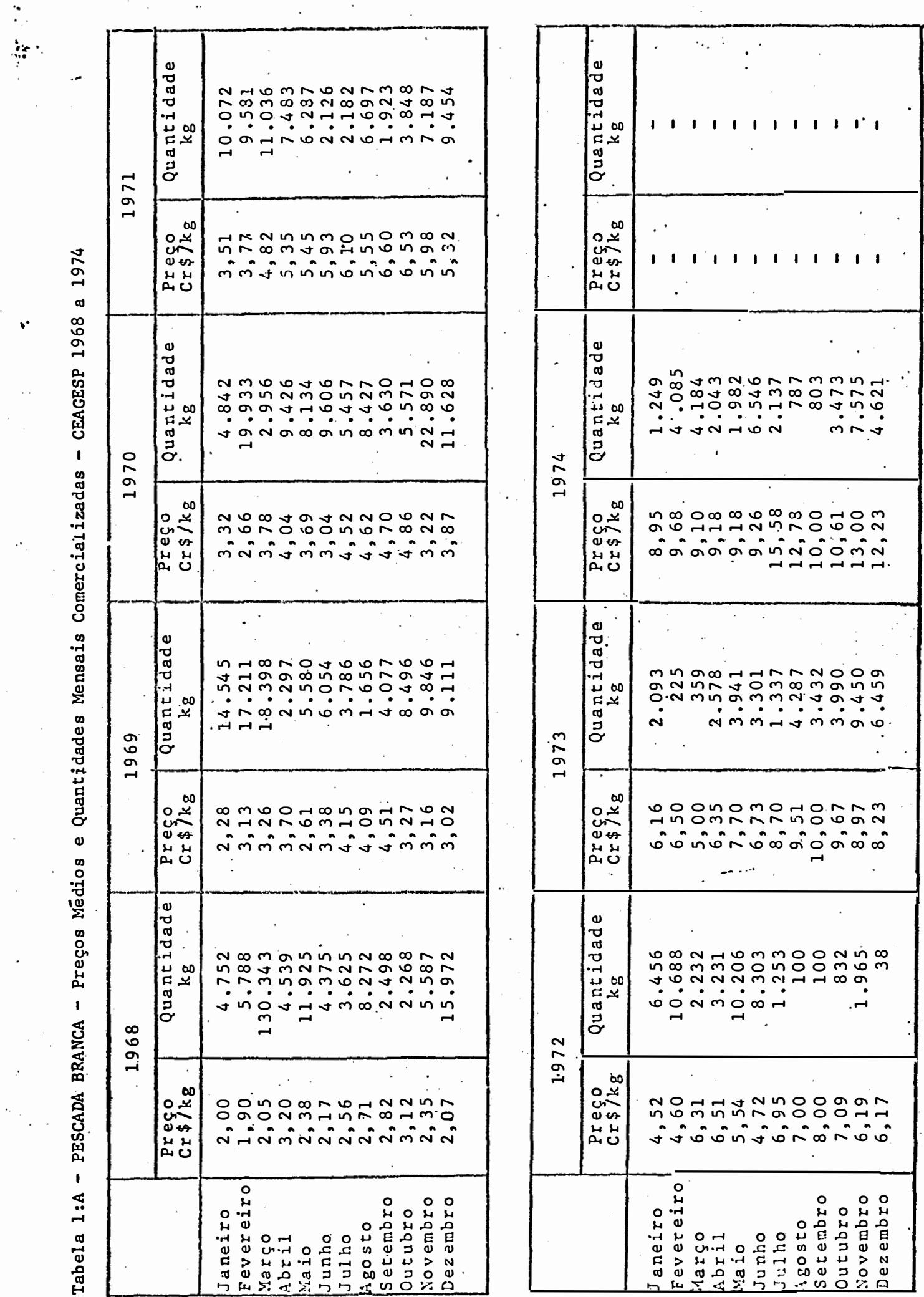


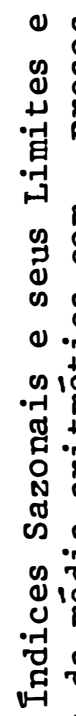

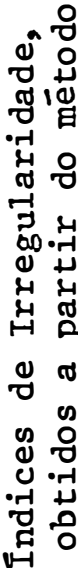

os

1

.

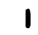

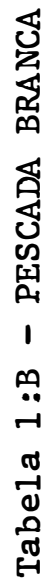

亗

唯

ต อ

年

\section{辰} 品 융의

ㅇํㅇ요요

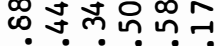

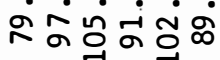

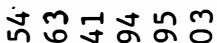
ด. ํ.

훙ㅇㅇㅇㅛ

$\infty a b v i$ ษักำ ํํำ

事 응ㅇㅇㅇㅇㅇ

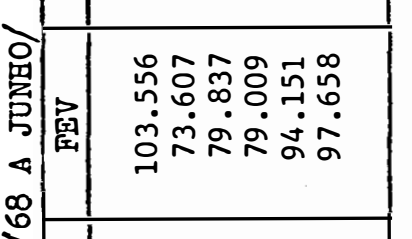

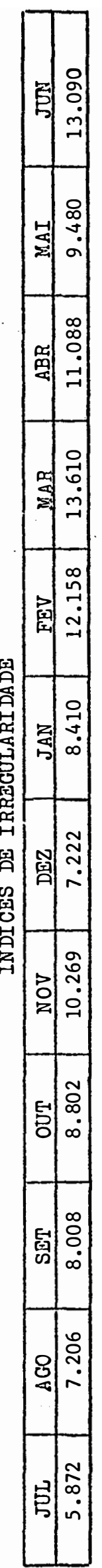

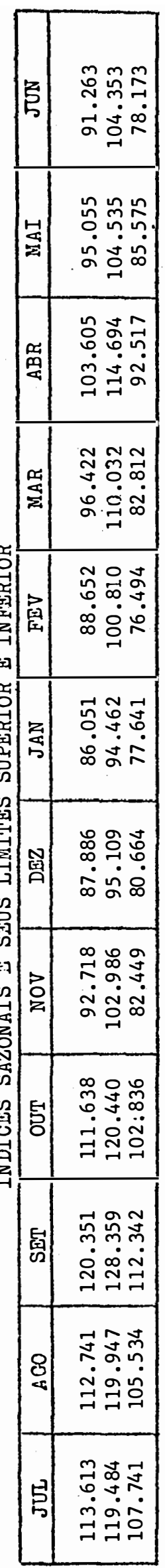

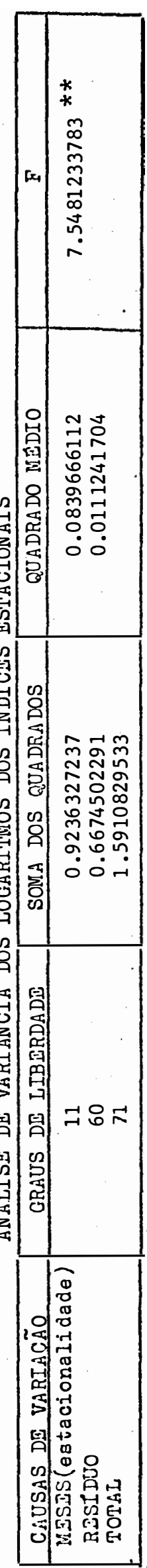



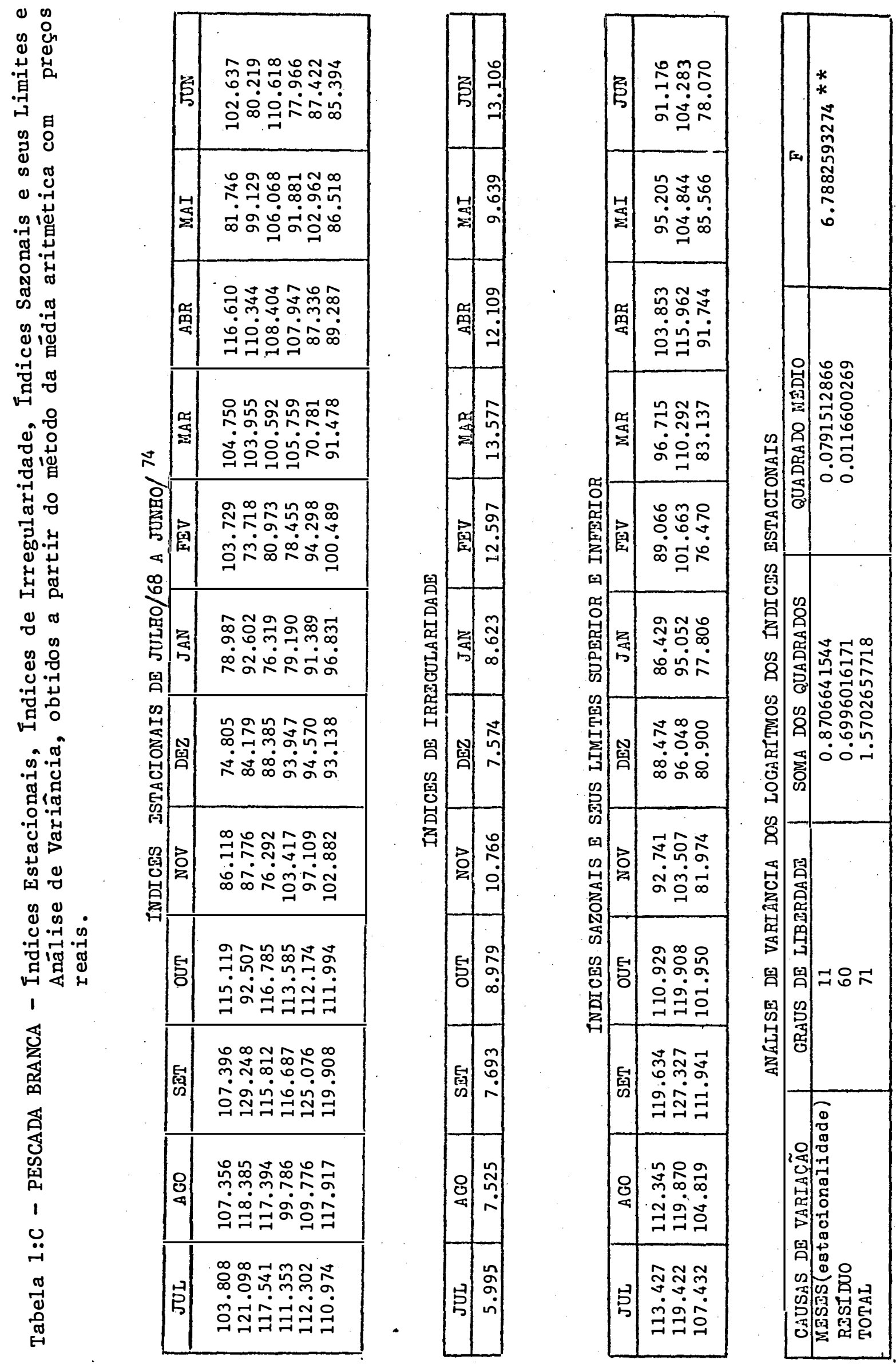

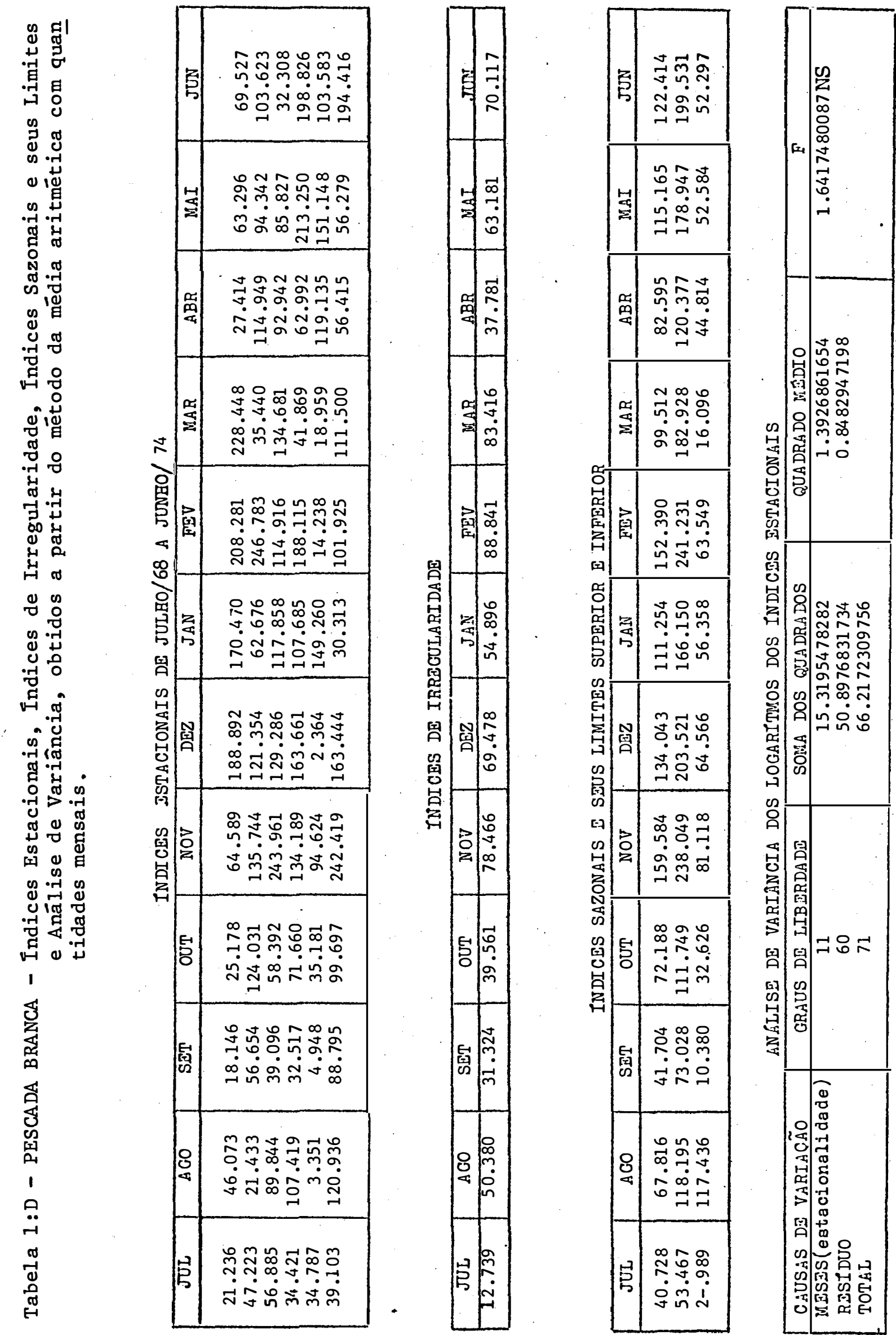

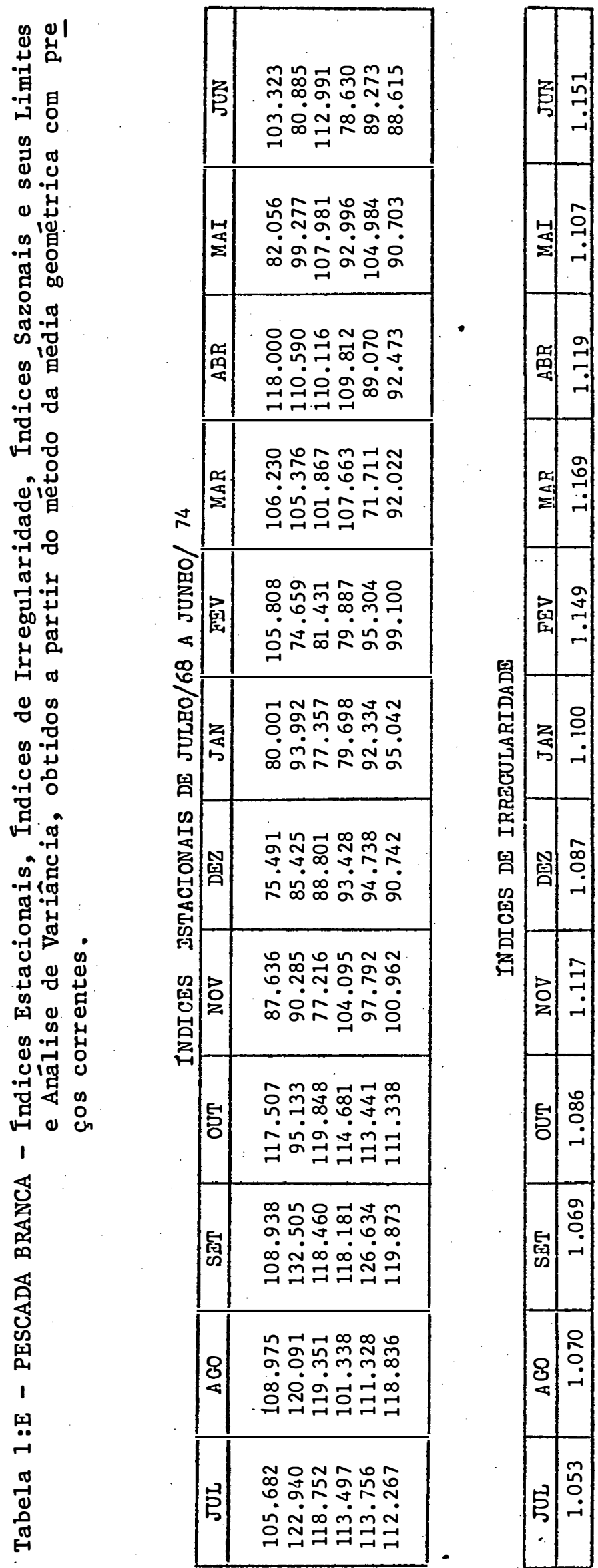

\begin{tabular}{|c|c|}
\hline 茨 & 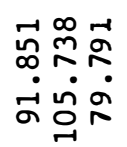 \\
\hline$\stackrel{-1}{\Sigma}$ & 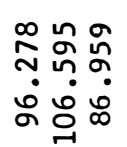 \\
\hline 品 & 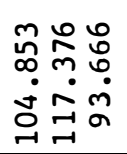 \\
\hline 㿣 & 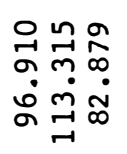 \\
\hline 国 & 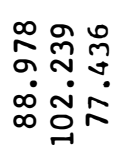 \\
\hline 染 & 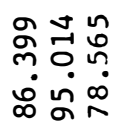 \\
\hline 鱼 & 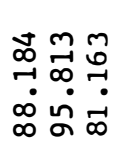 \\
\hline 宫 & 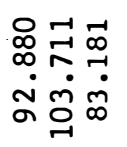 \\
\hline 통 & 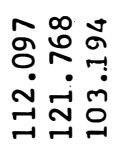 \\
\hline 鼠 & 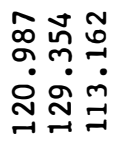 \\
\hline 8 & 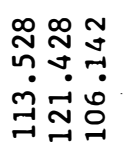 \\
\hline 宫 & 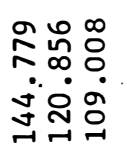 \\
\hline
\end{tabular}

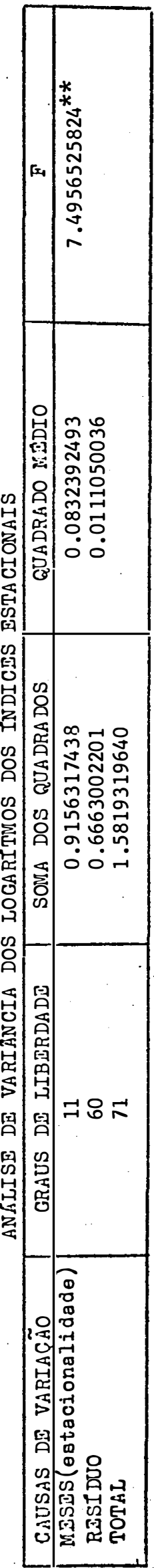



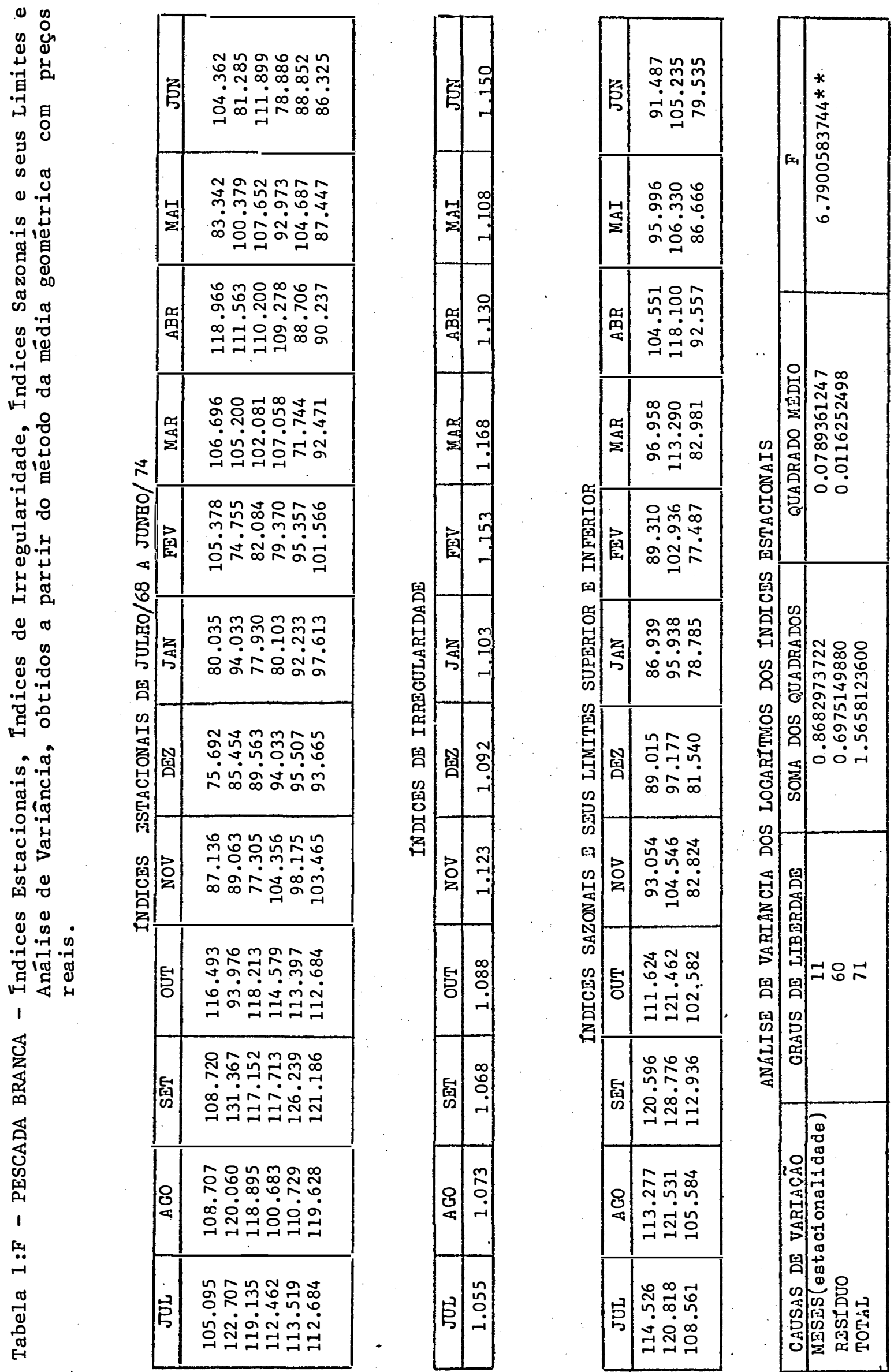

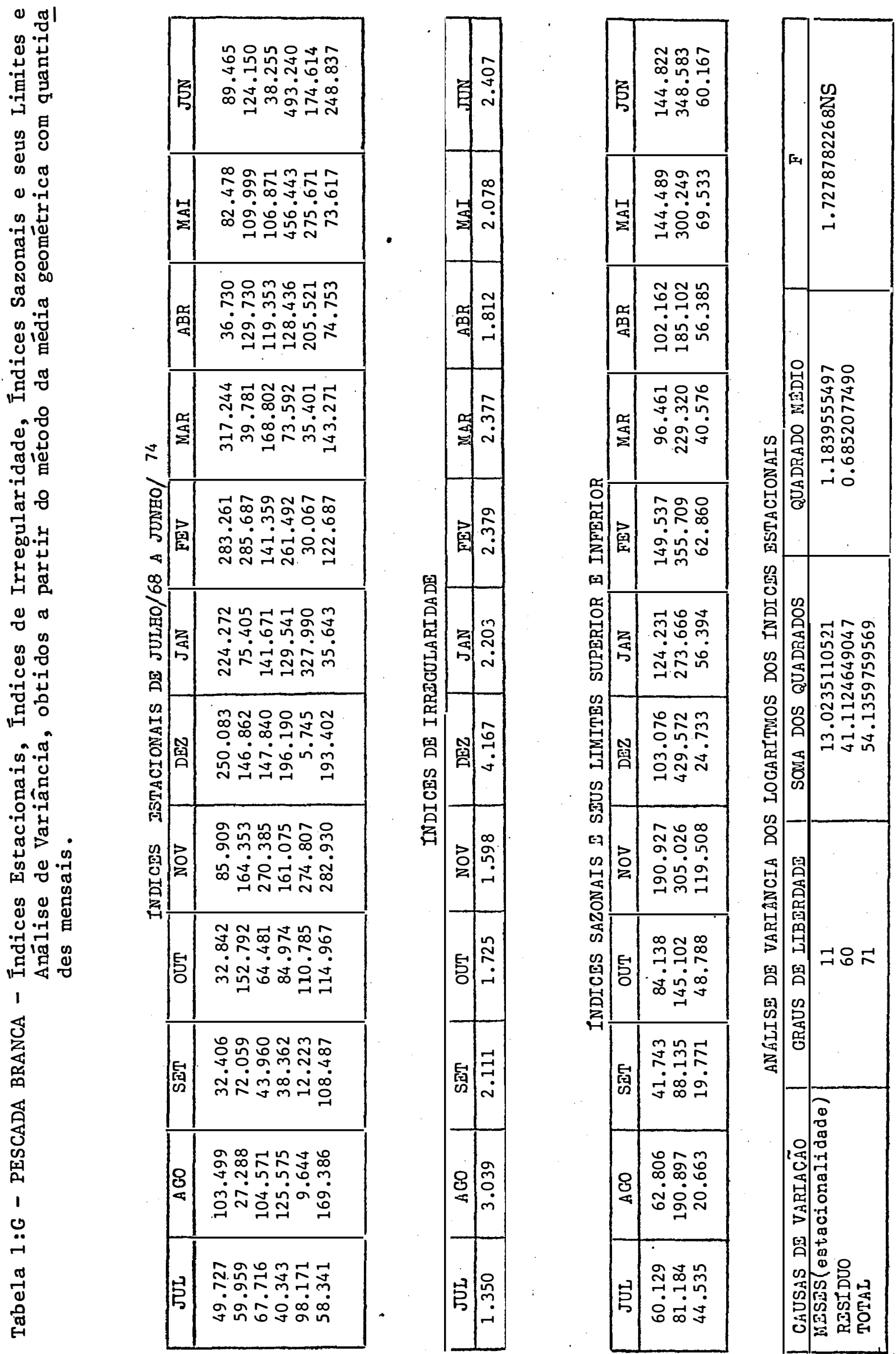


$$
\begin{gathered}
\text { A N E X O } 02 \\
\text { P E S C A D A G O E T E }
\end{gathered}
$$



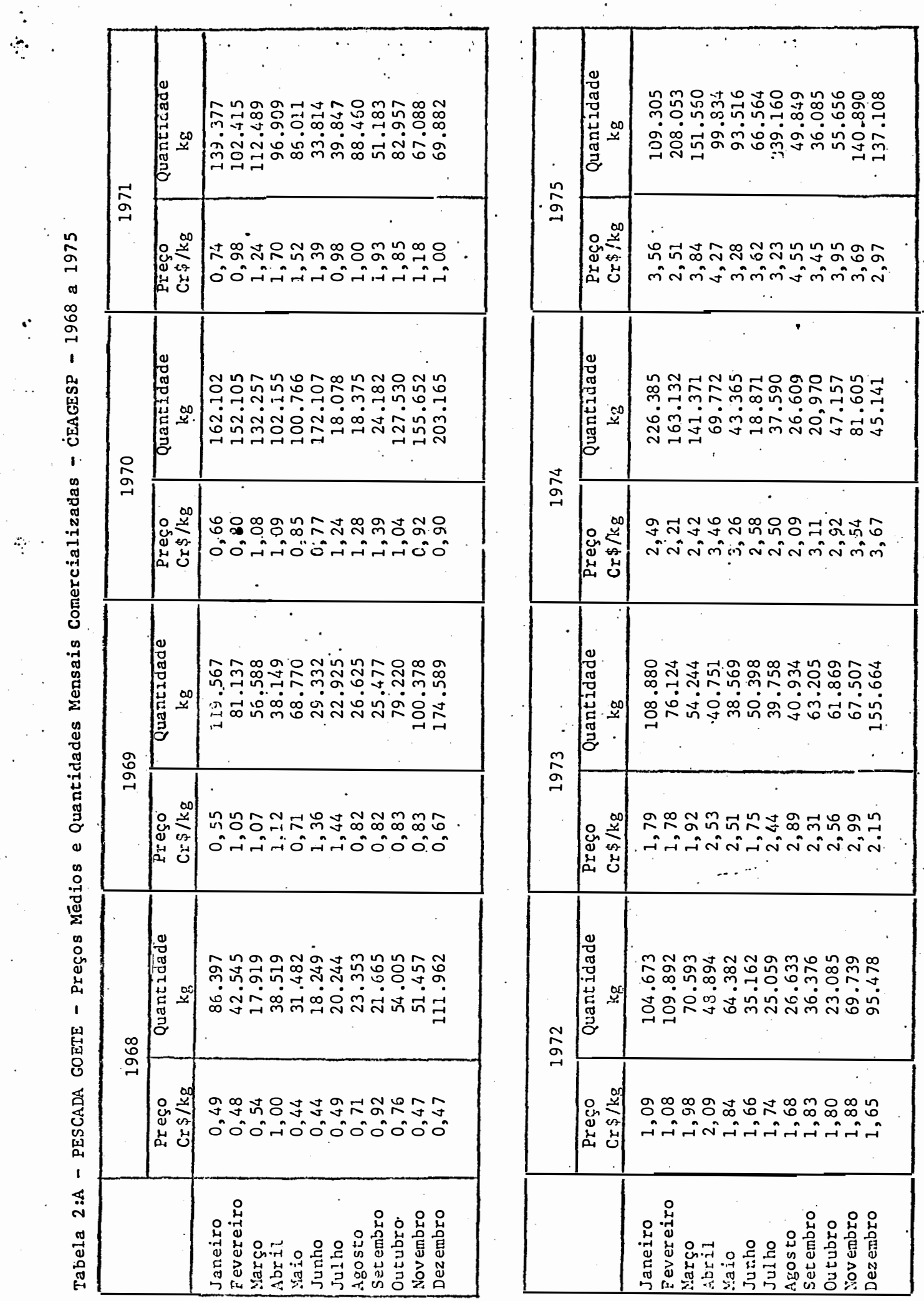
萡
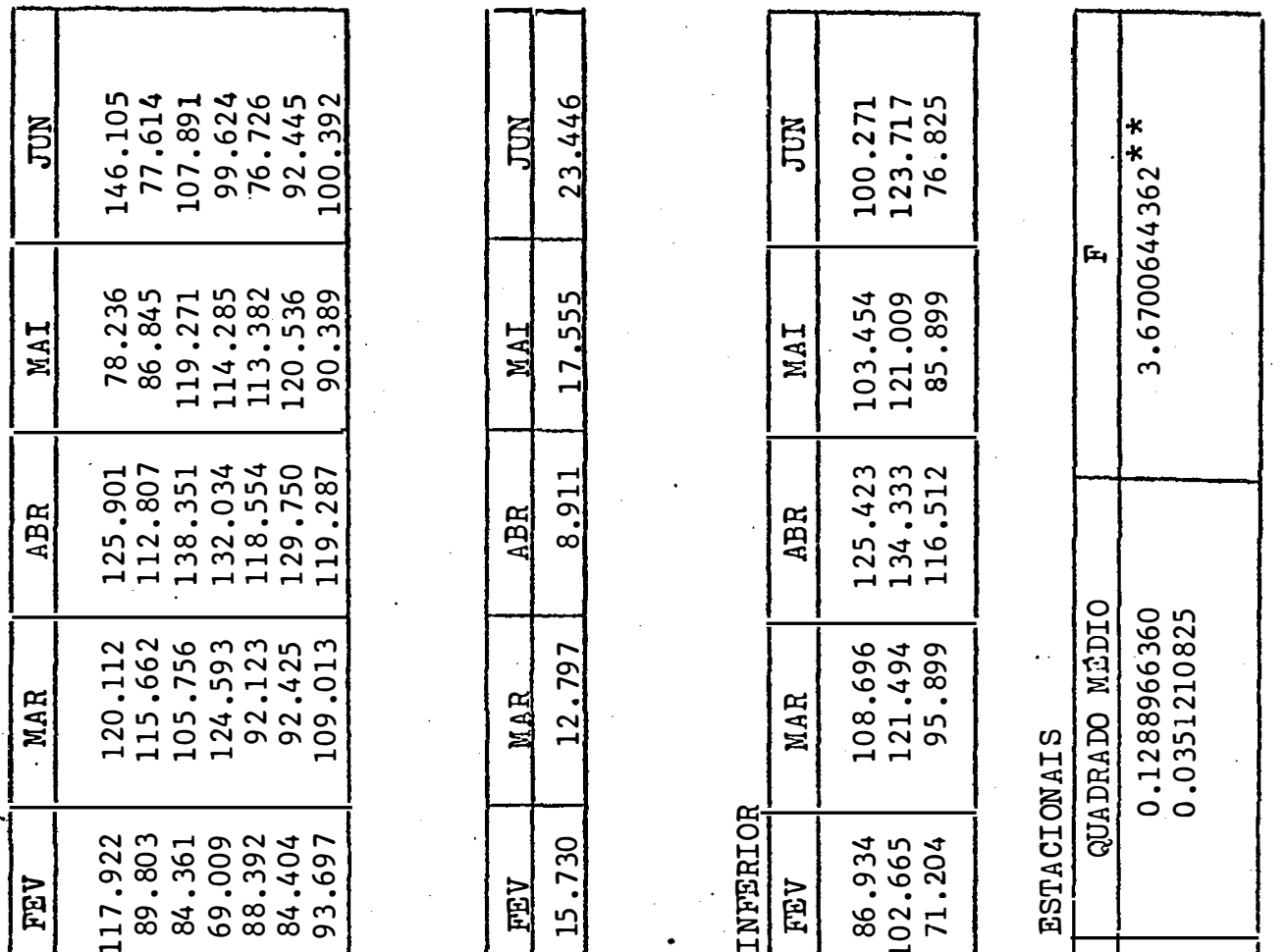

s.

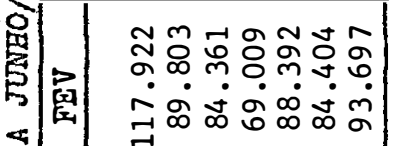

๙

क क

U.

苨苜

烍

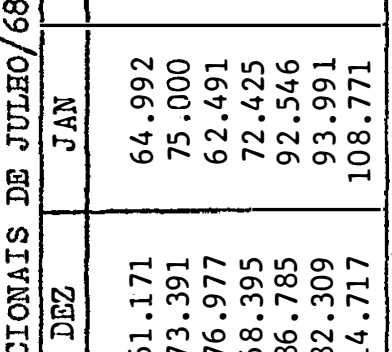

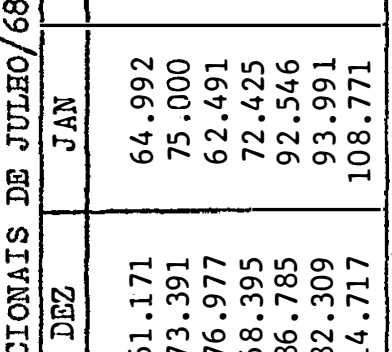

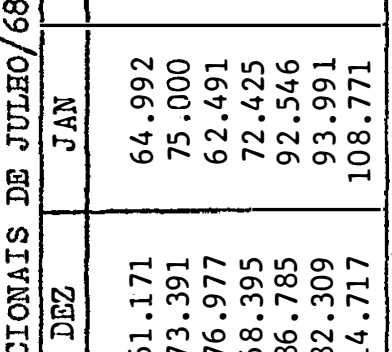

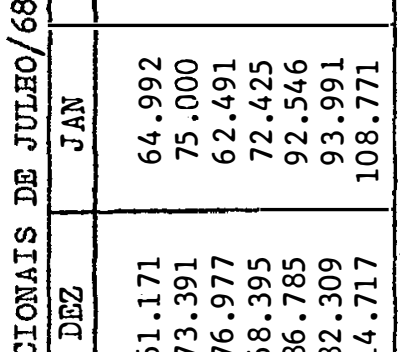

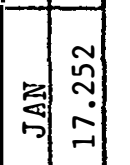

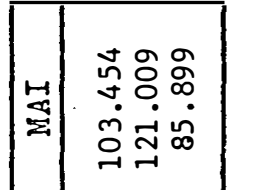

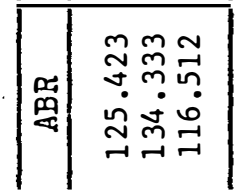

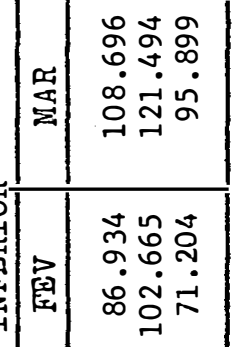

है

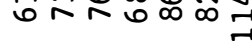

4กำกล

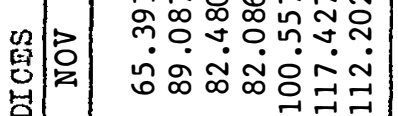

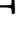

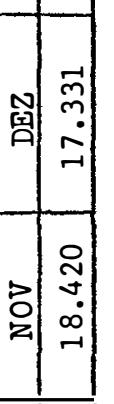

r.

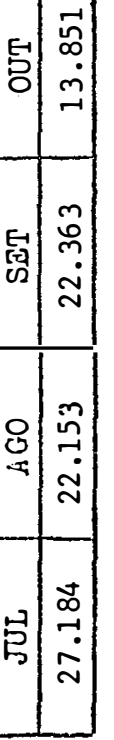

\begin{tabular}{|c|c|}
\hline 窝 & 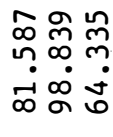 \\
\hline 兒 & 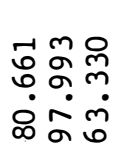 \\
\hline 完 & 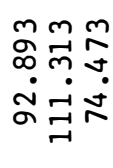 \\
\hline 点 & 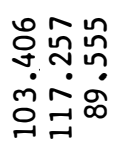 \\
\hline 舅 & 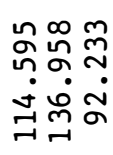 \\
\hline O্বি & 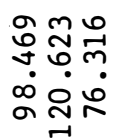 \\
\hline 官 & 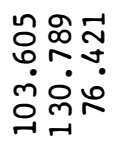 \\
\hline
\end{tabular}

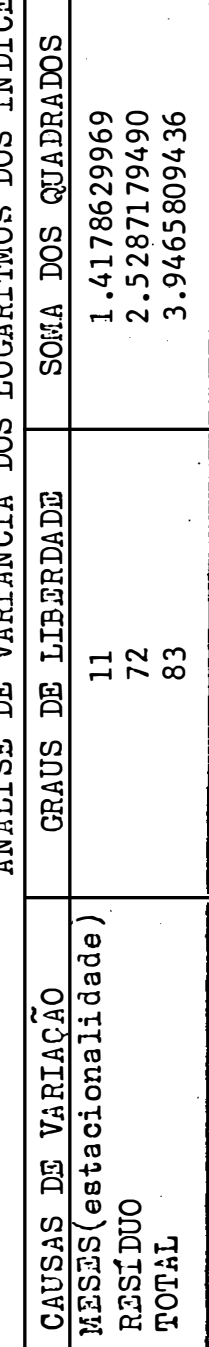



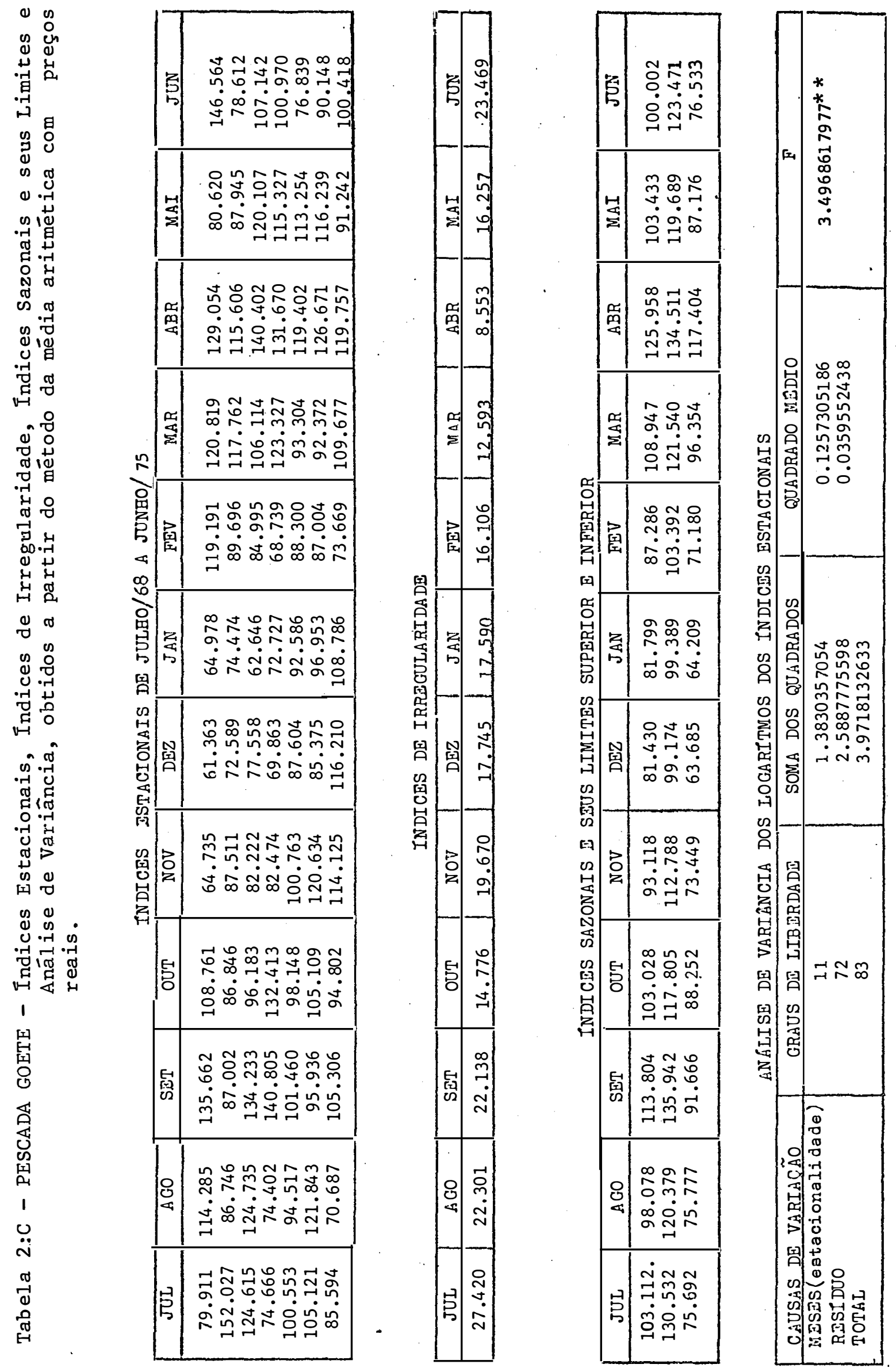

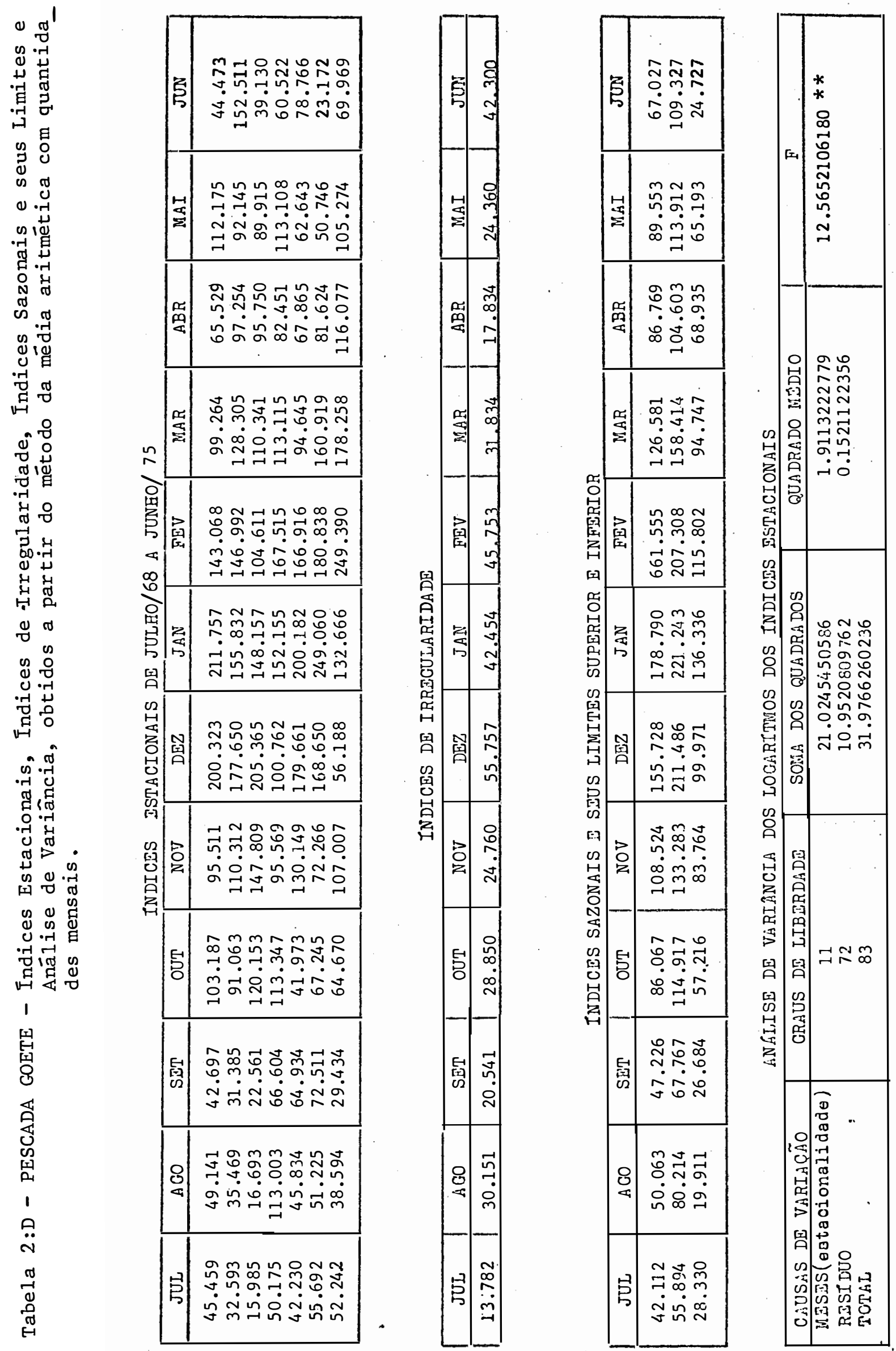

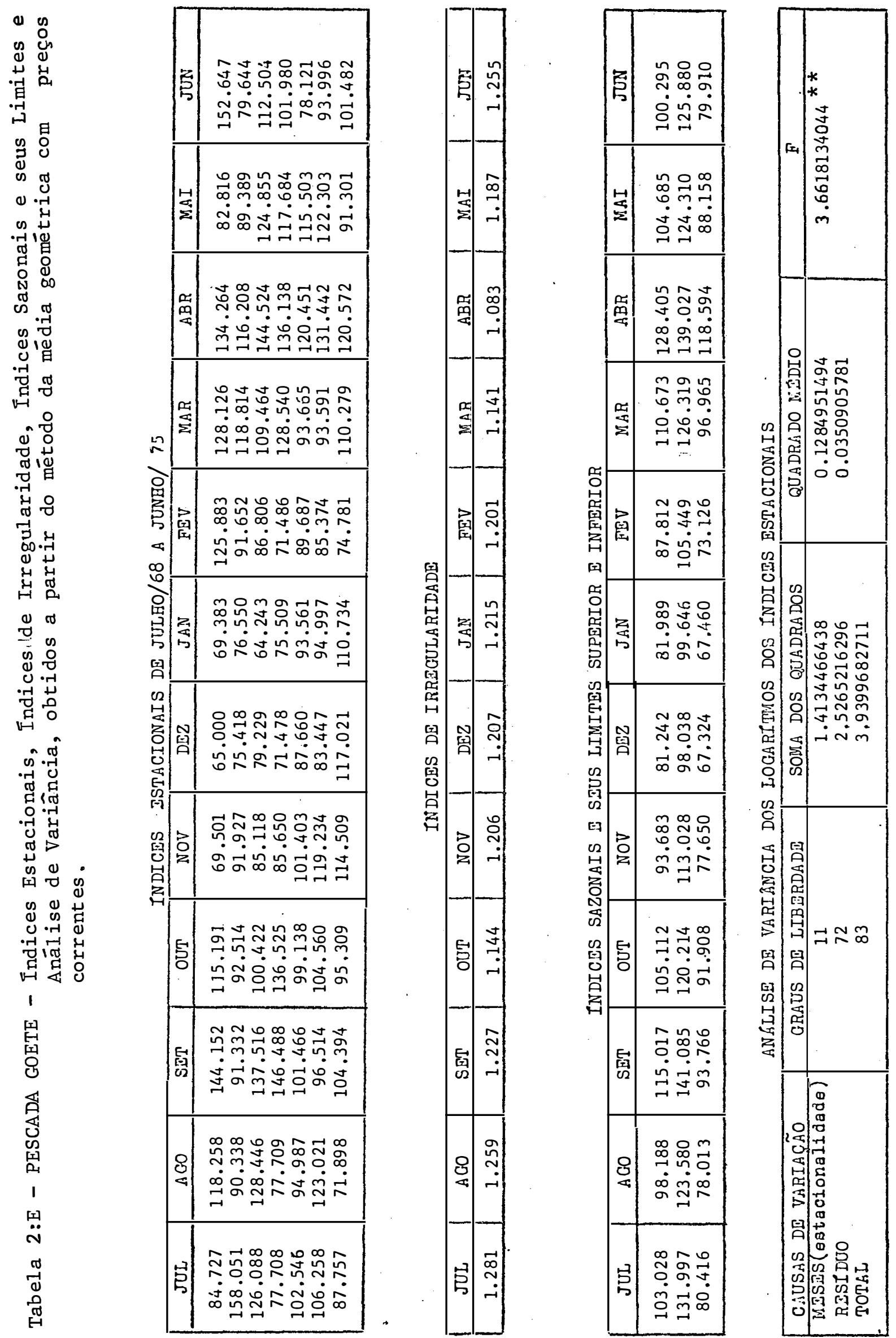

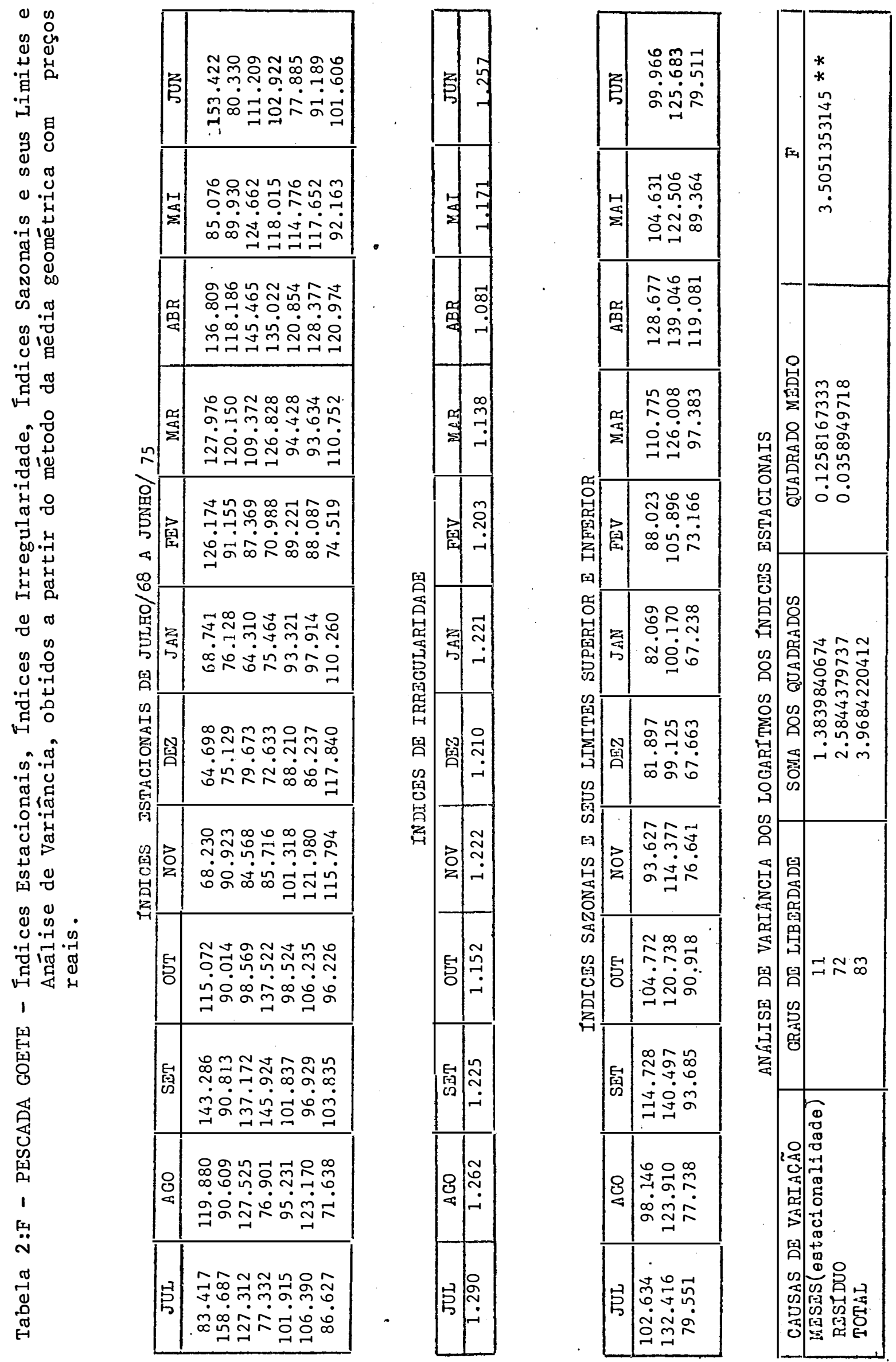

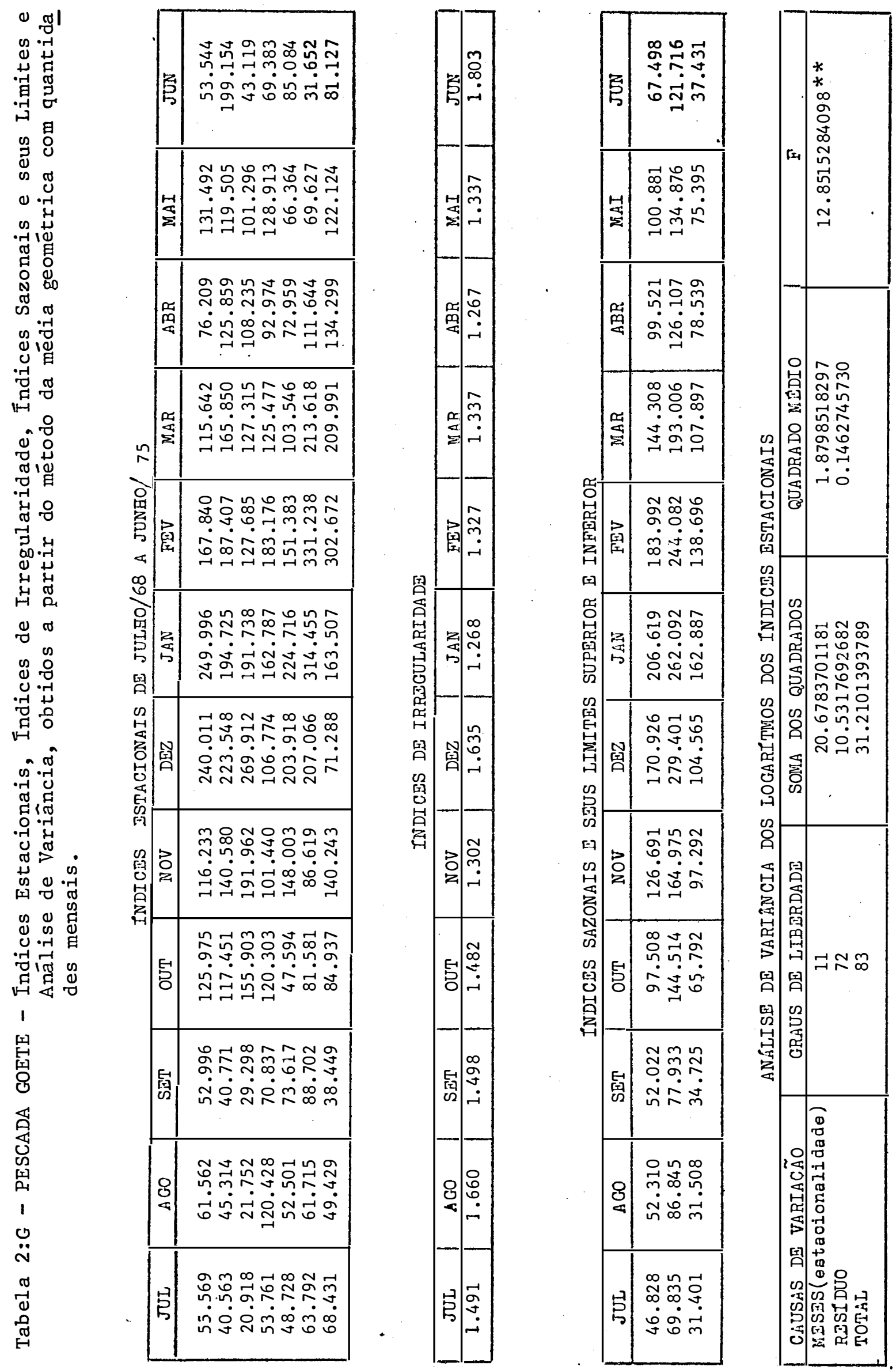


$$
\begin{aligned}
& \text { A N E X O } 03
\end{aligned}
$$

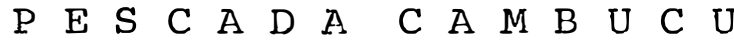



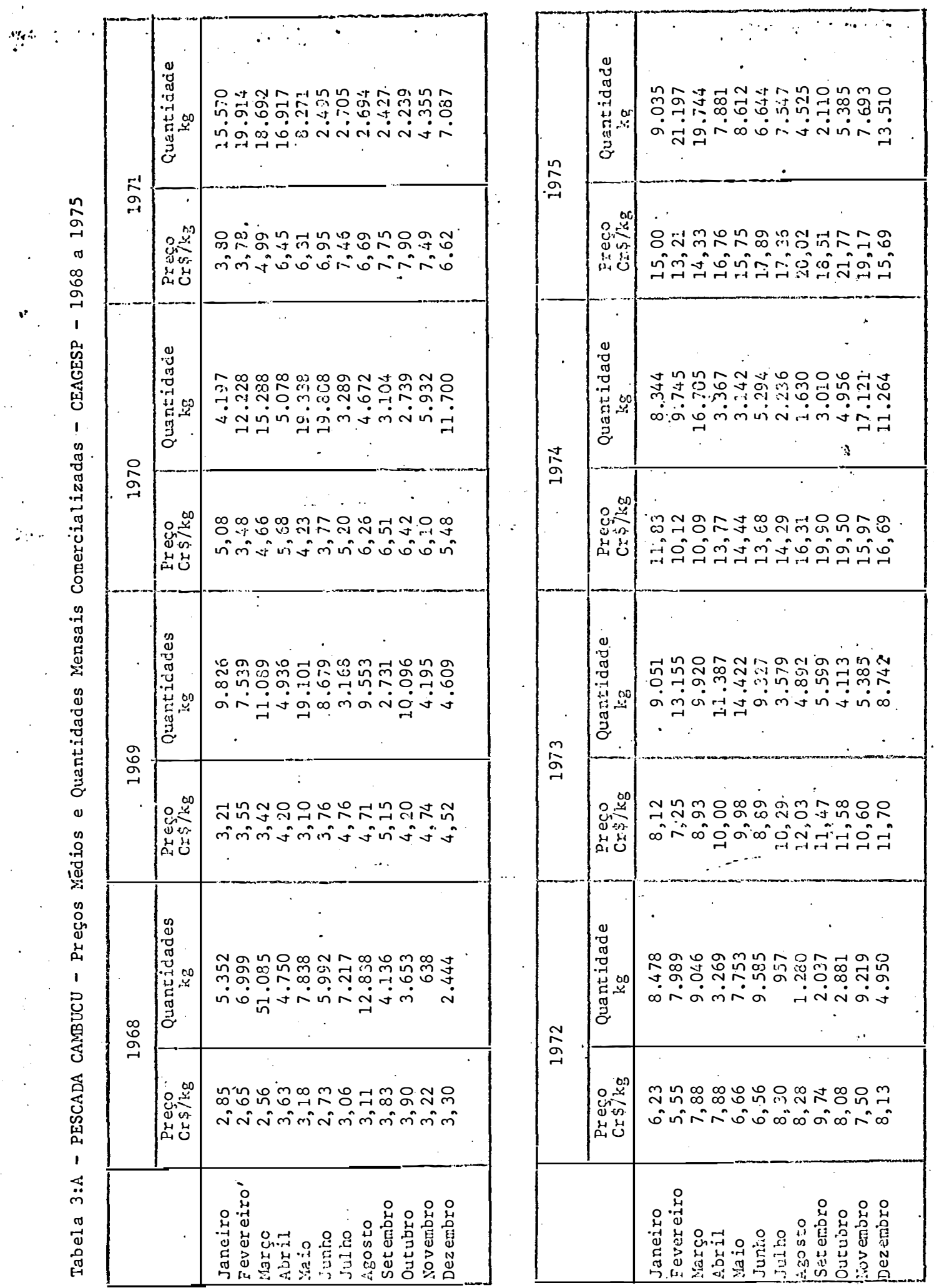

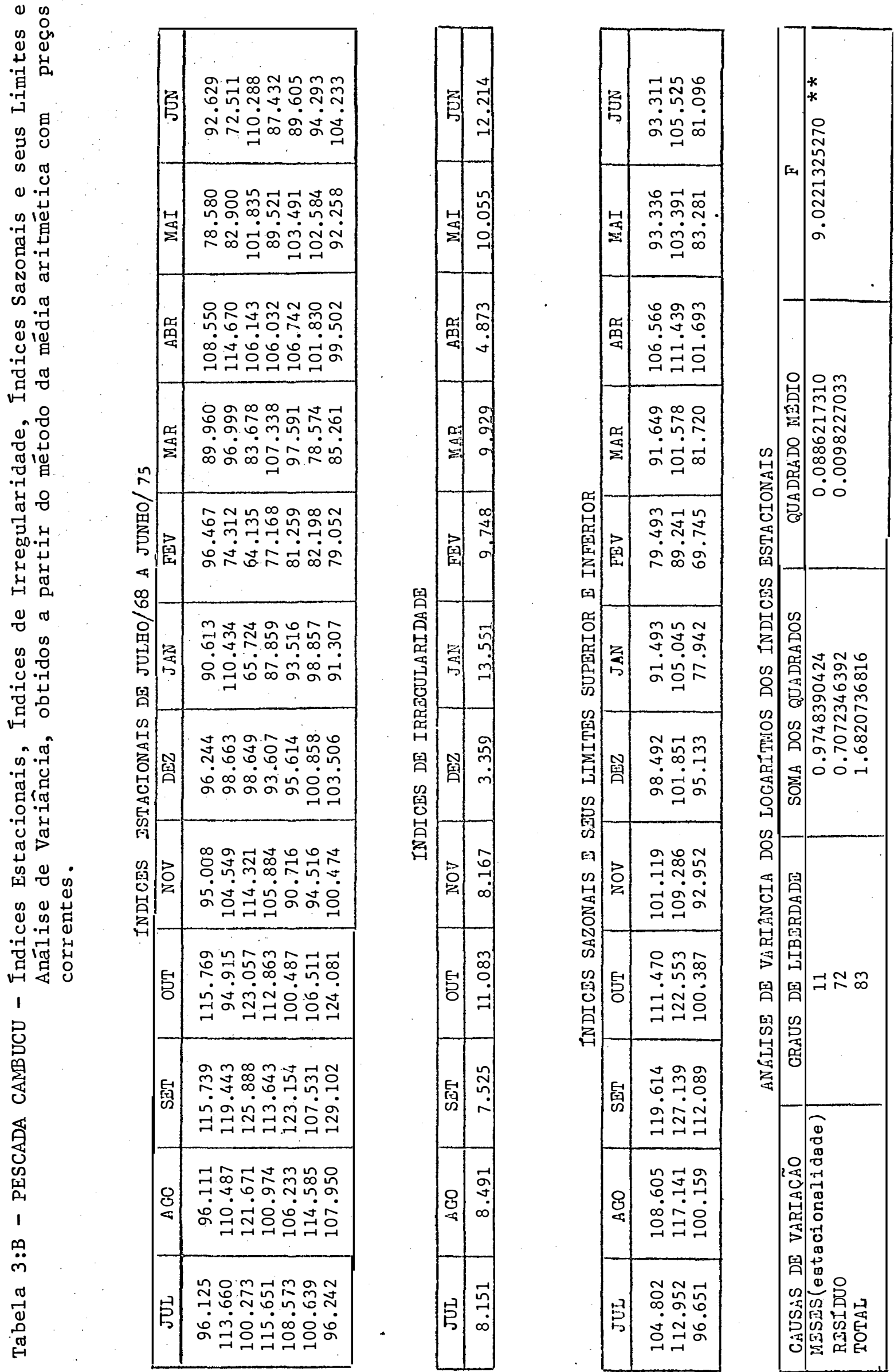

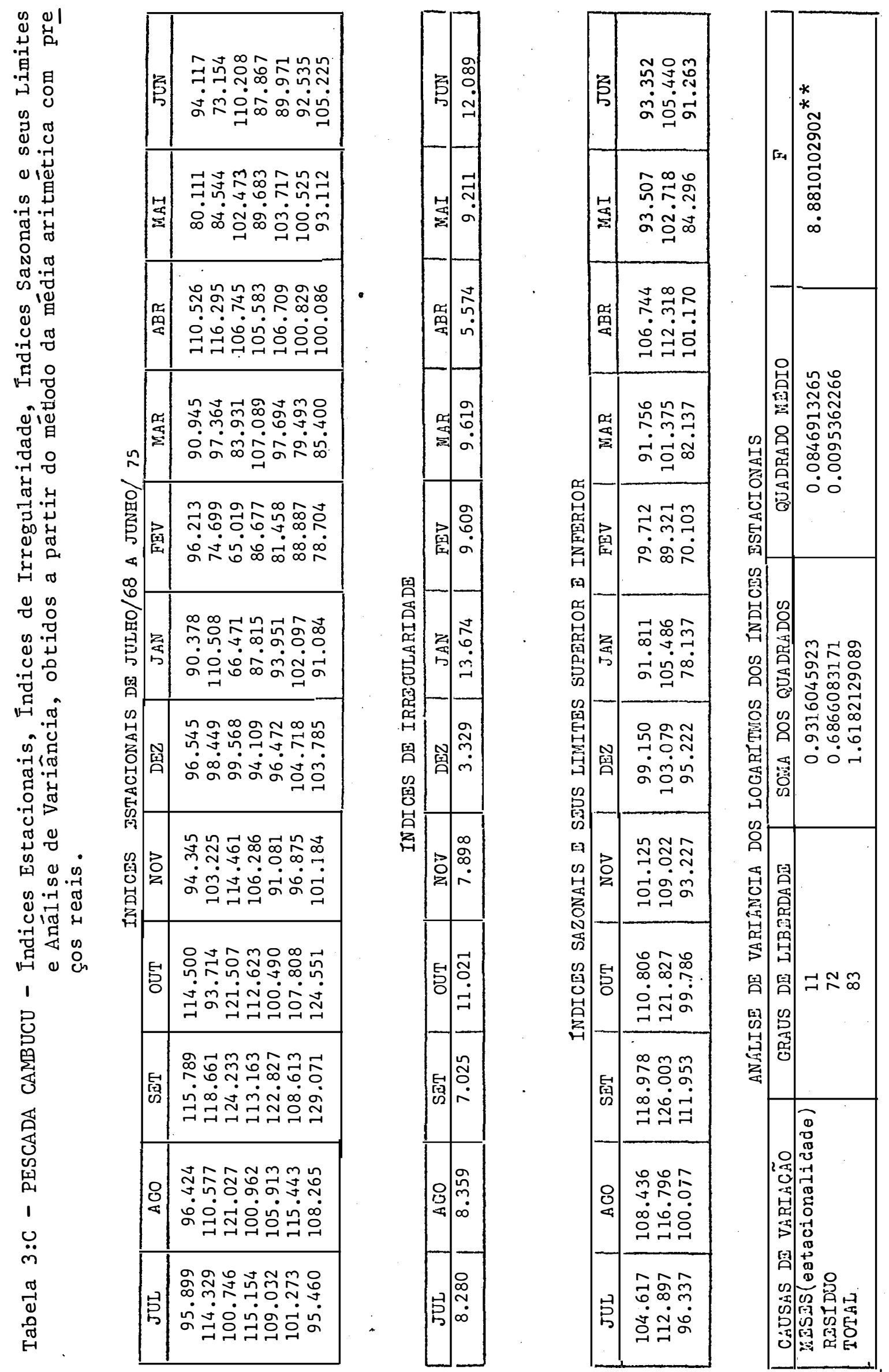

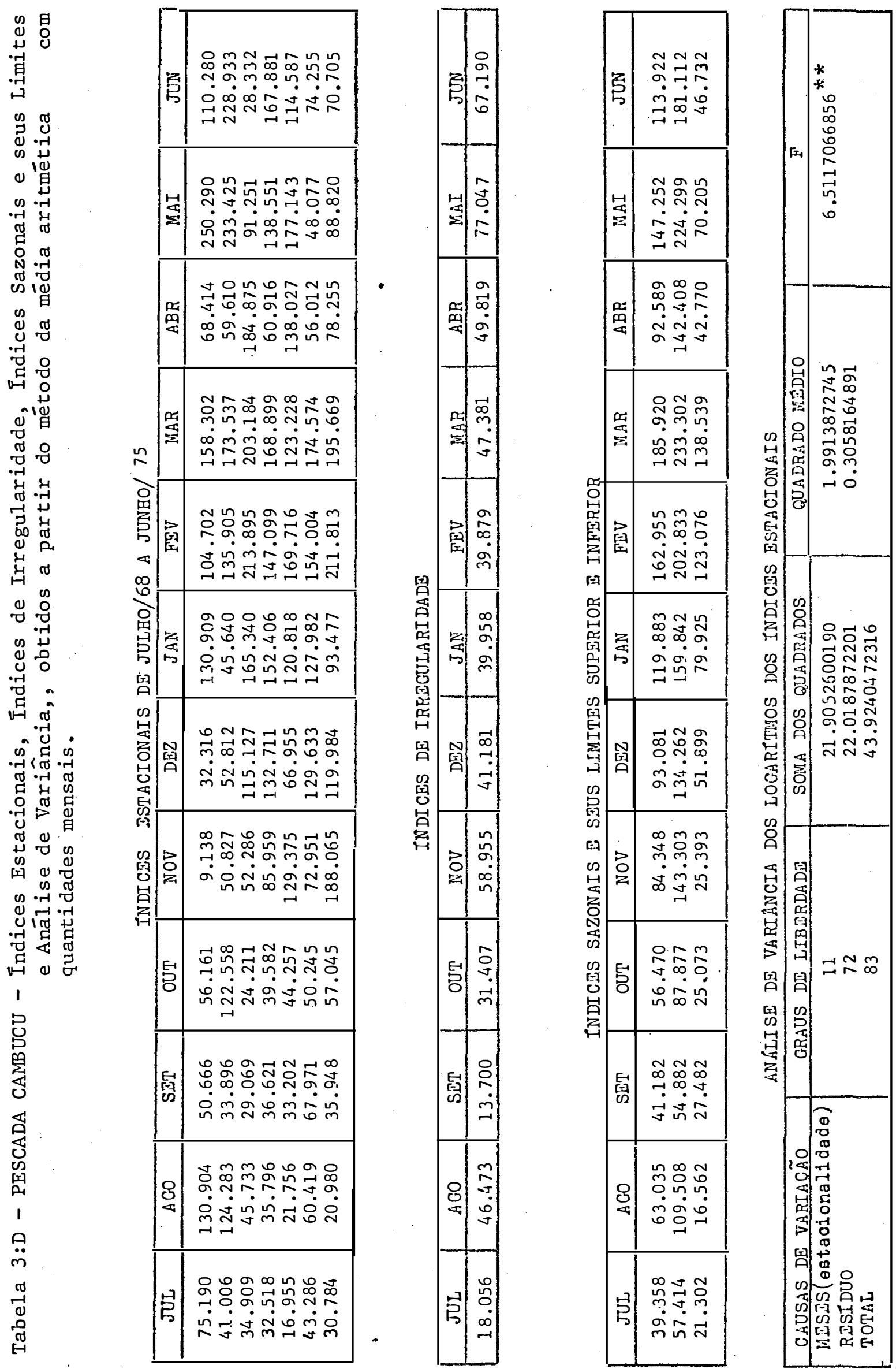

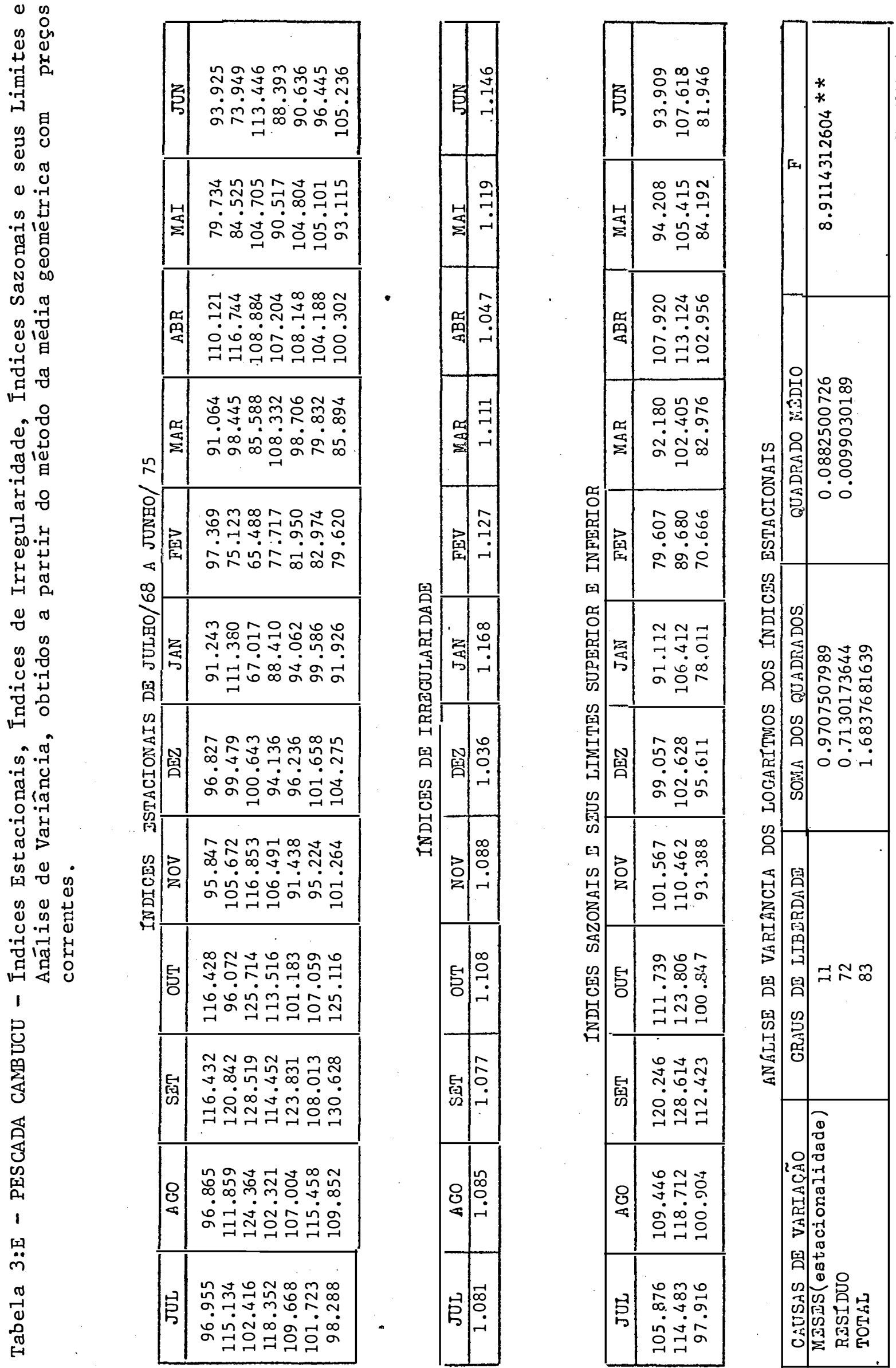

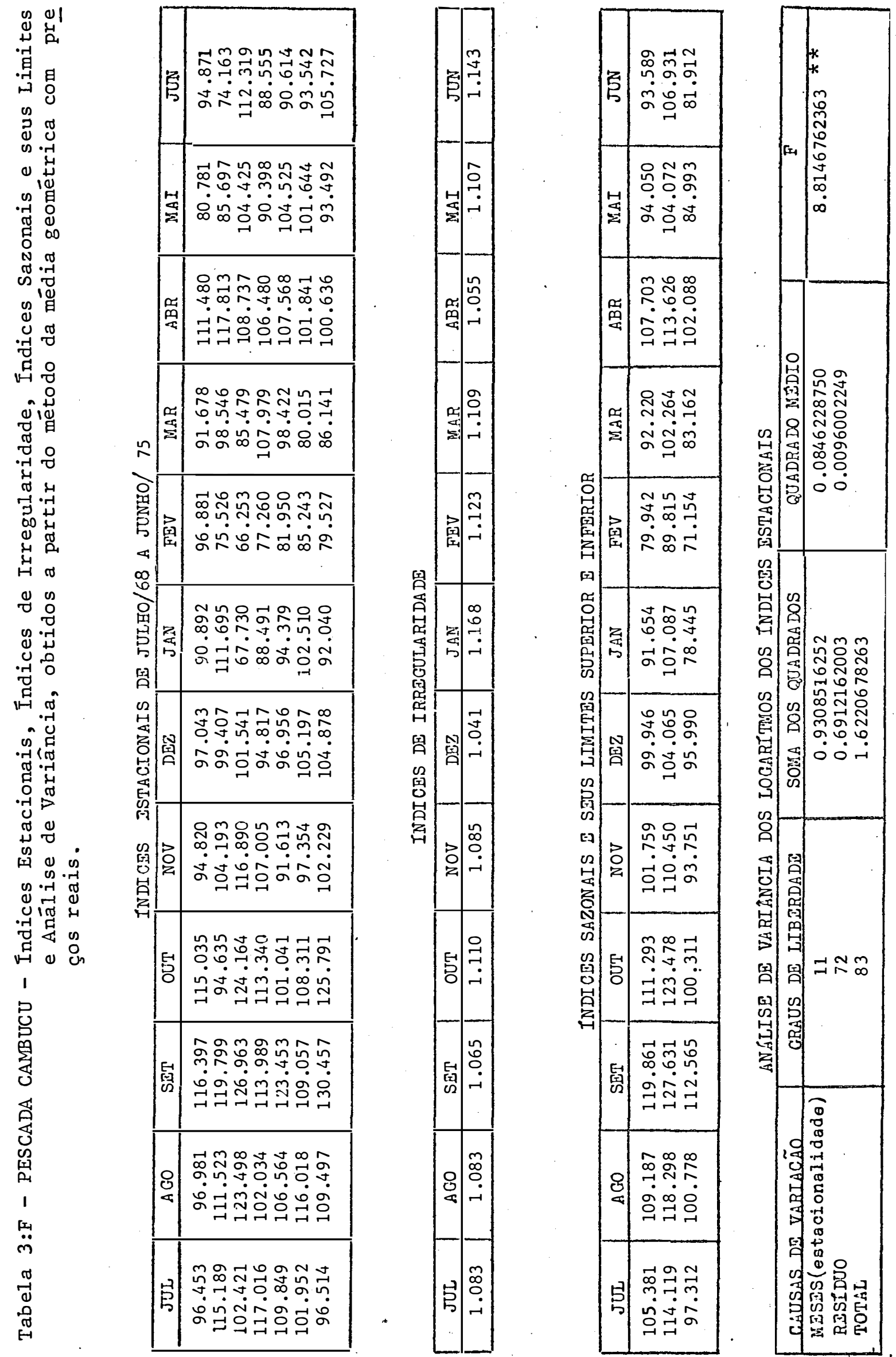

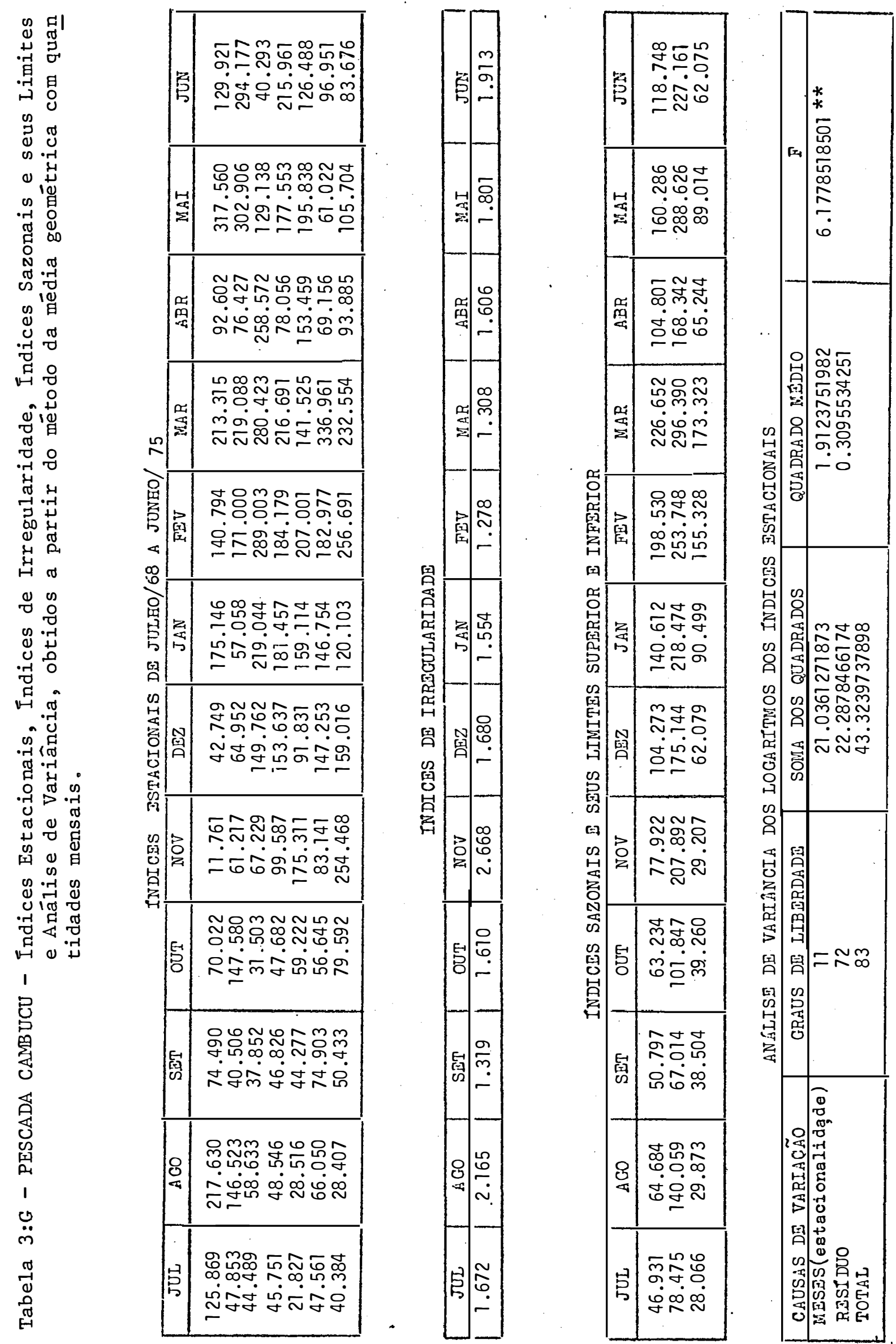
$\begin{array}{lllllll}A & N & E & X & O & 04\end{array}$

P E S C A D A T O R T I N H A 

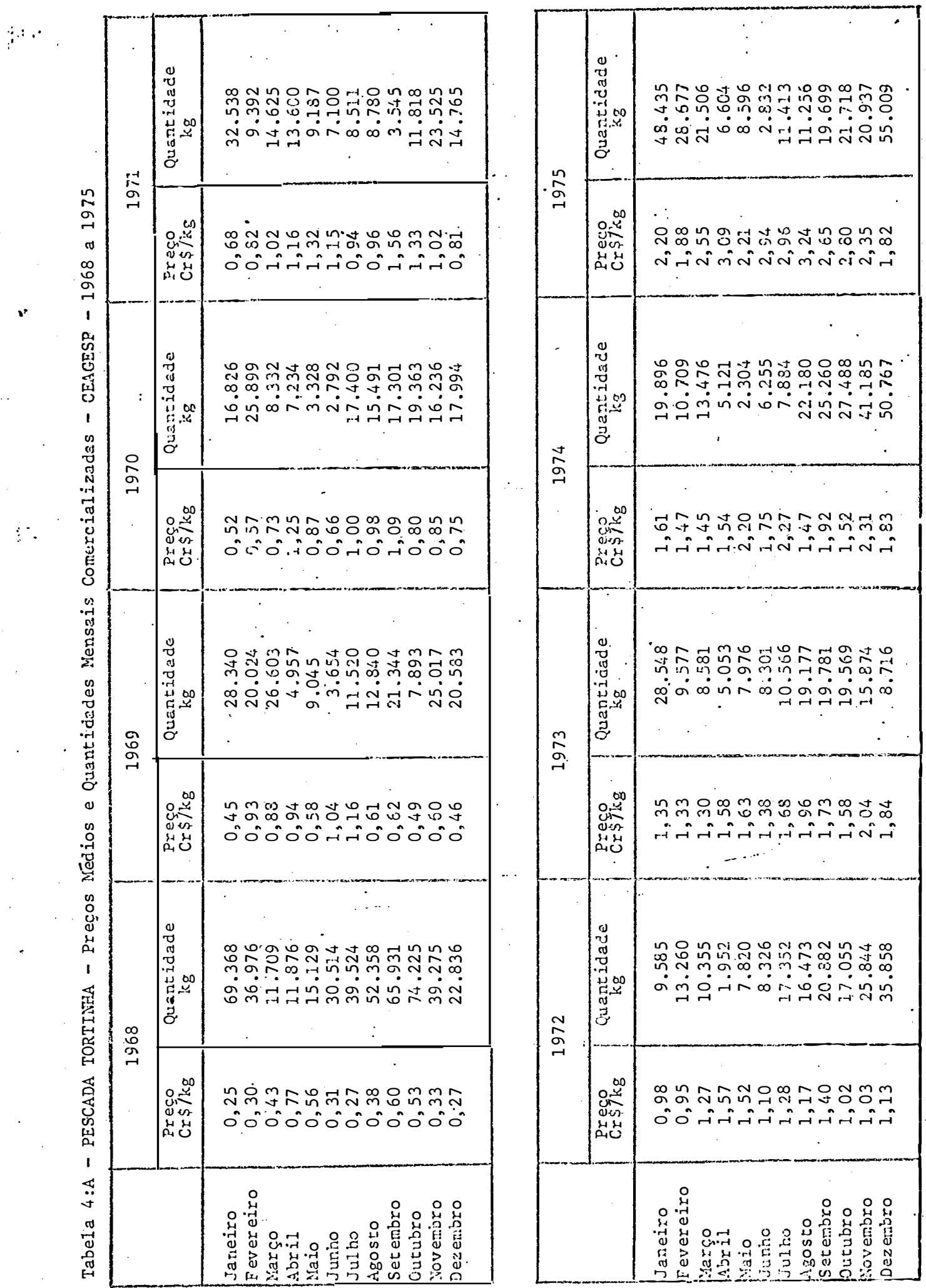

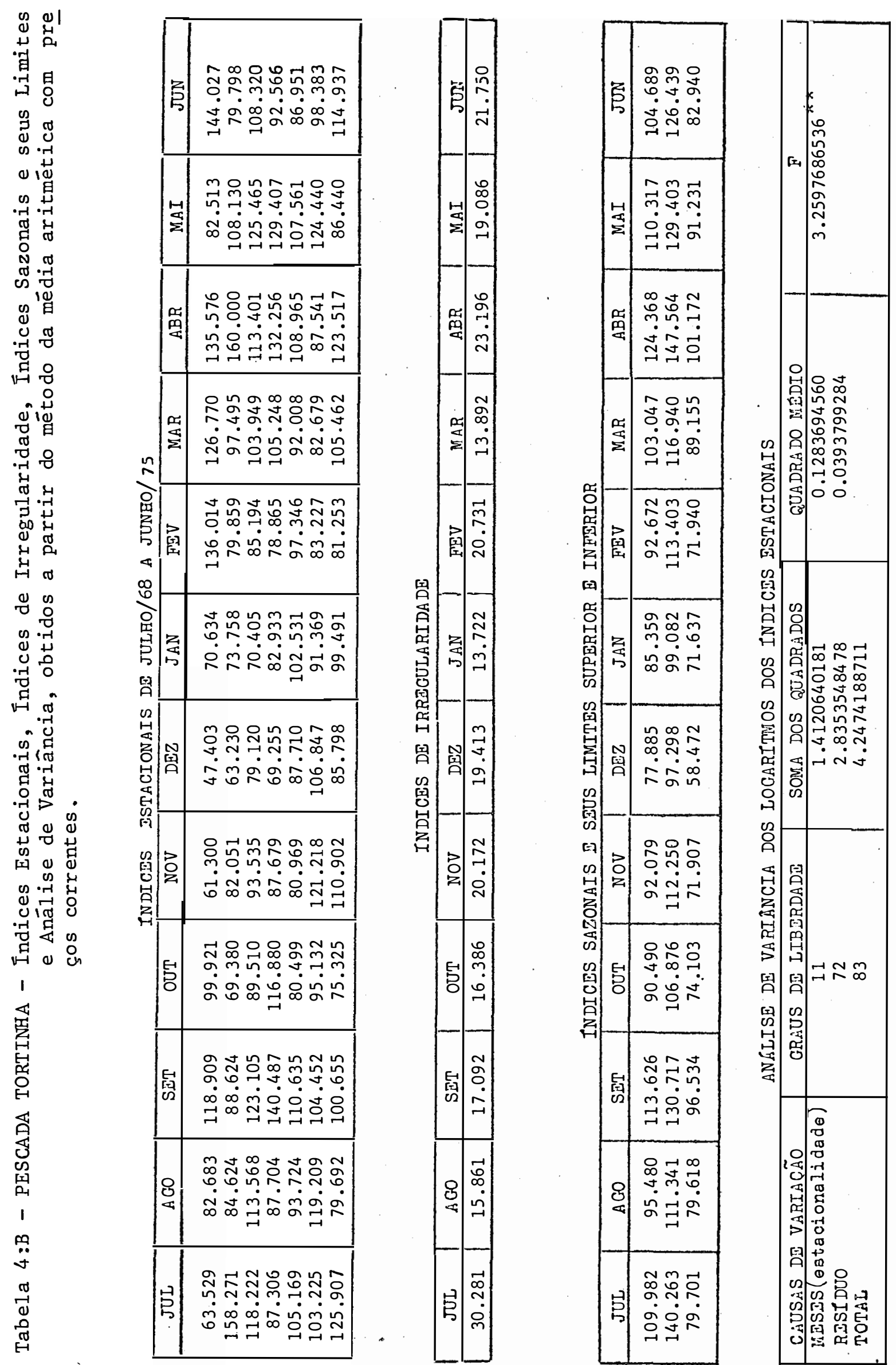

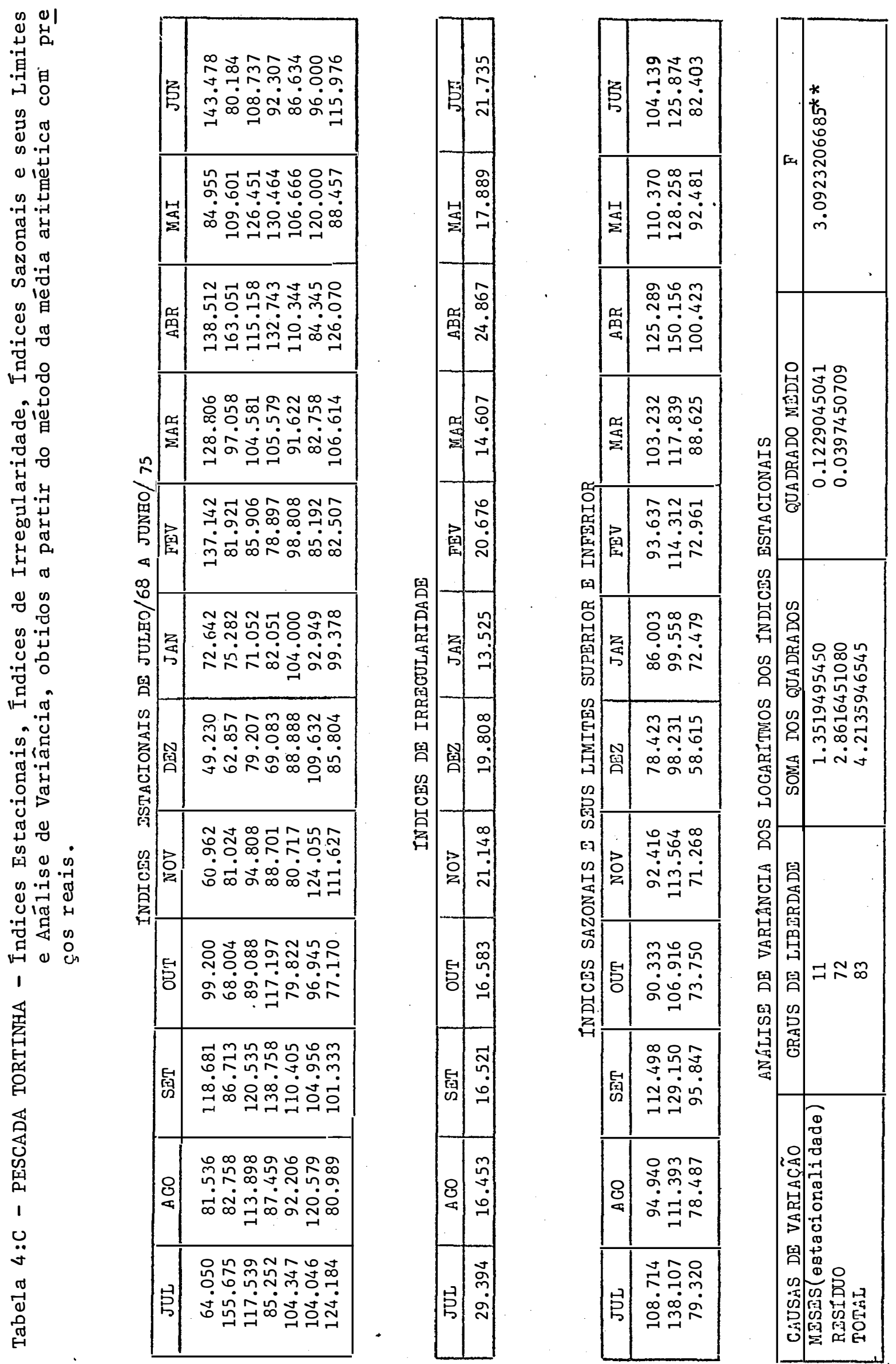

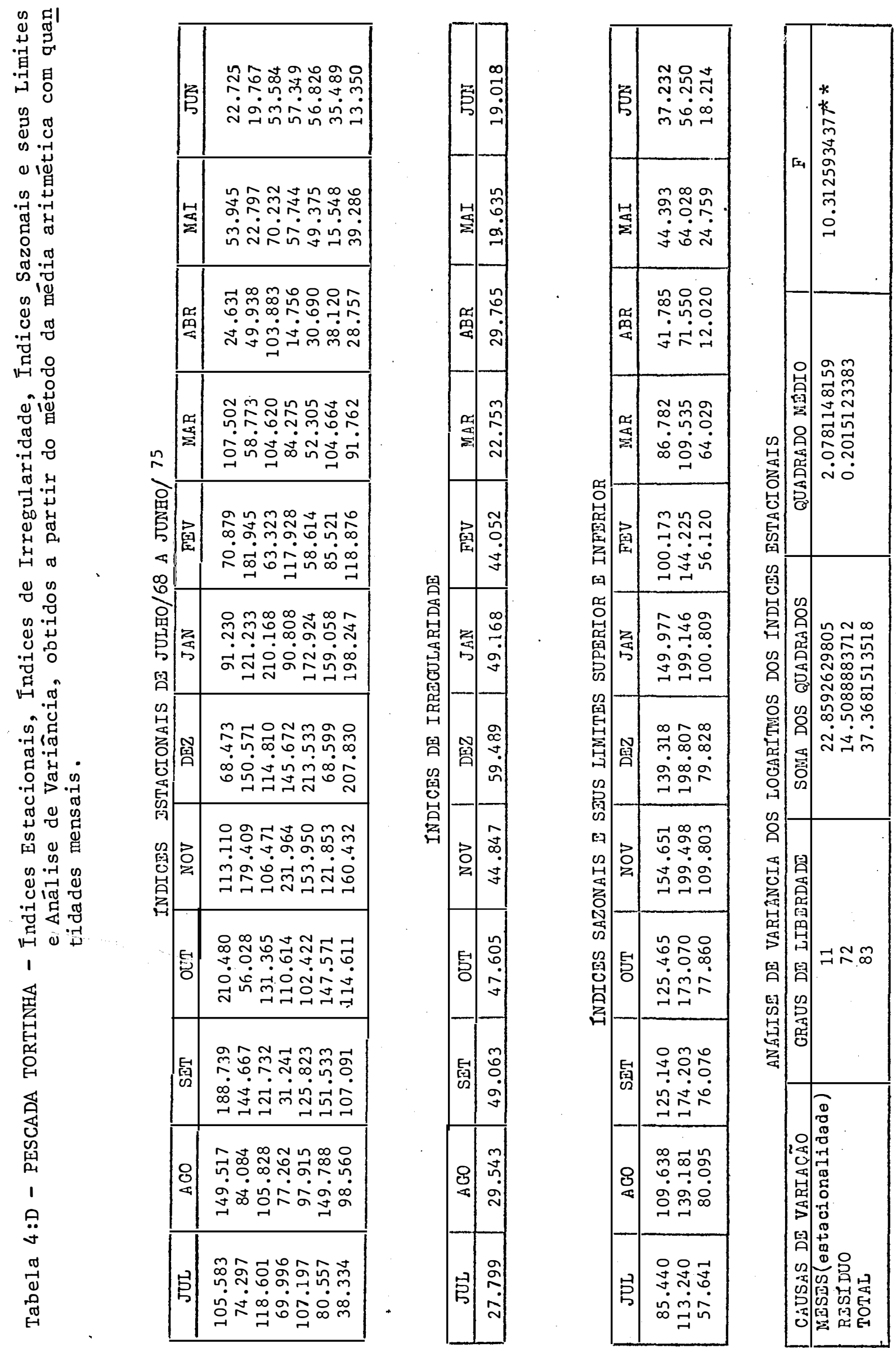

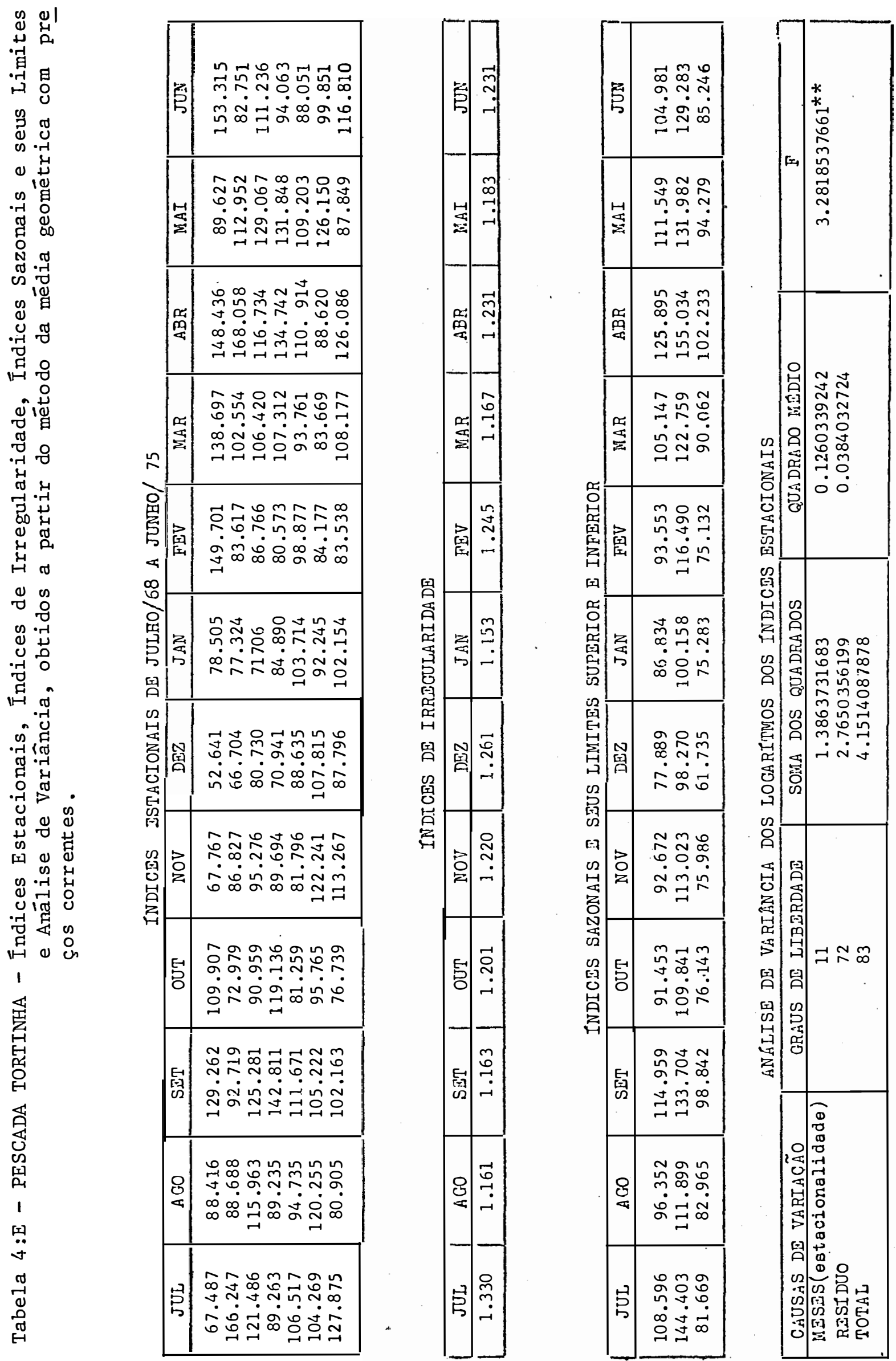

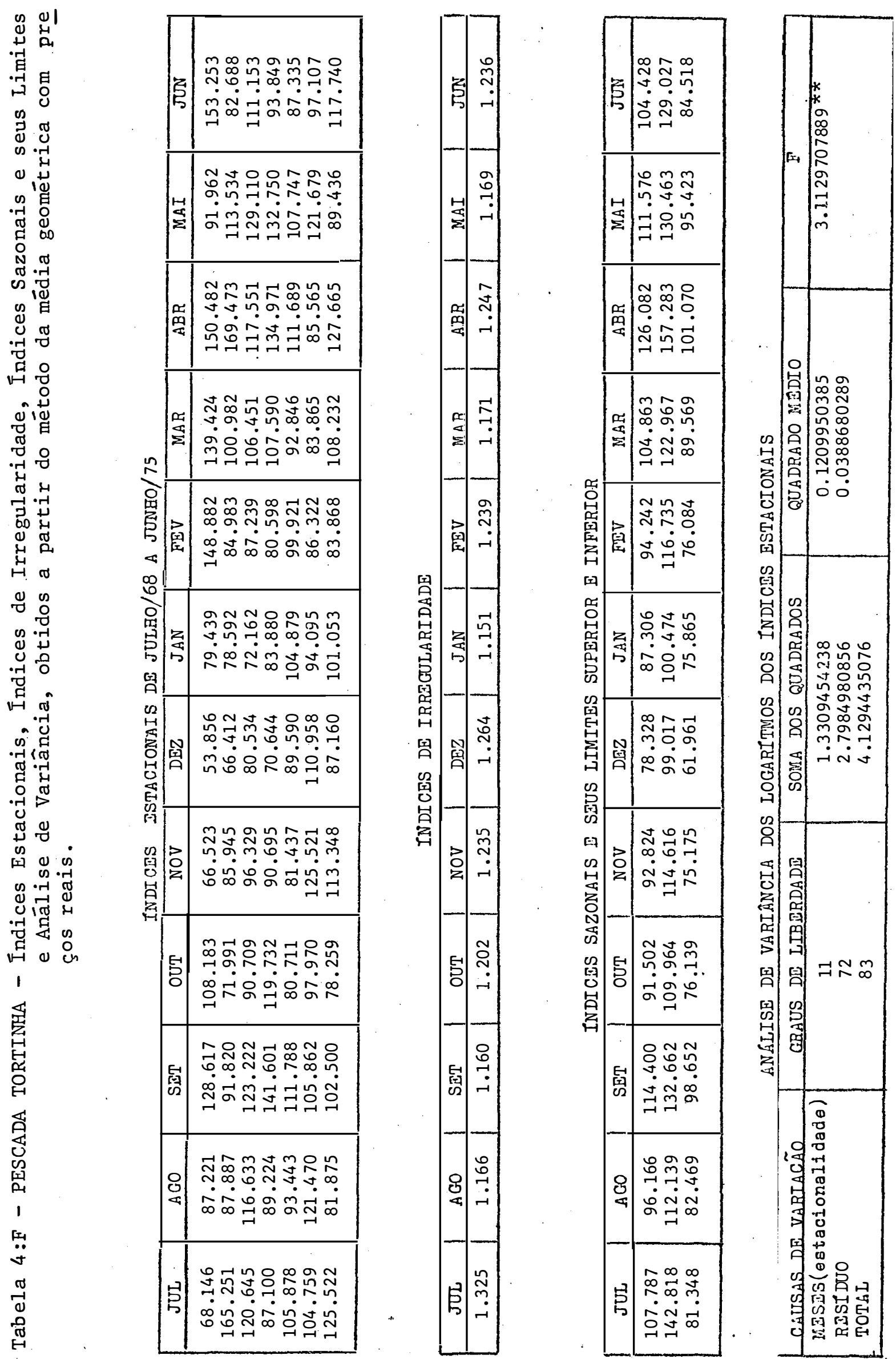

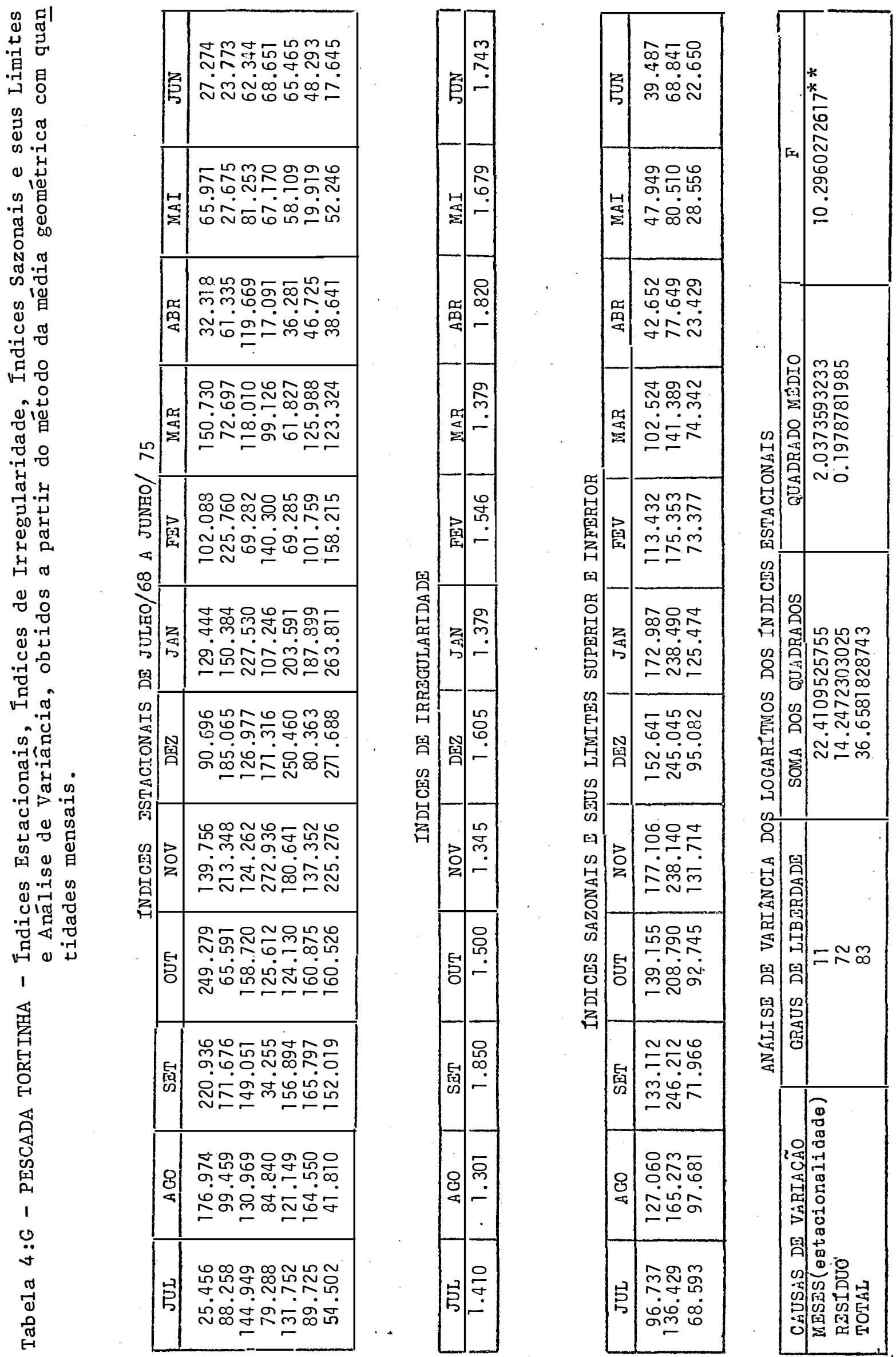


$$
\begin{gathered}
\text { A N } N \text { E X O } 05 \\
\text { P E S C A D A G R A N D E }
\end{gathered}
$$



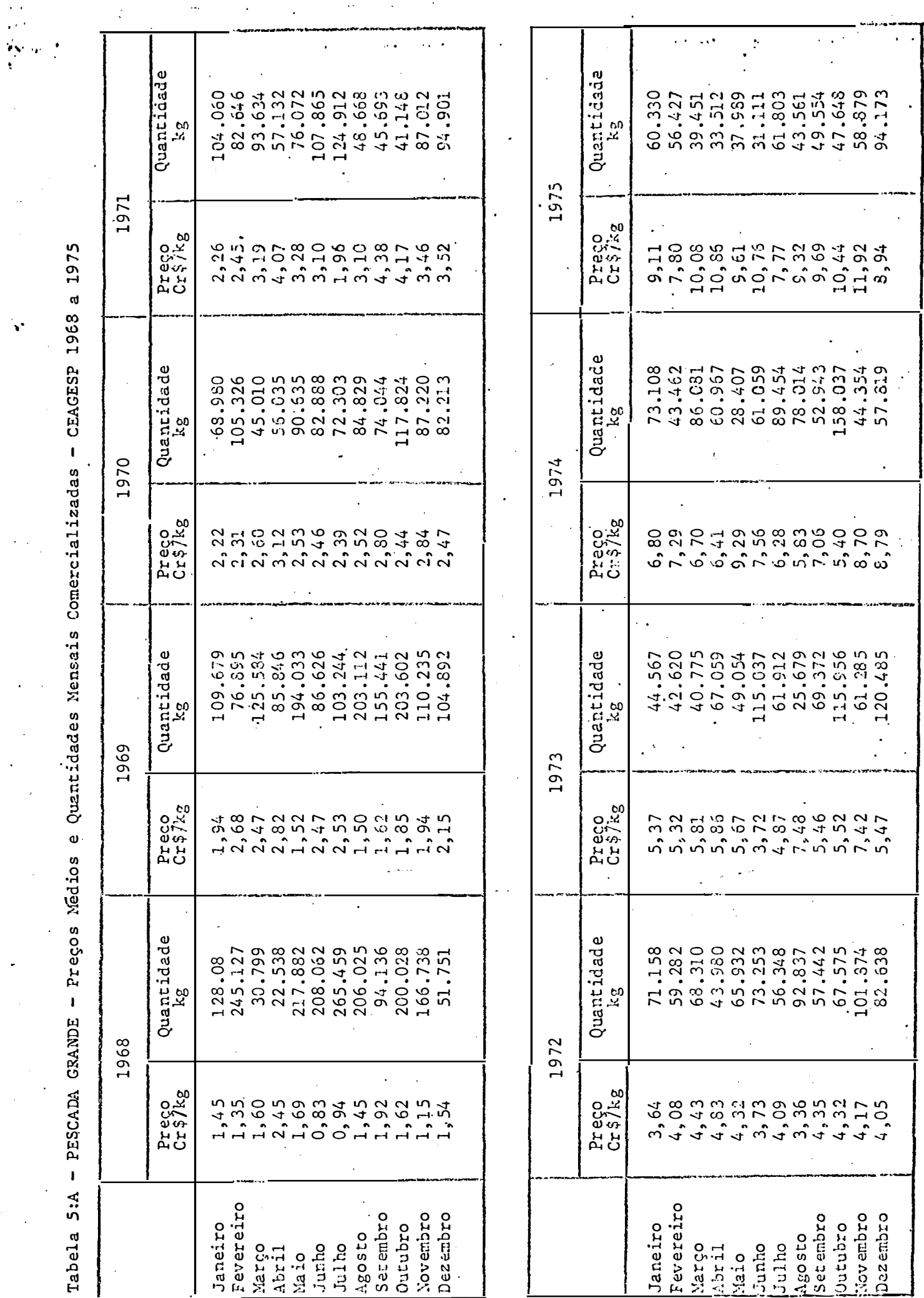

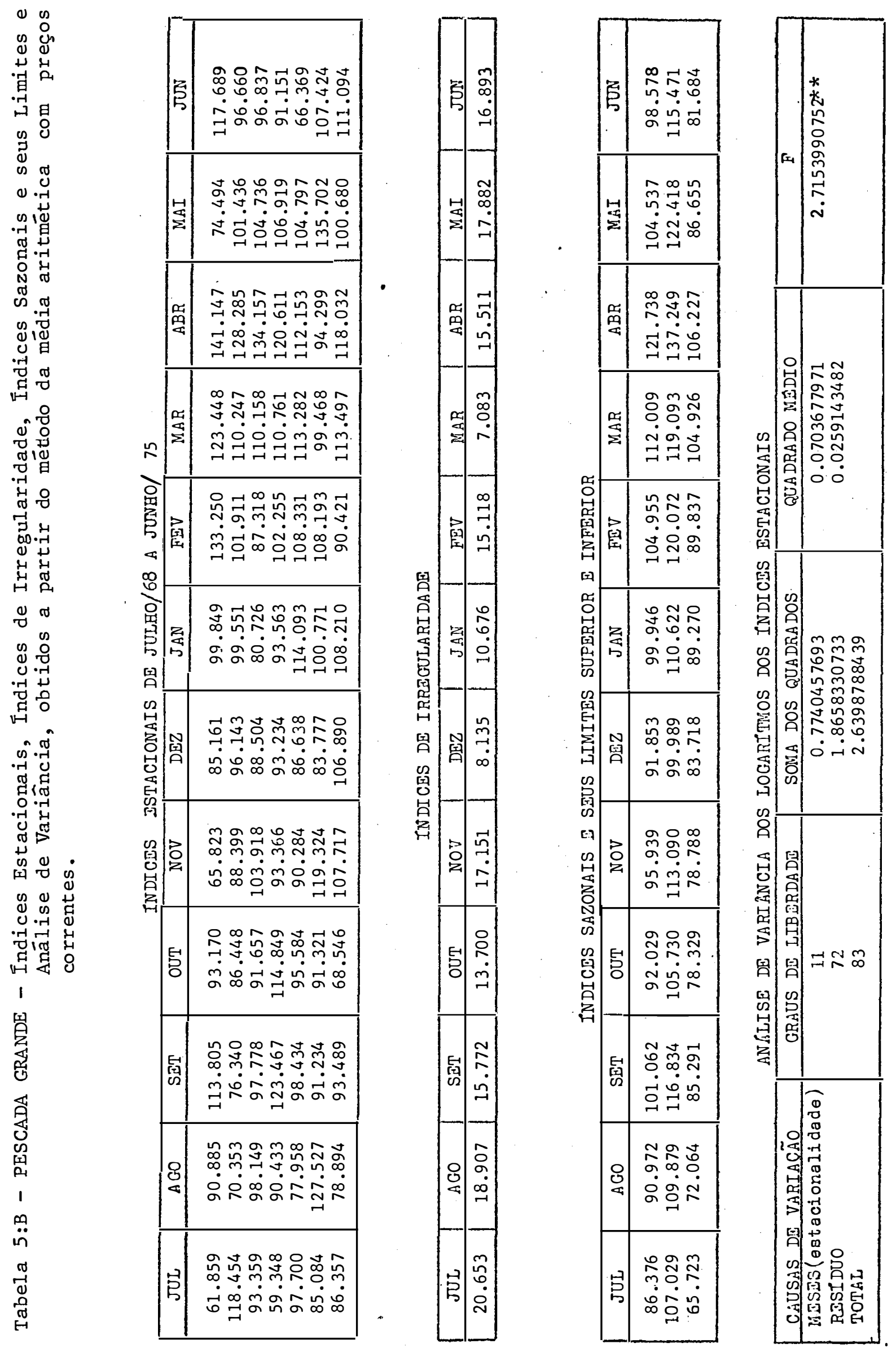

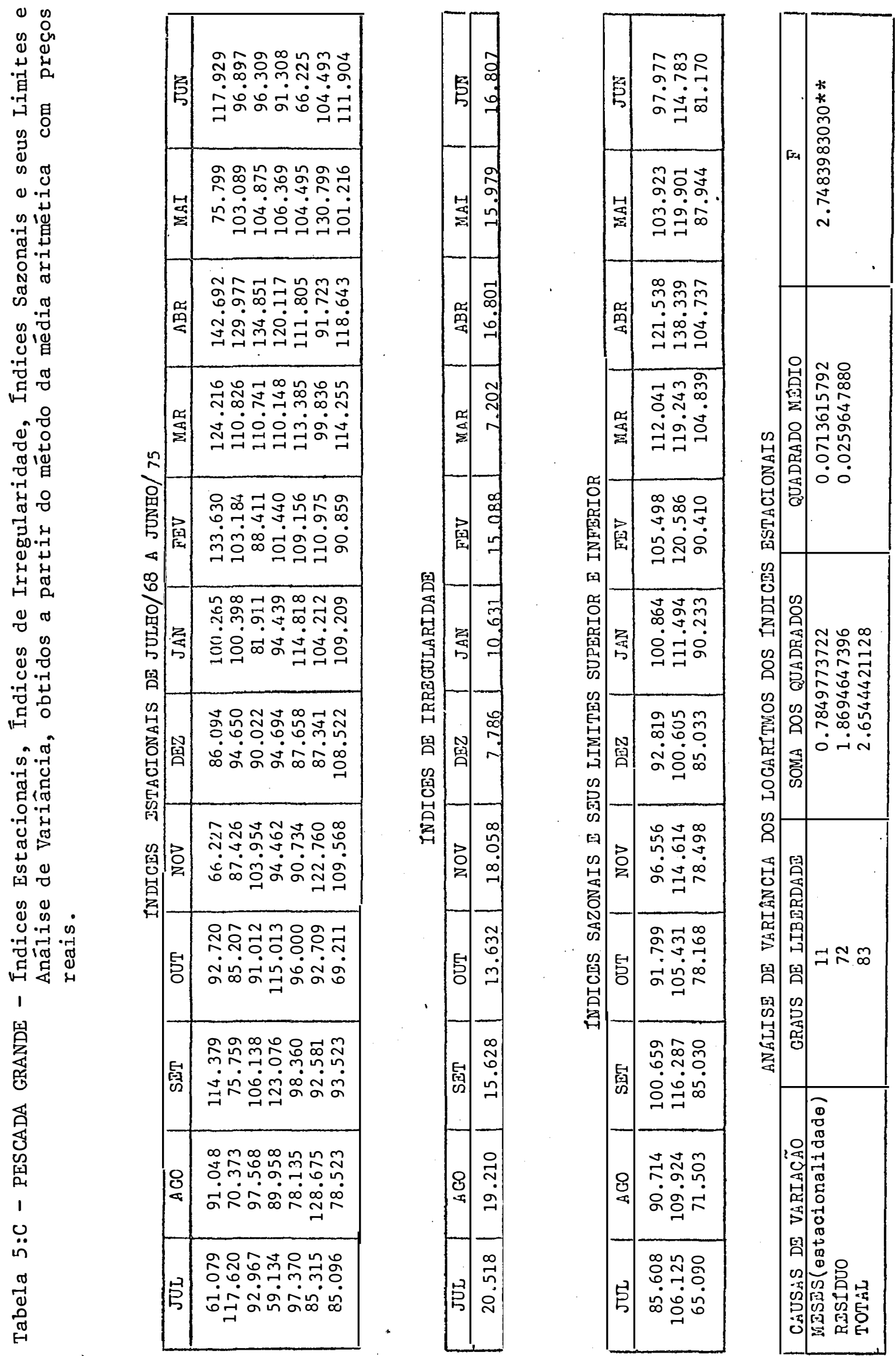

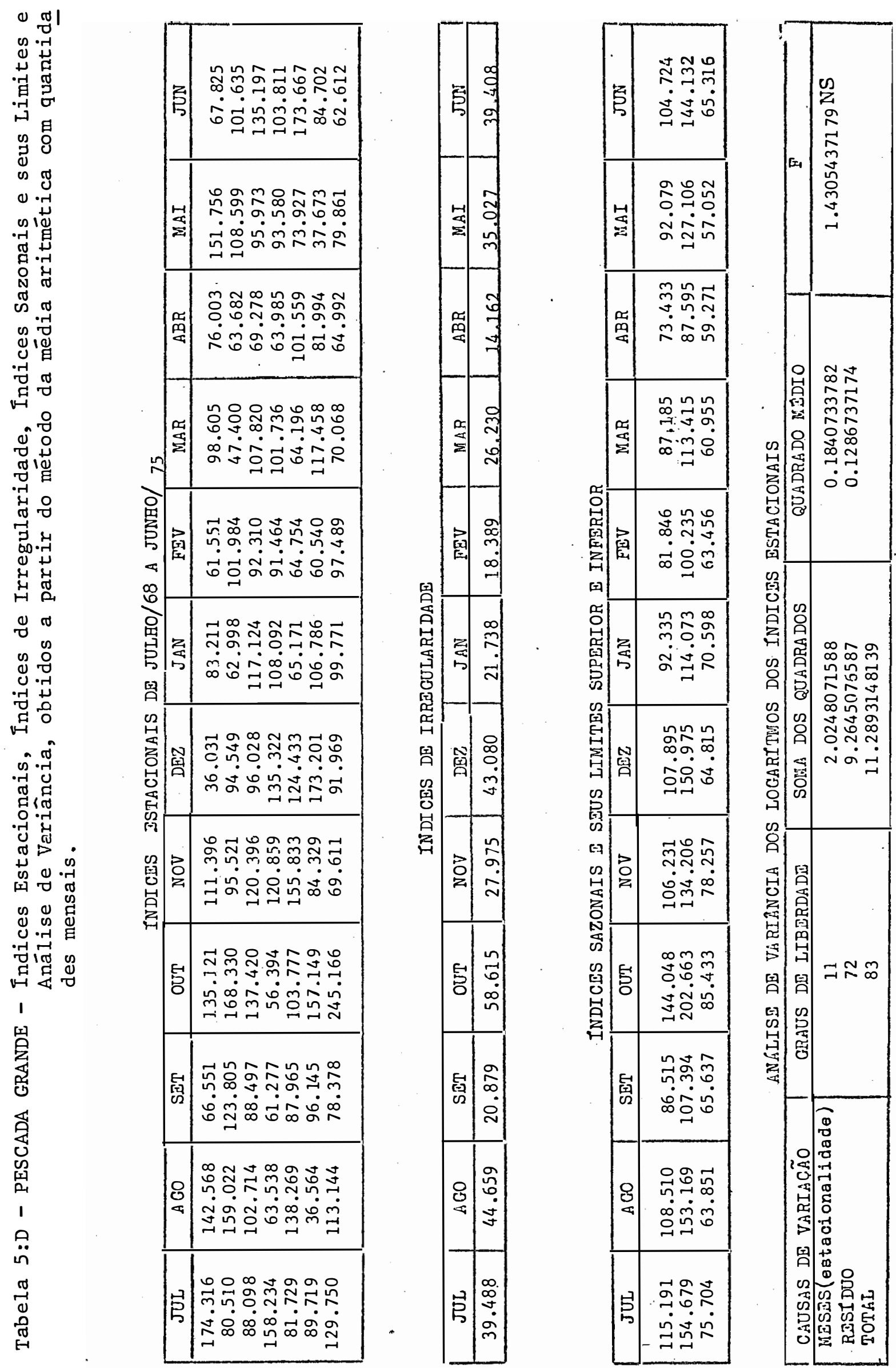


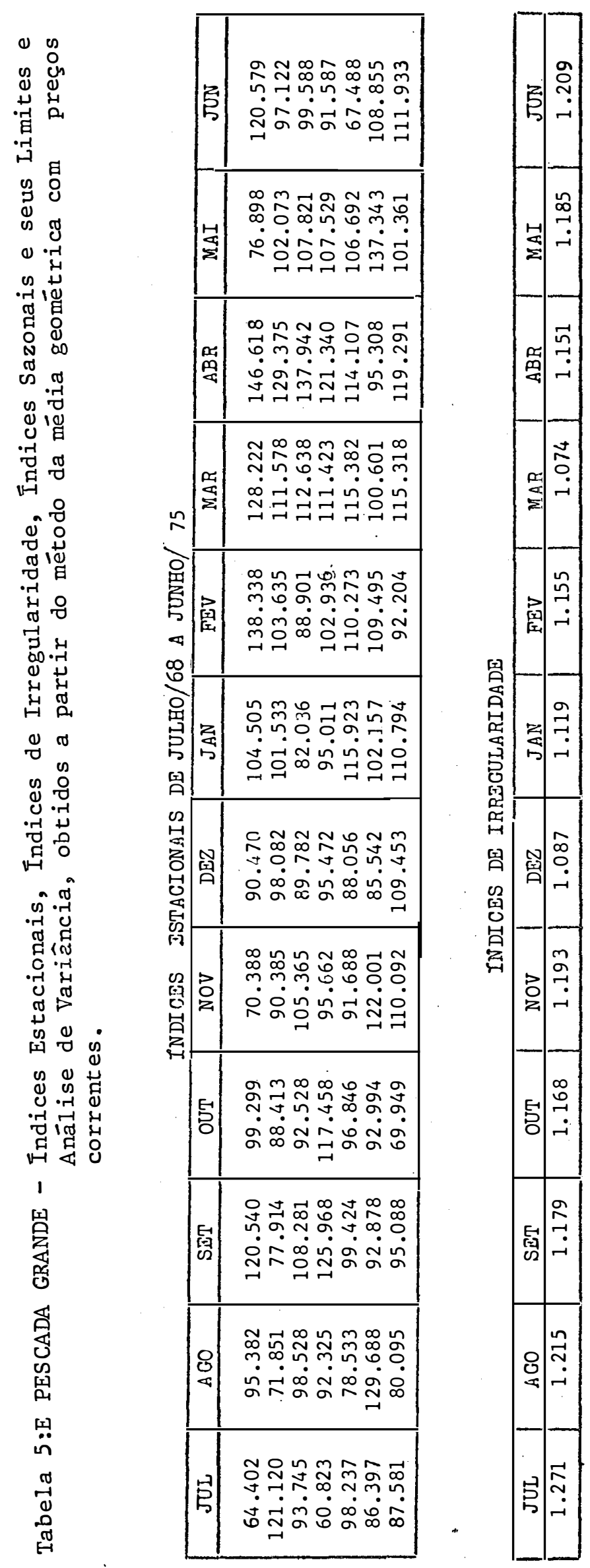

\begin{tabular}{|c|c|}
\hline 官 & 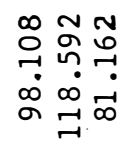 \\
\hline 哺 & 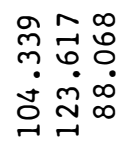 \\
\hline $\mid \begin{array}{c}0 \\
\text { 品 } \\
\alpha\end{array}$ & 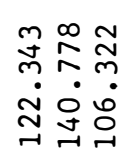 \\
\hline$\left|\begin{array}{l}a \\
\Sigma \\
\Sigma\end{array}\right|$ & 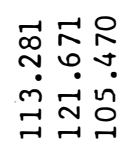 \\
\hline 忞 & 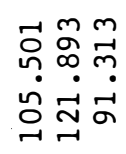 \\
\hline $\mid \begin{array}{l}z \\
5 \\
5\end{array}$ & 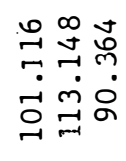 \\
\hline 舄 & 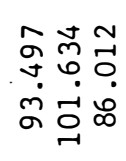 \\
\hline $\begin{array}{l}3 \\
0 \\
2\end{array}$ & 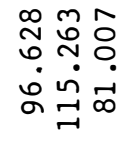 \\
\hline 臬 & 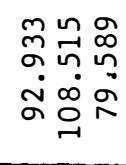 \\
\hline 毁 & 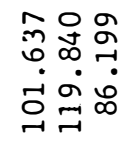 \\
\hline $\begin{array}{l}0 \\
\end{array}$ & 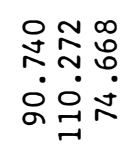 \\
\hline 宫 & 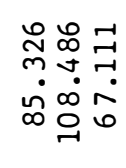 \\
\hline
\end{tabular}

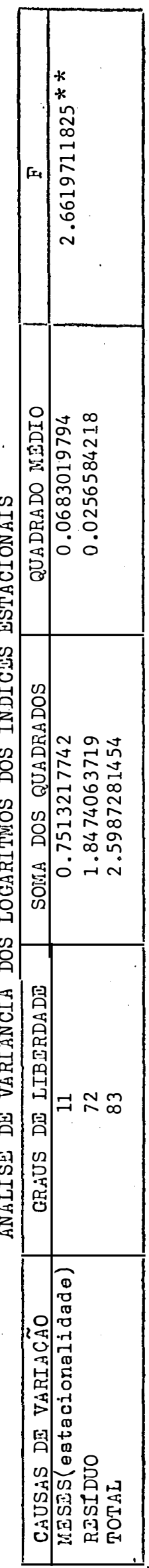



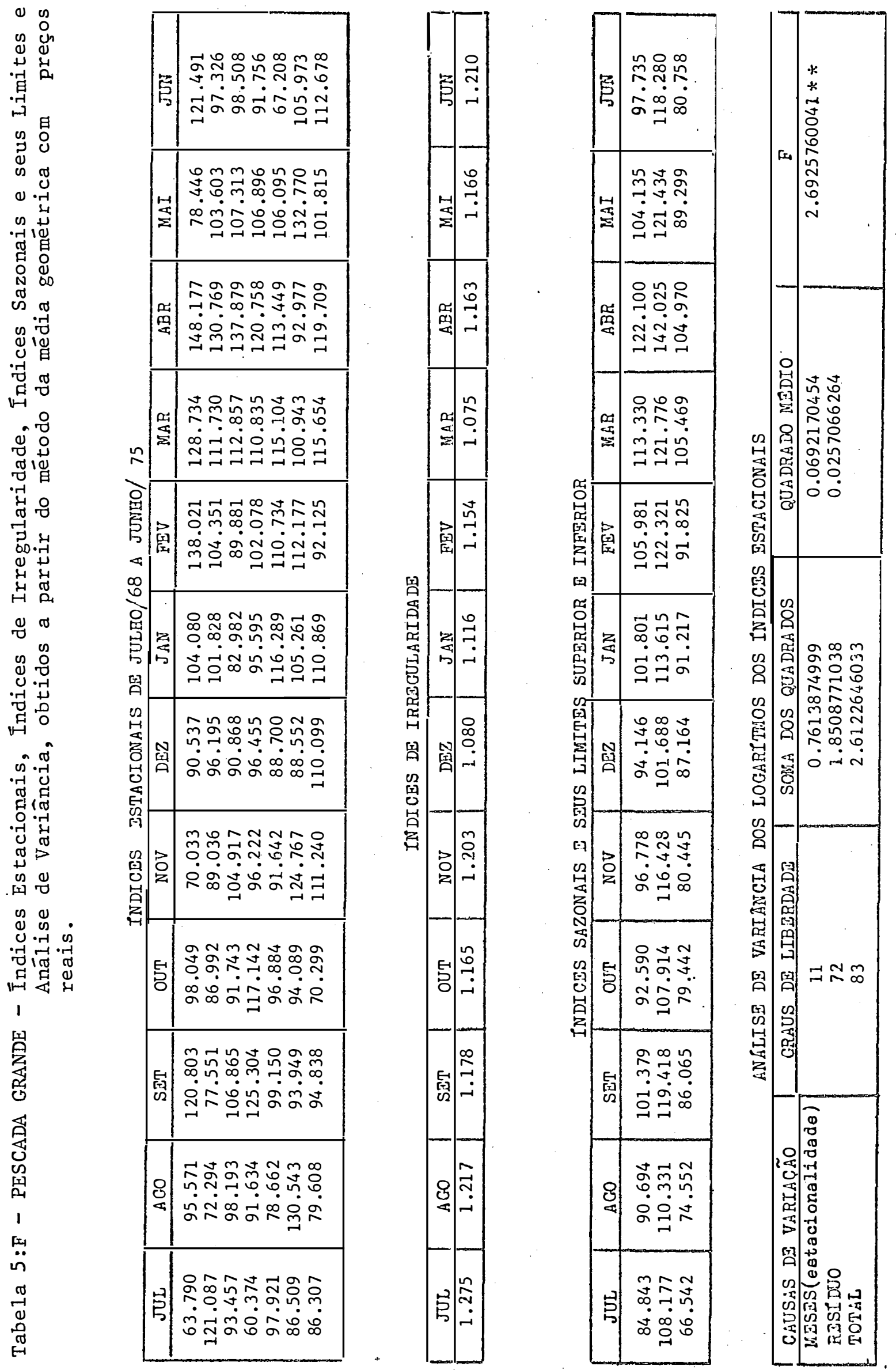

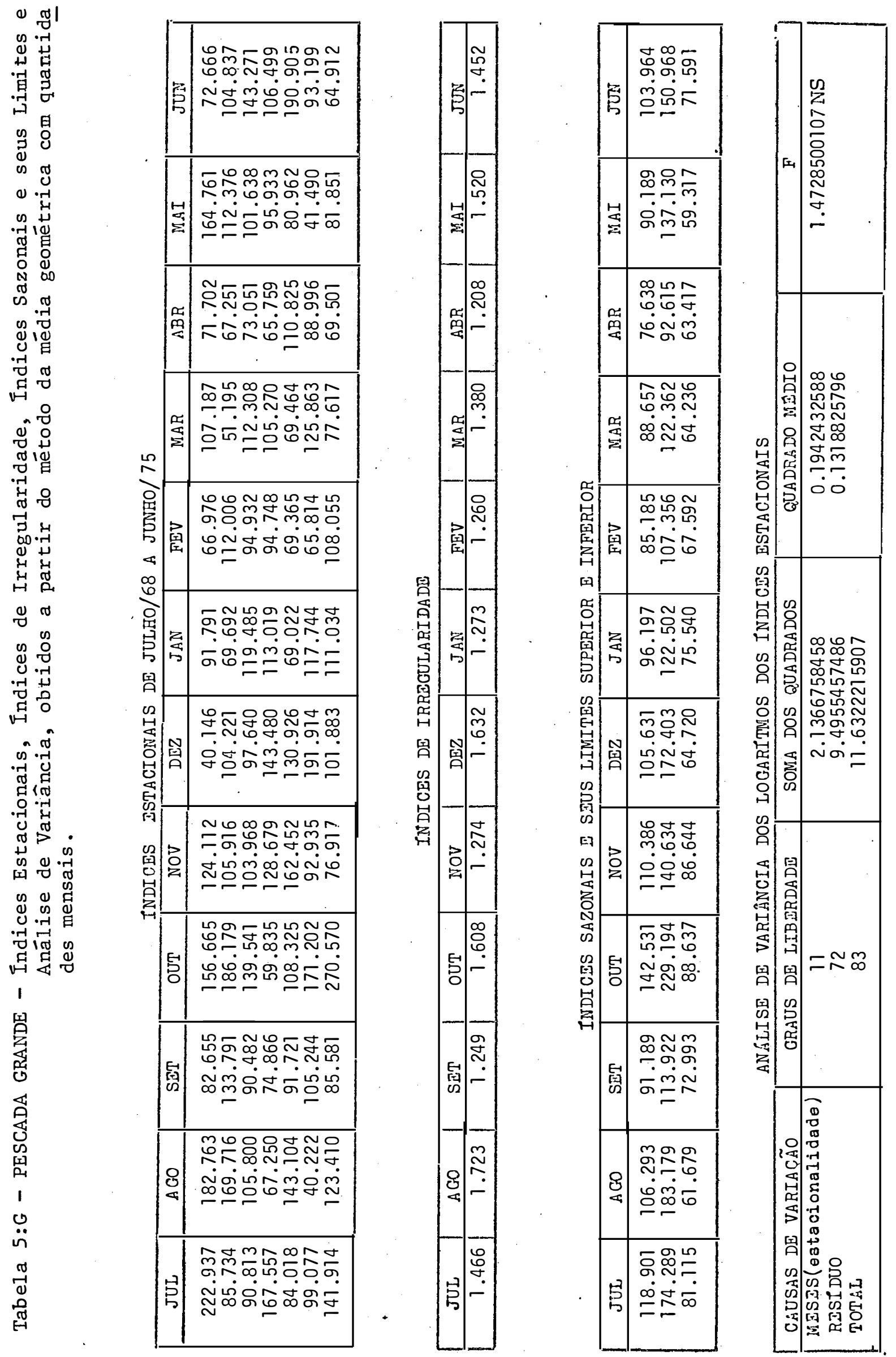


$$
\begin{aligned}
& \text { A } N E X O O C \\
& P E S C A D A M D I A
\end{aligned}
$$



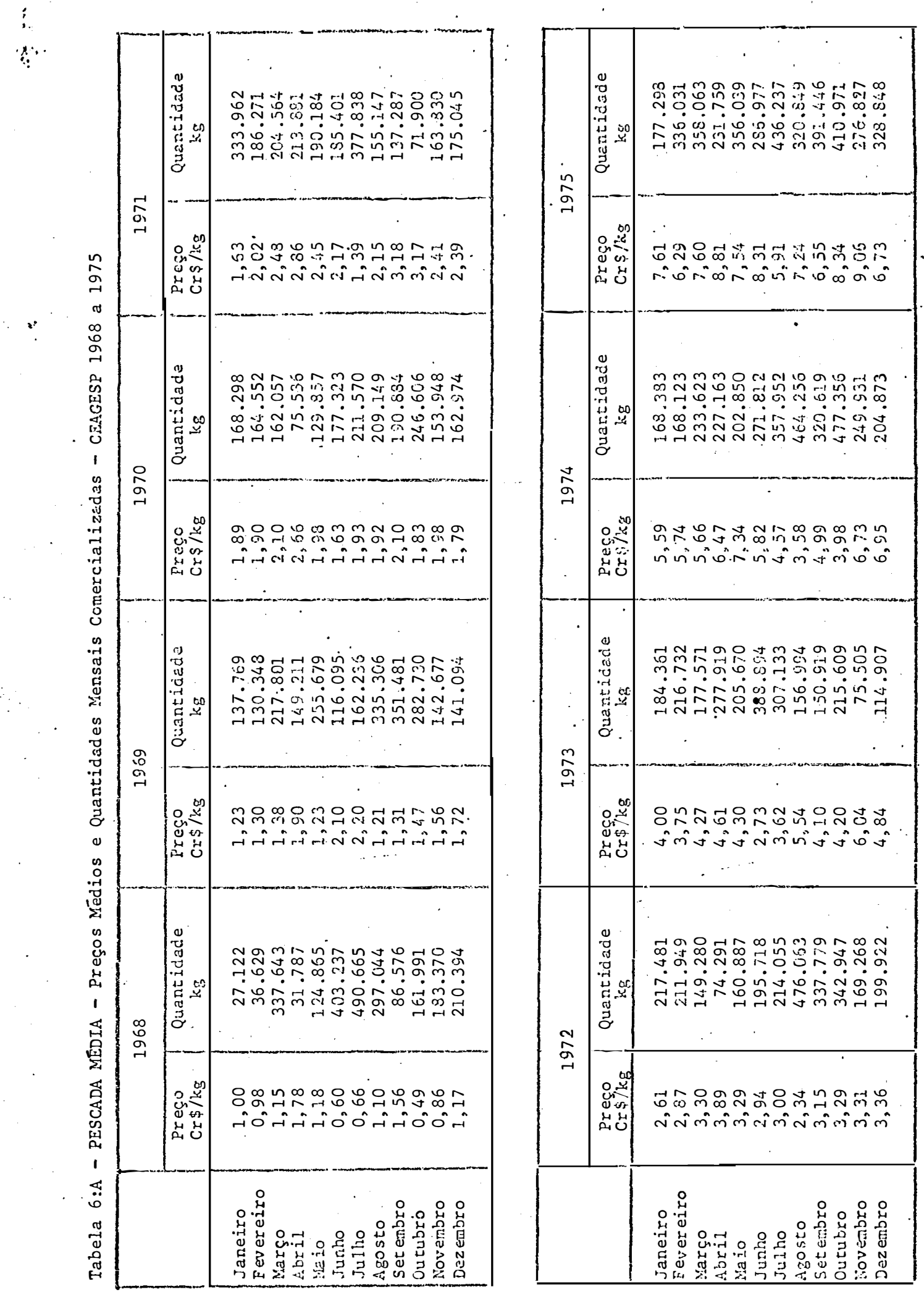

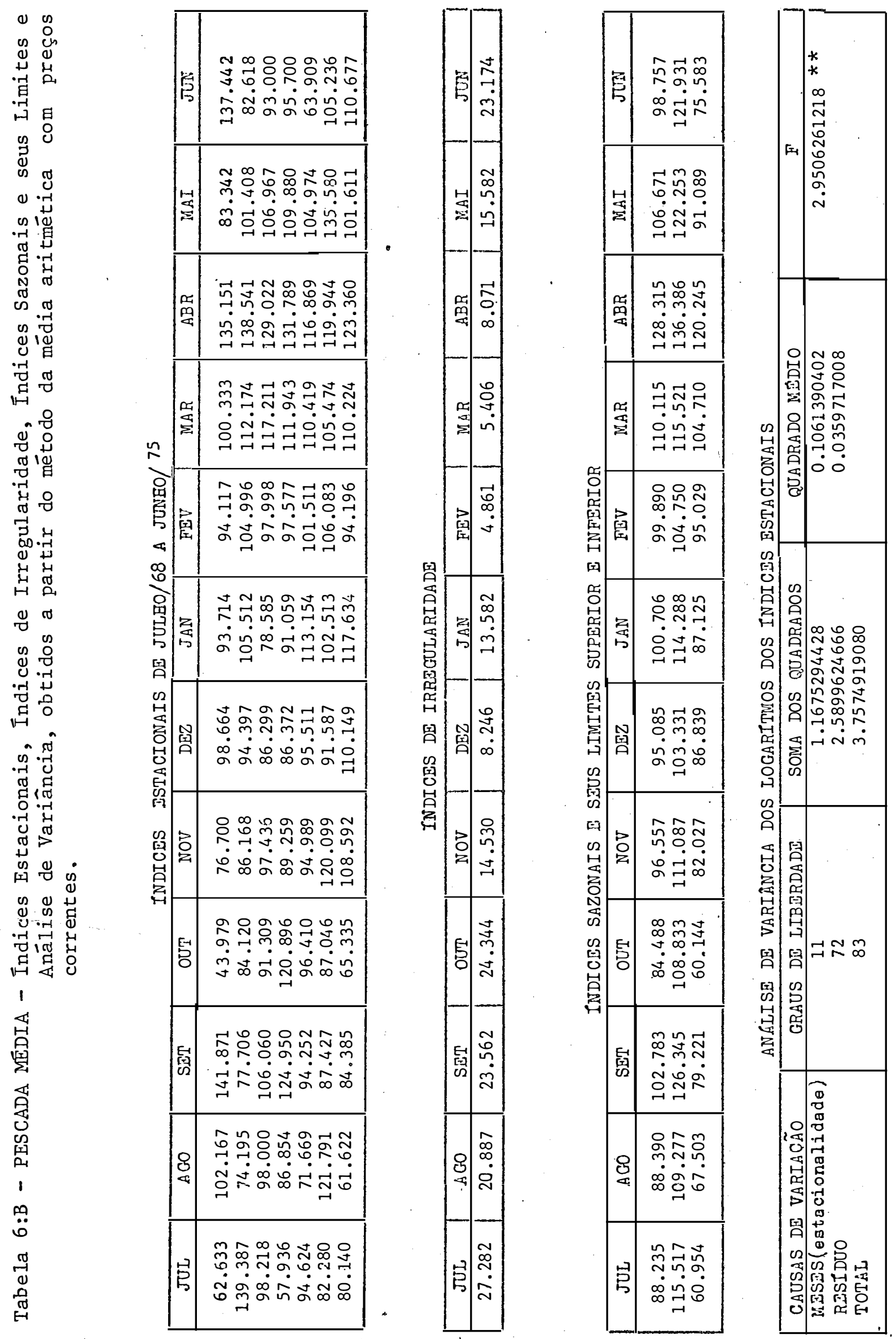

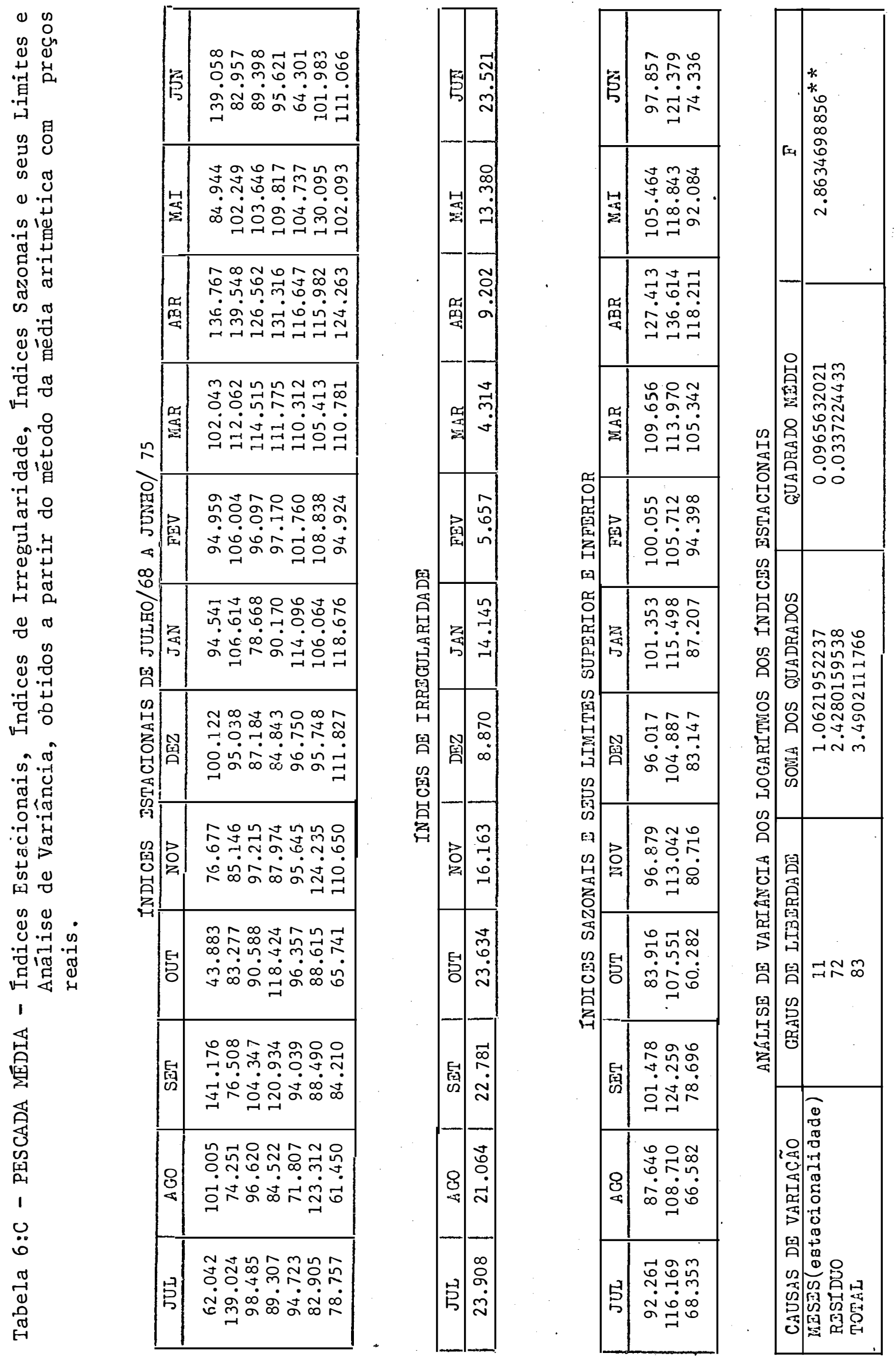

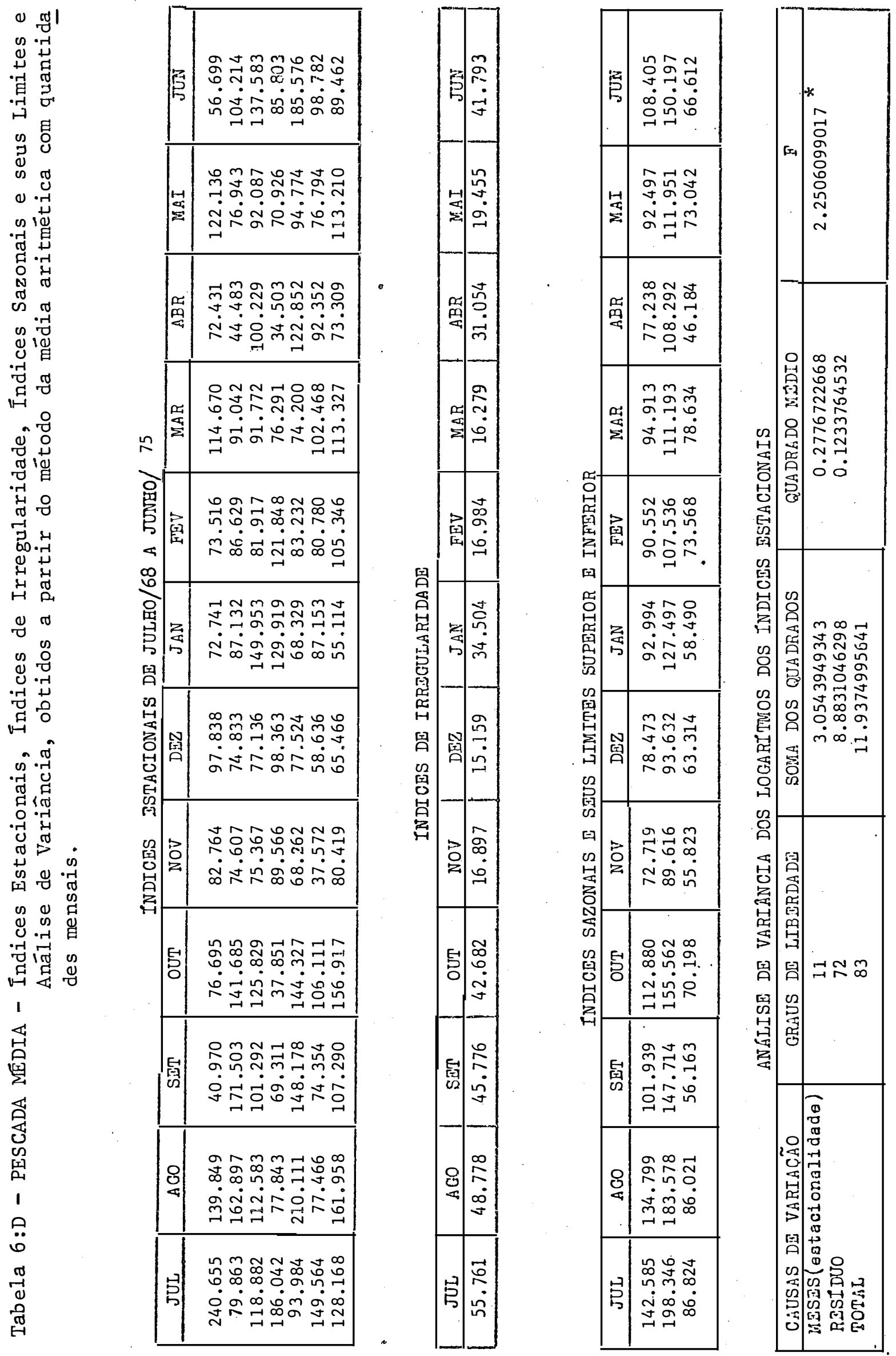

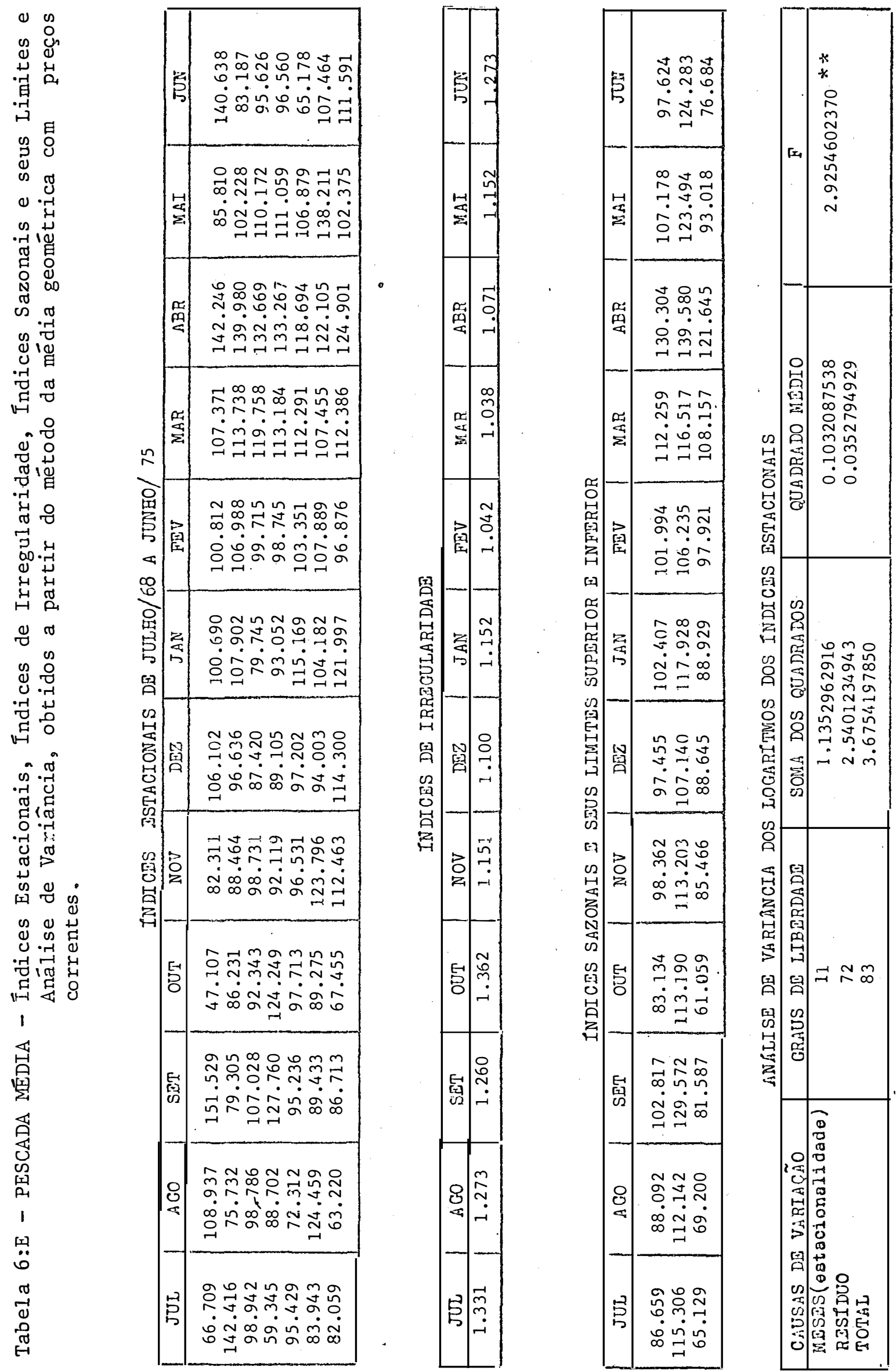

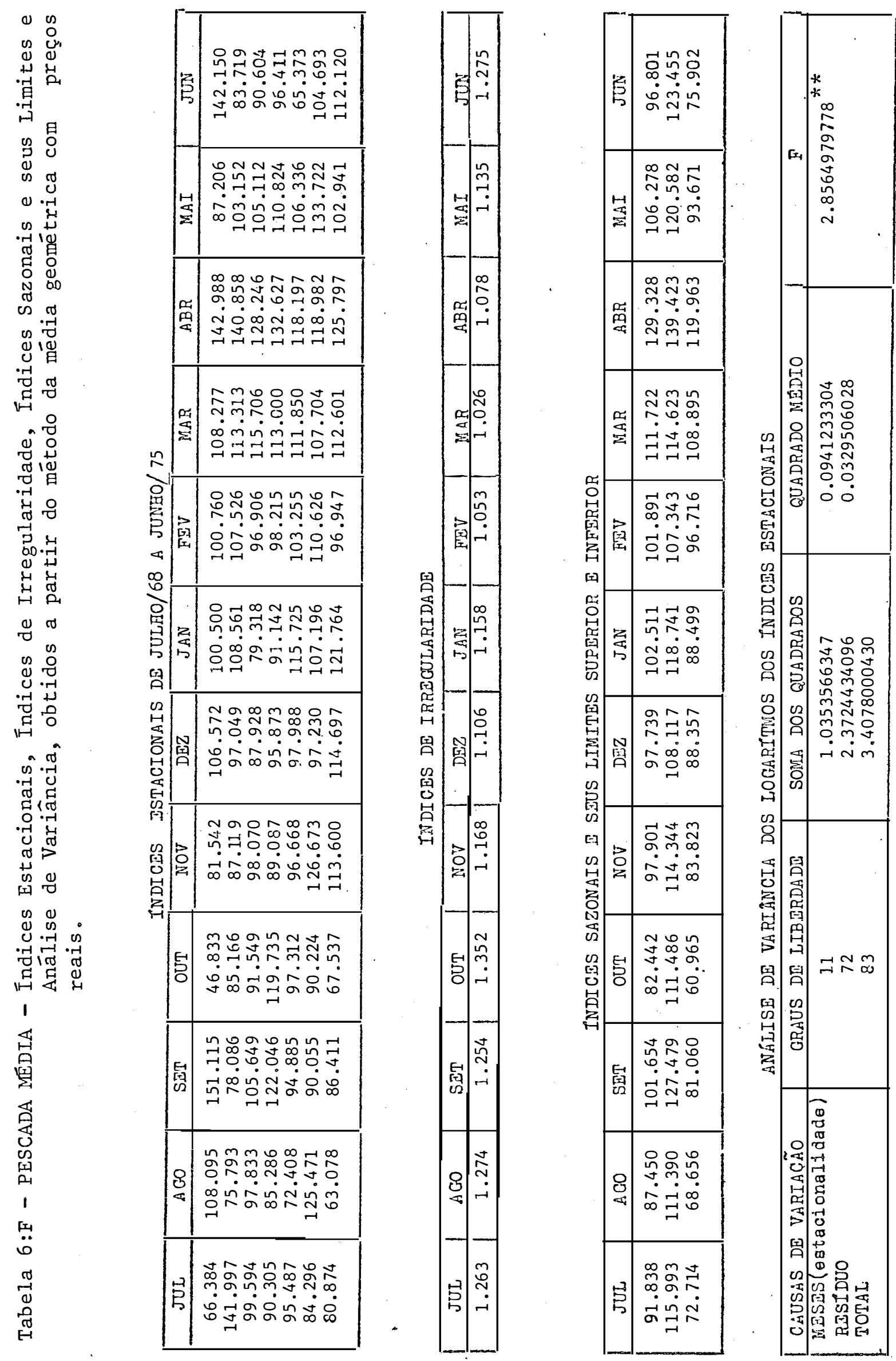

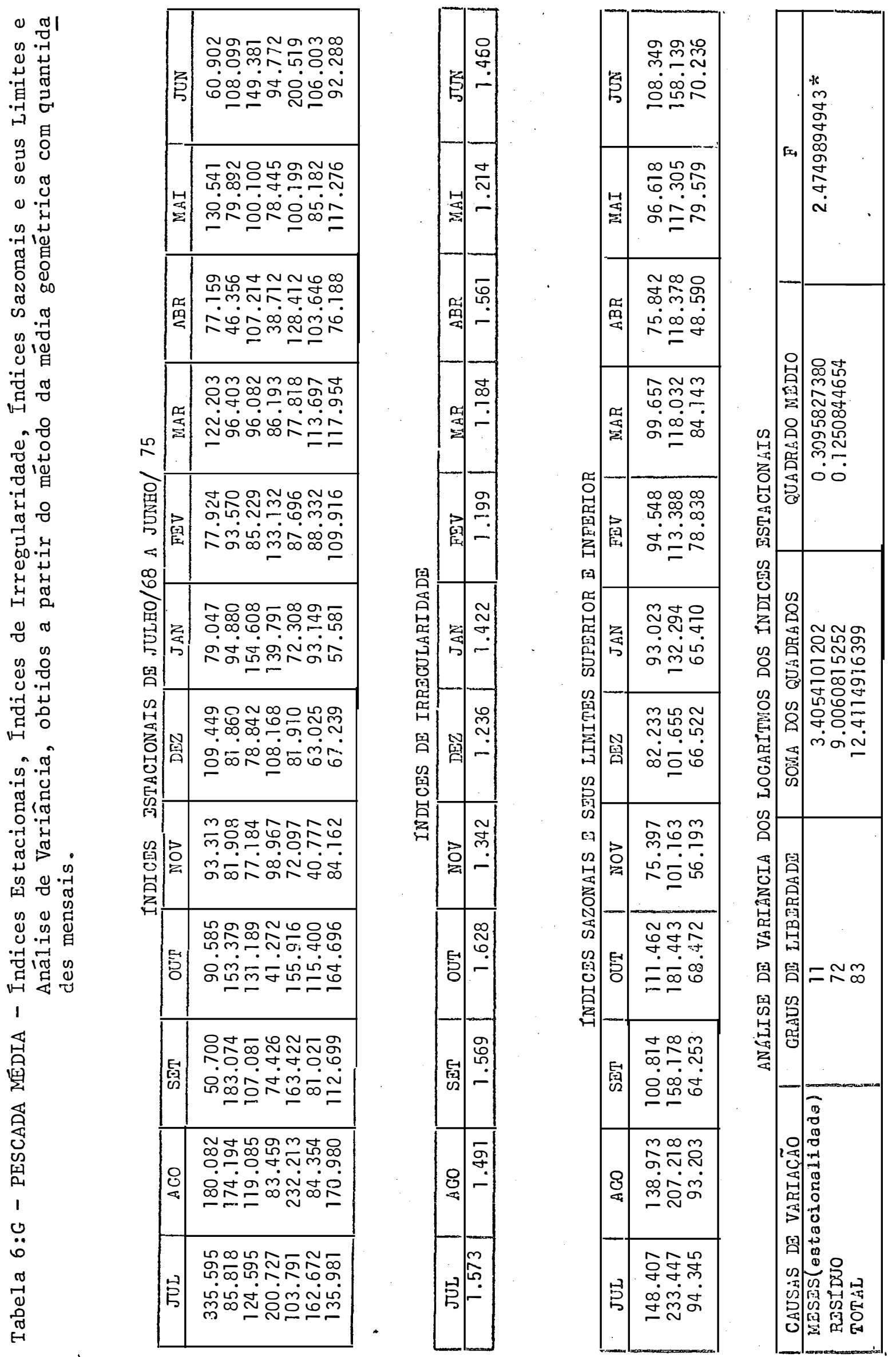
$\begin{array}{llllll}A & \mathrm{~N} & \mathrm{X} & \mathrm{O} & 07\end{array}$

$P E S C A D A \quad P E Q U E N A$ 


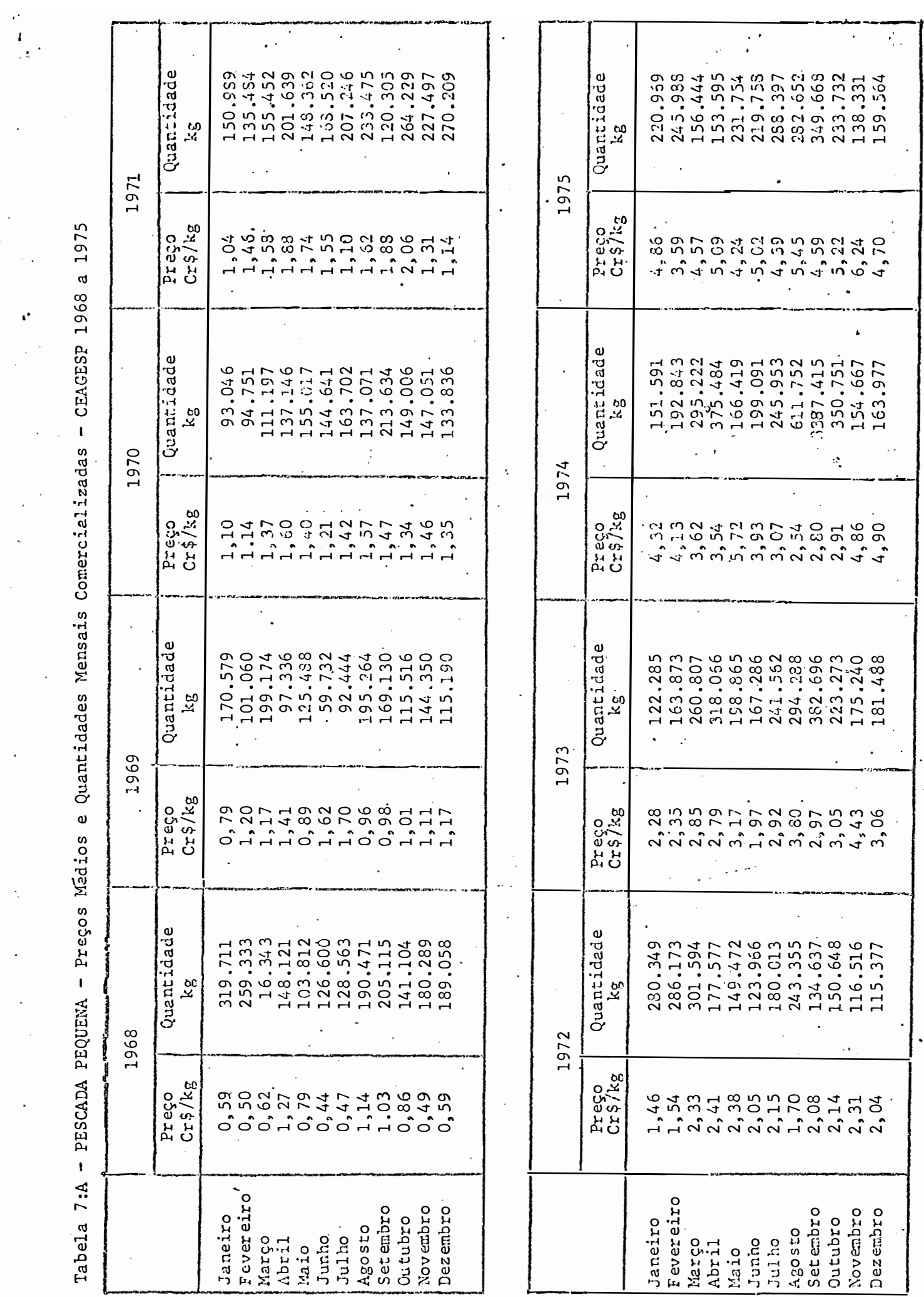



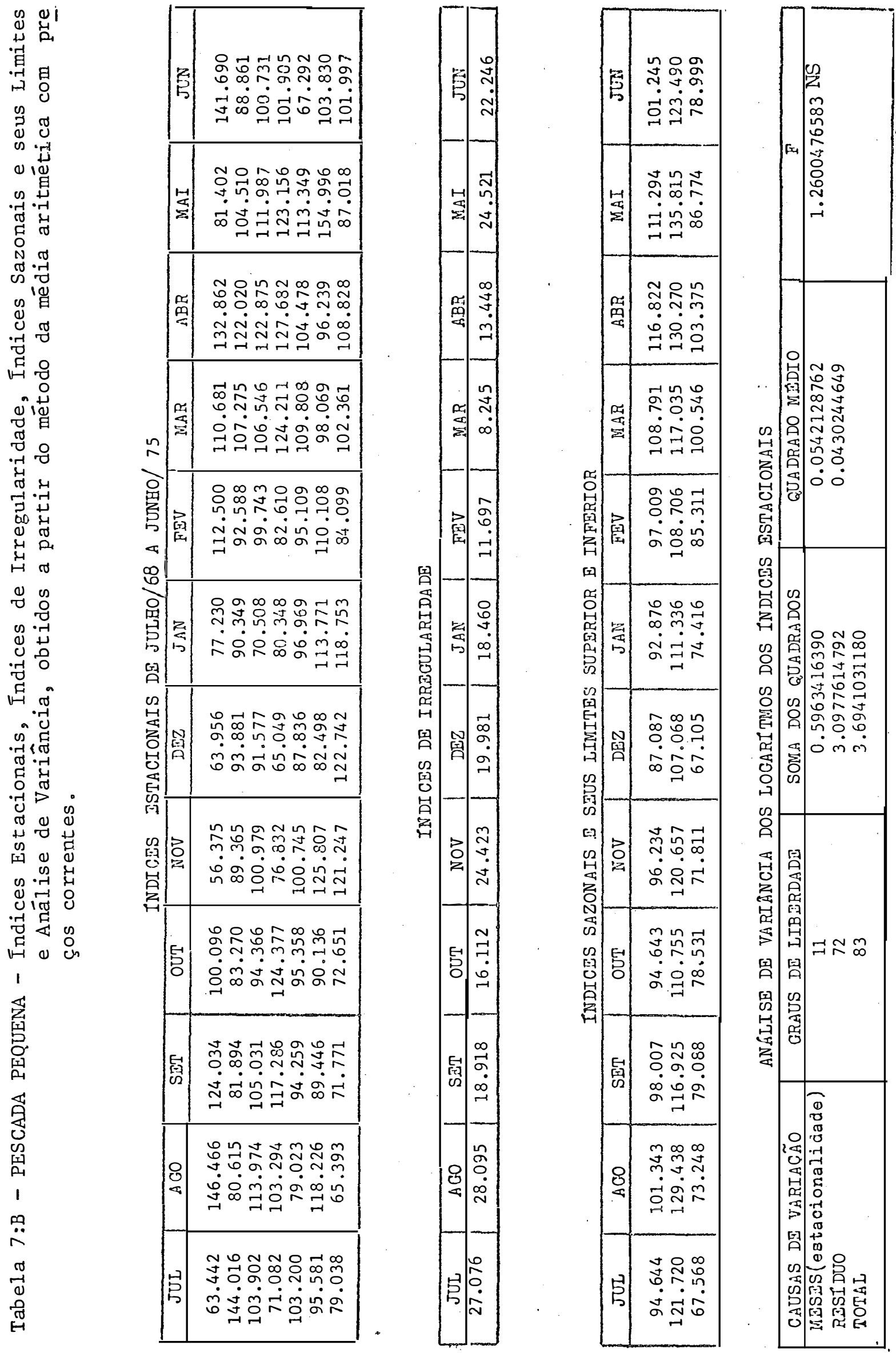

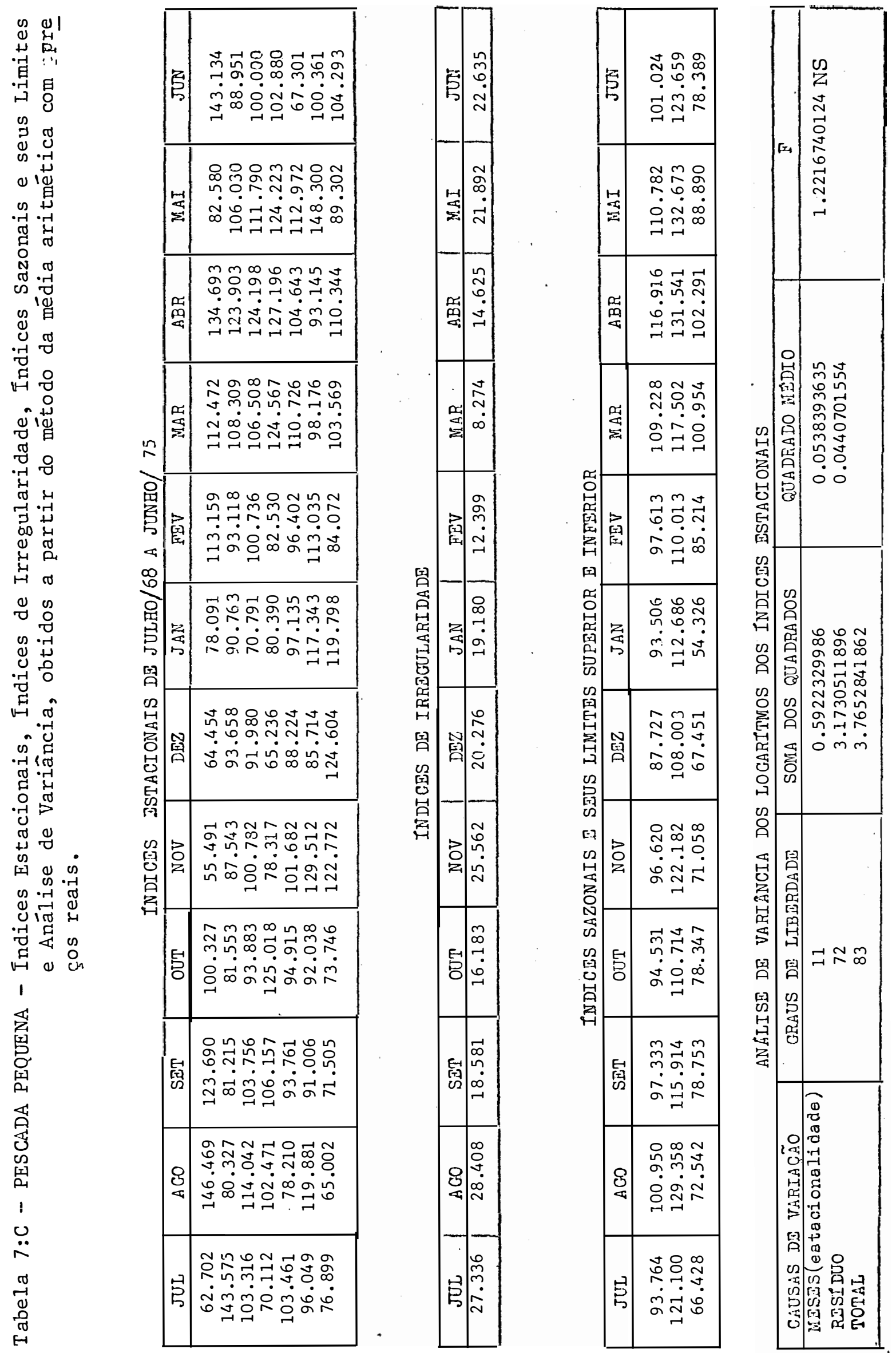

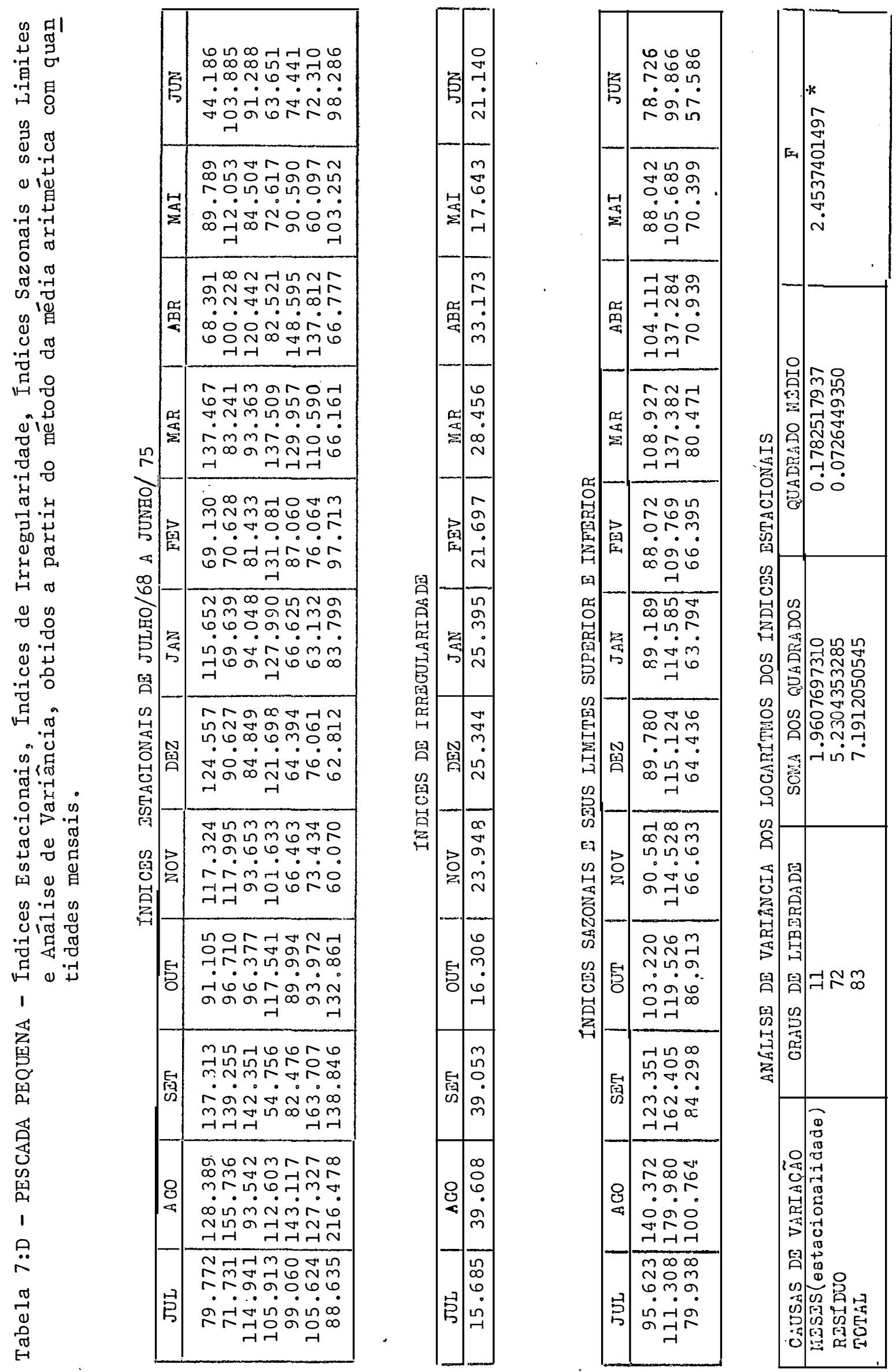


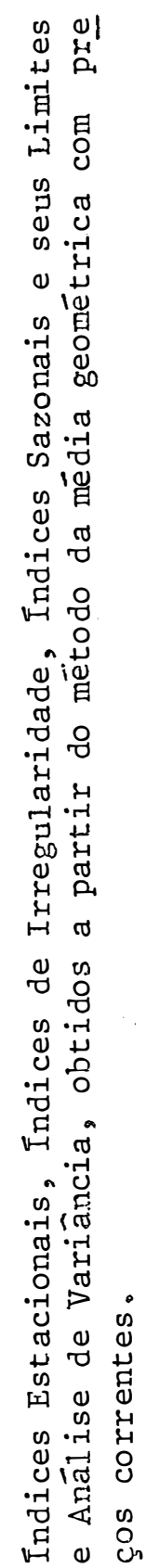

蓆

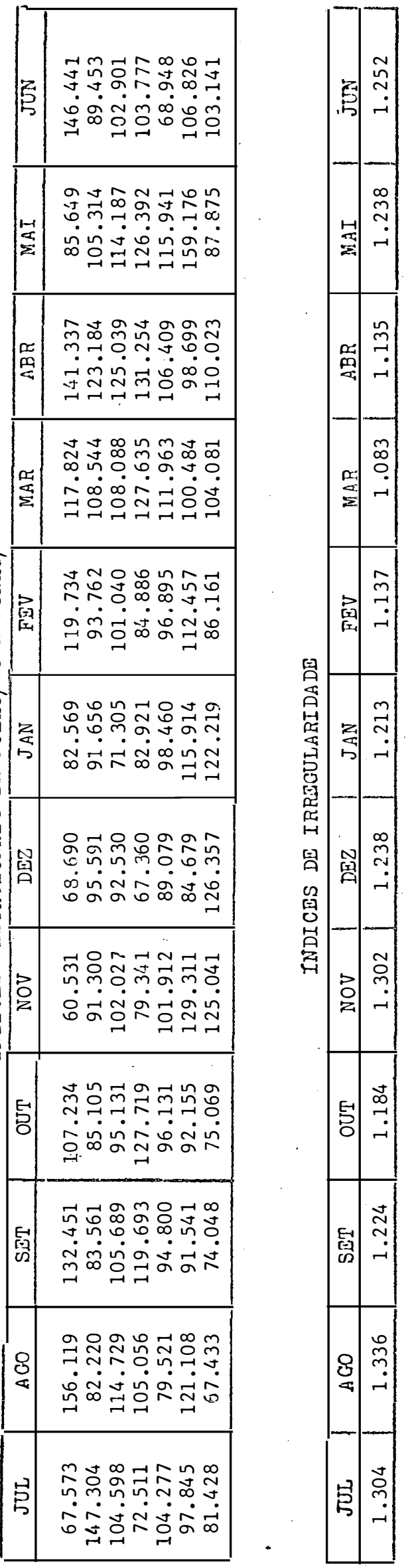

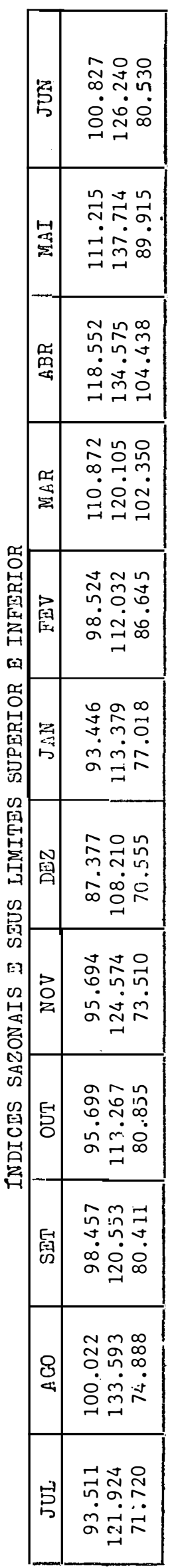




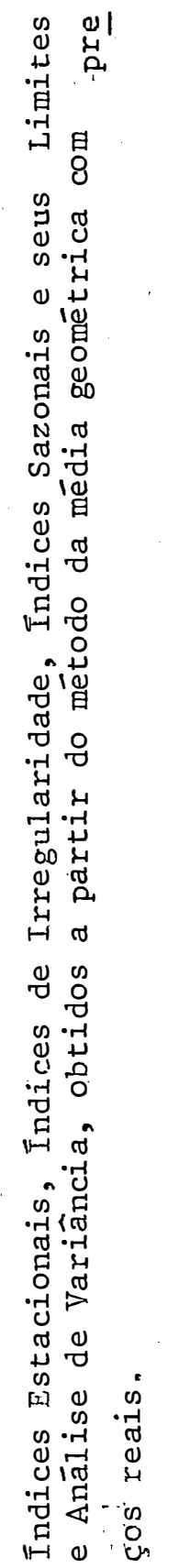
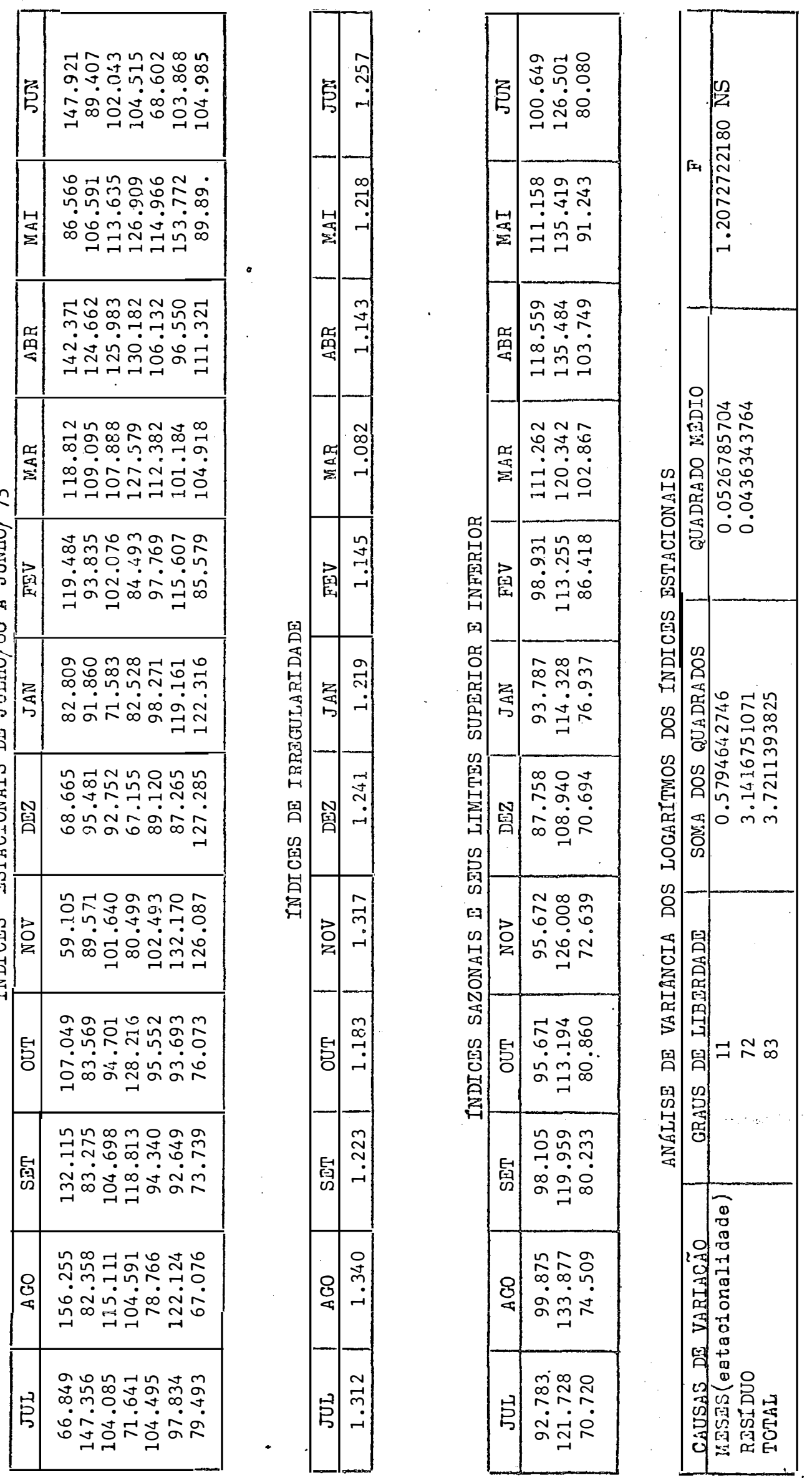

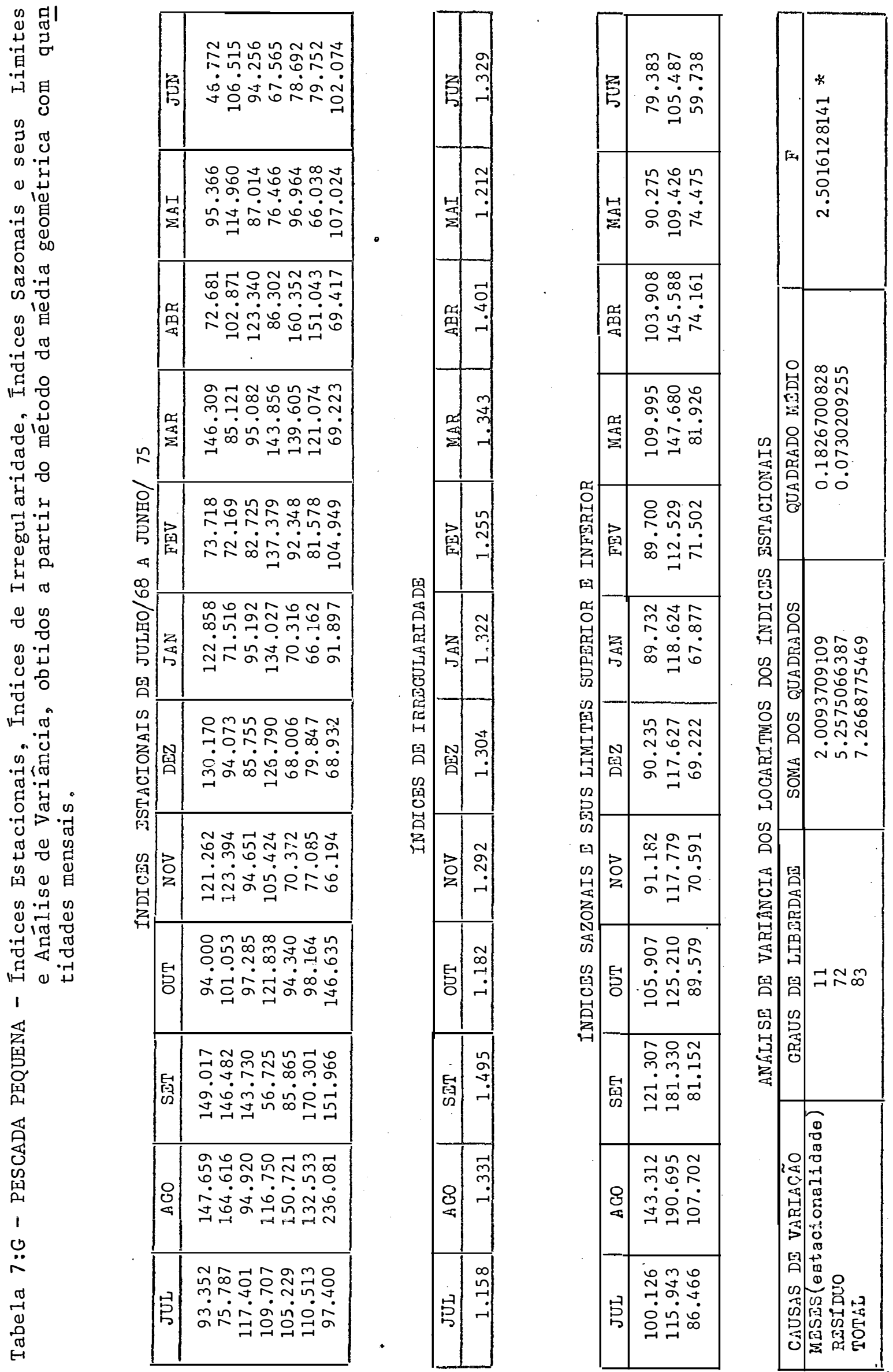
A N E X O 08

C A $M A R A$ 

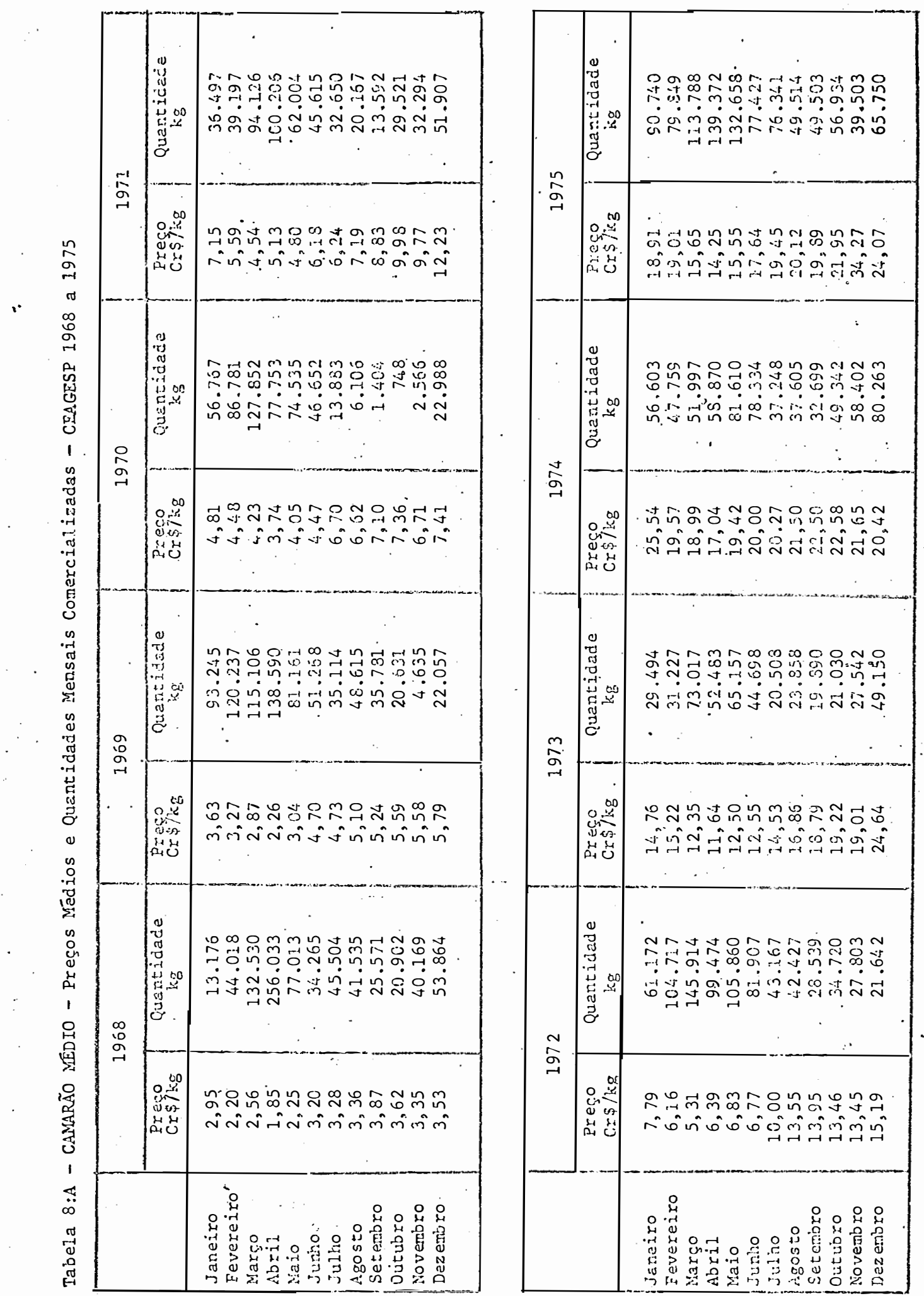

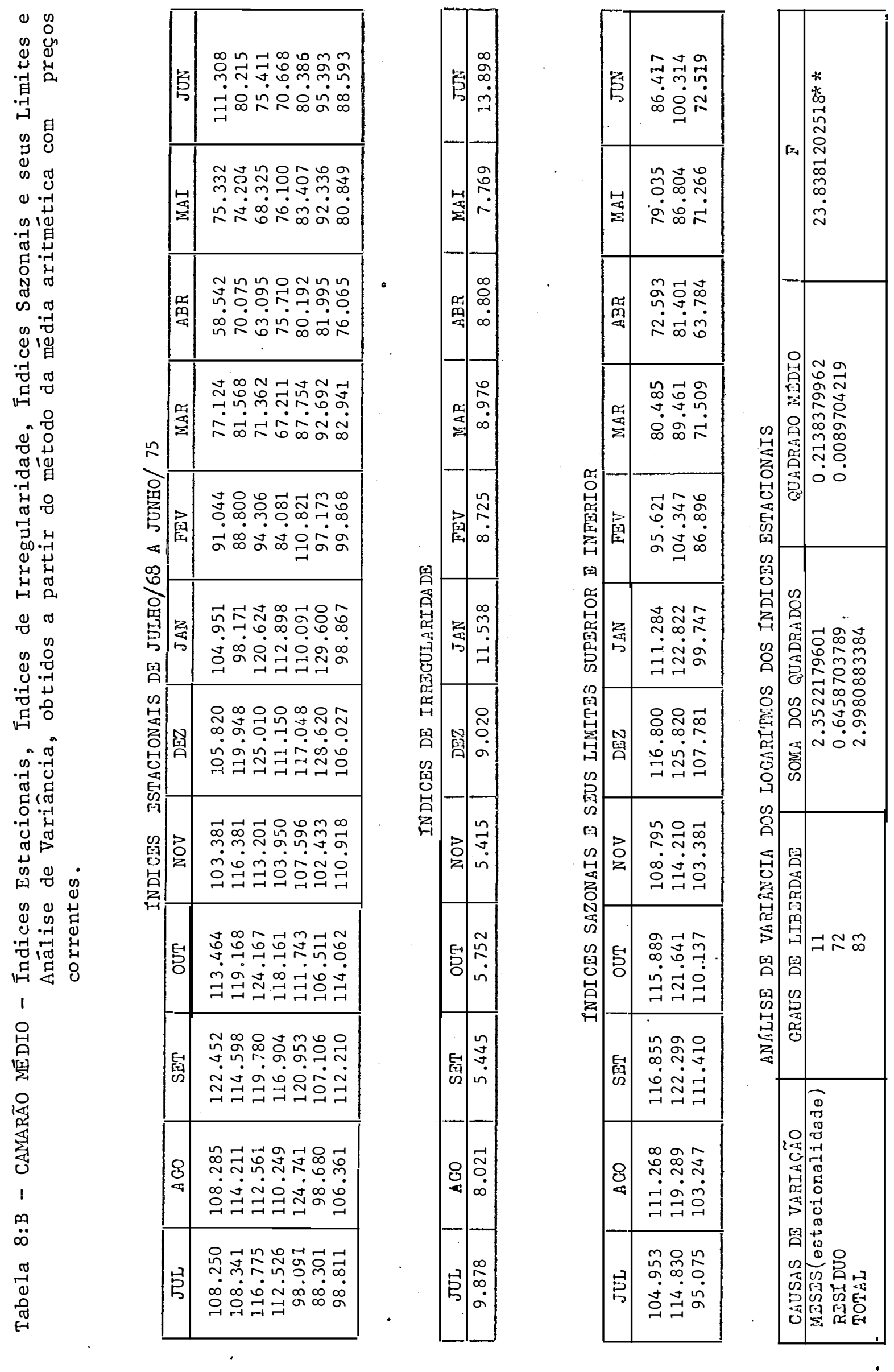


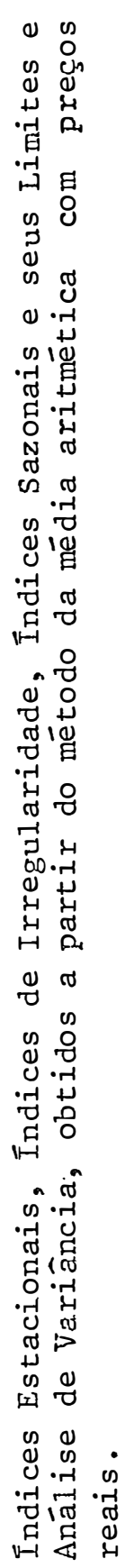
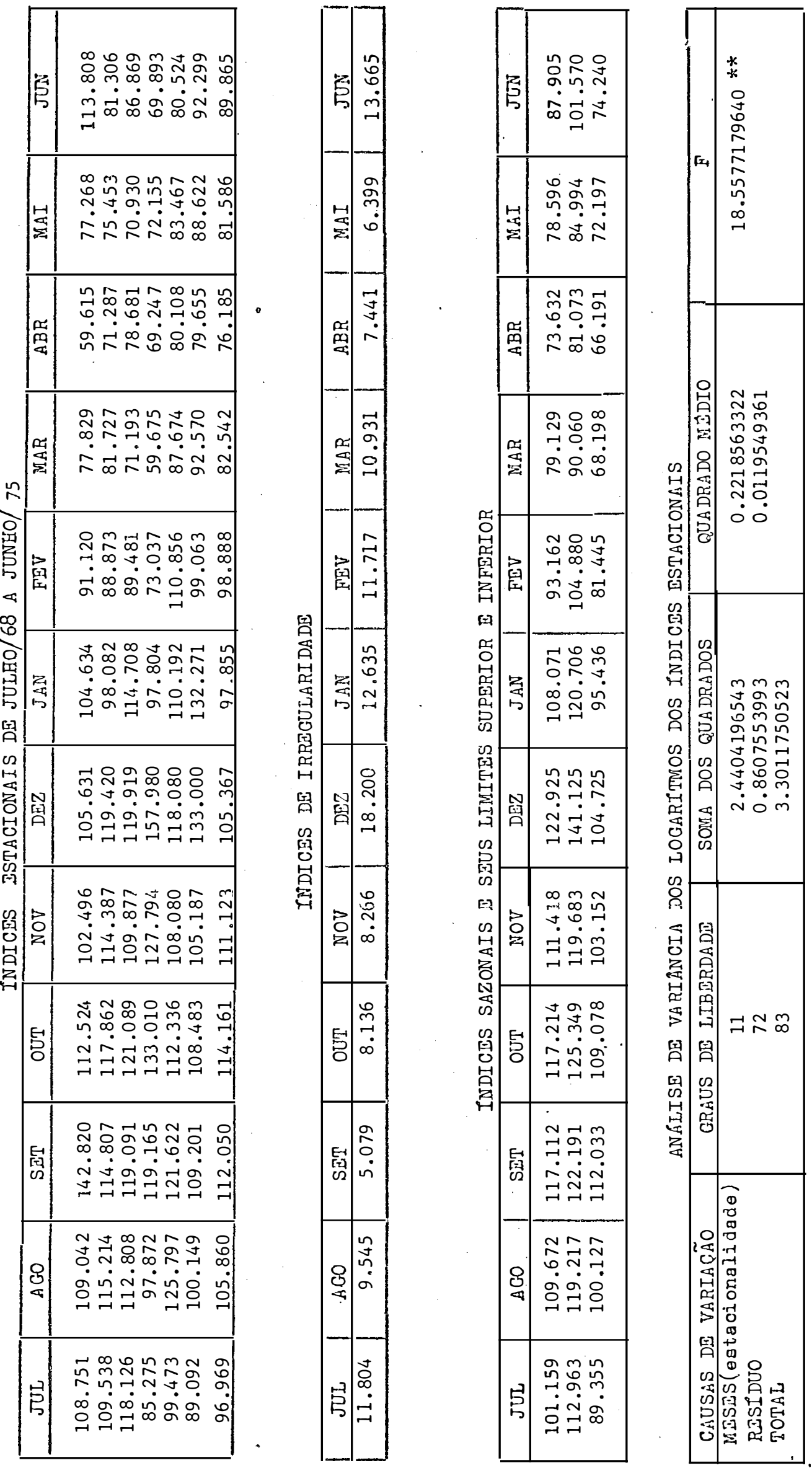

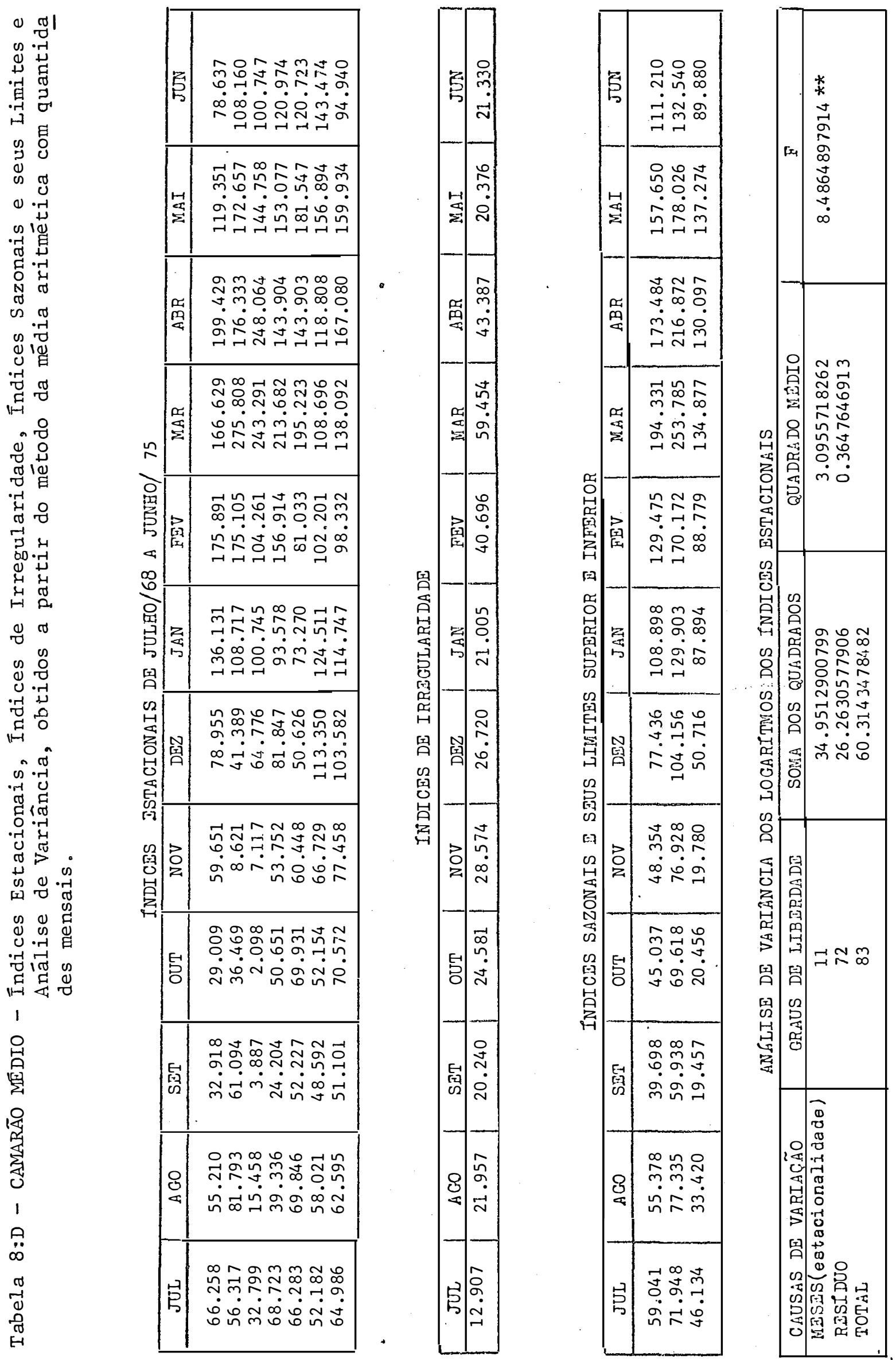

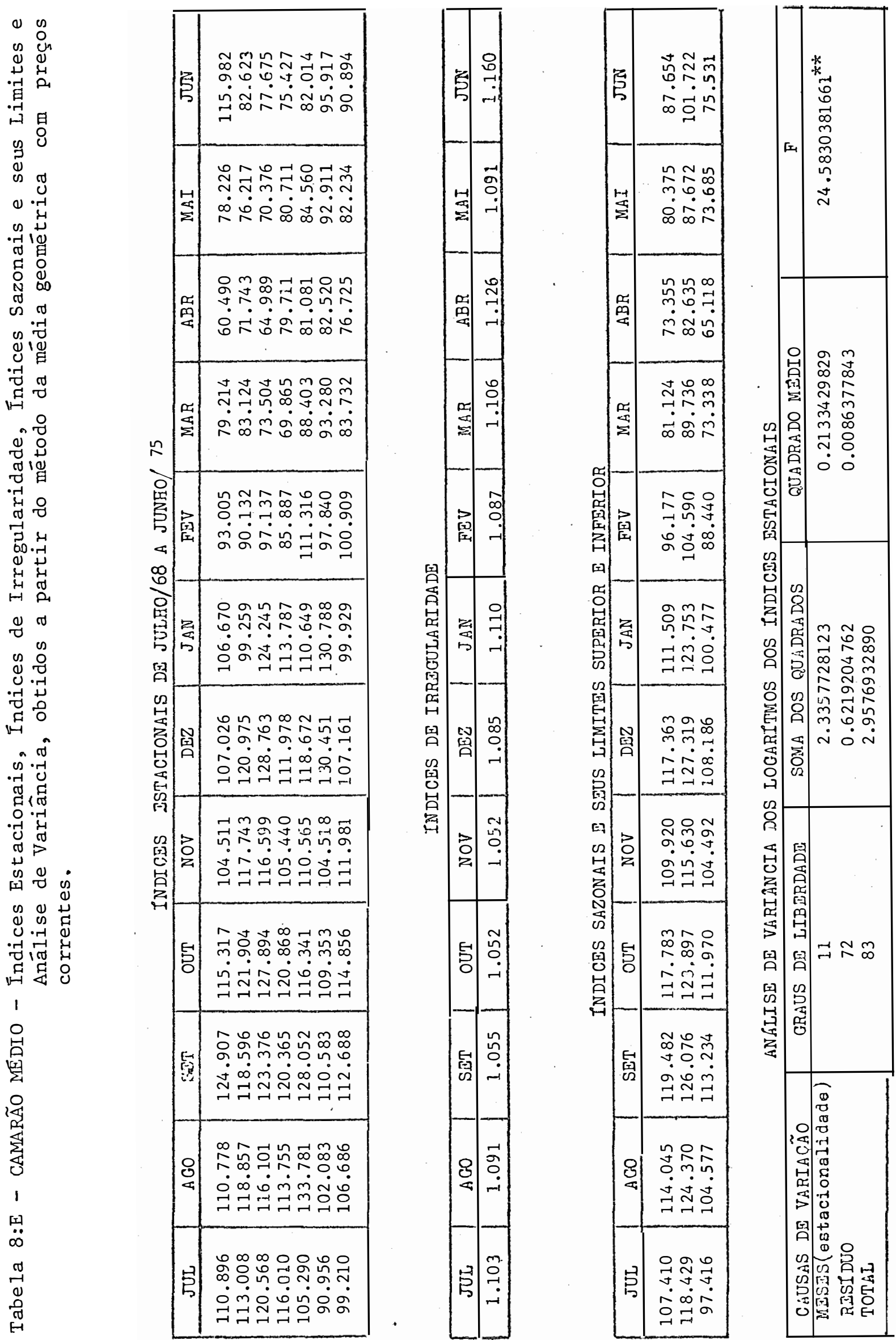

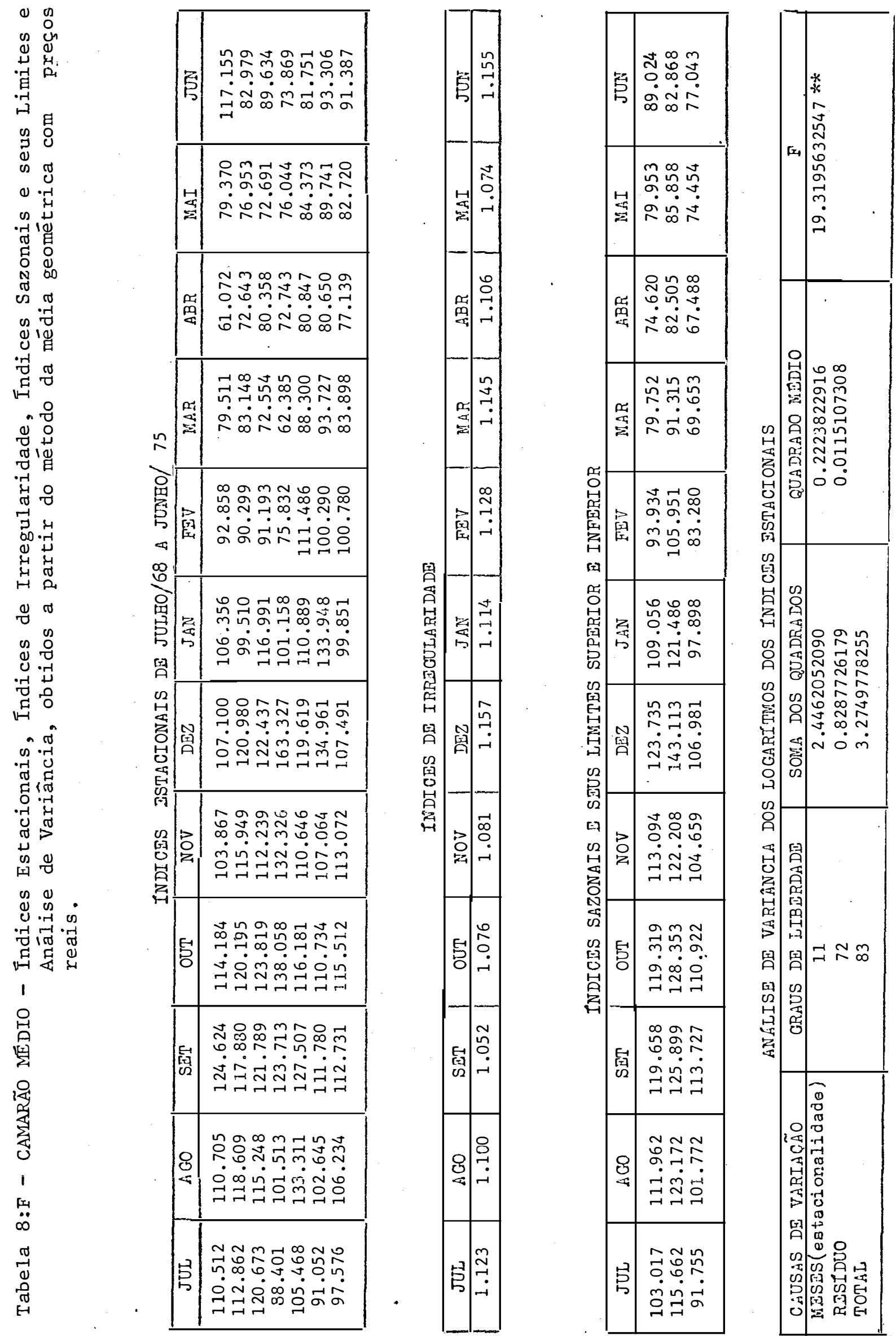

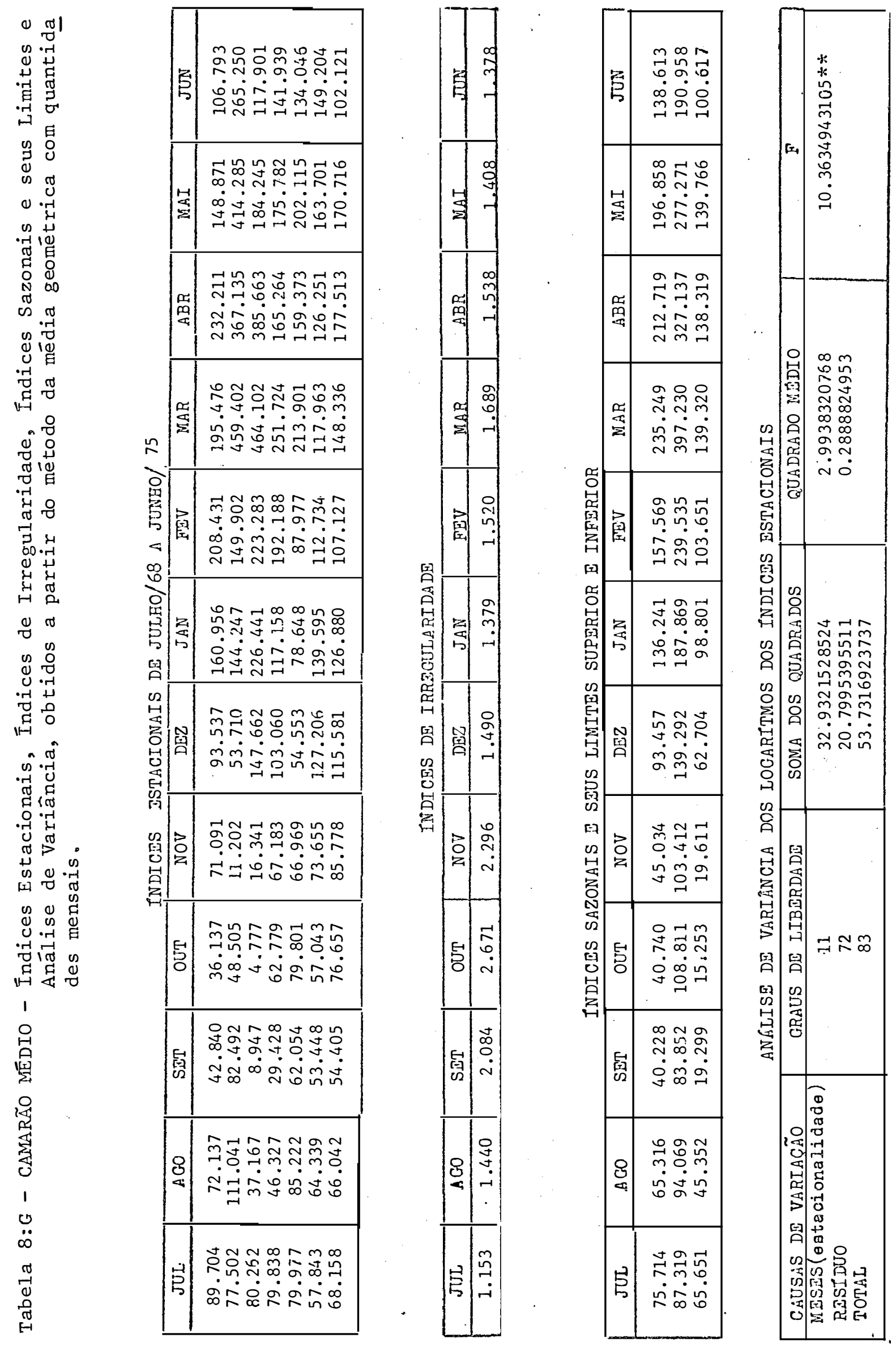

A N E $\quad \mathrm{X} O$
09
C A $M A R ~ \widetilde{A} O$
R O S A 

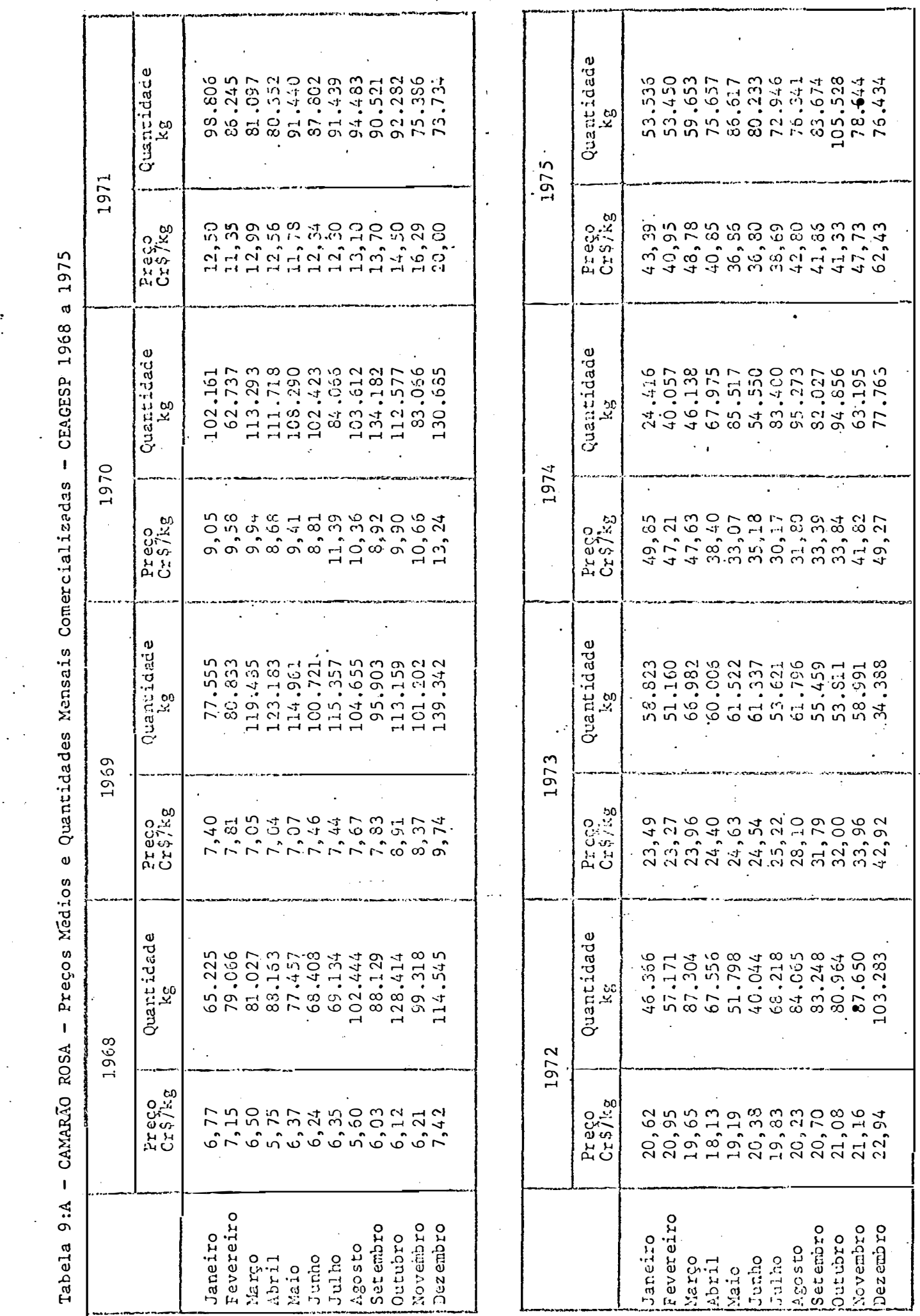

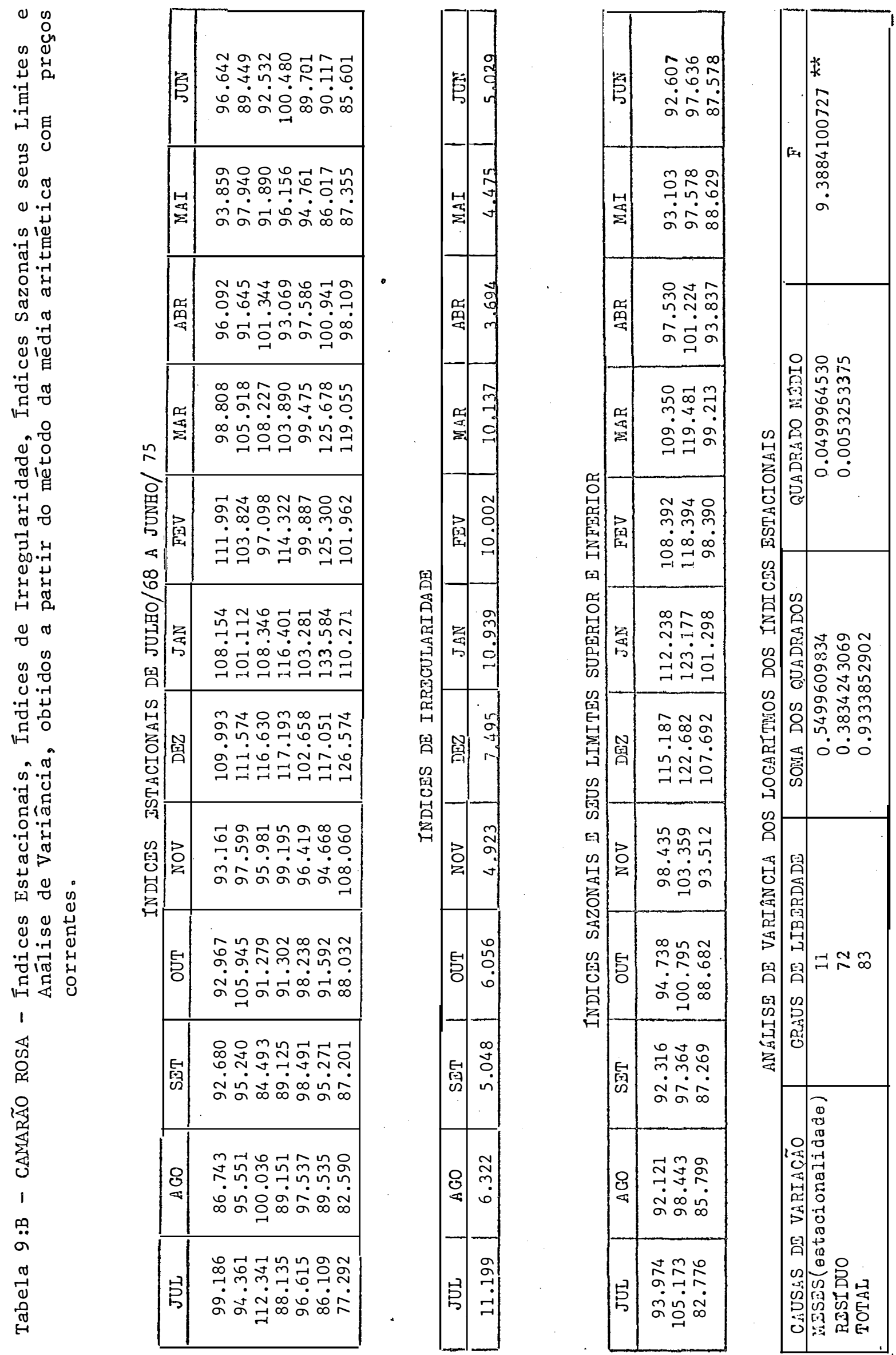

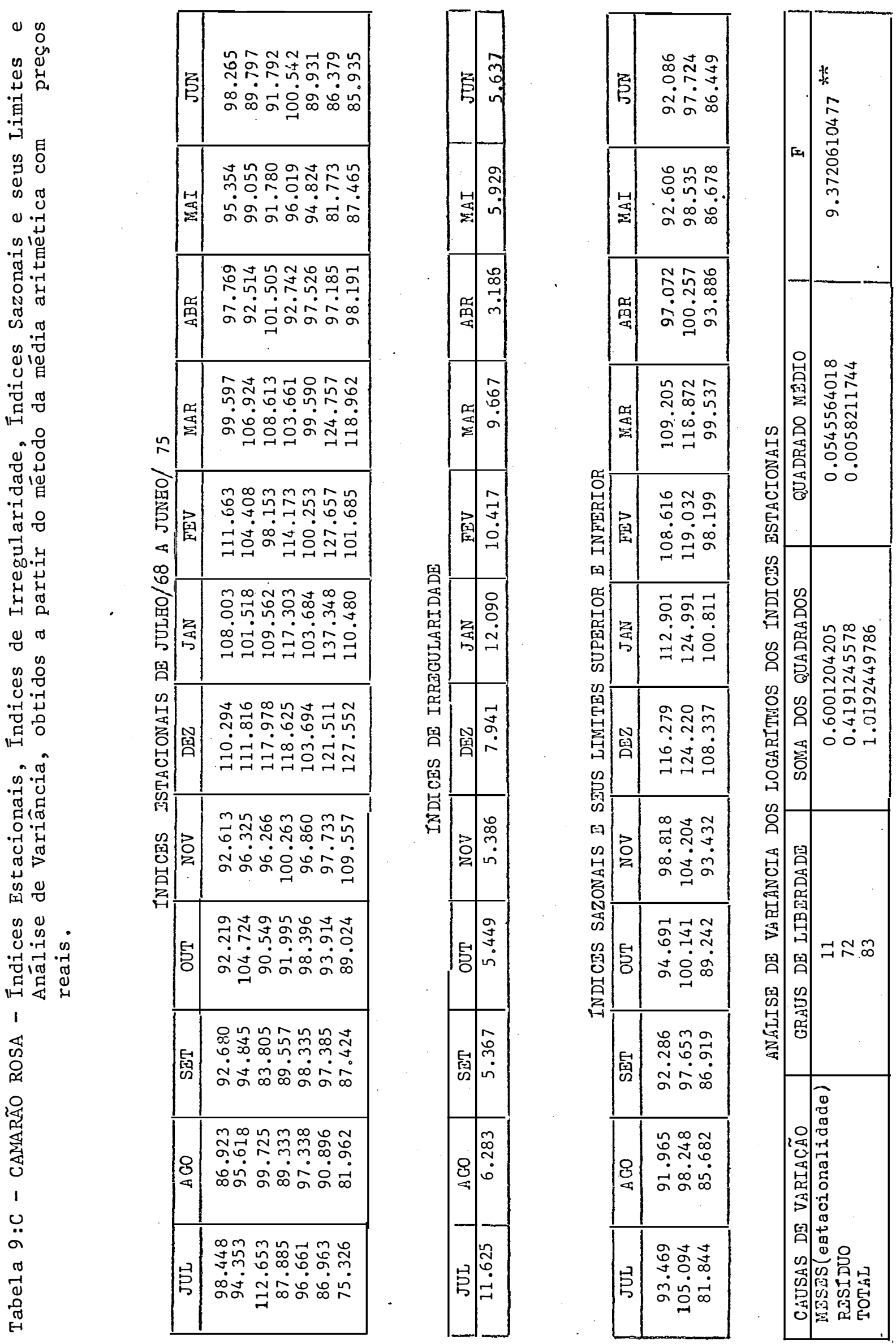

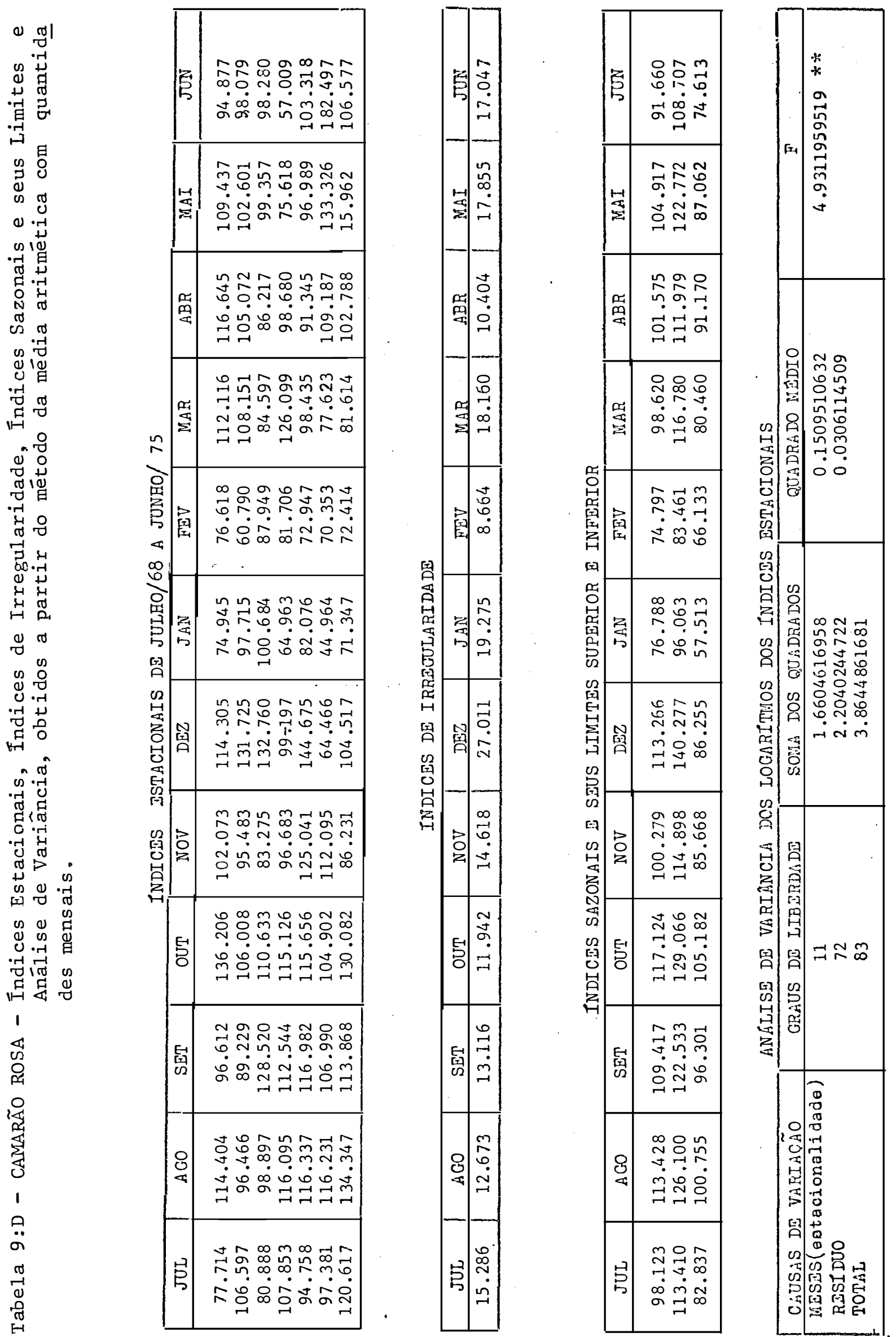


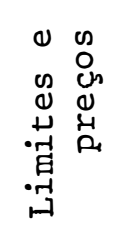

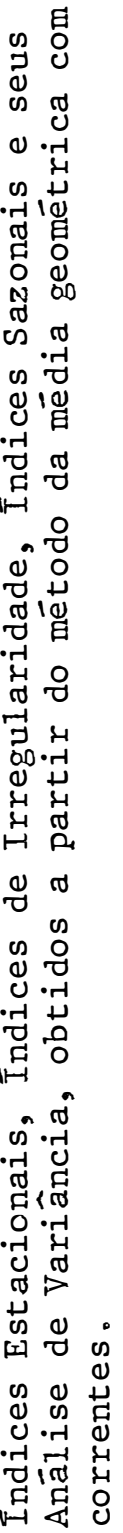

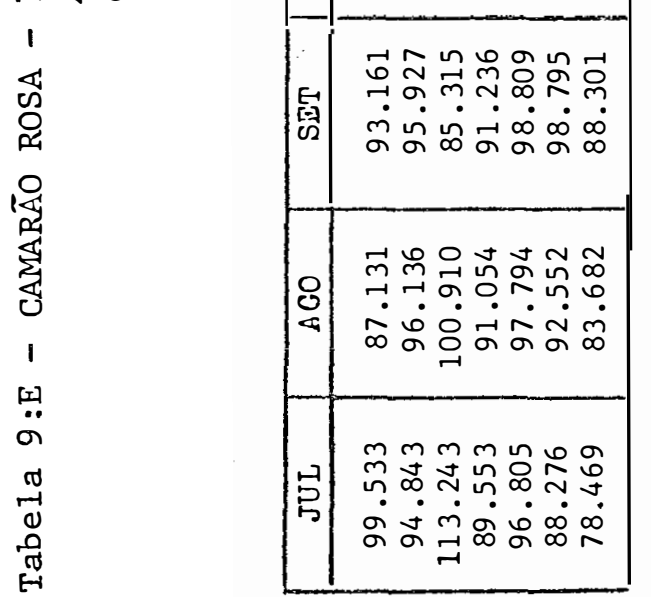

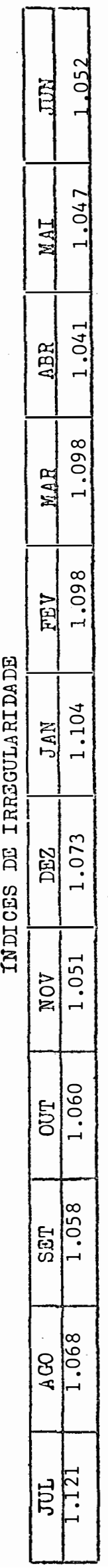

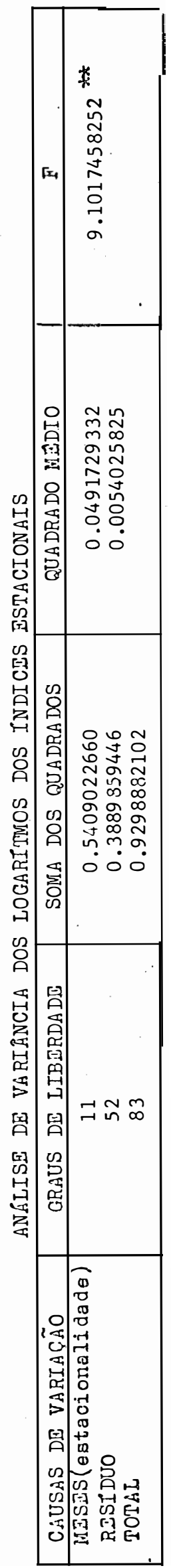



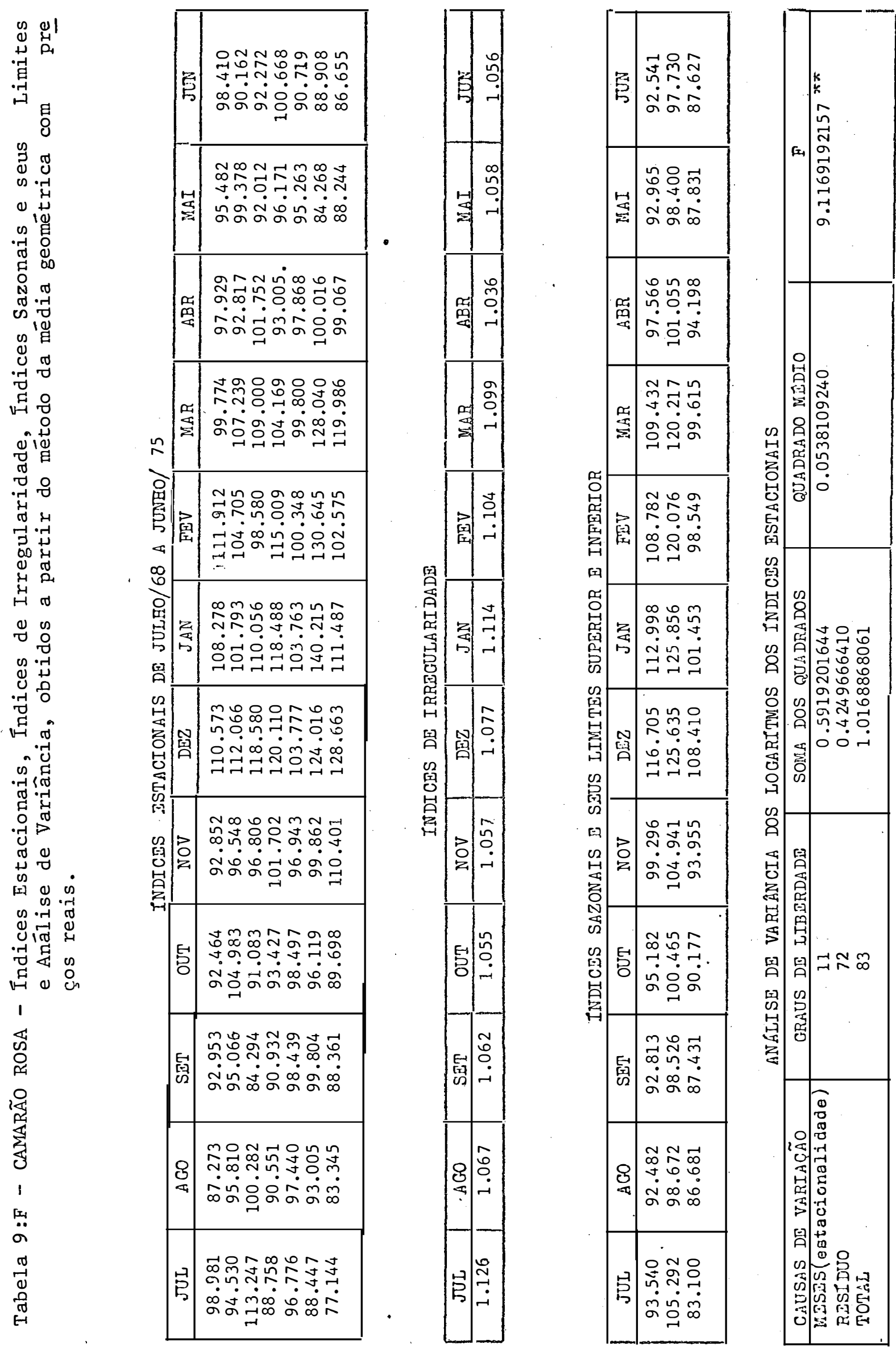

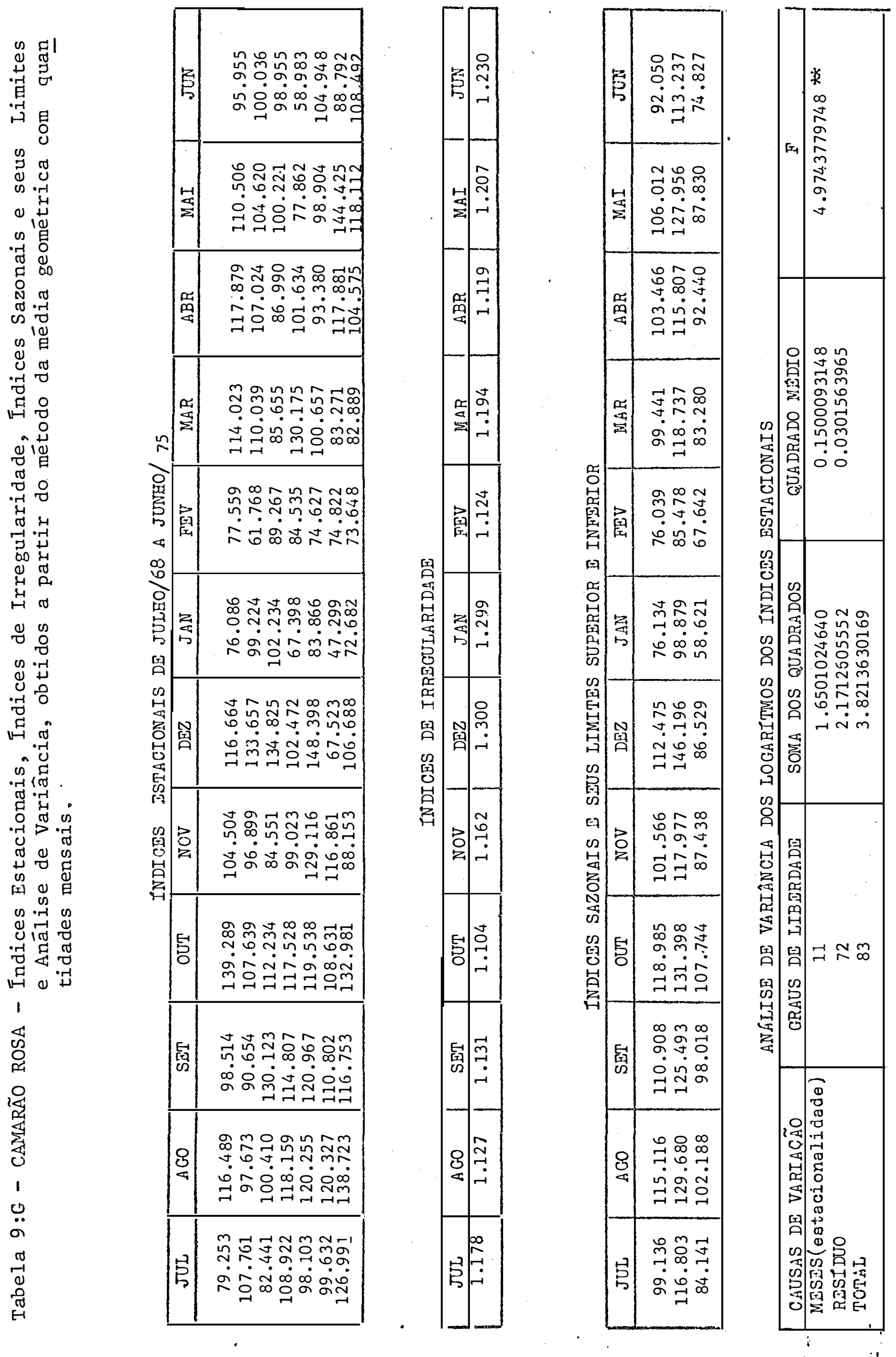


$$
\begin{aligned}
& \text { A } N \text { E X O } 10
\end{aligned}
$$

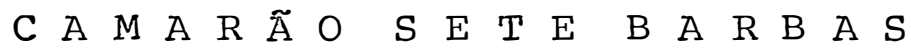



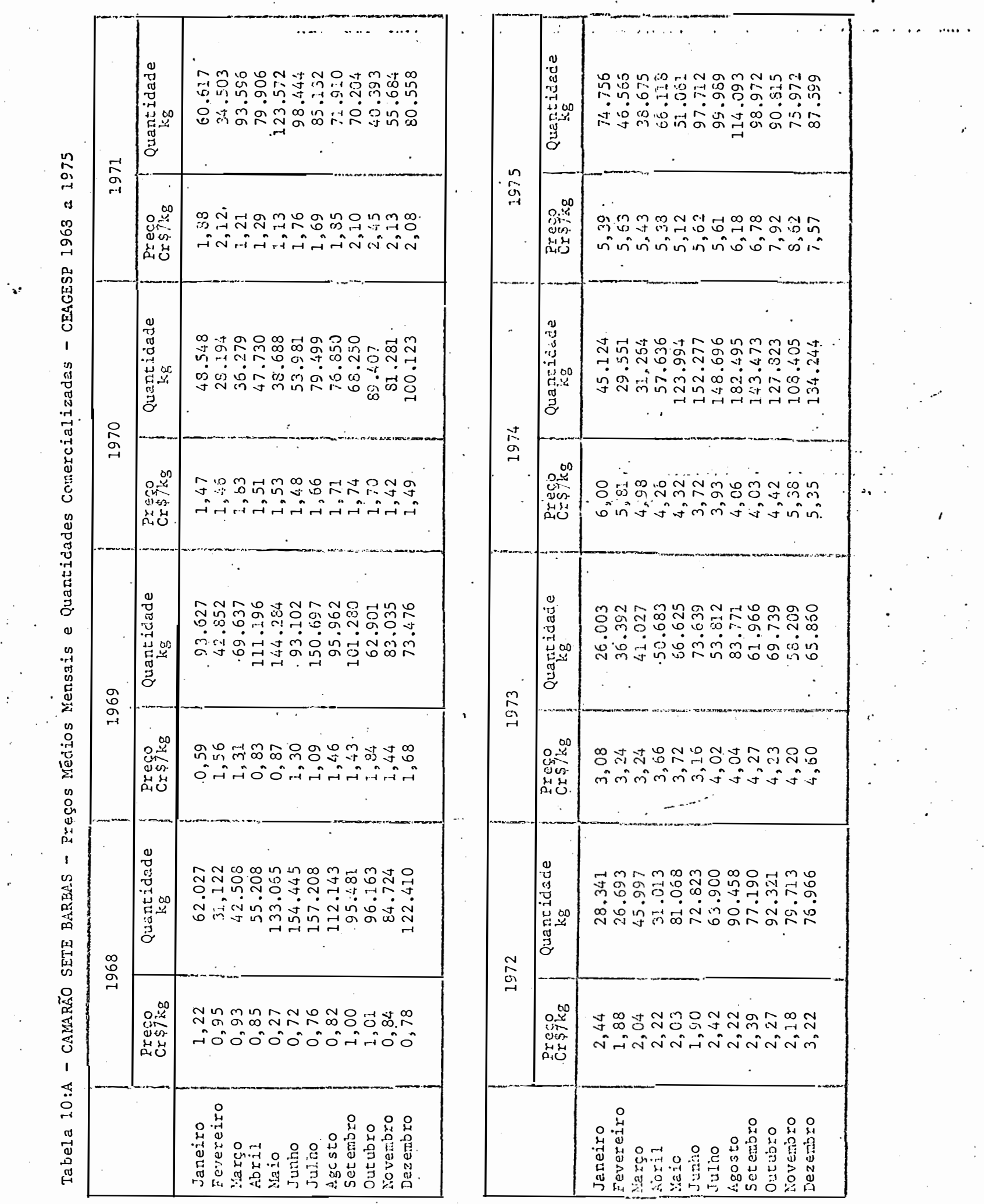

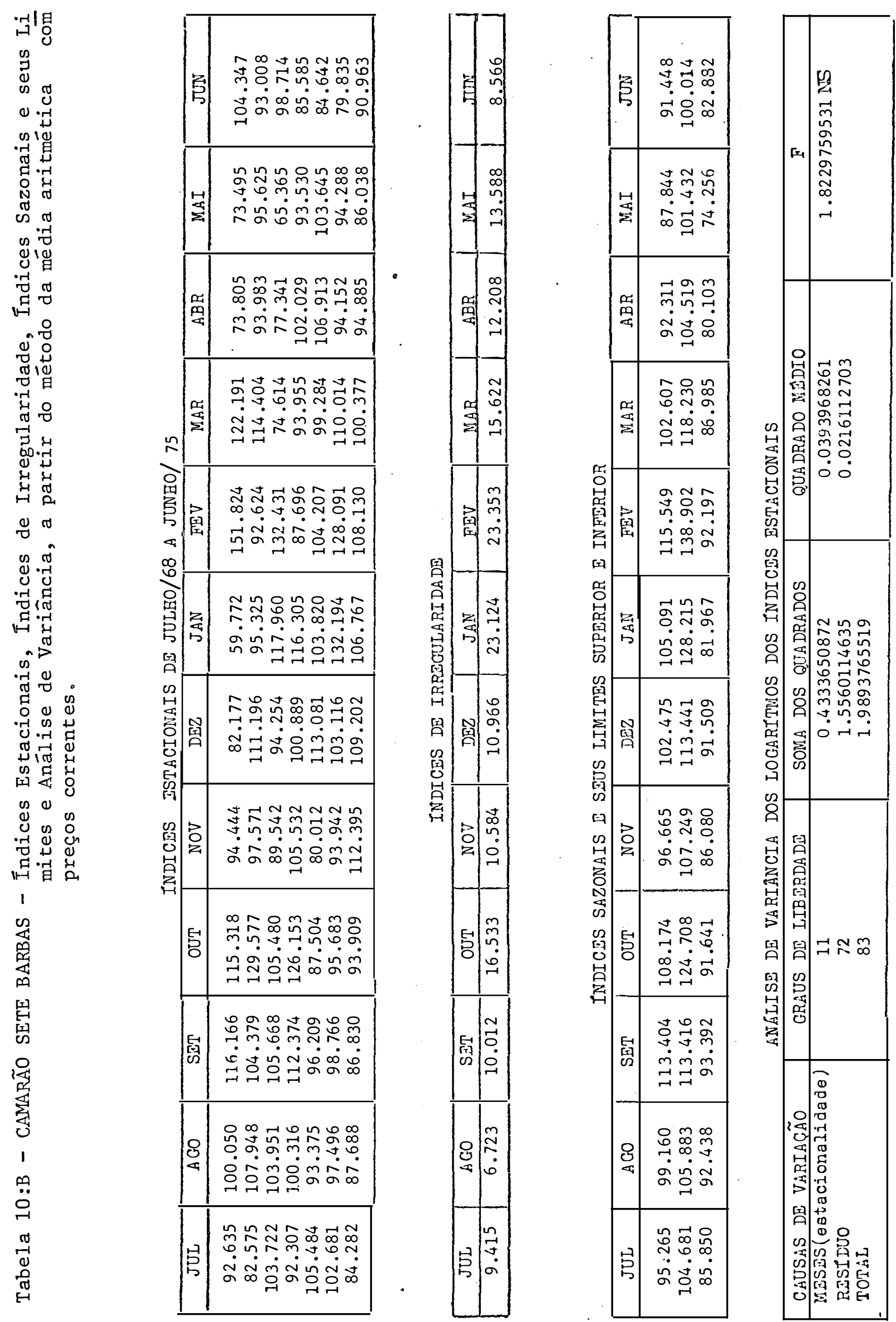

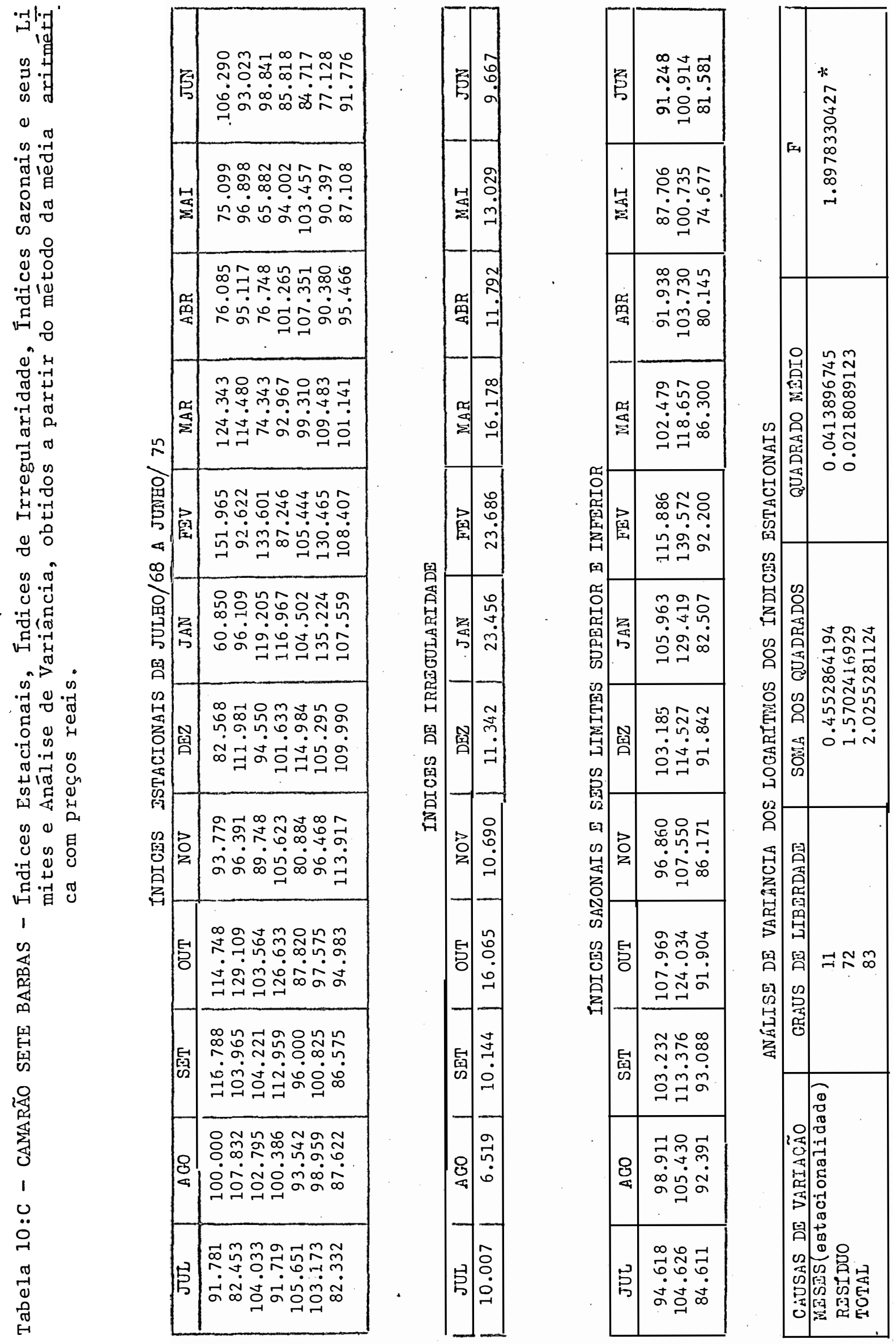

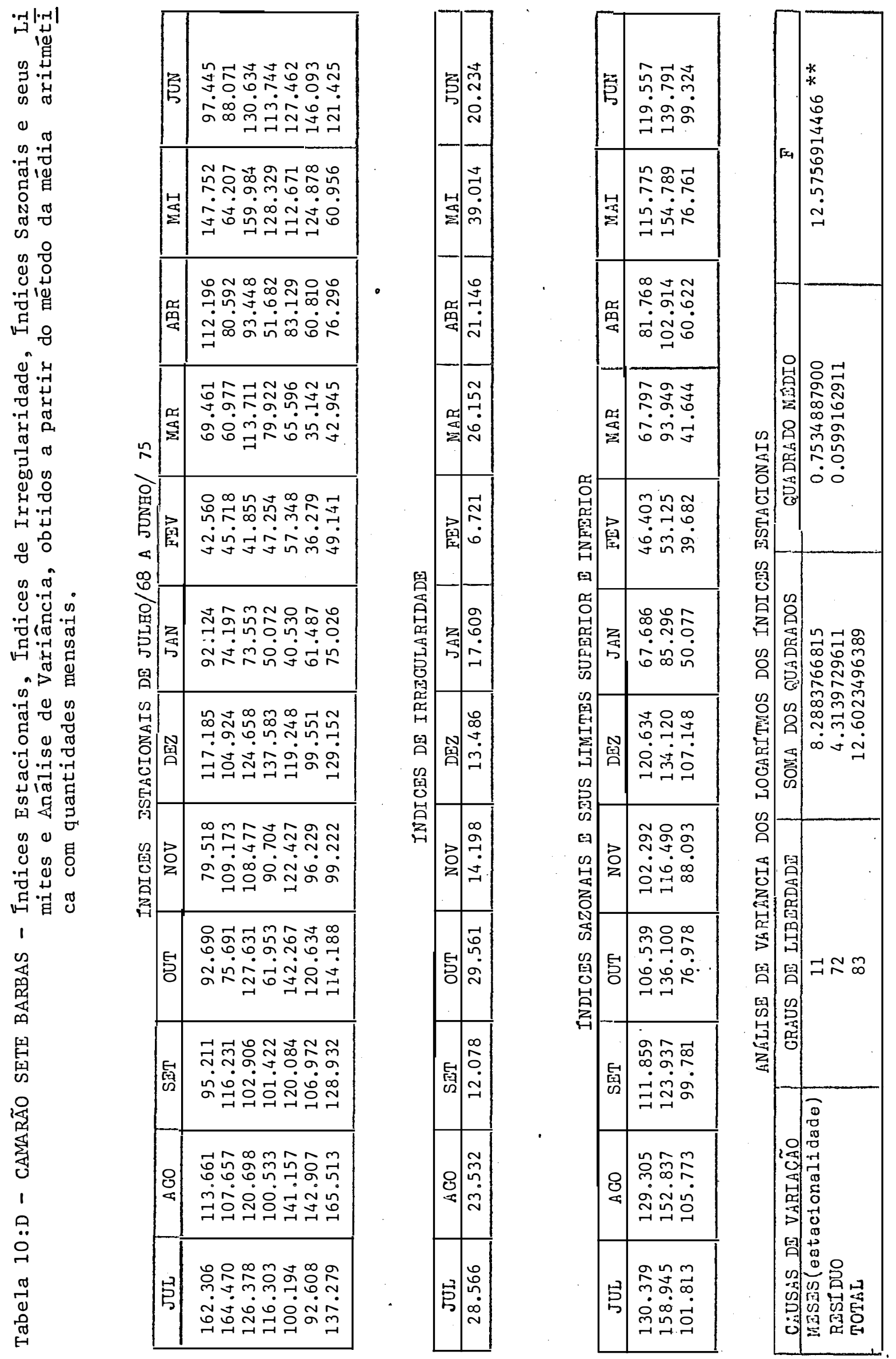

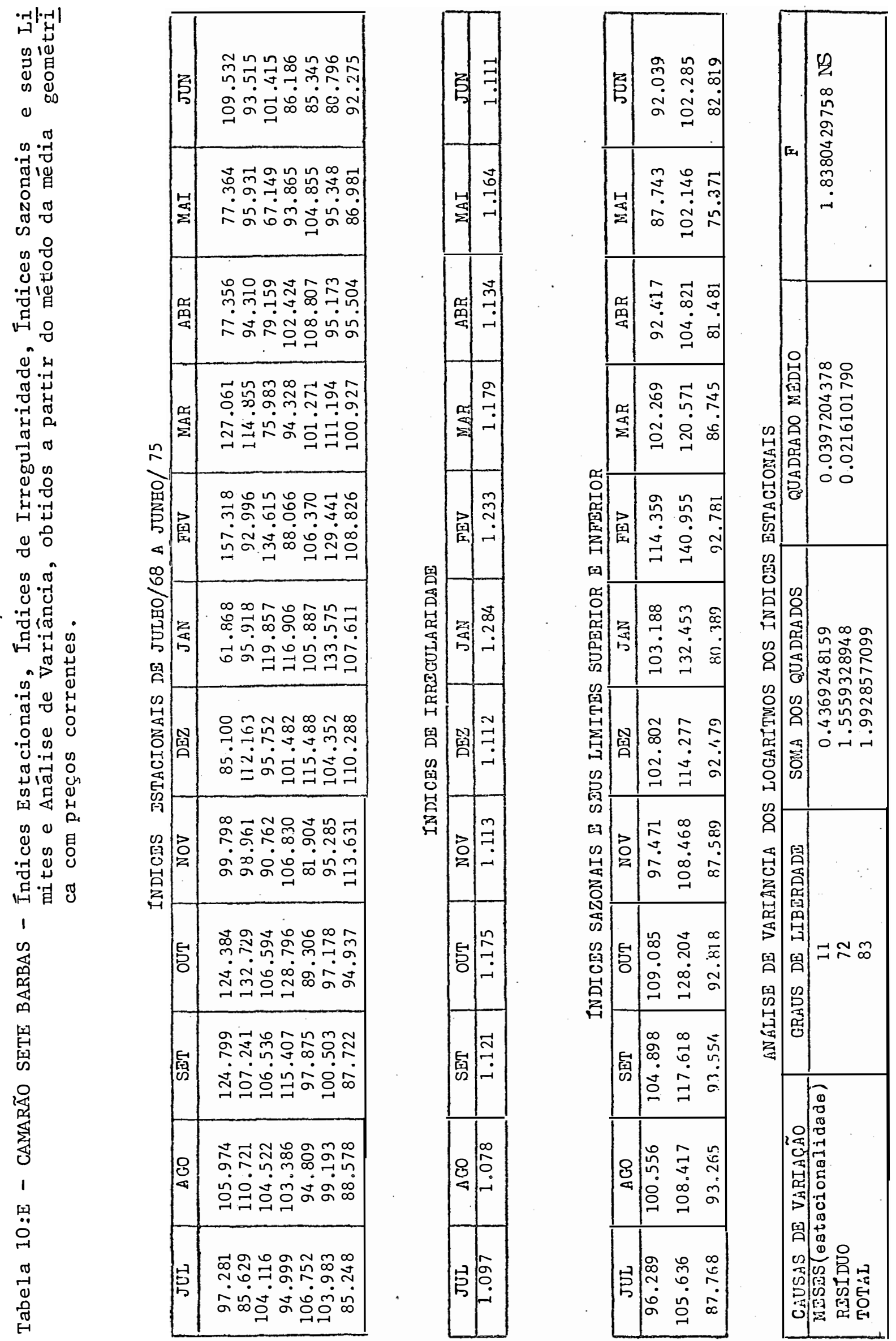

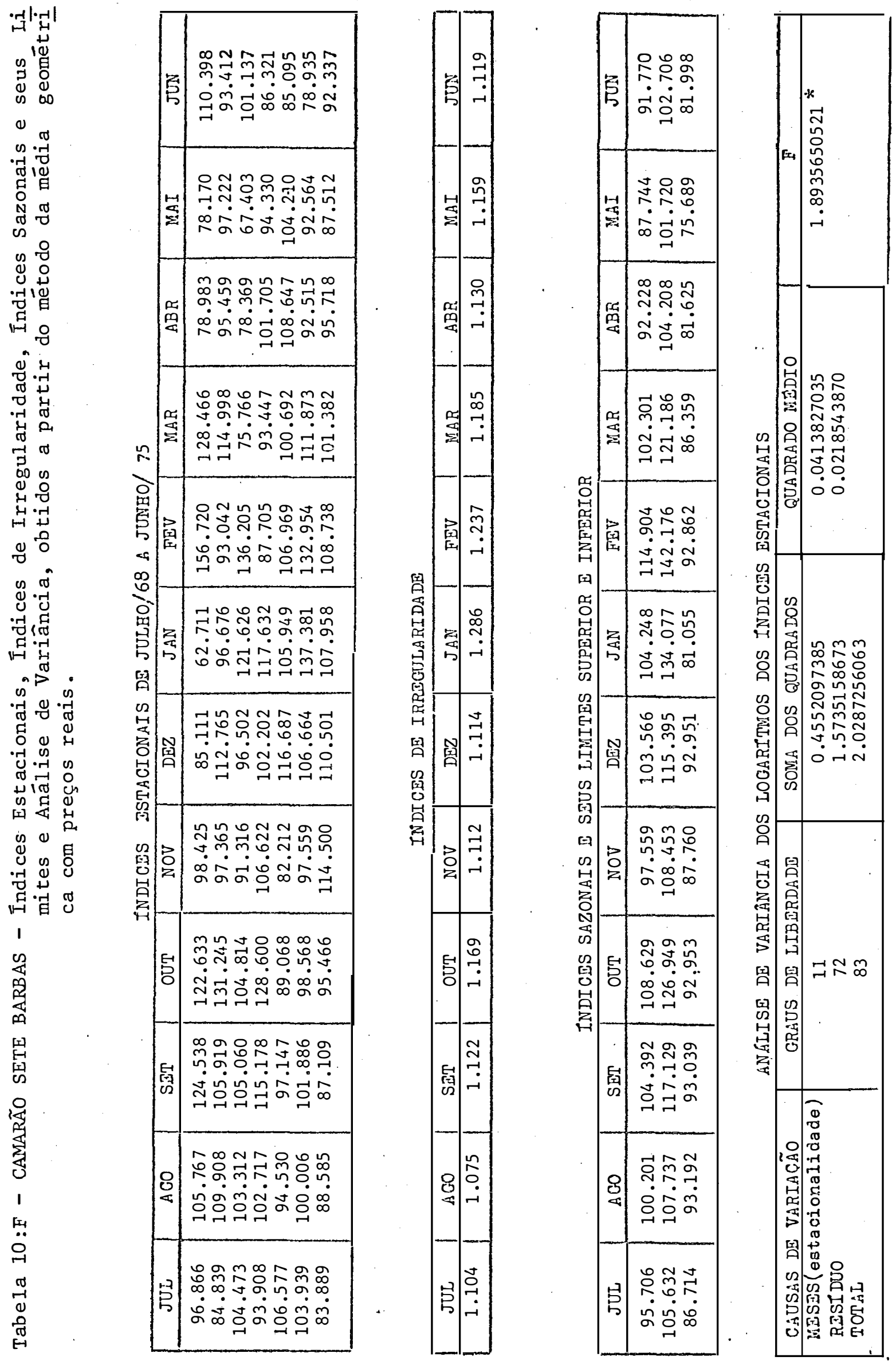

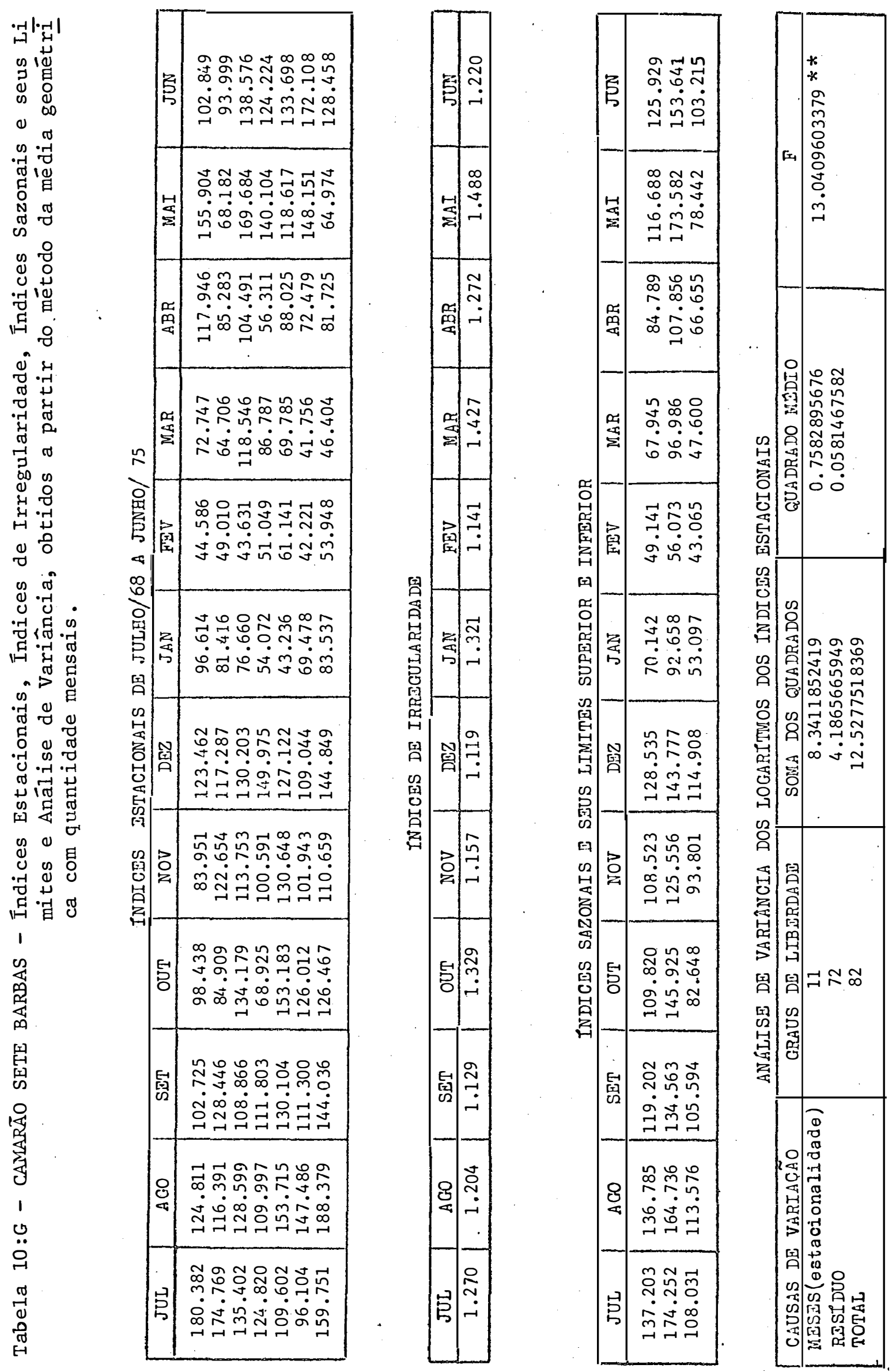
A N E X O 11

$S A R D I N H A$ 

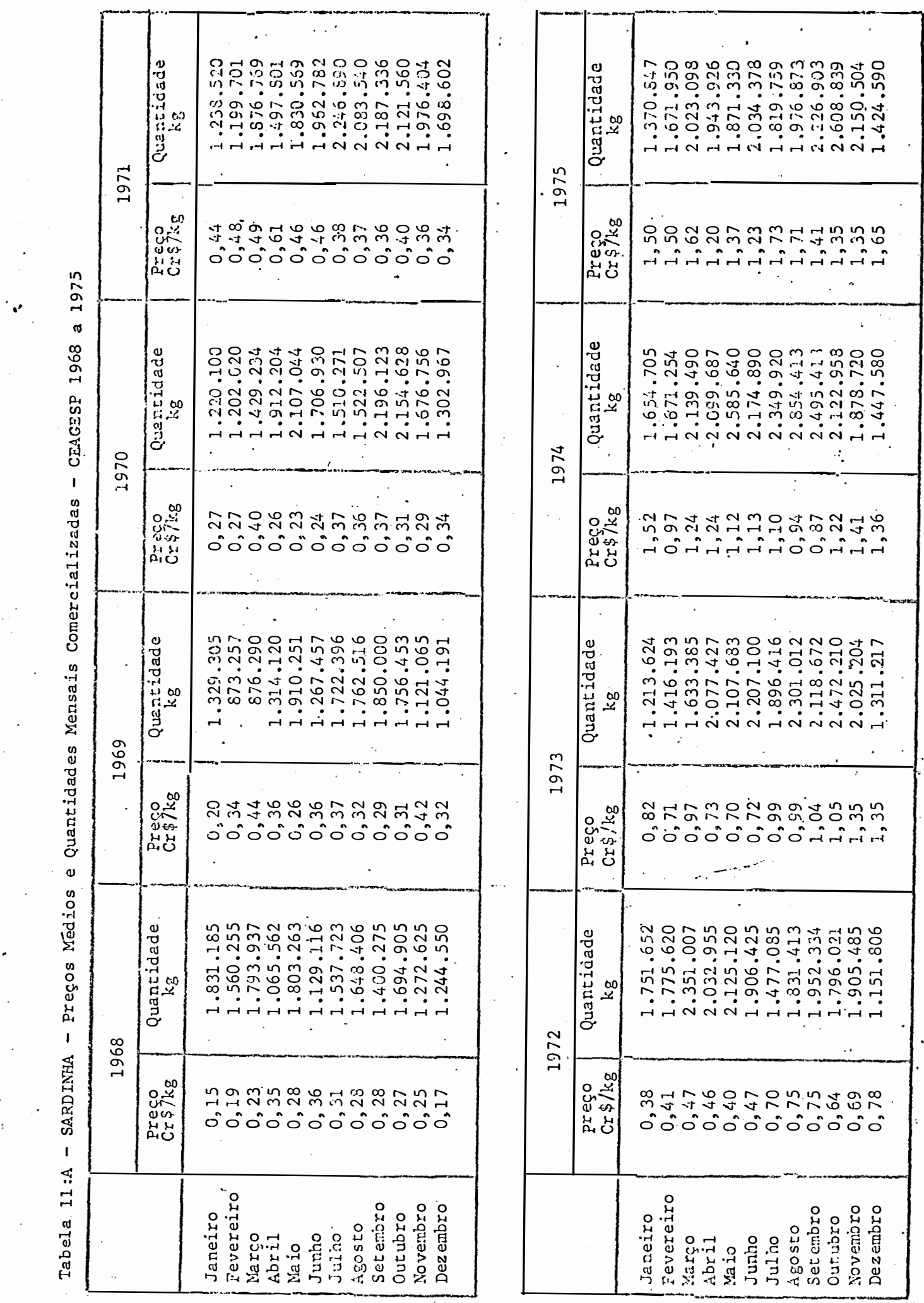

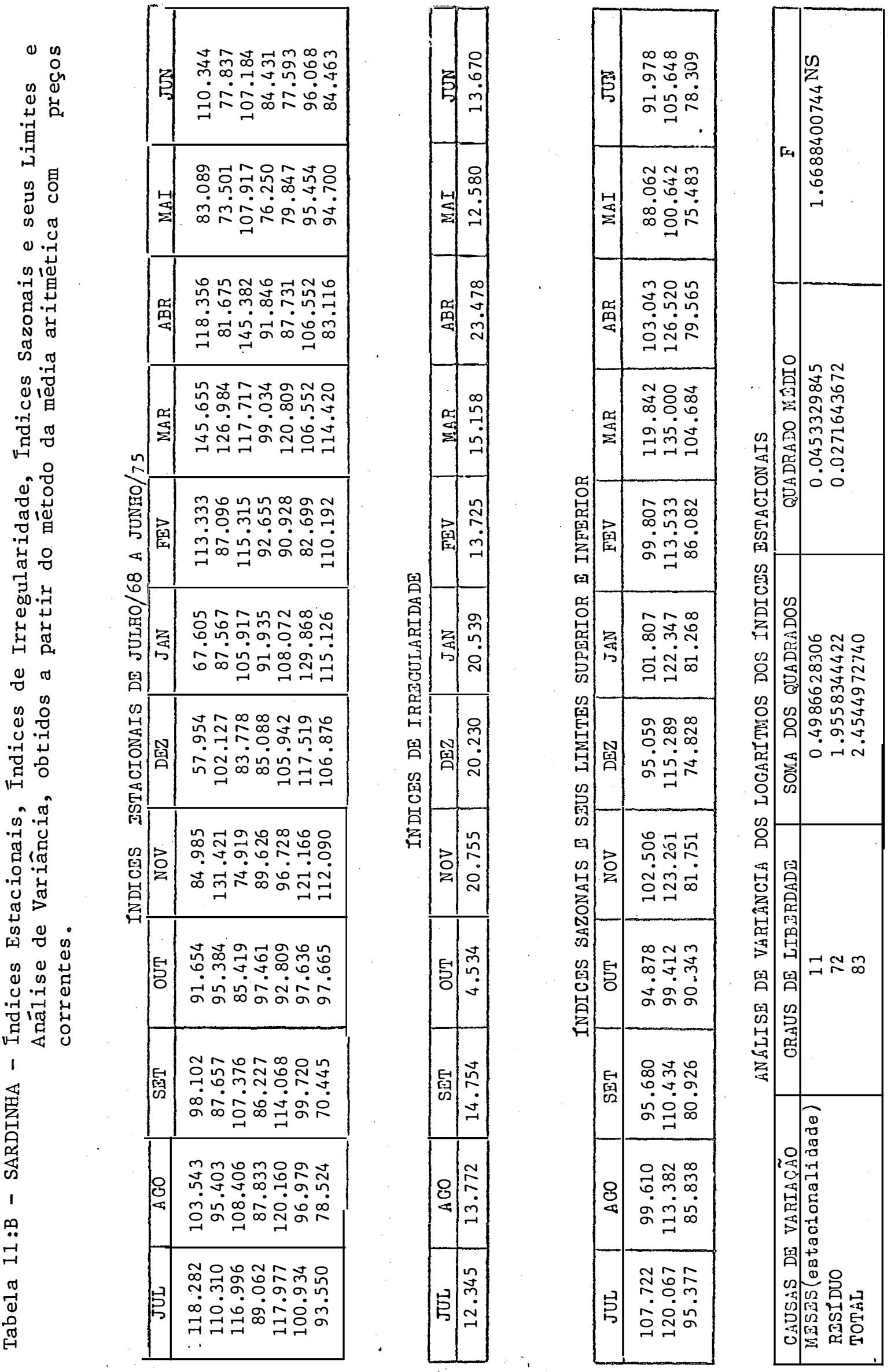

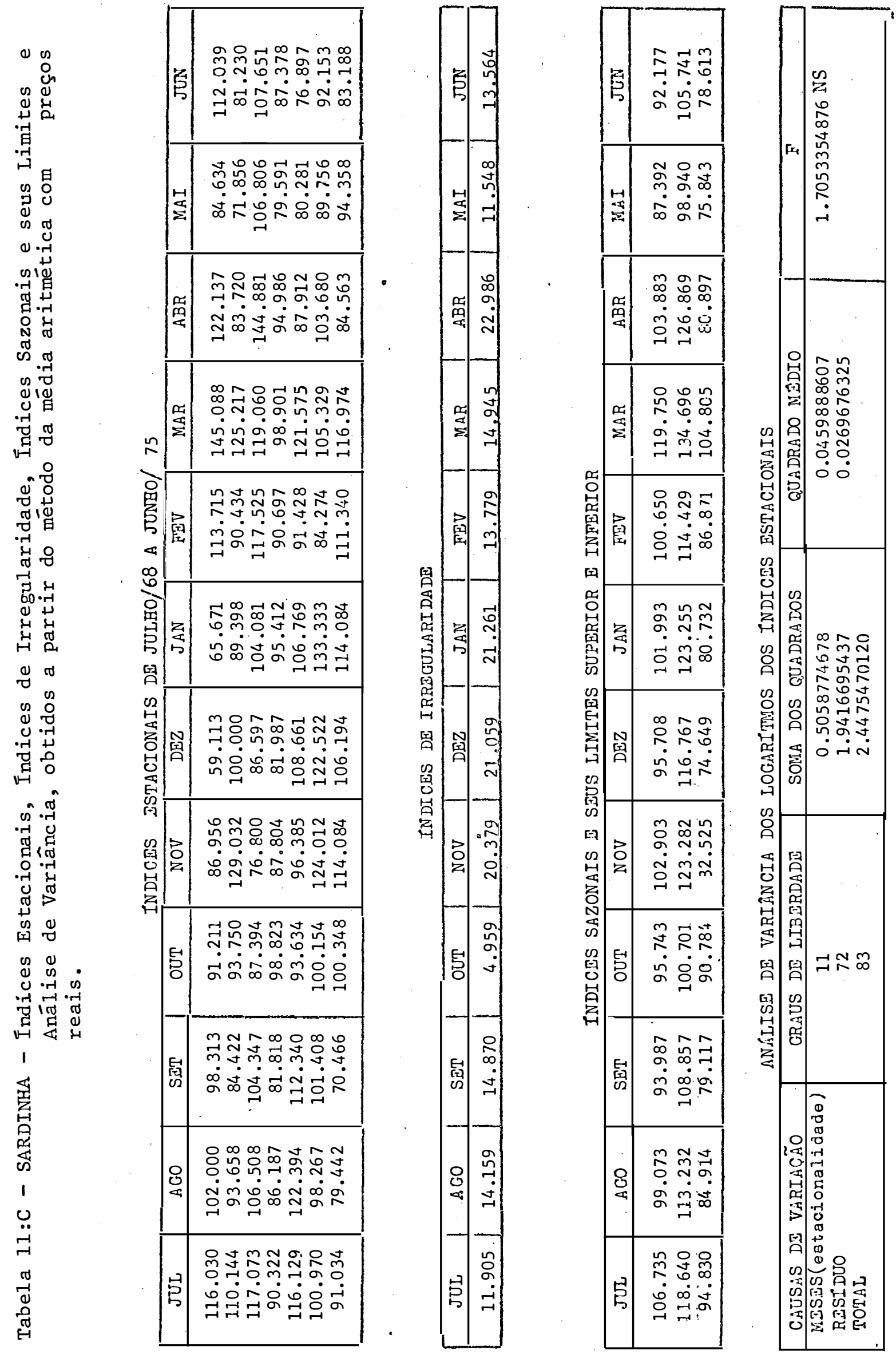

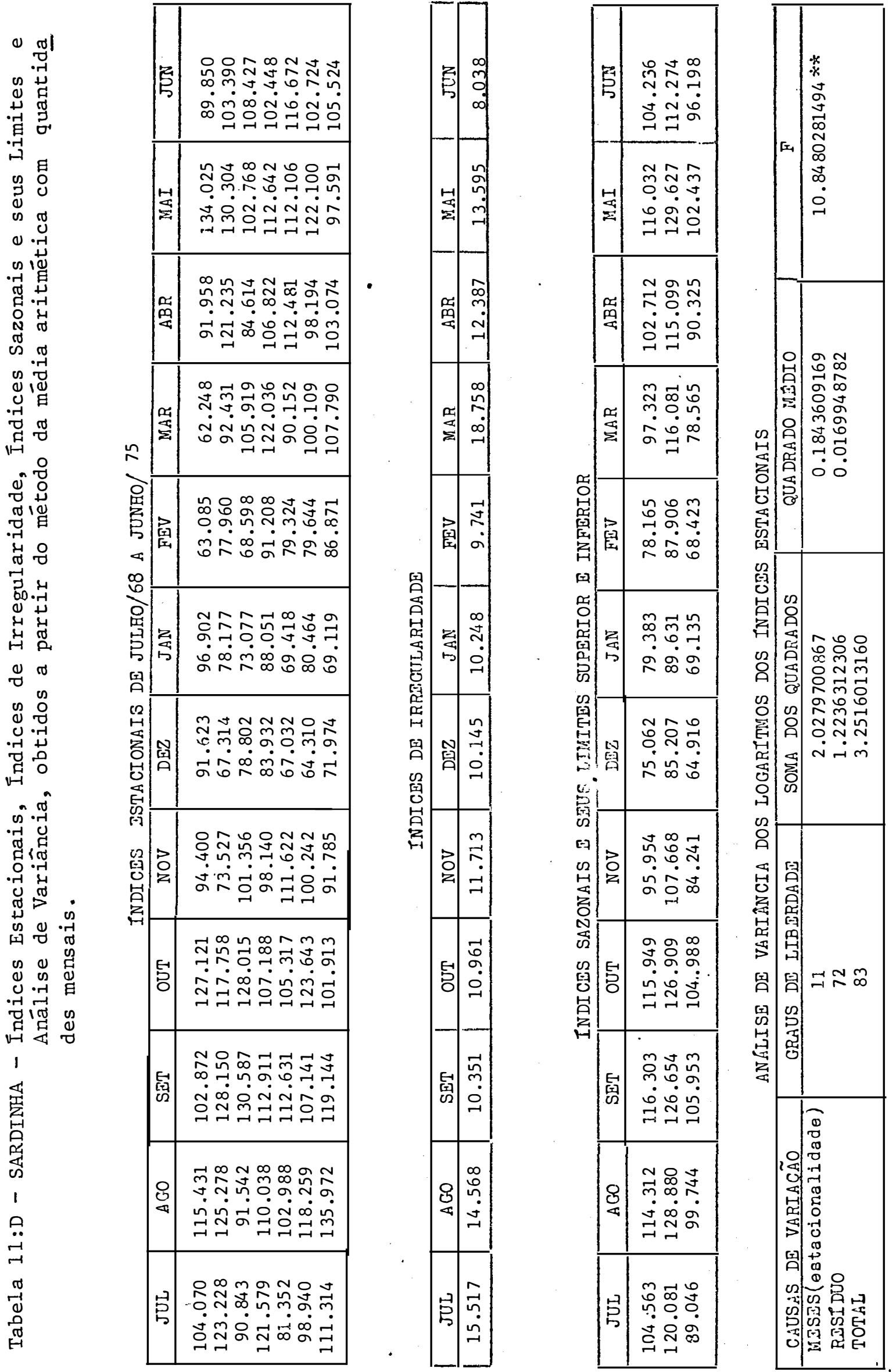

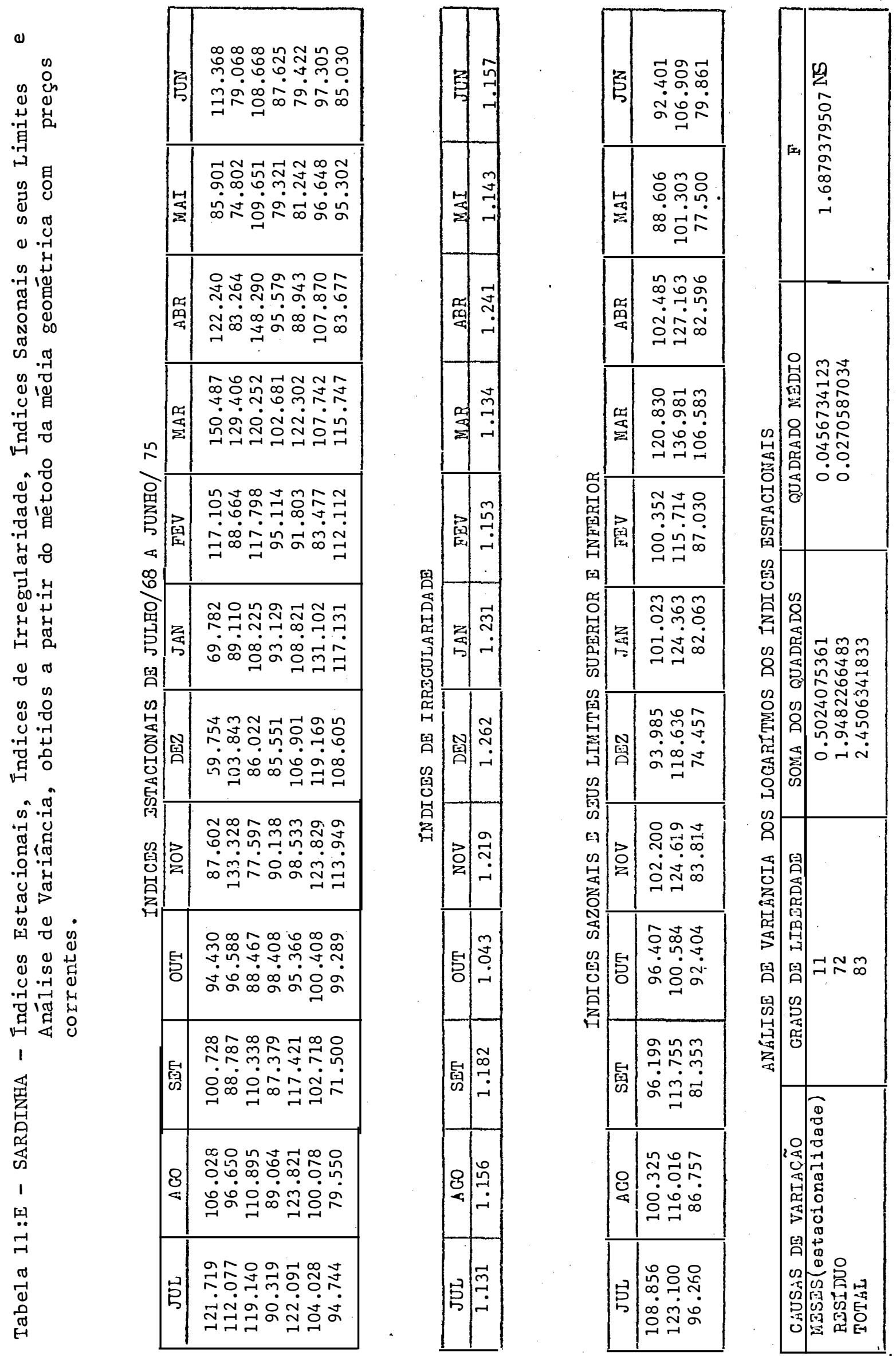

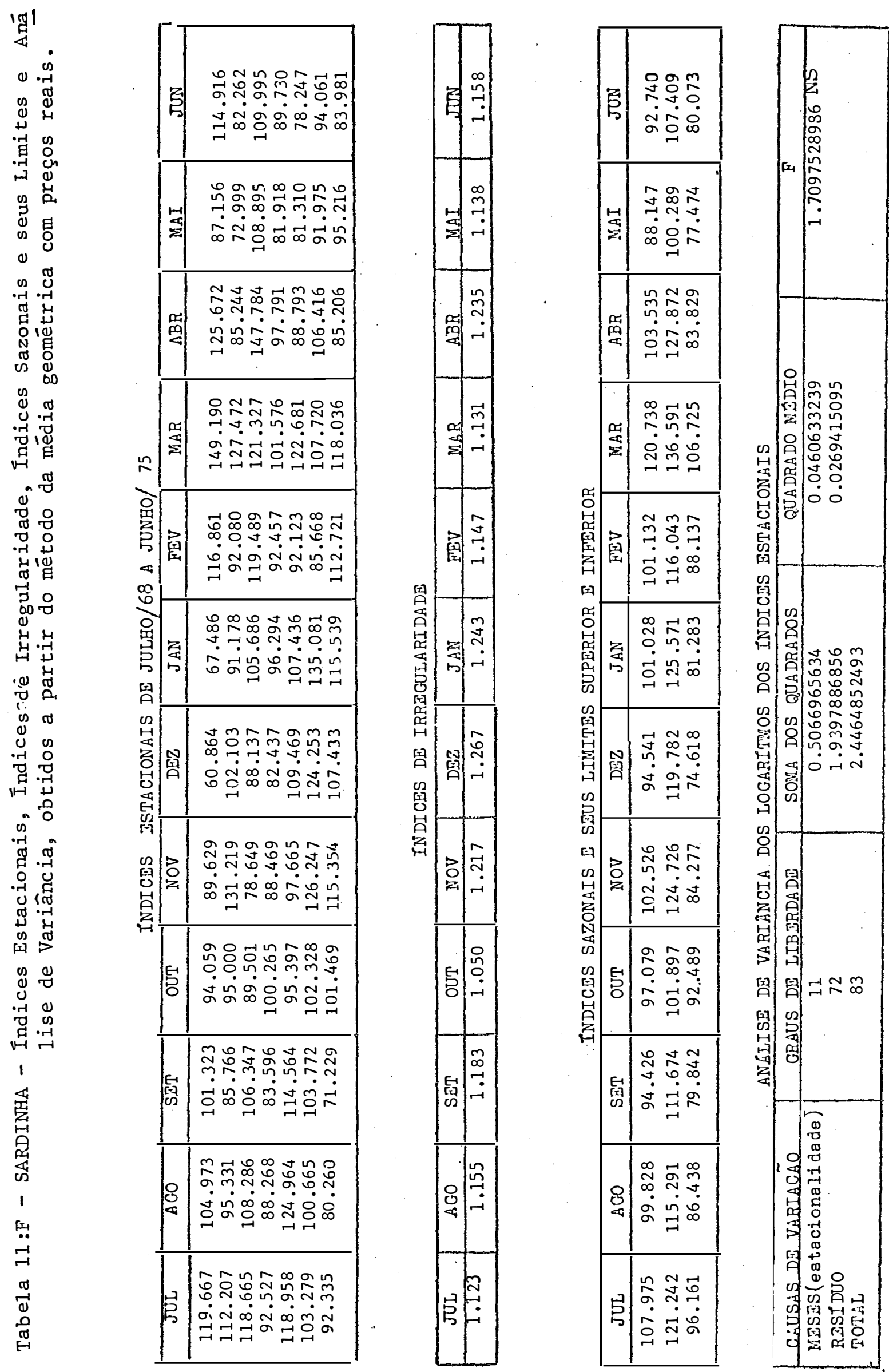

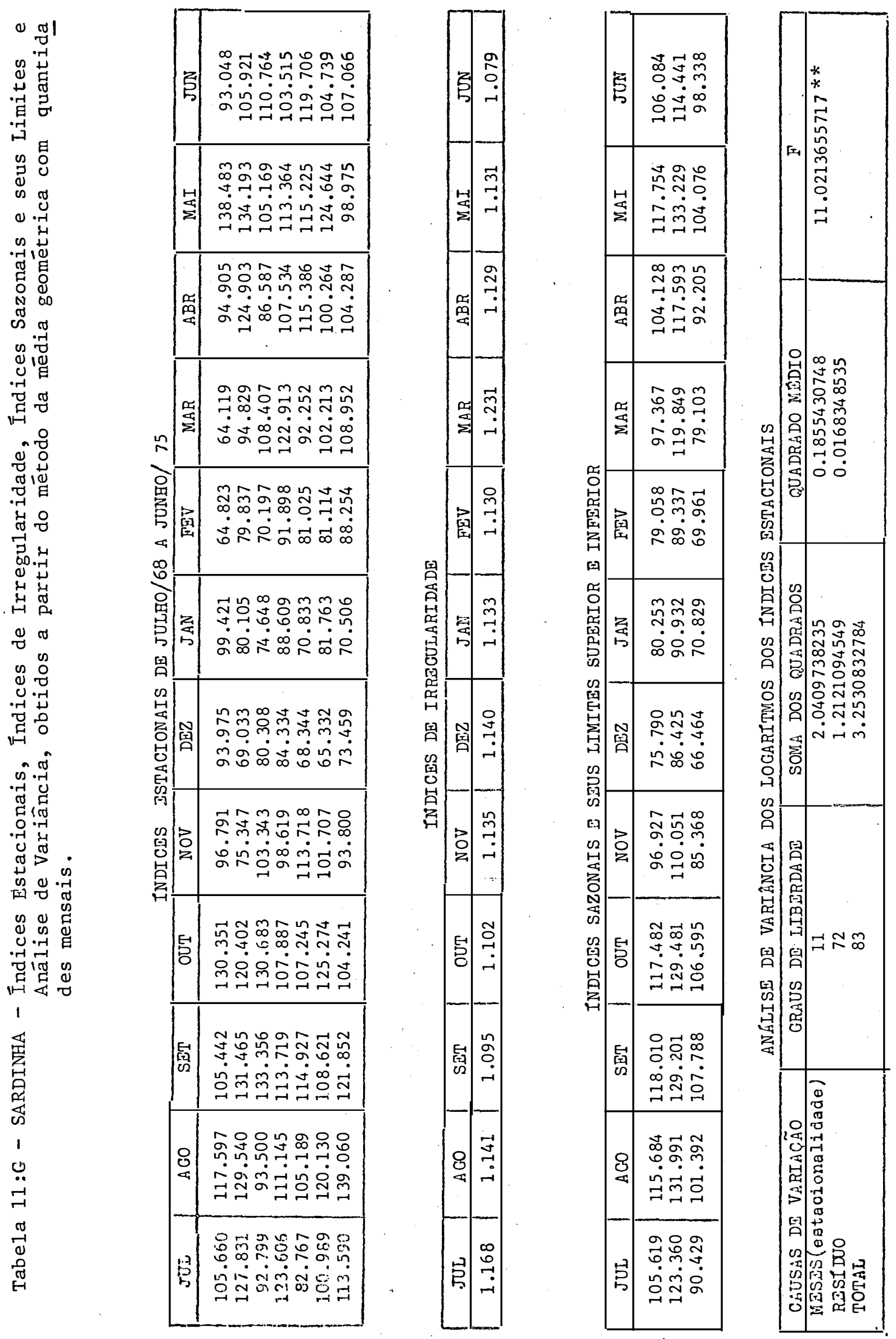
A N E X O 12

$\mathrm{T} A \mathrm{I} N \mathrm{~N}$ 

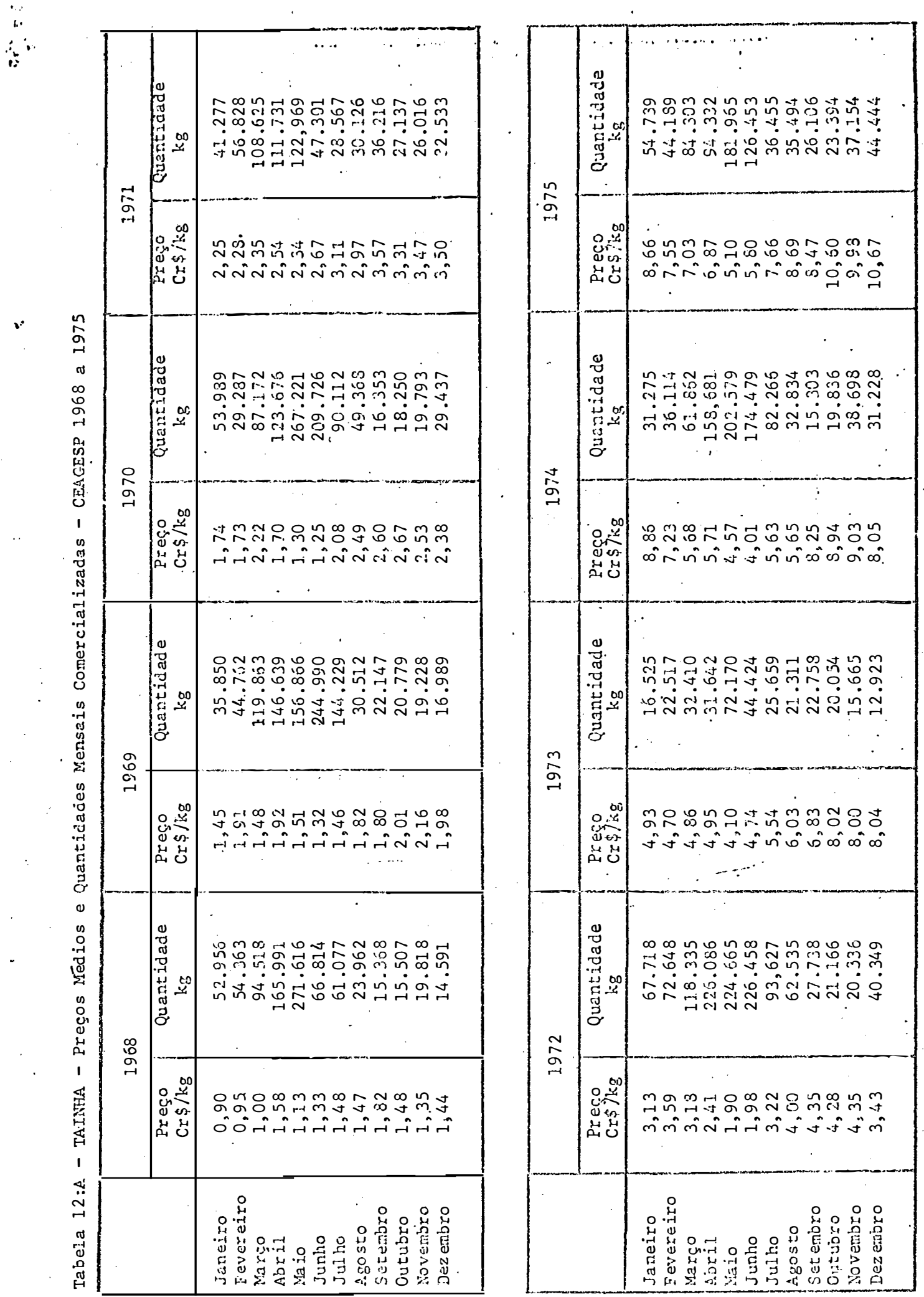

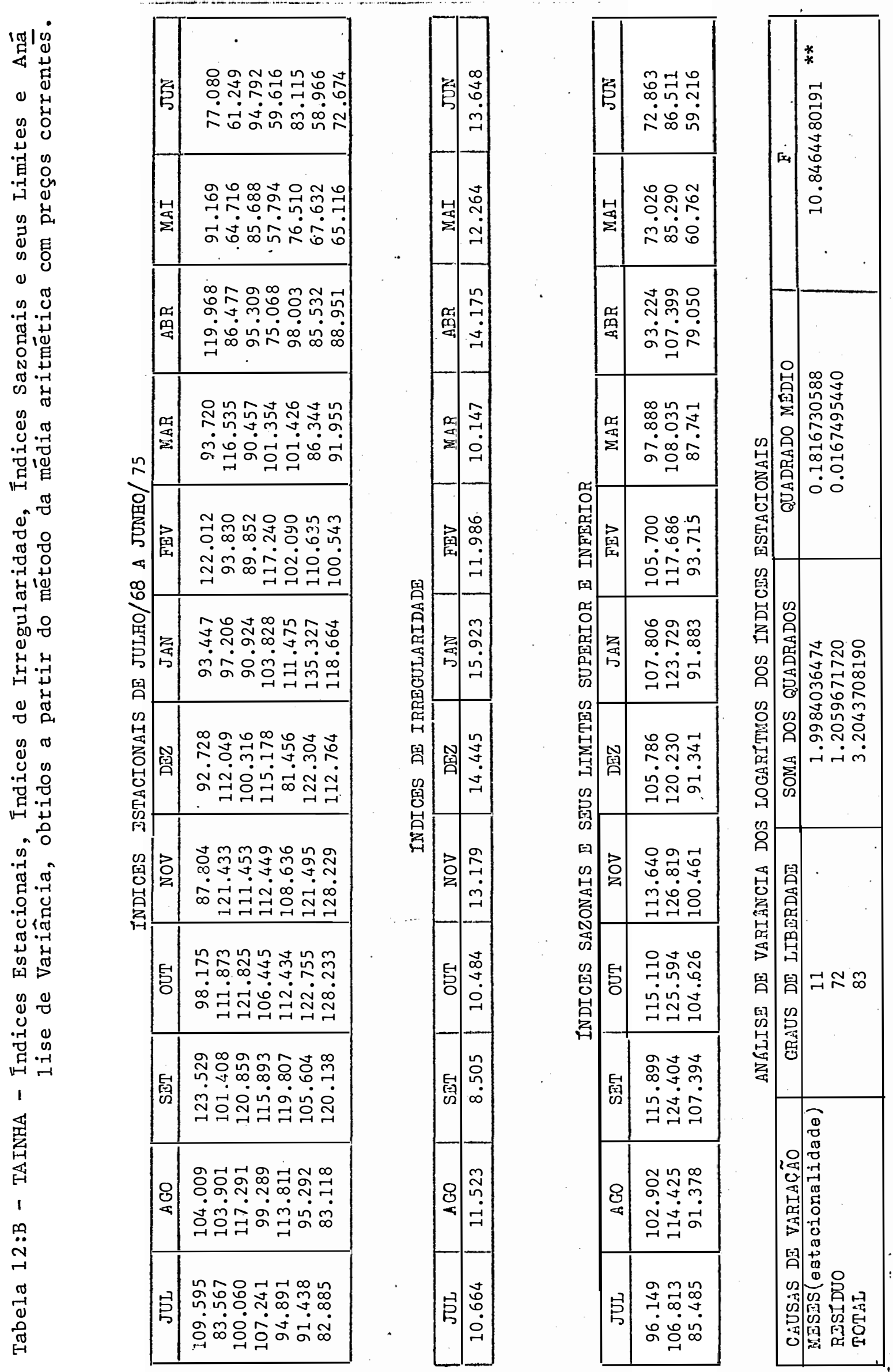

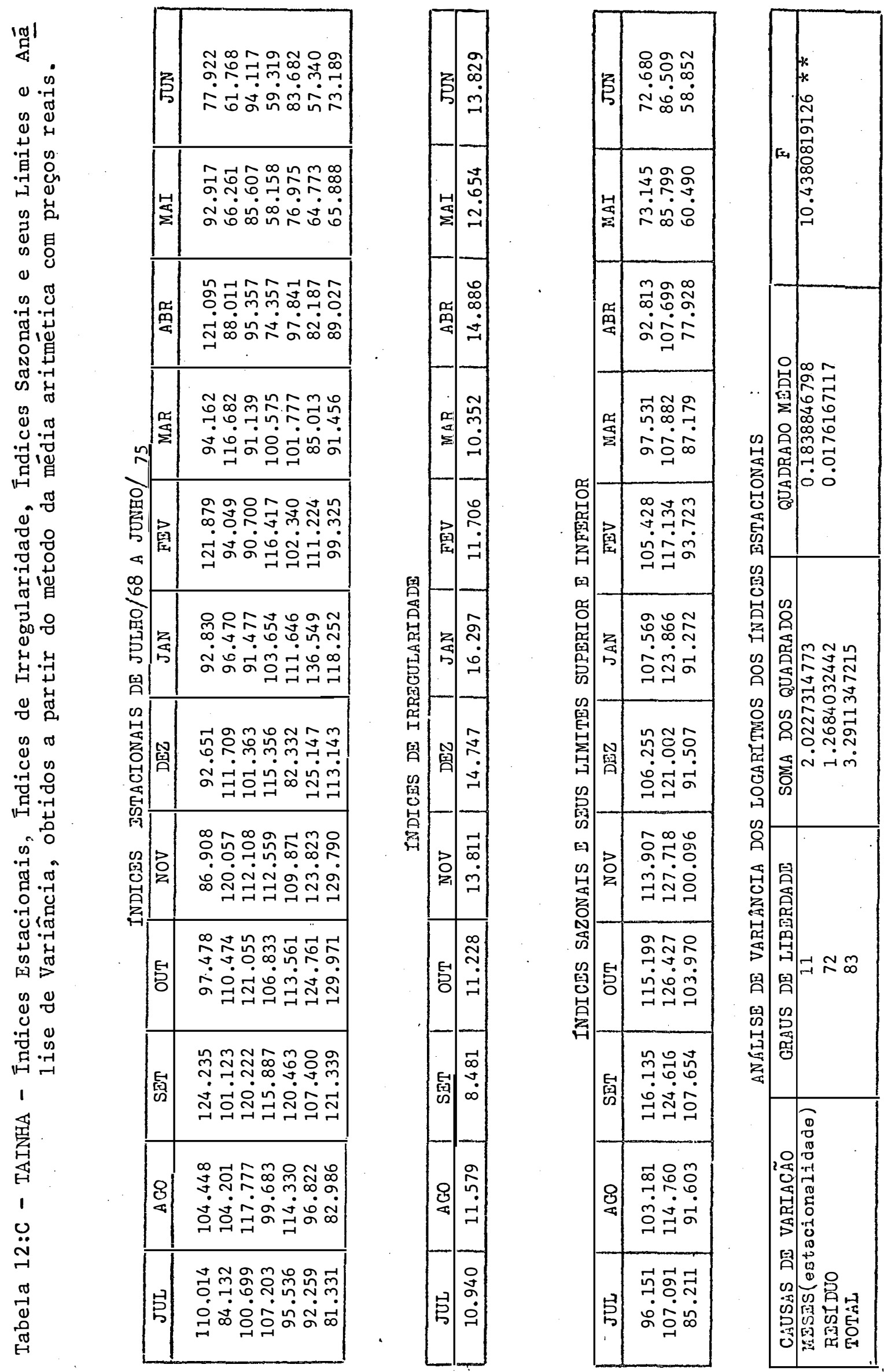

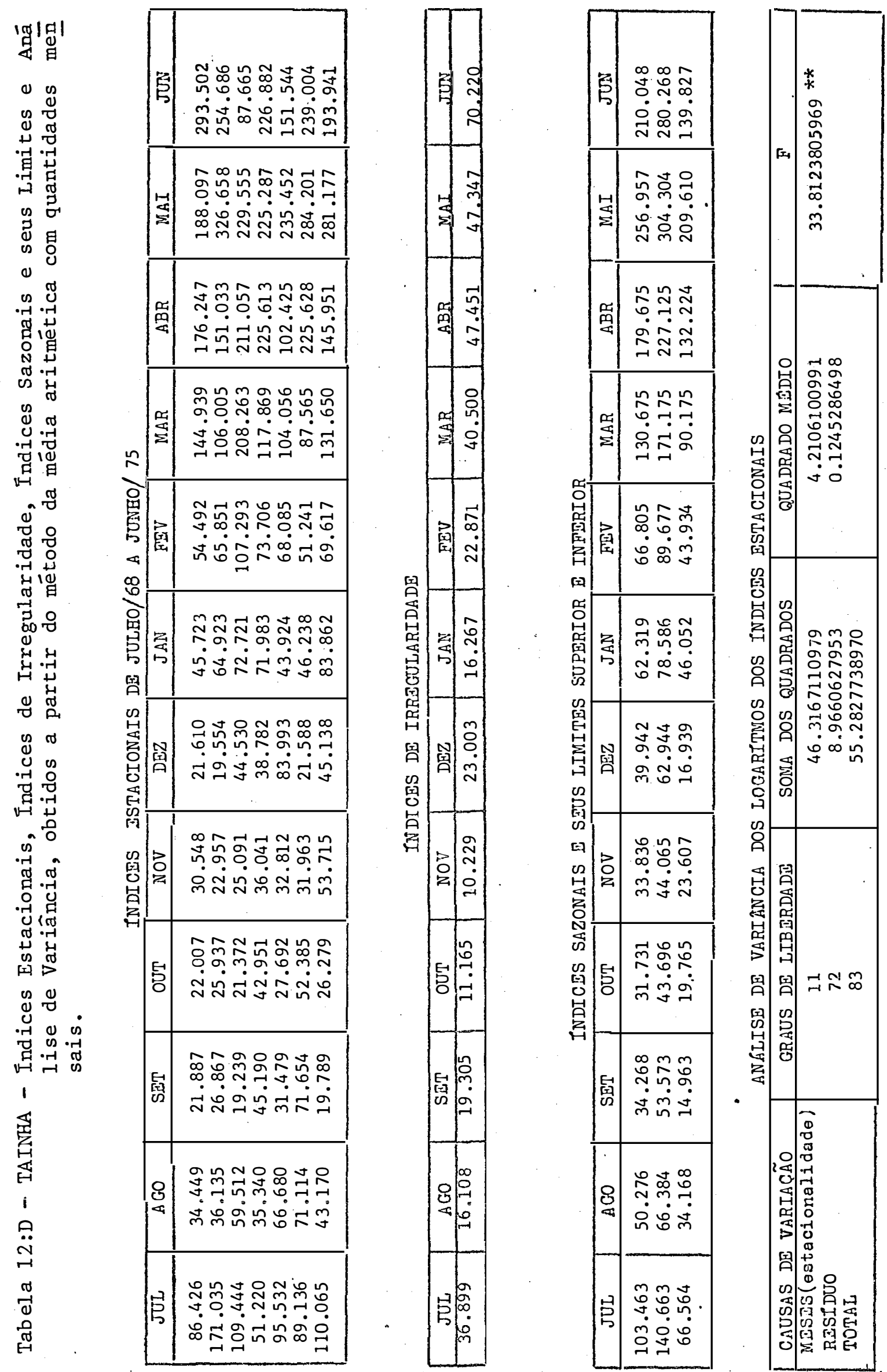

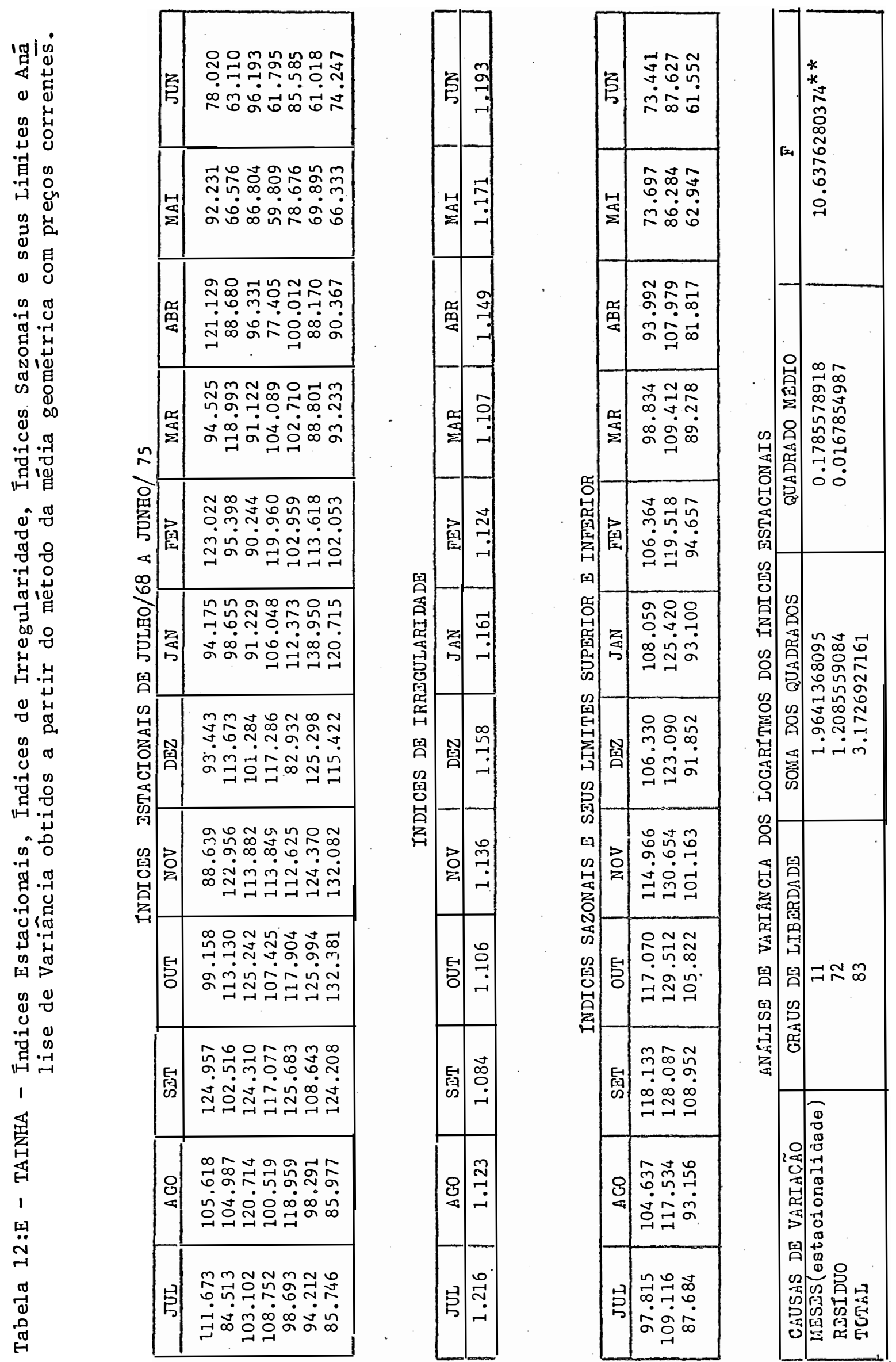

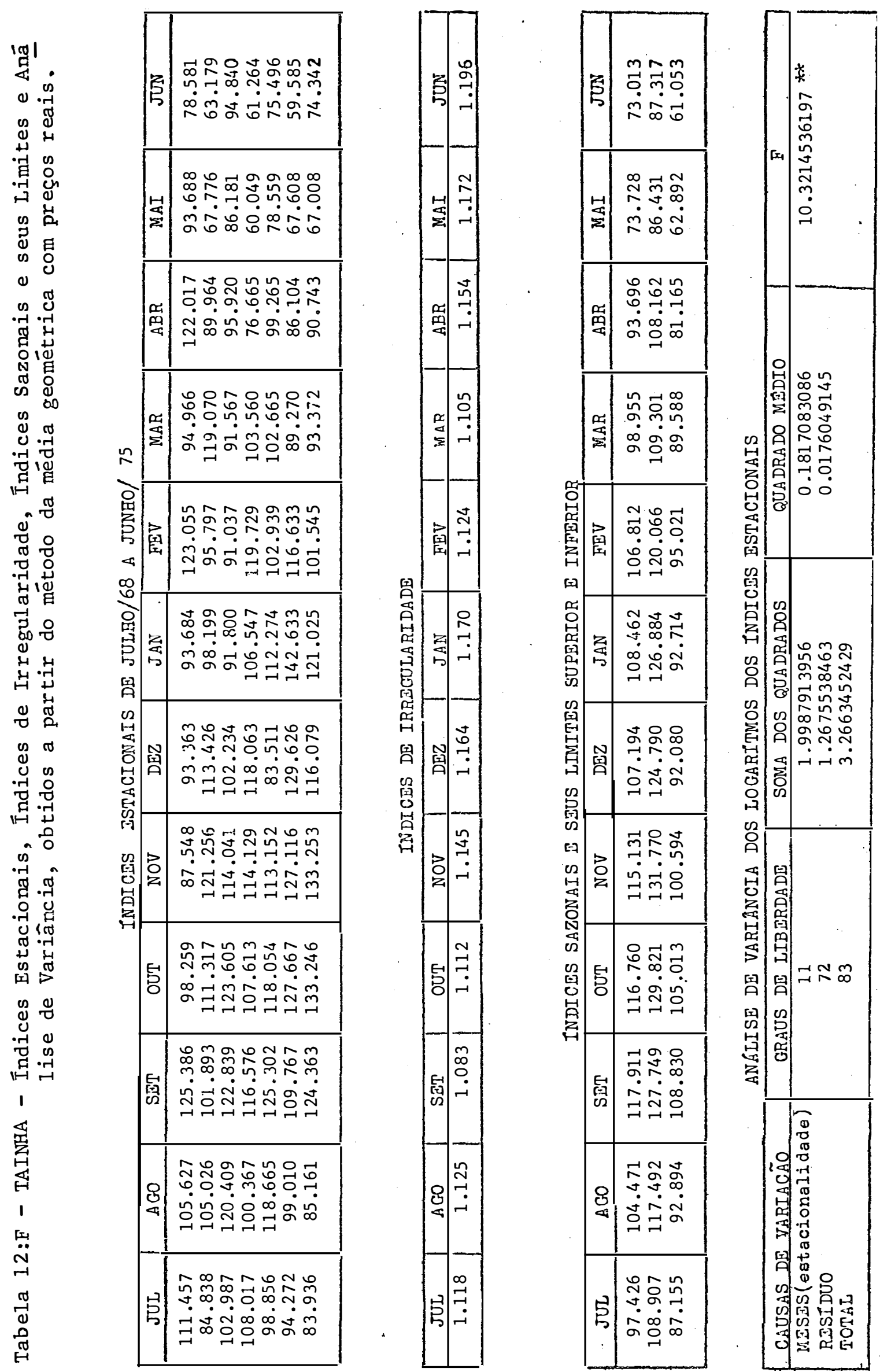

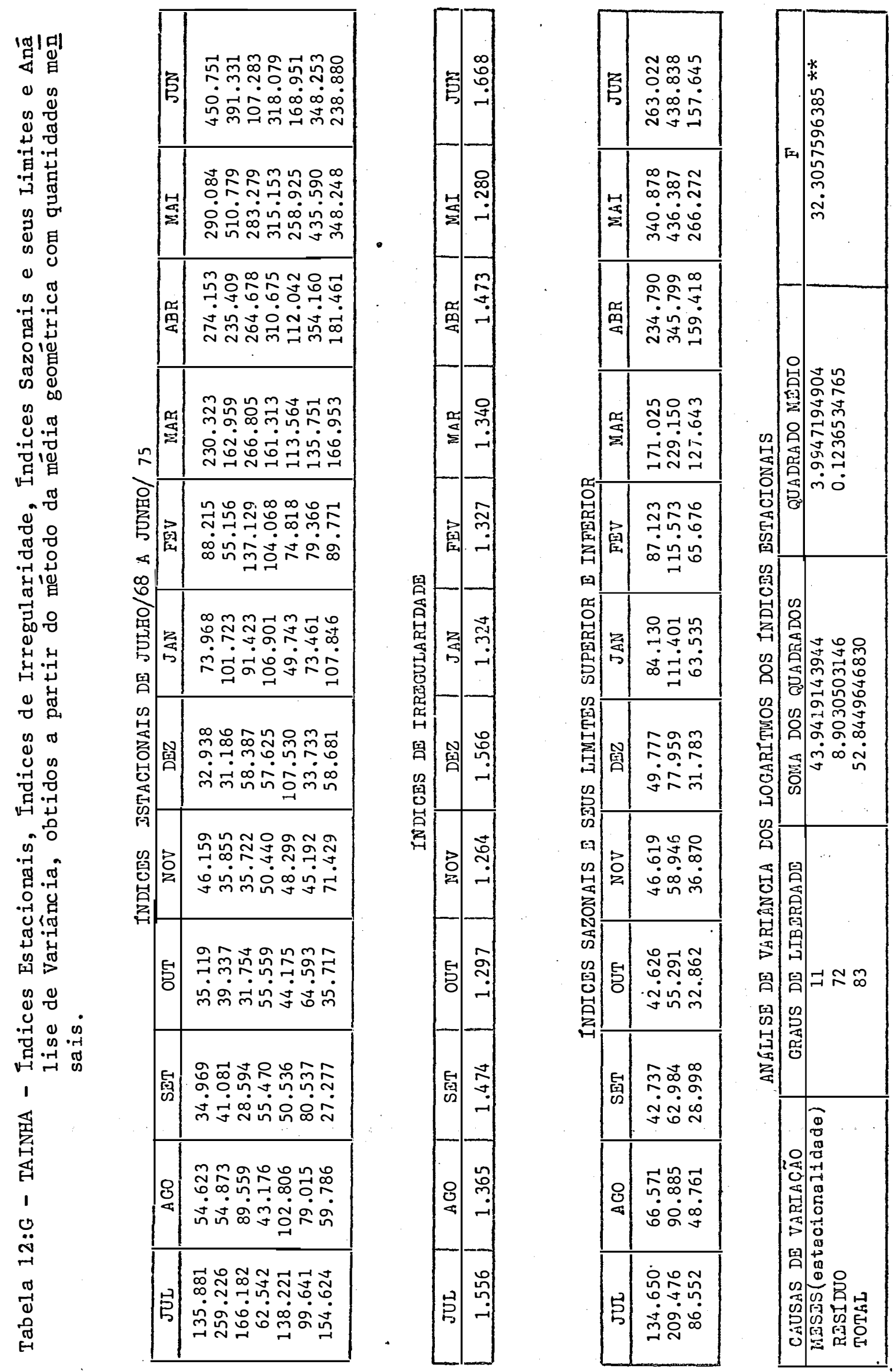
A N E X O 13

$\mathrm{E} N \mathrm{CH}$ O $\mathrm{VA}$ 

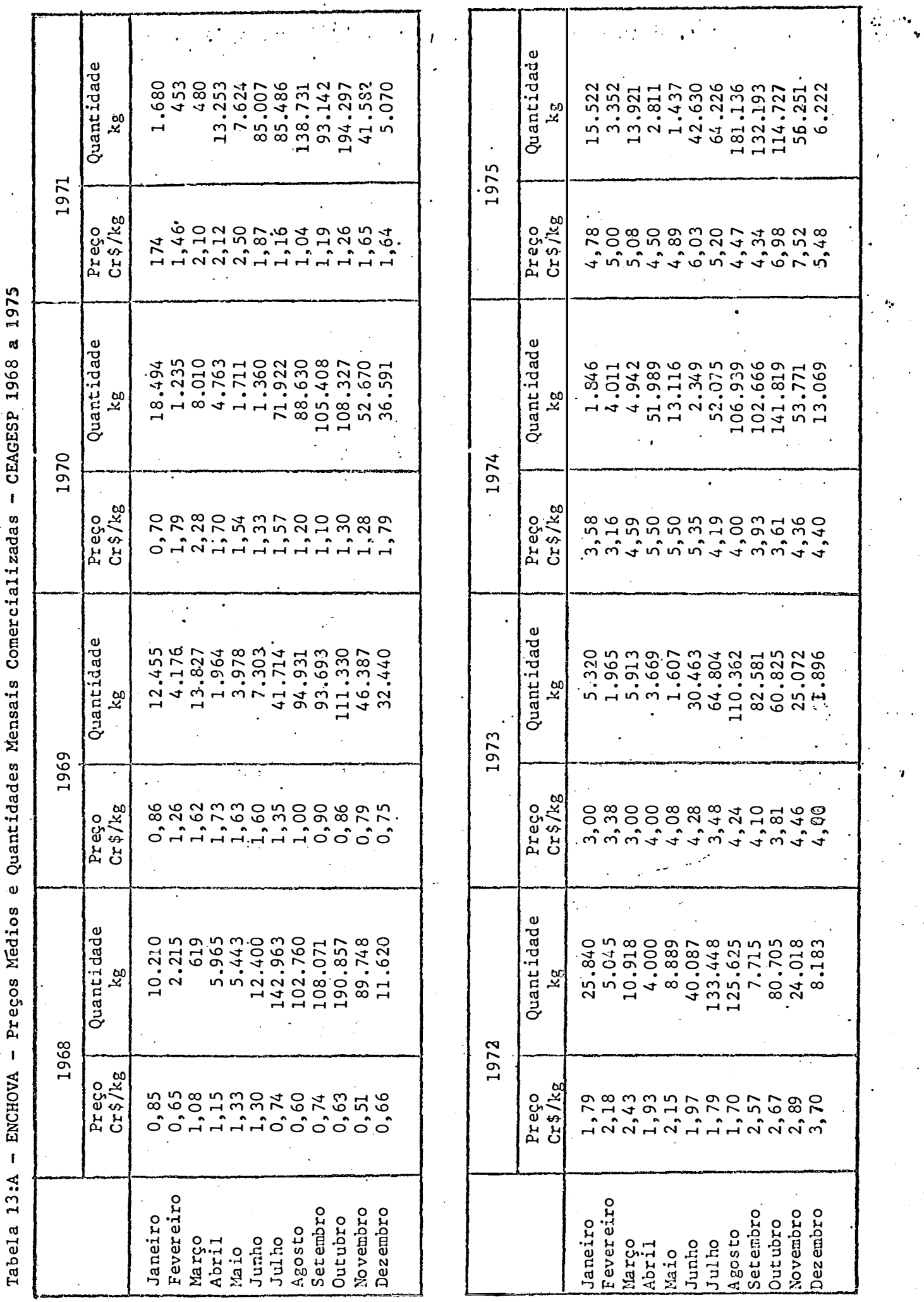


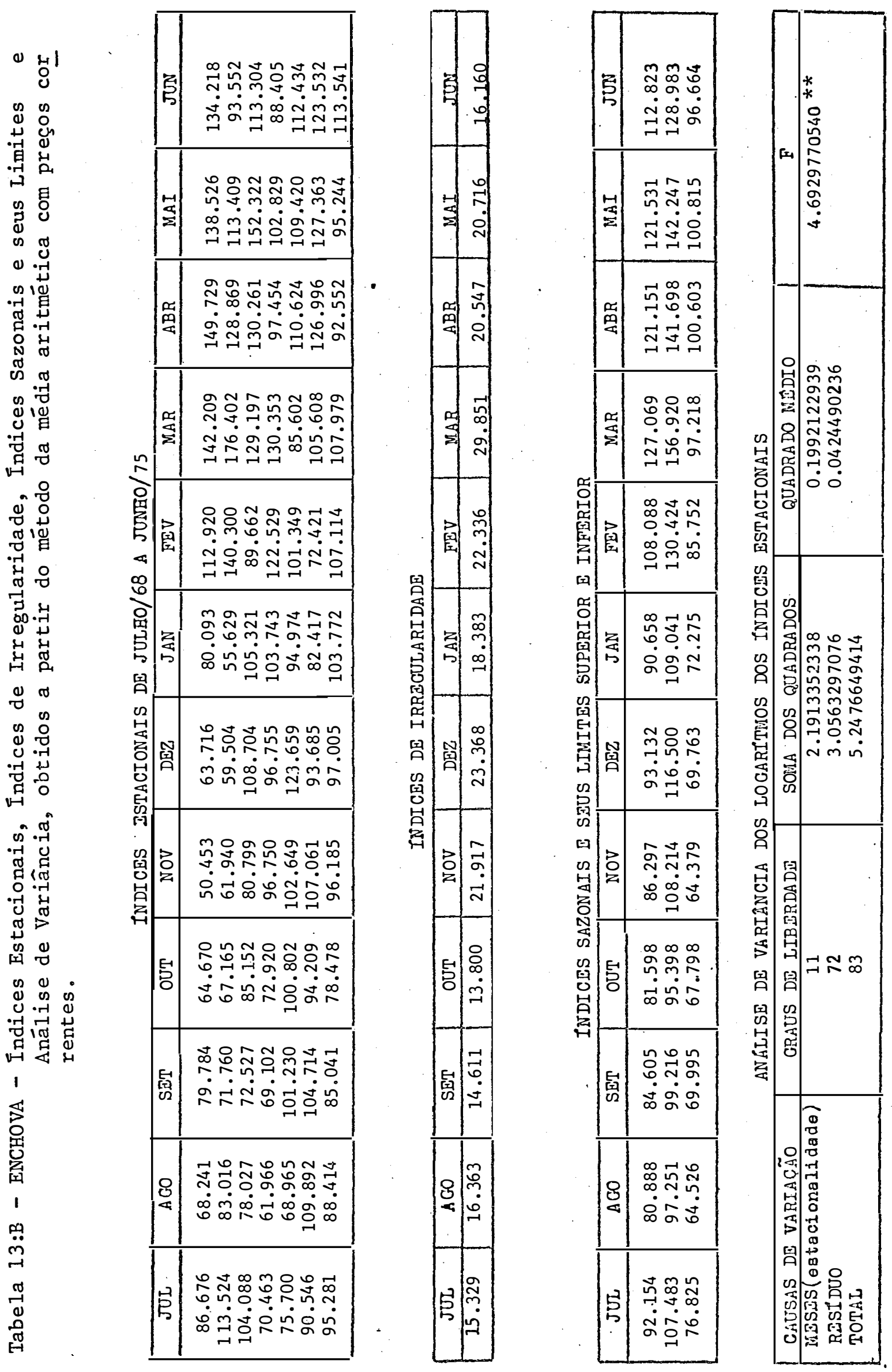



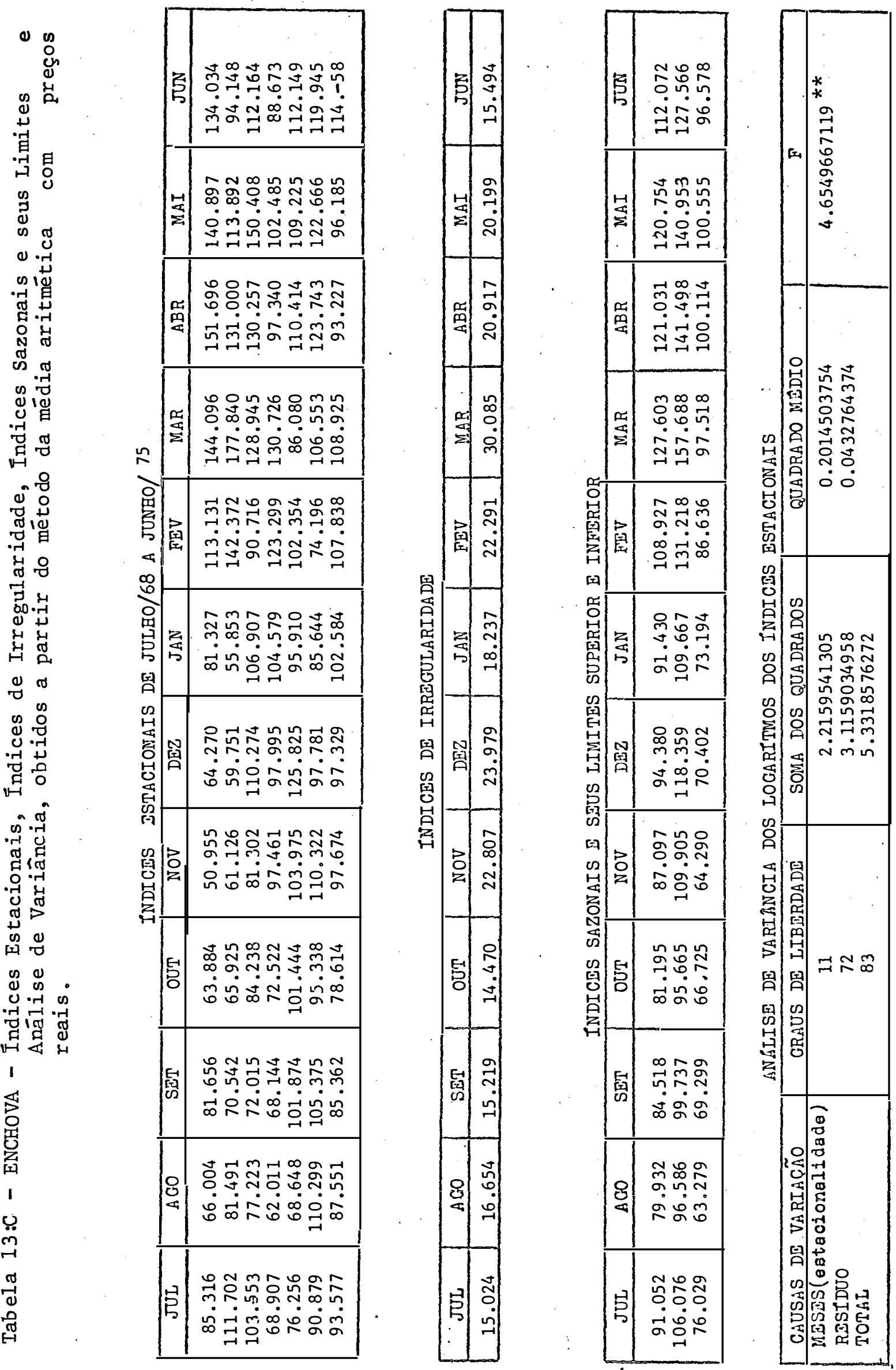

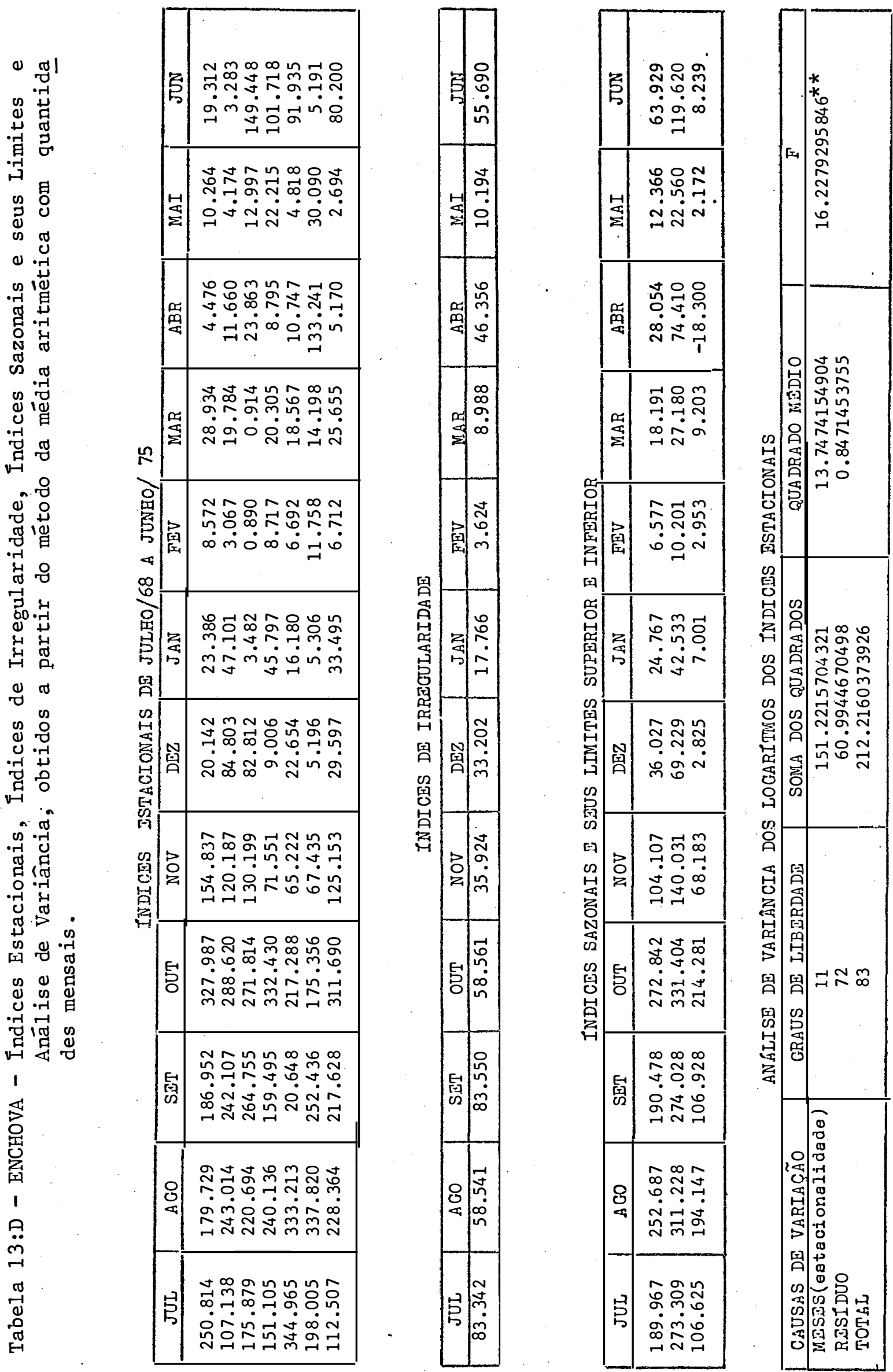

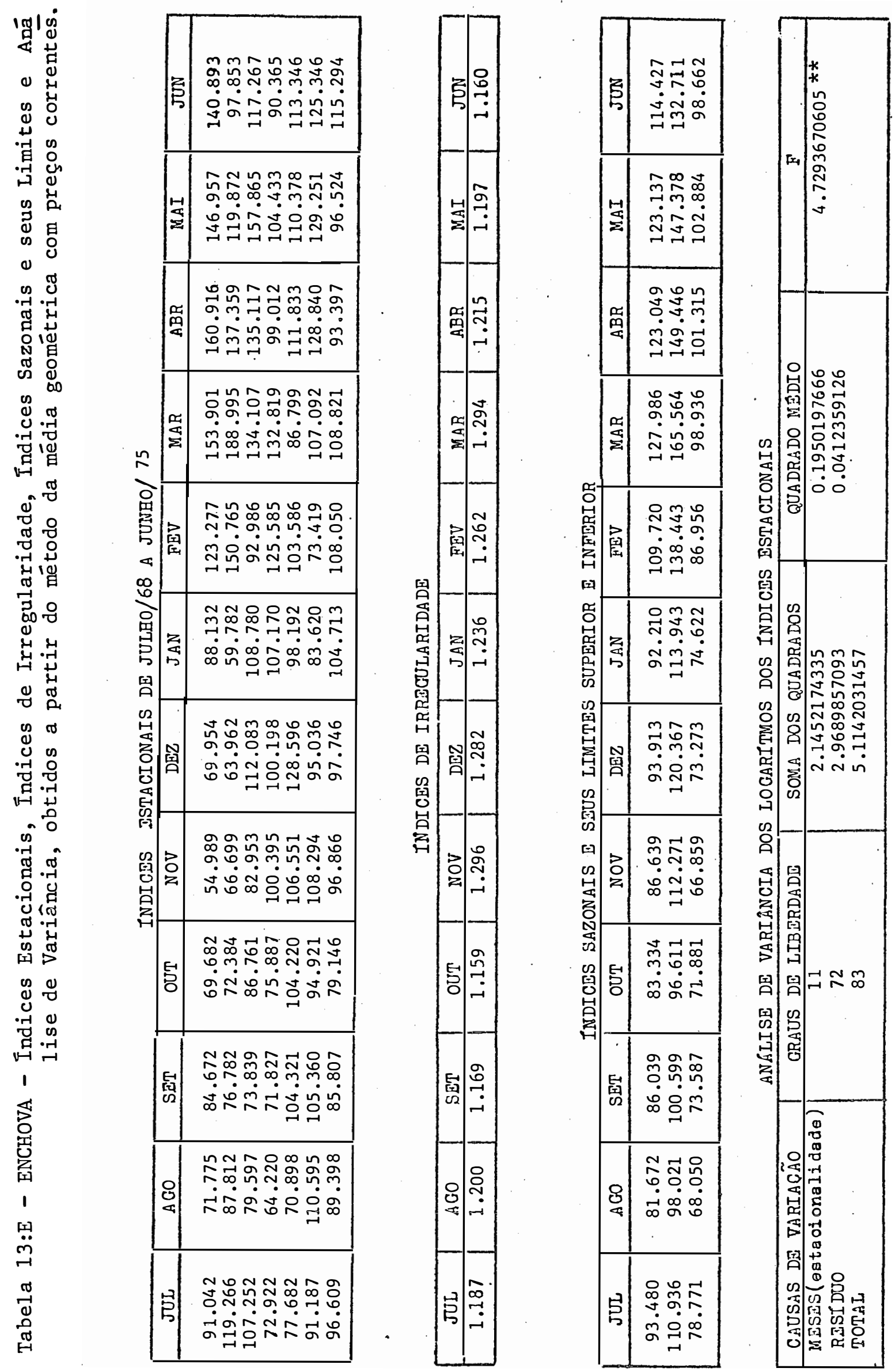

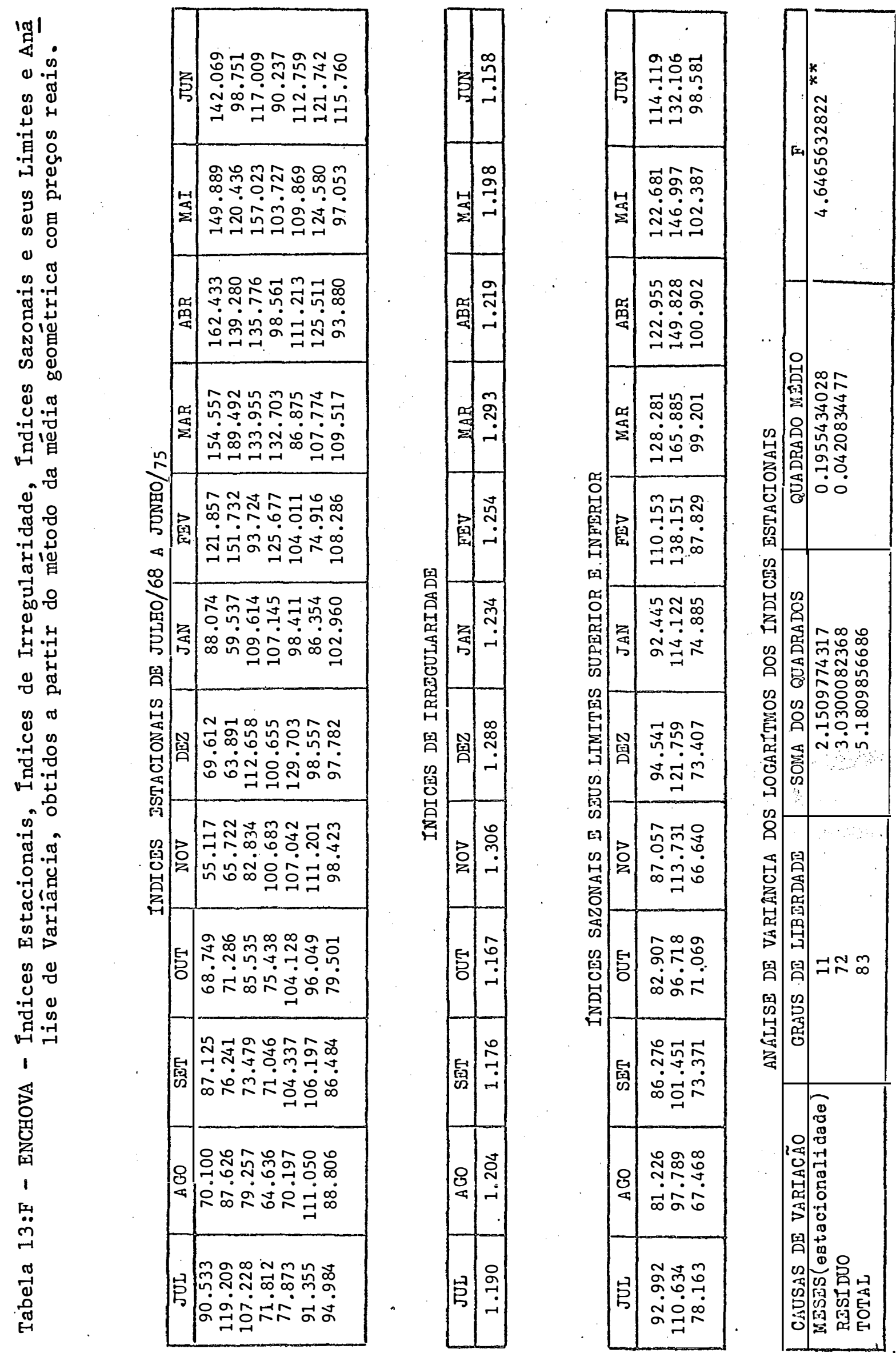

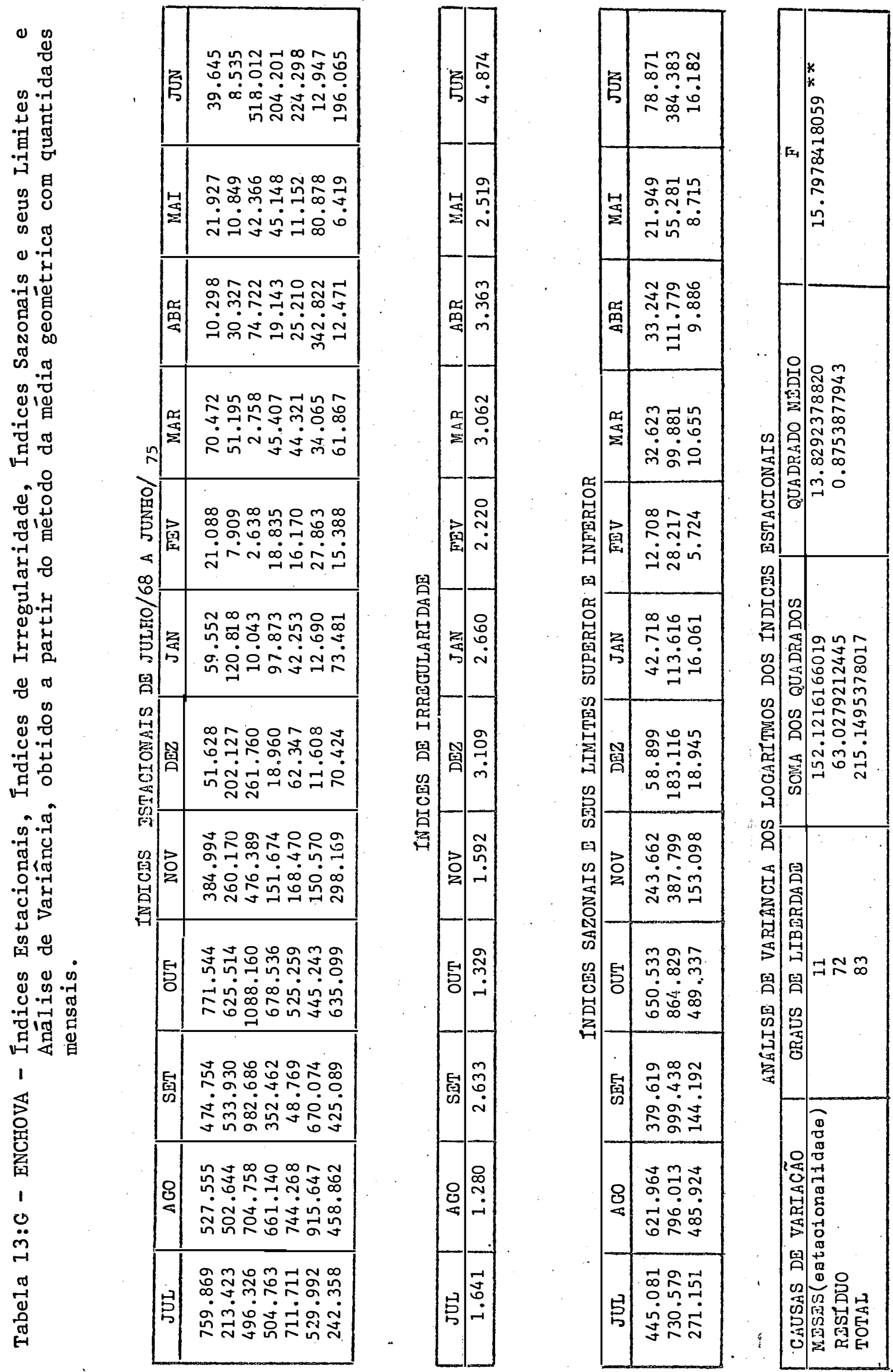